On the cover: When the U.S. Geological Survey (USGS) opened the Landsat archive to users at no charge in October 2008, nobody could have predicted that three million scenes would have been distributed by August 2010. The main image on the cover is the three millionth Landsat scene downloaded from the (USGS) Earth Resources Observation and Science (EROS) Center. What's unique about the image is that it shows an area within the Wrangell-St. Elias Park and Wilderness Reserve of Alaska acquired by Landsat 1 on July 8,1973 , which shows the value of the long-term archive. Imagery from the Landsat archive, spanning more than 38 years, provide continuous data of the Earth's land mass, coastal boundaries, and coral reefs - creating an unprecedented comprehensive record of landscape dynamics.

The smaller images on the front cover are Landsat 5 scenes of (from left to right) Washington, DC; Red River flooding at Fargo, North Dakota; Long Butte fire, Idaho; California fires; irrigation expansion in Chihuahua, Mexico.

On the back cover, the images are (from left to right) forest fires near Nizhniy Novgoro, near the Volga River in Russia; Lake Powell and Glen Canyon National Recreation Area, Utah and Arizona; Rio De Janeiro, Brazil; Las Vegas, Nevada; Mar Chiquita, Argentina; artificial Palm Islands in Dubai, United Arab Emirates; Beijing, China; Gran Canaria, Canary Islands; eastern Tennessee; and the eruption of Mt. Redoubt volcano, Alaska. 


\section{U.S. Geological Survey (USGS) Earth Resources Observation and Science (EROS) Center-Fiscal Year 2010 Annual Report}

Compiled by Janice S. Nelson

Open-File Report 2011-1057

U.S. Department of the Interior

U.S. Geological Survey 


\section{U.S. Department of the Interior \\ KEN SALAZAR, Secretary \\ U.S. Geological Survey \\ Marcia K. McNutt, Director}

\section{U.S. Geological Survey, Reston, Virginia: 2011}

For more information on the USGS - the Federal source for science about the Earth, its natural and living resources, natural hazards, and the environment, visit http://www.usgs.gov or call 1-888-ASK-USGS.

For an overview of USGS information products, including maps, imagery, and publications, visit http://www.usgs.gov/pubprod

To order this and other USGS information products, visit http://store.usgs.gov

Any use of trade, product, or firm names is for descriptive purposes only and does not imply endorsement by the U.S. Government.

Although this report is in the public domain, permission must be secured from the individual copyright owners to reproduce any copyrighted materials contained within this report.

Suggested citation:

Nelson, J.S. comp., 2011, U.S. Geological Survey (USGS) Earth Resources Observation and Science (EROS) Centerfiscal year 2010 annual report: U.S. Geological Survey Open-File Report 2011-1057, 118 p. 


\section{Contents}

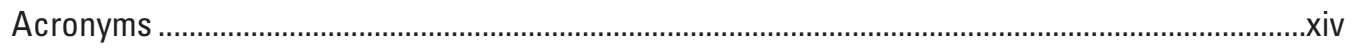

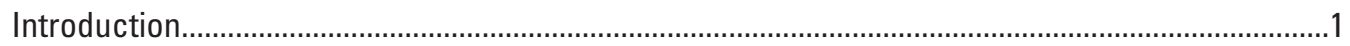

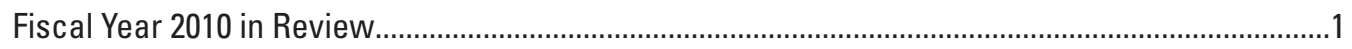

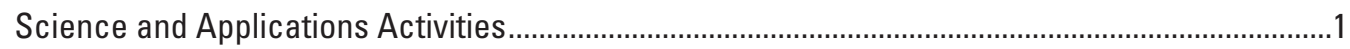

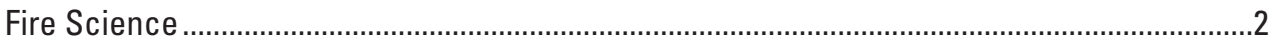

Forest Change Detection using ICESat Data and VCT Output..........................................

The LANDFIRE Program: Consistent and Comprehensive National Vegetation and Wildland Fuel Mapping .....................................................................................

Monitoring Trends in Burn Severity...............................................................................

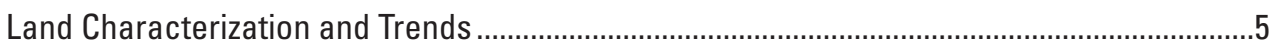

The 2006 National Land Cover Database Reaches 80 Percent Completion......................5

USGS Delivers New Sagebrush Characterization and Monitoring for Wyoming .............6

USGS Collaborates with Canada and Mexico to Produce the North American Land Change Monitoring System ....................................................................................

Land Cover Forecasting Methodology and Prototype Developed for Ecological Carbon Assessment .............................................................................................

Historical Land Use and Land Cover Modeling in the Western High Plains.....................8

National Assessment of Land Use and Land Cover Change ..........................................

Land Cover Applications and Global Change .....................................................................10

Ecosystem Performance Assessment for the Greater Platte River Basin: Applications on Optimal Land Uses for Bioenergy ...........................................10

Carbon Fluxes in the Great Plains ................................................................................11

eMODIS: Useful MODIS Products for Alaskan Vegetation Studies ................................11

Mapping Aboveground Biomass for the Yukon Flats using Landsat Images, Ancillary Data, and Field Measurements ...........................................................12

Lidar-Derived Biomass in the Yukon River Basin ...........................................................13

Estimating Big Sagebrush Productivity Decline in the Owyhee Uplands .......................13

Ecosystem Performance Anomalies in the Owyhee Uplands..........................................14

Dynamic Monitoring of Ecosystem Performance for Upper Colorado River Basin........15

Climate Change: Are High Latitude Lakes Drying? ...................................................15

Boreal Forest Performance Anomalies in the Yukon River Basin ................................16

Adapting to Climate Change by Re-Greening Landscapes in West Africa's Sahel ........17

Monitoring Biodiverse Forests and Protected Areas in West Africa's Upper

Guinean Forest Ecoregion .............................................................................19

Assessing Human Impacts on Critical Environments in Senegal...................................20

Mapping Land Cover through the Decades in East Africa ..............................................22

Topographic Processing Service for South America - Andean Development Bank

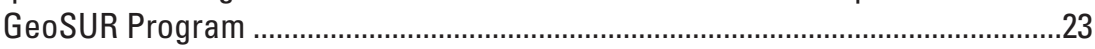

EcoServ: An Integrated Web-Services-Based Ecosystem Services Modeling

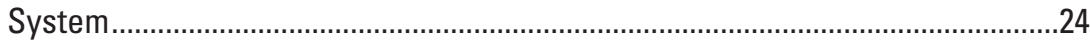

Collateral Effects of Carbon Sequestration on Ecosystem Services ..............................25

Quantifying Water Storage Capacity of Topographic Depressions in the Prairie Pothole Region from Lidar and National Wetland Inventory Datasets ...............25

The Methodology Development for the USGS Land Carbon Project..............................27

GEMS Simulation Results for the Land Carbon Pilot Study Area ......................................27 
Simulation of Lateral Movement of Soil and Carbon on Landscape ..............................29

Contemporary Carbon Dynamics in U.S. Eastern Terrestrial Ecosystems .......................30

Spatiotemporal Dynamics of Water Loss because of Evapotranspiration in the Great Plains

Modeling Gross Primary Productivity in the Mid-Continent Intensive Campaign Region of the North American Carbon Program ..................................................31

Computing Seasonal Evapotranspiration in the Great Plains Using Satellite Images ...32

Effects of Spatial Resolution of Satellite Sensors on Seasonal Evapotranspiration Estimates

Sensitivity of Hydrological Processes to Climate Change in the Upper Mississippi River Basin

Hydrological Responses to Rising Atmospheric Carbon Dioxide $\left(\mathrm{CO}^{2}\right)$ Concentration in the Upper Mississippi River Basin

Grazing Affects DOI Land Carbon Dynamics, but with High Uncertainty.........................36

General Ensemble Biogeochemical Modeling System (GEMS) Development................37

Impacts of Management Practices on Cropland Carbon Sequestration in MidContinent Intensive Region...

Will Climate Change Stimulate Greenhouse Gas Fluxes in Wetlands? Greenhouse Gas Research in the Prairie Pothole Region ..........................................................38

Evaluating Ecosystem Sustainability under Biofuel Pressure .........................................39

A New Approach for Estimating Global Evapotranspiration and Gross Primary Production

Improving Biogeochemical Simulations with Data Assimilation in the Yukon River Basin

Topographic Science, Elevation, and Lidar...

The Global Multi-Resolution Terrain Elevation Data (GMTED2010)................................41

Hydrologic Derivatives Extracted from High-Resolution Lidar Elevation Data: USGS Scientific Investigations Report 2010-5059

Geographic Information System Tools for Estimating Post-Wildfire Debris Flow

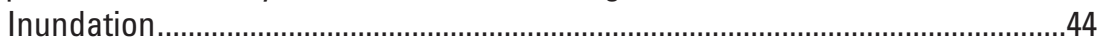

National Atlas Million Scale Mapping .......................................................................4

The National Elevation Dataset: Lidar for Science ………............................................45

CLICK Passes a One-Trillion Milestone ............................................................................46

Lidar Research Highlighted in Prestigious Industry Journal...........................................47

Early Warning, Environmental Monitoring, and Hazards Management ...................................48

Global Environmental Alert Service...............................................................................

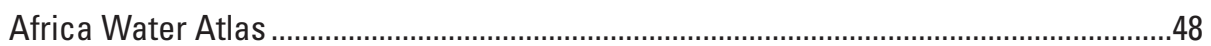

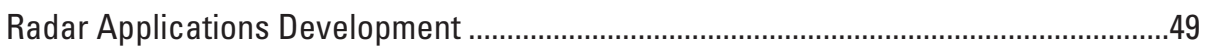

Mapping Irrigated Agriculture across the Country .......................................................50

U.S. Evapotranspiration Project ...................................................................................50

eMODIS Normalized Difference Vegetation Index for Food Security Monitoring ..........51

The USGS FEWS NET Informing Climate Adaptation Series.........................................53

Crop Area Estimation for Haiti with Very High Resolution Satellite Imagery...................55

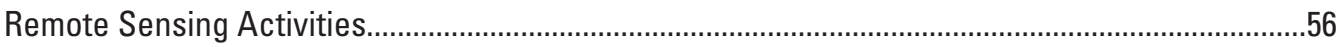

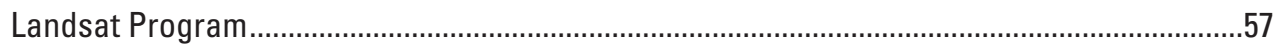

Survey of Landsat Users Demonstrates Value of Landsat Data ....................................57 
Landsat Users Break Records_-Over 2.4 Million Images Delivered ..............................58

Landsat Data Revival—Multispectral Scanner Data Improvements..............................59

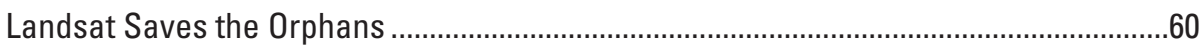

Landsat Global Archive Consolidation —-The World at EROS.........................................60

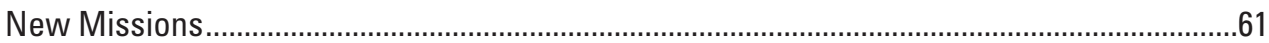

LDCM Ground Network Element Critical Design Review..............................................61

LDCM Ground Network Element (GNE) Testing with Spacecraft Engineering Model

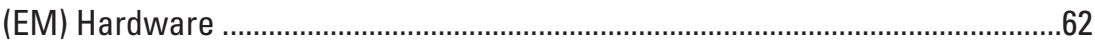

LDCM Collection Activity Planning Development Element..............................................62

Landsat Science Team Activities ....................................................................................62

Data Processing and Archive System Critical Design Review ......................................63

Landsat Data Continuity Mission Ground System Critical Design Review ......................64

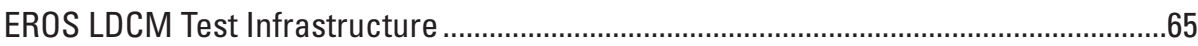

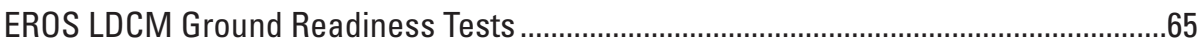

Calibration and Validation Technical Interchange Meetings ............................................66

Phase 2 Algorithms for Operational Land Imager and Thermal Infrared Sensor

Delivered to Development .................................................................................67

International Cooperator Meeting: 38th Landsat Ground Station Operators Working

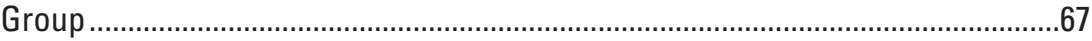

International Cooperator Meeting: 19th Landsat Technical Working Group...................68

Land Satellites Data System Consolidated Exhibit 300...................................................69

Data Management and Distribution .........................................................................................69

Image Server/ArcGIS Server Now Providing NAIP Web Mapping Service and

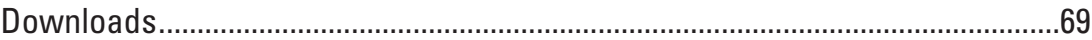

DATA.gov: Access to High Resolution Orthoimagery ………….....................................70

Hazards Data Distribution System Graphical User Interface ............................................71

New EarthExplorer Implementation ......................................................................

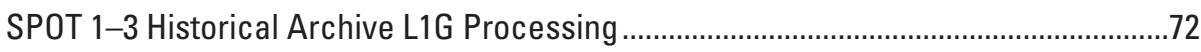

SPOT North America Data Buy ................................................................................

Phoenix V Archive Scanning ........................................................................................

eMODIS System Enhancements Support New Users ....................................................74

NASA EOS Terra Mission Celebrates 10 Years at LP DAAC ...........................................74

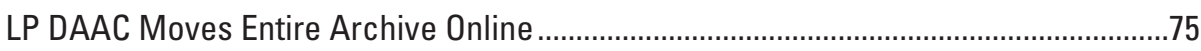

LP DAAC Supports Emergency Response Activities ........................................................75

LP DAAC Develops ASTER GDEM Case Study …………...........................................77

Interagency Agreement Signed for FY 2010-14 Operation of LP DAAC at EROS.............78

Distribution of Earth Science Data .................................................................................

Archive Strategic Direction Committee ...................................................................

Scientific Records Appraisal ................................................................................

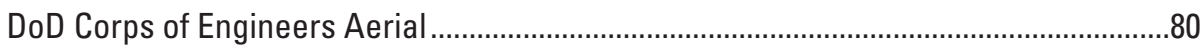

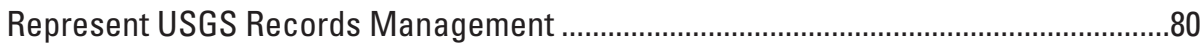

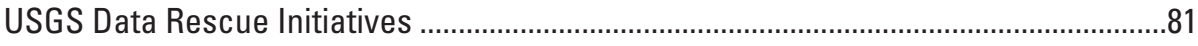

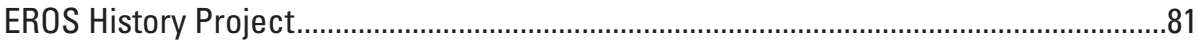

Consolidated Archive and Distribution Data Report: A Monthly "Consolidated Report" for All Data Managed and Distributed at EROS .....................................................81 
Calibration and Validation

Satellite Data Characterization and Joint Agency Civil Imagery Evaluation (JACIE) Team

USGS Quality Assurance Plan for Digital Aerial Imagery.............................................8

Aerial Mapping Camera Calibration and Characterization...............................................89

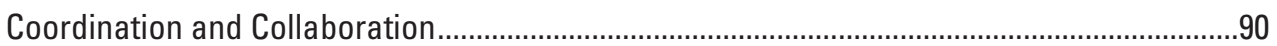

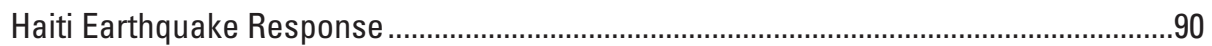

Chile Earthquake Response ........................................................................................

Deepwater Horizon Oil Spill Response .....................................................................92

Facilitating Access to Landsat Data for Developing Countries ........................................93

USGS Supports CEOS Working Group on Information Systems and Services...............93

Coordinating a Successful CEOS WGCV Plenary Meeting..............................................94

Coordinating a Successful QA4EO Workshop ................................................................94

First Ever GEO Work Plan Symposium.............................................................................94

USGS Supports CEOS Working Group on Education: Fourth Jay Feuquay Memorial

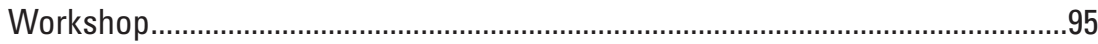

CEOS Land Surface Imaging Constellation Portal for GEOSS ......................................95

Coordination of Space Data Acquisition in Support of GEO Forest Carbon Tracking ....97

GEO Forest Carbon Tracking Science and Data Summit and Space Data Coordination

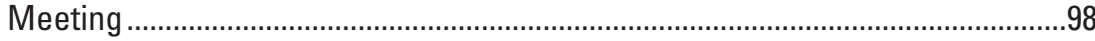

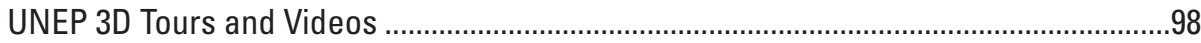

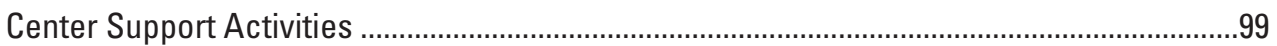

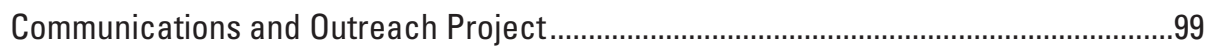

Preparing for the Financial Business Management System Implementation...............102

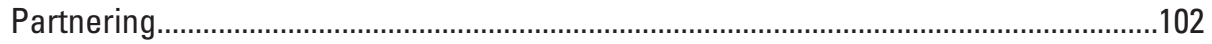

Student and Volunteer Programs ................................................................................103

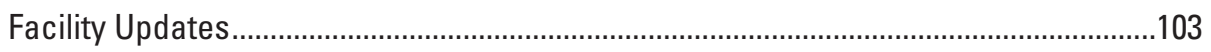

Support Service Contracts at the USGS EROS ………...............................................103

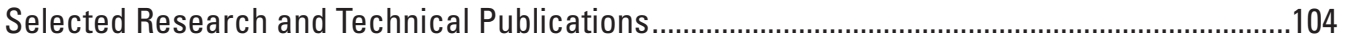

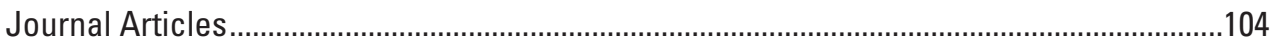

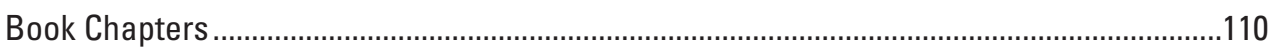

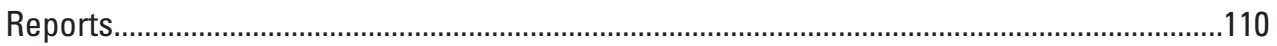

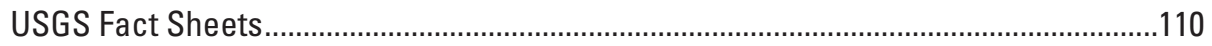

USGS Open-File Reports..........................................................................................111

USGS Scientific Investigations Reports..................................................................111

Non-USGS Discussion Paper ………............................................................................12

Conference Papers......................................................................................................

Conference Presentations ............................................................................................112

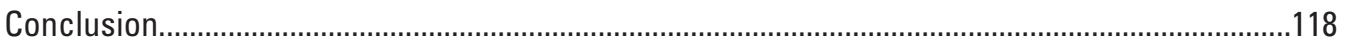

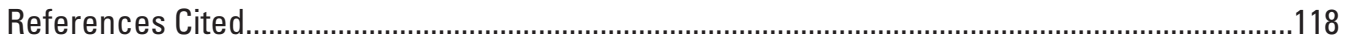




\section{Figures}

1. Transect line of photon-counting lidar data flown over SERC is shown in yellow (left). The yellow circle indicates the area of data extracted and histogrammed (right). The histogram shows that for this area a clear ground signal is difficult to identify

2. Illustrates the level of landscape change resulting from wildland fire since LANDFIRE national datasets were produced...

3. The graphic illustrates the number and extent of the fires (more than 13,000 ) assessed by the Monitoring Trends in Burn Severity project from 1984 to 2008 (northeast historical not yet complete).

\section{4}

4. The graphic illustrates the number and extent of the fires (more than 900) in Alaska assessed by the Monitoring Trends in Burn Severity project from 1984 to 2003. Assessments of historical fires in Alaska, Hawaii, and the Northeast is scheduled to be completed by May 2011

5. Example of NLCD 2006 and NLCD 2001 land cover change in Houston, Texas .................5

6. Example of four statewide primary components from combined Landsat and Advanced Wide Field Sensor predictions including percent estimates of shrub, herbaceous, litter, and bare ground for each 30 -meter cell

7. Completed 2005 land cover map produced for the North American Land Change Monitoring System.

8. Land use and land cover modeling prototype results for the reference $(R)$ and mitigation (L) scenarios for two Level III ecoregions, the Mississippi Valley Alluvial Plain and the Mississippi Valley Loess Plain. Obvious differences between the $R$ and $L$ scenarios are evident in the 2010 to 2050 land cover change images. The scenario-based LULC forecasts can be utilized to assess carbon sequestration and other greenhouse gas mitigation strategies on a regional basis.

9. The amount of change between 1973 and 2000 as a percent of each ecoregion for the conterminous United States. Results show the variability in the amount of overall change across the United States and point out how responses to various economic, policy, technological, and social driving forces differ substantially based on the unique environmental and socioeconomic factors shaping each ecoregion

10. Site potential map for grassland in Greater Platte River Basin. The areas in blue represent pixels that either overperformed or normally performed for three of four years from 2005 to 2008. Overperforming and normal performing areas are where productivity is greater or similar to a weather-based estimate and represent good condition vegetation and fair condition vegetation

11. Photosynthetic capacity ( $A_{\max }$ ) for grassland systems (2000-2008) (left) and grassland mean annual ecosystem exchange (2000-2008) and flux tower locations (right).

12. Grayscaled 250-meter Normalized Difference Vegetation Index calculated from Terra MODIS data acquired August 20-26, 2007, over Alaska and the adjacent Canadian Yukon River Basin

13. The map of 30-meter resolution aboveground biomass for the Yukon Flats, Alaska ......12

14. Location of lidar data acquisition within the Yukon River Basin study area and preliminary biomass product generated from lidar canopy height data and height-based allometric biomass equations.

15. The time-series cluster analysis reveals a long-term decline of higher producing Big Sagebrush areas, especially from the present time (2010) to 2040. Trends of similar or slightly increased productivity levels were predicted for the lowest producing areas. Areas of moderate productivity trended downward or remained at similar productivity levels....... 
16. The persistent anomaly map displays areas that overperformed or underperformed at least 6 of 9 years studied. Areas on the map in shades of red or gray show areas of possible concern for land managers...............................................................................14

17. Example Ecosystem Performance for Big Sagebrush in the Upper Colorado River Basin (2006)

18. An example of a lake (name unknown, Yukon Flats, Alaska) with no significant surface water change between May 1979 and May 2009.

19. An example of a lake (Twelve Mile Lake, Yukon Flats, Alaska) with significant drying between May 1979 and May 2009

20. Time series analysis of boreal forest performance anomalies to identify linear and nonlinear trends.

21. General location (white areas) of landscape regreening, where farmers have adopted practices that have substantially improved environmental and agricultural conditions.

22. Hand-irrigated vegetable cultivation surrounded by dense tree parkland dominated by the winter thorn tree (Faidherbia albida). Tree parklands have increased in density and extent across 5 million hectares of southern Niger. The winter thorn tree provides many benefits, including boosting crop yields by fixing nitrogen in the soil, and providing fodder for livestock. Adouna Valley, Niger. Photo: C. Reij..

23. Comparison of an aerial photograph (left, 1975) and a QuickBird satellite image (right, 2005) showing the much increased tree cover of agricultural landscapes in southern Niger. Note that the large village in the 2005 image did not yet exist when the 1975 photograph was taken.

24. A view of the cloud forest near the top of Mount Nimba. The Mount Nimba range is a transboundary reserve located on the border between Guinea, Cote d'Ivoire, and Liberia. It preserves unusually rich flora and fauna including a number of endemic species. It is one of the hotspots in the Upper Guinea Forest Ecoregion

25. This pair of maps compares primary and secondary dense forest cover in Sierra Leone from 1976 (left) to 2005-2009 (right). The remaining forest fragments and blocks are islands of biodiversity. Forest cover during this period declined from about 6 percent to just more than 2 percent of the national land area. Forest cover was mapped using Landsat and ASTER imagery.

26. One of 13 ASTER-based image maps produced of eastern Sierra Leone where existing maps are 30 years out-of-date. The maps are being used by the PAGE Project in support of formulating land use and forest management plans with local communities....20

27. EROS environmental scientists and their counterparts from CSE are monitoring vegetation structure and biodiversity changes at hundreds of ground sites across Senegal, including sites like this one in southeast Senegal. This photo pair compares the same landscape in 1995 (top) and 2006 (bottom). Woody species inventories show significant decline in biodiversity and habitat quality. The team is revisiting sites they originally established in 1983

28. This map is a small portion of a Land Cover Map of the Kedougou Region of Senegal. The map is being prepared from ASTER and Landsat imagery. The map and supporting field work will be used to produce several derivative themes, including a Relative Wildness Map and a Biodiversity Hotspot Map..

29. Participants from five East African countries attended the workshop in time-series land cover mapping at the Regional Centre for Mapping of Resources for Development, Nairobi, May 2010 .

30. Participants field-checked their draft land cover maps at a study area near Lake Naivasha, in Kenya's Rift Valley 
31. Composite image of Topographic Processing Services available as digital elevation model derivative products...

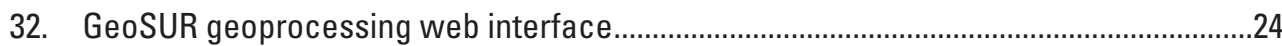

33. EcoServ Online Modeling System in a pilot study area of the Prairie Pothole Region...24

34. Ecosystem Services Change Indicator of the reference and optimized scenarios compared to the baseline

35. Prairie Pothole storage capacity and the capability of floodwater regulation. a) Floodwater potential distribution. Blue indicates the water when individual and isolated wetlands are full. Red indicates extended water when the wetland connectivity is considered. b) With the water level of May 17, 2008, before the flood event, the absolute and relative floodwater regulation under different precipitation events was modeled.

36. Flow chart of the GEMS. LANDFIRE, Landscape Fire and Resource Management Planning Tools Project; VCT, vegetation change tracker; MTBS, Monitoring Trends in Burn Severity Project; FIA, Forest Inventory and Analysis Program (U.S. Forest Service); C, carbon; K, potassium; USPED, unit stream power-based erosion and deposition; NASS, National Agricultural Statistics Service; NASW0, National Action Plan for Salinity and Water Quality; MODIS, moderate resolution imaging spectroradiometer; JDF, joint frequency distribution; BGC, biogeochemical; EDCM, erosion deposition carbon model; DNDC, denitrification-decomposition; IBIS, integrated biosphere simulator; EnKF, ensemble Kalman filter; NetCDF, network common data form; NLCD, national land cover database; DEM, digital elevation model; STATSGO, U.S. general soil map; SSURG0, soil survey geographic database; $\mathrm{NWI}$, national wetland inventory; $\mathrm{CO}_{2^{\prime}}$ carbon dioxide; Ndep, nitrogen deposition.

37. Total ecosystem carbon stock simulated by GEMS-CENTURY in the pilot study area...28

38. Comparisons of annual carbon sequestration rates of biomass carbon stock among three methods (GEMS-spreadsheet, GEMS-CENTURY, and GEMS-EDCM) using the "enhanced land use and land cover with reference land management" (L) scenario for the whole pilot study area from 2001 to 2050. Comparison made using the same models and the "reference land use, land cover, and land management" (R) scenario yielded similar results. $\mathrm{Tg} \mathrm{C} / \mathrm{yr}$, teragrams of carbon per year.

39. Spatial distribution of soil erosion and deposition is shown on the left. Trends of total soil erosion are shown on the right with blue lines indicating business as usual and purple lines indicating reduced forest cutting and increased wetland restoration........29

40. Panel A displays the annual variation of carbon fluxes in the Ridge and Valley ecoregion from 1973 to 2000, where total carbon sink refers to the net carbon uptake by terrestrial ecosystems (that is, increase of plant biomass carbon and soil organic carbon (SOC), and harvest carbon in grain and wood). Panel B shows the impact of land cover change on net ecosystem exchange (NEE) in 40 sample blocks each year, where Cs and $\mathrm{Cd}$ denotes NEE under static and dynamic land covers, respectively

41. Evapotranspiration maps showing the water loss because of evapotranspiration on (a) July 4, (b) August 5, (c) August 13, (d) August 29, (e) September 30, (f) October 16, (g) October 24, and (h) December 11, 2001. Location of the study area and legend for evapotranspiration maps are shown in the lower-right corner.

42. Gross primary productivity maps derived from Landsat (path 28, row 31) for (a) July 4, (b) August 5, (c) August 29, (d) September 30, (e) October 16, and (f) December 11, 2001. The GPP values are in $\mathrm{g} \mathrm{C} \mathrm{m}^{-2}$ day $^{-1}$

43. Cumulative seasonal evapotranspiration (July-December) for 2001 growing season using (a) cubic, (b) fixed, and (c) linear methods

44. Density plot of seasonal evapotranspiration for (a) cubic and fixed methods, (b) cubic

and linear methods, and (c) fixed and linear methods. 
45. Seasonal evapotranspiration (millimeters) from July to December 2001 growing season using (a) Landsat and (b) MODIS images ......................................................................3

46. Effect of spatial resolution on estimated seasonal evapotranspiration...........................34

47. Comparison of simulated streamflow and soil water content under changing precipitation and temperature scenarios.

48. Simulation of streamflow increase because of the elevated atmospheric $\mathrm{CO}_{2}$ concentration and contribution percentage since 1987.

49. Relation between the increase in streamflow per unit precipitation and the increase in $\mathrm{CO}_{2}$ concentration

50. Spatial distribution of carbon sinks and sources in the Green River Basin simulated by General Ensemble Biogeochemical Modeling System from 1970 to 2000 ......................37

51. Structure of the General Ensemble Biogeochemical Modeling System

52. Annual soil organic carbon (SOC) changes in the top 20 centimeters between 2000 and 2007 per county in the Mid-Continent Intensive region for three tillage scenarios........38

53. 2007 Prairie Pothole Region. .38

54. Top: Soil organic carbon (SOC) stock in 1972. Bottom: Total change in soil organic carbon (SOC) from 1972 to 2007

55. Top: Simulated global evapotranspiration (ET) pattern. Bottom: Simulated global Gross Primary Production (GPP) distribution

56. Upper panel shows comparisons of net ecosystem exchange (NEE) simulated by data assimilation (that is, SEnKF) (blue diamond) and by GEMS alone (green triangle: with pre-determined parameters, blue triangle: with parameters adjusted by data assimilation) against eddy covariance measurements (red square) at a boreal forest tower site in Alaska. Lower panel shows comparisons of corresponding ensemble-based standard deviations of NEE against errors of eddy covariance measurements

57. The Global Multi-resolution Terrain Elevation Data 2010 (GMTED2010) replaces GTOP030 as the elevation dataset of choice for global and continental scale applications.

58. GMTED2010 Spatially Referenced Metadata

59. The U.S. Geological Survey developed selective drainage methods to extract hydrologic information from high-resolution, high-vertical accuracy light detection and ranging (lidar) digital elevation models in Minnehaha County, South Dakota

60. Cover of U.S. Geological Survey Scientific Investigations Report 2010-5059 “Using Selective Drainage Methods to Extract Continuous Surface Flow From 1-Meter LidarDerived Digital Elevation Data." The selective drainage methods that the U.S. Geological Survey tested and developed for Minnehaha County, South Dakota, are published in this Scientific Investigations Report

61. This aerial view is an example of an inundation zone for 10,000-cubic-meter debris flow volume produced using the LAHARZ tool. Zones like these are typically compiled as a series to show a range of magnitudes for conveying risk to decision makers. .......44

62. The image shows mapping that has been completed for the western half of the conterminous United States, or about 7,950 waterbodies.

63. Fiscal year $\mathbf{2 0 1 1}$ holds great promise for the amount of available high-resolution lidar data to be added to the National Elevation Dataset collection.

64. The image depicts approximately 20,000 lidar points in downtown Sioux Falls, South Dakota.

65. Lidar featured on PE\&RS covers depicting Mount Rainier, Washington, (left) and Falls Park in Sioux Falls, South Dakota (right) 
66. Screenshot of the Global Environmental Alert Service website (http://www.na.unep. net/geas)

67. Cover of the Africa Water Atlas

68. InSAR image of Dec 6, 2006-June 8, 2007, showing land surface subsidence because of mining activity over Utah

69. The 2002 irrigated agriculture results from the MIrAD-US model. The six inset boxes show MIrAD-US model results next to 2002 mid-summer Landsat scenes.

70. Annual evapotranspiration for three study regions showing spatial distribution of vegetation water use across different landscapes in the United States, northeast Africa, Iraq, and surrounding regions. Green indicates high water use in high rainfall and irrigated regions. Brown indicates low water use in arid and semiarid regions...

71. An example of the improvement in spatial resolution with the expedited MODIS (eMODUS) Normalized Difference Vegetation Index (NDVI) (upper right) compared to coarse resolution Advanced Very High Resolution Radiometer data (lower right). The Haiti land cover map (left) shows an area of dense agriculture along the west central coast that, when compared to the NDVI maps, illustrates the benefits that eMODIS quality and resolution will provide for improved agricultural monitoring in current Famine Early Warning Systems Network countries and other remote monitoring locales.

72. A 10-day eMODIS NDVI composite of Africa at 250-meter resolution

73. Suitable crop growing areas shrink in central Kenya. The backdrop image shows key crop surplus and crop deficit areas. The three overlain polygons show areas typically receiving enough rain to support a healthy crop (areas receiving, on average, more than 500 millimeters of rainfall) during 1960-1989, 1990-2009, and 2010-2039

74. Observed and projected change in rainfall and temperature (left), together with smoothed central Kenyan rainfall and a smoothed version of the Indian-Pacific-Area climate index (right).

75. WorldView panchromatic image of Central Haiti, L'Artibonite Department from November 23,2009 . This image captures agricultural areas (green points) and nonagricultural areas (orange points) as interpreted by expert image analysts in the region . .56

76. Preliminary survey information shown by this scatter diagram indicates that Landsat data are very important and valuable to a broad user community ..................................58

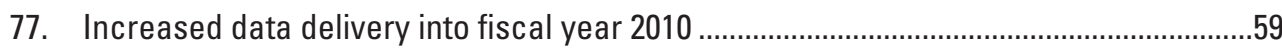

78. Landsat scenes (left to right) illustrate improved research capabilities with increased availability and use of free data. Hansen, and others, 2008.

79. Example Multispectral Scanner image includes a JPEG of geometrical accuracy........59

80. Example of a recovered image (Landsat 2, path 40, row 35, June 27, 1978) not previously archived at EROS, but processed using the updated MSS processing software.

81. Graphic of unique Landsat 1-3 image data held at international ground stations (IGS)

82. High-level architectural diagram of the LDCM Ground Network Element.

83. Illustration of the equipment used in the June 2010 test (image courtesy of Orbital Sciences Corporation).

84. No-charge Landsat time series datasets contribute to natural resources management by providing an affordable means to detect threats to resources. The images show areas of forest change associated with western spruce budworm (yellow and red) at San Pedro Peaks, New Mexico and was produced by Landsat Science Team member Jim Vogelmann (USGS). The two images represent a 1998 Landsat 5 image (left) and a 1998 to 2008 land change map (right)...... 
85. Browse image of a sample Level 1 user product...

86. High-level architectural diagram of the Landsat Data Continuity Mission Ground System

87. LDCM Data Processing and Archive System housed in a secure, climate controlled equipment room. Computer operators will test the system from the operations room adjacent to the computer room.

88. This is a graphical representation of the configuration needed for Ground Readiness Test 1, where the Mission Operation Center will generate commands that the EROS Ground Station will transmit to a spacecraft simulator. Simulated telemetry will be received and verified as valid responses by the flight operation team.

89. The Operational Land Imager design concept by Ball Aerospace and Technology Corporation

90. The algorithm maturity level is mapped from the instrument provider to the Calibration and Validation Team for algorithm design to Data Processing and Archive Segment development. The green box (across center of diagram) identifies the phase of development along with interfaces and a rough event synchronization.

91. Group photogrpah from the 38th Landsat Ground Station Operators Working Group (LGSOWG \#38) meeting held in Berlin, Germany, September 28-0ctober 5, 2009

92. Group photograph from the 19th Landsat Technical Working Group Meeting held in Phuket, Thailand, March 22-26, 2010.

93. The map illustrates the coverage area in the continental 48 states of NAIP imagery. ...70

94. Search page at DATA.gov.

95. Downloaded image from search results. Pierre, South Dakota, 0.30 -meter resolution natural color, April 2005 acquisition

96. The new graphical user interface in the Hazards Data Distribution System. ..................71

97. The new EarthExplorer System ...............................................................................

98. A sampling of one of the 814,424 images out of the SPOT 1, 2, and 3 archive recently processed and now available for download by authorized users. (Copyright 2010 CNES Distribution Spot Image).

99. A sampling of the moderate-resolution optical imagery being received from the SPOT 4 and SPOT 5 satellites. (Copyright 2010 CNES Distribution Spot Image) ..........................73

100. A sampling of one of the $260,000+$ digital high-resolution images that originated from the USGS film collection that was scanned, archived, and made available for download.

101. Famine Early Warning System implementation of LANCE-based eMODIS expedited VI time series.

102. Land Processes Distributed Active Archive Center team shown inside and alongside one of the three tape silos removed from the system architecture.

103. Trends indicate LP DAAC data distribution will continue to increase as the archive

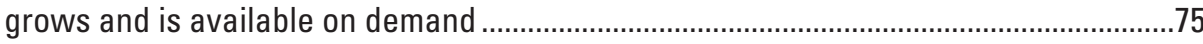

104. LP DAAC ASTER California Station Fire poster..............................................................76

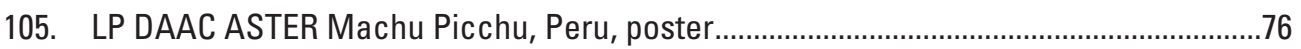

106. LP DAAC ASTER Eyjafjallajökull Volcano, Iceland, poster................................................77

107. ASTER global digital elevation model visualization ......................................................78

108. Quantity and percentage of traffic through DOI's four nodes for August 2010 ................79

109. Total inbound and outbound data flow for the past eight years .....................................79

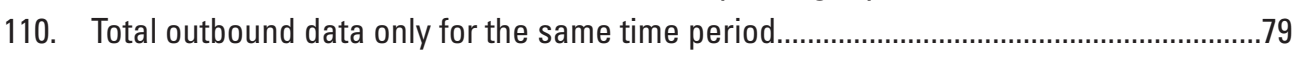

111. Fiscal year 2010 Land Processes Distributed Active Archive Center, Landsat, other satellite, non-satellite, and geospatial data distributed. 
112. Fiscal year 2010 Land Processes Distributed Active Archive Center, Landsat, other satellite, non-satellite, and geospatial data distributed

113. Fiscal year 2010 Land Processes Distributed Active Archive Center, Landsat, other satellite, non-satellite, and geospatial data managed.

114. Fiscal year 2010 Land Processes Distributed Active Archive Center, Landsat, other satellite, non-satellite, and geospatial data

managed .82

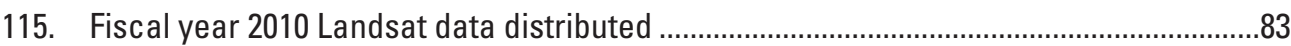

116. Fiscal year 2010 Landsat data managed .......................................................................83

117. Fiscal year 2010 Land Processes Distributed Active Archive Center data distributed...83

118. Fiscal year 2010 Land Processes Distributed Active Archive Center data managed .....84

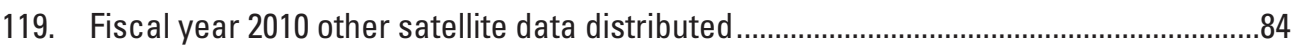

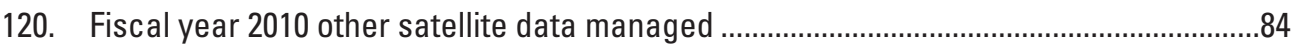

121. Fiscal year 2010 non-satellite data distributed .............................................................85

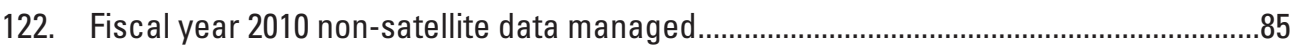

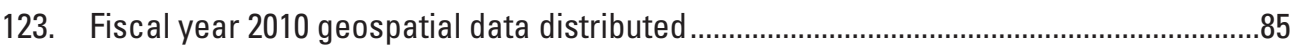

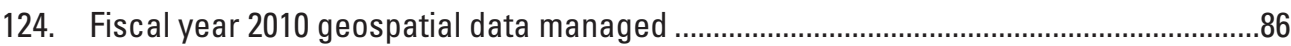

125. The ninth Joint Agency Civil Imagery Evaluation Workshop, Fairfax, Virginia, March 2010.

126. An illustration of the web-based "Spec \& Check Tool" developed as the basis of standard digital aerial imagery specifications and imagery product verification...................88

127. The graphic shows the number of film mapping cameras calibrated at the OSL for the last four years

128. The illustration depicts the 10 International Charter members and satellite imagery showing the Presidential Palace at Port-au-Prince, Haiti, before (IKONOS data) and immediately after (GEOEYE-1 data) the January 12,2010 , earthquake

129. This map illustrates an overview damage assessment for the area of Concepcion and Talcahuano, Chile.

130. Experimental Marine Pollution Surveillance Report provided by National Oceanic and Atmospheric Administration on May 8, 2010, used in analysis of the Deepwater Horizon Oil Spill. Data source: RADARSAT2.

131. Oil swirls in the Gulf of Mexico off the Mississippi Delta in this natural-color image from Landsat 5, May 25, 2010

132. The Working Group on Calibration and the Validation and Working Group on Information Systems and Services participants at the Canadian Space Agency, Montreal,

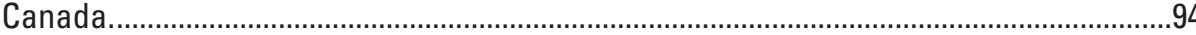

133. Screenshot of QA4EO website banner..................................................................94

134. Training session during the Fourth Jay Feuquay Memorial Workshop, Santa Maria,

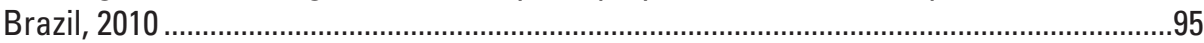

135. Participants of the Fourth Jay Feuquay Memorial Workshop ......................................95

136. Example browse image that includes the Vancouver, Canada, region, acquired by Landsat 7 on September 22, 2002

137. Committee on Earth Observation Satellites Land Surface Imaging Constellation Portal web page for additional information about mid-resolution, optical satellites and sensors.

138. National Institute for Space Research (INPE) web page linked from CEOS LSI Constellation Portal for access to CBERS-2 browse images and data 
139. Group on Earth Observation established the Forest Carton Tracking national demonstrators

140. Participants at Group on Earth Observation established the Forest Carton Tracking meetings in Woods Hole Research Center

141. Communications and Outreach designed the National Land Cover Dataset 2001 display, which now hangs outside the training rooms at EROS.

142. The new display at Sioux Falls Regional Airport shows satellite and high-resolution orthoimagery

143. Example from the Earth As Art 3 image gallery ………...............................................100

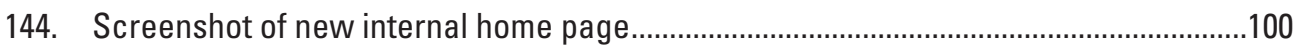

145. Communications and Outreach designed the National Land Cover Dataset 2001 display, which now hangs outside the training rooms at EROS......................................101

146. Image of the Week poster depicting the shrinking of the Aral Sea as revealed by Landsat imagery ..101

147. C\&O developed posters of the Gulf Oil Spill to show the public how satellite imagery was helping responders assess the crisis . .102

\section{Tables}

1. Predicted relative changes in annual average hydrological components for the climate change sensitivity simulations.

2. Cropped area estimates for all of Haiti and broken down by Department. Area estimates are in thousands of hectares.

3. UNEP 3-D environmental change videos and YouTube viewer statistics. .98

\section{Acronyms}

$A A G$

ARRA

ARTS

ASB

ASPRS

ASRC

ASTER

AVHRR

BATC

BER

BFRI

BLM

$\mathrm{C} \& \mathrm{DH}$

C\&O

CAF

CCSDS
Association of American Geographers

American Recovery and Reinvestment Act

ASRC Research and Technology Solutions

Administrative Service Branch

American Society for Photogrammetry and Remote Sensing

Arctic Slope Regional Corporation

Advanced Spaceborne Thermal Emission and Reflection Radiometer

Advanced Very High Resolution Radiometer

Ball Aerospace and Technologies Corporation

bit error rate

Basin Floodwater Regulation Index

Bureau of Land Management

command and data handling

Communications and Outreach

Andean Development Bank

Consultative Committee on Space Data Systems 


\begin{tabular}{|c|c|}
\hline CDR & Critical Design Review \\
\hline CEN & Climate Effects Network \\
\hline CEOS & Committee on Earth Observation Satellites \\
\hline CFDP & CCSDS File Data Protocol \\
\hline CIDR & CRSSP Imagery Derived Requirements \\
\hline CLICK & Center for Lidar Information Coordination and Knowledge \\
\hline CNES & Centre National d'Etudes Spatiales \\
\hline $\mathrm{CO}_{2}$ & carbon dioxide \\
\hline COE & Corps of Engineers \\
\hline CONAE & Comisión Nacional de Actividades Espaciales \\
\hline CRICKet & Center for Radar Information Coordination and Knowledge et al \\
\hline CRP & Conservation Reserve Program \\
\hline CRSSP & Commercial Remote Sensing Space Policy \\
\hline CSA & Canadian Space Agency \\
\hline CSE & Center for Ecological Monitoring \\
\hline CSW & Catalog Service for the Web \\
\hline CVT & Calibration and Validation Team \\
\hline CWIC & CEOS/WGISS Integrated Catalog \\
\hline DCRS & Data Collection and Routing Subsystem \\
\hline DEM & Digital Elevation Model \\
\hline DIQAP & Digital Imagery Quality Assurance Plan \\
\hline DIRSIG & Digital Imaging and Remote Sensing Image Generation \\
\hline DLR & German Aerospace Center \\
\hline DNDC & Denitrification-Decomposition \\
\hline DOD & Department of Defense \\
\hline DOI & Department of the Interior \\
\hline DPAS & Data Processing and Archive System \\
\hline DSTF & Data Sharing Task Force \\
\hline ECHO/WIST & EOS ClearingHOuse/Warehouse Inventory Search Tool \\
\hline EC-LUE & Eddy Covariance-Light Use Efficiency \\
\hline EDCM & Erosion-Deposition-Carbon-Model \\
\hline EDU & Engineering Development Unit \\
\hline EISA & Energy Independence and Security Act \\
\hline EM & engineering model \\
\hline eMODIS & "enhanced" Moderate Resolution Imaging Spectroradiometer \\
\hline
\end{tabular}




\begin{tabular}{|c|c|}
\hline EOS & Earth Observing System \\
\hline EOSDIS & EOS Data and Information System \\
\hline EPA & ecosystem performance anomaly \\
\hline EPA & Environmental Protection Agency \\
\hline EROS & Earth Resources Observation and Science \\
\hline ERSDAC & Earth Remote Sensing Data Analysis Center \\
\hline ERTS-1 & Earth Resources Technology Satellite 1 \\
\hline ES & Ecosystem Services \\
\hline ESA & European Space Agency \\
\hline $\mathrm{ESCl}$ & ES Change Indicator \\
\hline ESDIS & Earth Science Data and Information System \\
\hline ESRI & Environmental Systems Research Institute \\
\hline ET & Evapotranspiration \\
\hline ETM+ & Enhanced Thematic Mapper Plus \\
\hline EVI & enhanced vegetation index \\
\hline FAO & Food and Agriculture Organization \\
\hline FBMS & Financial Business Management System \\
\hline FCT & Forest Carbon Tracking \\
\hline FEC & forward error correction \\
\hline FEWS NET & Famine Early Warning System Network \\
\hline FEWS & Famine Early Warning System \\
\hline FFP & Food for Peace \\
\hline FORE-SCE & Forecasting Scenarios \\
\hline FRED & Framed Raw Expanded Data \\
\hline FY & fiscal year \\
\hline GALS & Geoscience Laser Altimeter System \\
\hline GDEM & Global Digital Elevation Model \\
\hline GEMS & General Ensemble biogeochemical Modeling System \\
\hline GEO & Group on Earth Observation \\
\hline GEOSS & Global Earth Observation System of Systems \\
\hline GeoTIFF & Georeferenced Tagged Image File Format \\
\hline GHG & greenhouse gas \\
\hline GINA & Geographic Information Network of Alaska \\
\hline GIS & Geographic Information System \\
\hline GISTDA & Geo-Informatics and Space Technology Development Agency \\
\hline
\end{tabular}




\begin{tabular}{|c|c|}
\hline GMTED2010 & Global Multi-Resolution Terrain Elevation Data \\
\hline GNE & Ground Network Element \\
\hline GOFC/GOLD & $\begin{array}{l}\text { Global Observation of Forest Cover/Global Observation of Land } \\
\text { scape Dynamics }\end{array}$ \\
\hline GOS & Geospatial One Stop \\
\hline GPP & gross primary productivity \\
\hline GPRB & Greater Platte River Basin \\
\hline GRB & Green River Basin \\
\hline GRID & Global Resource Information Database \\
\hline GS NDVI & growing season Normalized Difference Vegetation Index \\
\hline GSFC & Goddard Space Flight Center \\
\hline HRO & High Resolution Orthoimagery \\
\hline ICESat & Ice, Cloud, and land Elevation Satellite \\
\hline IGARSS & International Geoscience and Remote Sensing Symposium \\
\hline INPE & Instituto Nacional de Pesquisas Espaciais \\
\hline InSAR & interferometric SAR \\
\hline IPCC & Intergovernmental Panel on Climate Change \\
\hline ISO & International Standards Organization \\
\hline ISPRS & International Society of Photogrammetry and Remote Sensing \\
\hline ISRO & Indian Space Research Organisation \\
\hline IVOS & Infrared and Visible Optical Sensors \\
\hline JACIE & Joint Agency Civil Imagery Evaluation \\
\hline JAXA & Japan Aerospace Exploration Agency \\
\hline LAADS & Level 1 and Atmospheric Distribution System \\
\hline LANCE & Land and Atmosphere Near real time Capability for EOS \\
\hline LANDFIRE & Landscape Fire and Resource Management Planning Tools \\
\hline LCLUC & Land Cover Land Use Change \\
\hline LDCC & Landsat Data Continuity Contract \\
\hline LDCM & Landsat Data Continuity Mission \\
\hline LDPC & Low Density Parity Check \\
\hline LGAC & Landsat Global Archive Consolidation \\
\hline LGN & LDCM ground network \\
\hline LGSOWG & Landsat Ground Station Operators Working Group \\
\hline lidar & light detection and ranging \\
\hline LLNL & Lawrence Livermore National Labs \\
\hline & Landsat Metadata Initiative \\
\hline
\end{tabular}




\begin{tabular}{|c|c|}
\hline LP DAAC & Land Processes Distributed Active Archive Center \\
\hline LPGS & Level-1 Product Generation System \\
\hline LPSO & Landsat Project Science Office \\
\hline LSDS & Land Satellites Data System \\
\hline LSI & Land Surface Imaging \\
\hline LST & land surface temperature \\
\hline LTAP-8 & Long Term Acquisition Plan 8 \\
\hline LULC & land use and land cover \\
\hline MAPPS & Management Association for Private Photogrammetric Surveyors \\
\hline $\mathrm{MCl}$ & Mid-Continent Intensive \\
\hline METI & Ministry of Economy Trade and Industry \\
\hline MIrAD-US & MODIS Irrigated Agriculture Dataset \\
\hline MISR & Multiangle Imaging SpectroRadiometer \\
\hline MOC & mission operations center \\
\hline MOD17A2 & MODIS Gross Primary Production \\
\hline MODIS & Moderate Resolution Imaging Spectroradiometer \\
\hline MRLC & Multi-Resolution Land Characteristics Consortium \\
\hline MSS & Multispectral Scanner \\
\hline MTBS & Monitoring Trends in Burn Severity \\
\hline $\mathrm{N}_{2} \mathrm{O}$ & nitrous oxide \\
\hline NAIP & National Agriculture Imagery Program \\
\hline NALCMS & North American Land Change Monitoring System \\
\hline NASA & National Aeronautics and Space Administration \\
\hline ND & “National Demonstrator" \\
\hline NDII & normalized difference infrared index \\
\hline NDVI & Normalized Difference Vegetation Index \\
\hline NED & National Elevation Dataset \\
\hline NEE & net ecosystem exchange \\
\hline NEPA & National Environmental Policy Act \\
\hline NGA & National Geospatial-Intelligence Agency \\
\hline NGB & National Guard Bureau \\
\hline NGP & National Geospatial Program \\
\hline NIH & National Institutes of Health \\
\hline NIST & National Institute of Standards and Technology \\
\hline NLAPS & National Landsat Archive Processing System \\
\hline
\end{tabular}




\begin{tabular}{|c|c|}
\hline NLCD & National Land Cover Database \\
\hline NPWRC & Northern Prairie Wildlife Research Center \\
\hline NSLRSDA & National Satellite Land Remote Sensing Data Archive \\
\hline NSTA & National Science Teacher Associa $\operatorname{tion}$ \\
\hline $0 \& M$ & Operations and Maintenance \\
\hline OGC & Open Geospatial Consortium \\
\hline OSL & Optical Science Laboratory \\
\hline PE\&RS & Photogrammetric Engineering and Remote Sensing \\
\hline PPR & Prairie Pothole Region \\
\hline QA & Quality Assurance \\
\hline QA4EO & Quality Assurance Framework for Earth Observation \\
\hline RCMRD & Regional Centre for Mapping of Resources for Development \\
\hline RFA & request for action \\
\hline RIT & Rochester Institute of Technology \\
\hline RSAC & Remote Sensing Applications Center \\
\hline RSS & Rich Site Summary \\
\hline RST & Remote Sensing Technologies \\
\hline SAN & Storage Area Network \\
\hline SAR & synthetic aperture radar \\
\hline SBA & Societal Benefit Area \\
\hline SDE & Spatial Database Engine \\
\hline SDSU & South Dakota State University \\
\hline SDT & Science Definition Team \\
\hline SERC & Smithsonian Environmental Research Station \\
\hline SERVIR & $\begin{array}{l}\text { Regional Visualization and Monitoring System for environmental } \\
\text { management and disaster response }\end{array}$ \\
\hline SOC & Soil organic carbon \\
\hline SPOT & Satellite Pour l'Observation de la Terre \\
\hline SRTM & Shuttle Radar Topography Mission \\
\hline SSEB & Simplified Surface Energy Balance \\
\hline SWAT & Soil and Water Assessment Tool \\
\hline TAA & Technical Assistance Agreements \\
\hline TIM & Technical Interchange Meetings \\
\hline TIR & thermal infrared \\
\hline TIRS & Thermal Infrared Sensor \\
\hline TM & Thematic Mapper \\
\hline
\end{tabular}




\begin{tabular}{|c|c|}
\hline TPS & Topographic Processing Service \\
\hline TSSC & Technical Support Services Contract \\
\hline UA & University of Arizona \\
\hline UAVs & Unmanned Aerial Vehicles \\
\hline UNFCCC & United Nations Framework Convention on Climate Change \\
\hline USAF & U.S. Air Force \\
\hline USAID & U.S. Agency for International Development \\
\hline USDA & U.S. Department of Agriculture \\
\hline USFWS & U.S. Fish and Wildlife Service \\
\hline USGS & U.S. Geological Survey \\
\hline USPED & Unit Stream Power-based Soil Erosion and Deposition model \\
\hline VCT & Vegetation Change Tracker \\
\hline Vis & vegetation indices \\
\hline VNIR & visible and near-infrared \\
\hline WBVT & Wide Band Video Tape \\
\hline WCS & Web Coverage Service \\
\hline WGCV & Working Group on Calibration and Validation \\
\hline WGISS & Working Group on Information Systems and Services \\
\hline WHRC & Woods Hole Research Center \\
\hline WMS & Web Mapping Service \\
\hline YRB & Yukon River Basin \\
\hline
\end{tabular}




\title{
U.S. Geological Survey (USGS) Earth Resources Observation and Science (EROS) Center- Fiscal Year 2010 Annual Report
}

\author{
Compiled by Janice S. Nelson
}

\section{Introduction}

The Earth Resources Observation and Science (EROS) Center is a U.S. Geological Survey (USGS) facility focused on providing science and imagery to better understand our Earth. The work of the Center is shaped by the earth sciences, the missions of our stakeholders, and implemented through strong program and project management, and application of state-of-the-art information technologies. Fundamentally, EROS contributes to the understanding of a changing Earth through "research to operations" activities that include developing, implementing, and operating remote-sensing-based terrestrial monitoring capabilities needed to address interdisciplinary science and applications objectives at all levels - both nationally and internationally.

The Center's programs and projects continually strive to meet, and where possible exceed, the changing needs of the USGS, the Department of the Interior, our Nation, and international constituents. The Center's multidisciplinary staff uses their unique expertise in remote sensing science and technologies to conduct basic and applied research, data acquisition, systems engineering, information access and management, and archive preservation to address the Nation's most critical needs. Of particular note is the role of EROS as the primary provider of Landsat data, the longest comprehensive global land Earth observation record ever collected.

This report is intended to provide an overview of the scientific and engineering achievements and illustrate the range and scope of the activities and accomplishments at EROS throughout fiscal year (FY) 2010. Additional information concerning the scientific, engineering, and operational achievements can be obtained from the scientific papers and other documents published by EROS staff or by visiting our web site at http://eros.usgs.gov.

We welcome comments and follow-up questions on any aspect of this Annual Report and invite any of our customers or partners to contact us at their convenience. To communicate with us, or for more information about EROS, contact: Communications and Outreach, USGS EROS Center, 47914 252nd Street, Sioux Falls, South Dakota 57198, jsnelson@usgs.gov, http://eros. usgs.gov/.

\section{Fiscal Year 2010 in Review}

\section{Science and Applications Activities}

The Center's science and applications activities include multidisciplinary earth science research, remote sensing applications development, and generation of associated products such as oral presentations, publications, workshops, databases, and websites. EROS science and applications activities are aligned with the USGS strategic science goals and priorities.

Disciplines and skills represented in science activities at EROS include geography, cartography, geology, soil science, hydrology, biology, ecology, forestry, range management, geochemistry, computer science, applied physics and remote sensing, mathematics, and statistics.

Science partners and collaborators include the USGS science centers, other USGS mission areas and offices and their associated bureau programs, other bureaus and agencies within the U.S. Department of the Interior (DOI), bureaus and agencies in other departments of the Federal Government, State agencies, tribal governments and universities, non-Government agencies, academic institutions, and international organizations.

The Center's research and applications activities are conducted via five teams and take full advantage of the Center's extensive national and global archive of remotely sensed data. On the following pages, the science and applications teams' primary objectives are highlighted followed by key accomplishments of each. 


\section{Fire Science}

The Fire Science Team conducts, applies, leads, and advances fire science by supporting the DOI, other land management agencies, and their fire management programs with scientifically credible, timely, reliable, and nationally consistent data, and constructive collaboration with other partners. Key accomplishments are given in the following sections.

\section{Forest Change Detection using ICESat Data and VCT Output}

The research encompassed by this work plan is being conducted in support of the ICESat-2 Science Definition Team (SDT). The work outlined in the proposal used large-footprint, waveform lidar data collected by the Geoscience Laser Altimeter System (GLAS) instrument onboard Ice, Cloud and land Elevation Satellite (ICESat) as well as products from the Vegetation Change Tracker (VCT) to study forest vegetation structure and change. The main objectives of this research are twofold:

(1) demonstrate that when used in combination with geospatial layers of change the three-dimensional information provided by GLAS waveform data will enable the characterization of the effects of that change on vegetation structure and (2) provide a set of data requirements in terms of lidar footprint size, density, and spacing needed to address the above. The EROS project lead serves on the ICESat-2 SDT. The ICESat-2 project decision to employ a photon-counting lidar system on ICESat-2 has resulted in the need for the SDT to conduct basic research into the expected performance of such an instrument from space, over different surfaces, and under different configurations. This has resulted in an additional work effort than initially anticipated based on the original proposal to the National Aeronautics and Space Administration (NASA).

In FY 2010, work has proceeded on the original proposed work including downloading and processing GLAS data for the study area on the southeastern coastal plain of the United States. The VCT outputs have been generated and the results largely validated for the study area. Work has also progressed in the analysis of airborne photon-counting data sub-canopy ground detection capability. The airborne data were collected over two study areas, the Pine Barrens in New Jersey and the Smithsonian Environmental Research Station (SERC) in Maryland. Early results indicate that in more open canopies ground-finding performance will be sufficient to meet the science requirements of the mission. However, finding sub-canopy ground is substantially more challenging in denser canopies (fig. 1), such as those found at SERC, and continued research is being done using the airborne data to test other instrument design configurations and to develop better algorithms. For further information, contact Matt Rollins, USGS EROS, mrollins@usgs.gov.
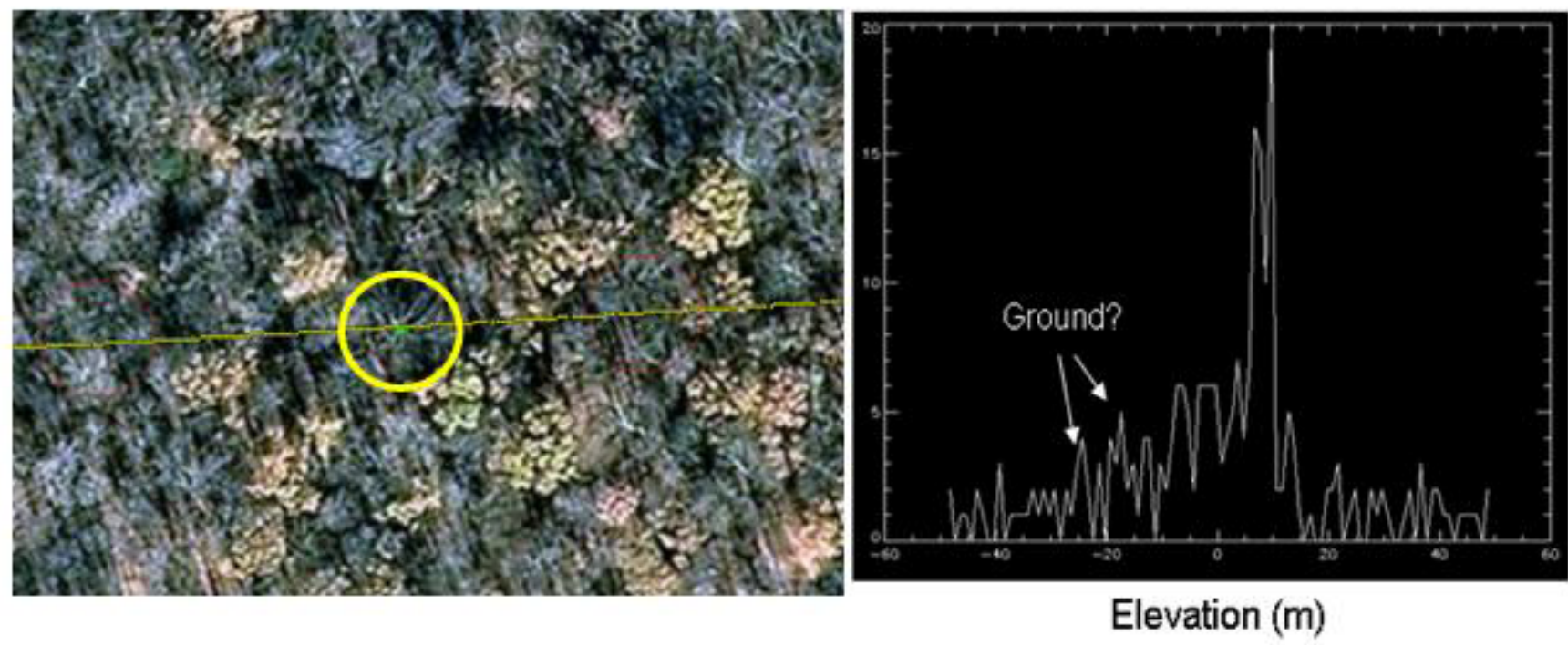

Figure 1. Transect line of photon-counting lidar data flown over SERC is shown in yellow (left). The yellow circle indicates the area of data extracted and histogrammed (right). The histogram shows that for this area a clear ground signal is difficult to identify.

\section{The LANDFIRE Program: Consistent and Comprehensive National Vegetation and Wildland Fuel Mapping}

The Landscape Fire and Resource Management Planning Tools (LANDFIRE) project was a 5-year (2004-2009), multipartner project that produced consistent and comprehensive maps and data describing vegetation, wildland fuel, and fire regimes 
across the United States. The LANDFIRE project produced national data products that included layers of vegetation composition and structure, surface and canopy fuel characteristics, and historical fire regimes. Having met the original mandate, the LANDFIRE Program now enters a phase that protects the significant investment of the original development project by updating products. Most importantly, the program will provide for data timeliness, quality, and distribution services to support Department and Agency mission needs across the country.

The LANDFIRE program supports and provides for updated data products that reflect dynamic changes in large landscape condition because of natural and human-caused environmental events. The level of landscape change resulting from wildland fire since LANDFIRE national datasets were produced is illustrated in figure 2. A key component in the development of the LANDFIRE project for existing vegetation and fuel layers has been satellite imagery; however, these originated from image acquisitions collected from 1999 to 2002. The LANDFIRE Program updates are based on disturbance information collected from a variety of different information sources including the Monitoring Trends in Burn Severity Project, from the analysis of remote sensing information that captures detectable changes (change vector analysis of Landsat data stacks), and from ground truthed data supplied by land managers. The updates will continue on a regular yearly schedule until a new National remapping can be scheduled. For further information, contact Donald Ohlen, USGS EROS, ohlen@usgs.gov.

\section{Yearly Acreage Impacted by Fire}

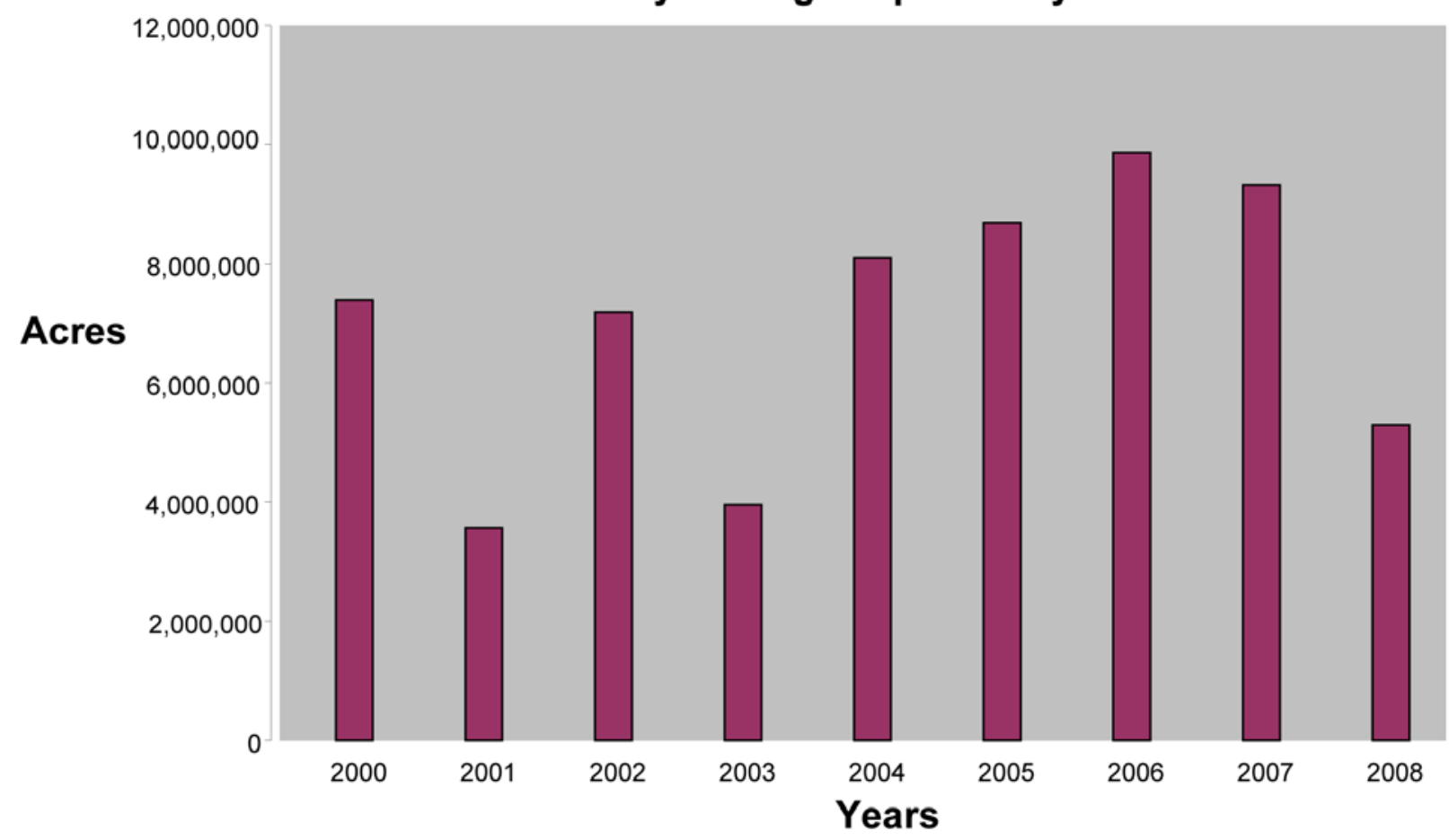

Figure 2. Illustrates the level of landscape change resulting from wildland fire since LANDFIRE national datasets were produced.

\section{Monitoring Trends in Burn Severity}

The USGS EROS and the U.S. Forest Service Remote Sensing Applications Center (RSAC) share responsibility to carry out the mandate of the Monitoring Trends in Burn Severity (MTBS) project to map and assess all large fires that occurred in the United States since 1984 (figs. 3 and 4). FY 2010 marked the last year of a 5-year reimbursable agreement to implement the program. This FY, USGS EROS completed the assessment of historical South Central fires and its allotment of calendar year 2008 fires across the United States and Alaska. At the end of FY 2010, more than 14,000 fire assessments were available at the MTBS website (http://mtbs.gov/). To reduce database duplication/synchronization issues and save costs, it was decided to retire the USGS data distribution website and concentrate MTBS website development resources at $h t t p: / / m t b s . g o v$. USGS EROS continued development of software to automate the post-processing of the free Level-1 Product Generation System (LPGS) data into standard products (reflectance, normalized burn ratio, tassel cap, and temperature) and populate the Multi-Resolution Land Characteristics (MRLC) image archive. Various formats of Landsat 4, 5, and 7 Thematic Mapper imagery can now be processed 
by the software. This year, more than 4,000 LPGS scenes were processed and added to the MRLC archive bringing the total to more than 13,000 .

In November 2009, the MTBS project conducted a day-long workshop at the Fourth International Fire Ecology and Management Congress in Savannah, Georgia. Workshop participants were given an overview of the project goals and procedures and were instructed on how to access MTBS datasets, modify the burn severity thresholds if necessary, and utilize the data for specific applications. The workshop slides form the basis of a web-enabled tutorial about MTBS applications.

The free Landsat data policy of the USGS has advanced the MTBS project. Analysts no longer face a constraint on the number of scenes that can be acquired. Early in the project, analysts were limited to two scenes per year and had to make compromises on the selection of the best scene to map a particular fire. The new policy has allowed the MTBS project the opportunity to review and revise previously mapped fires. Using automated techniques, all previously mapped fires throughout

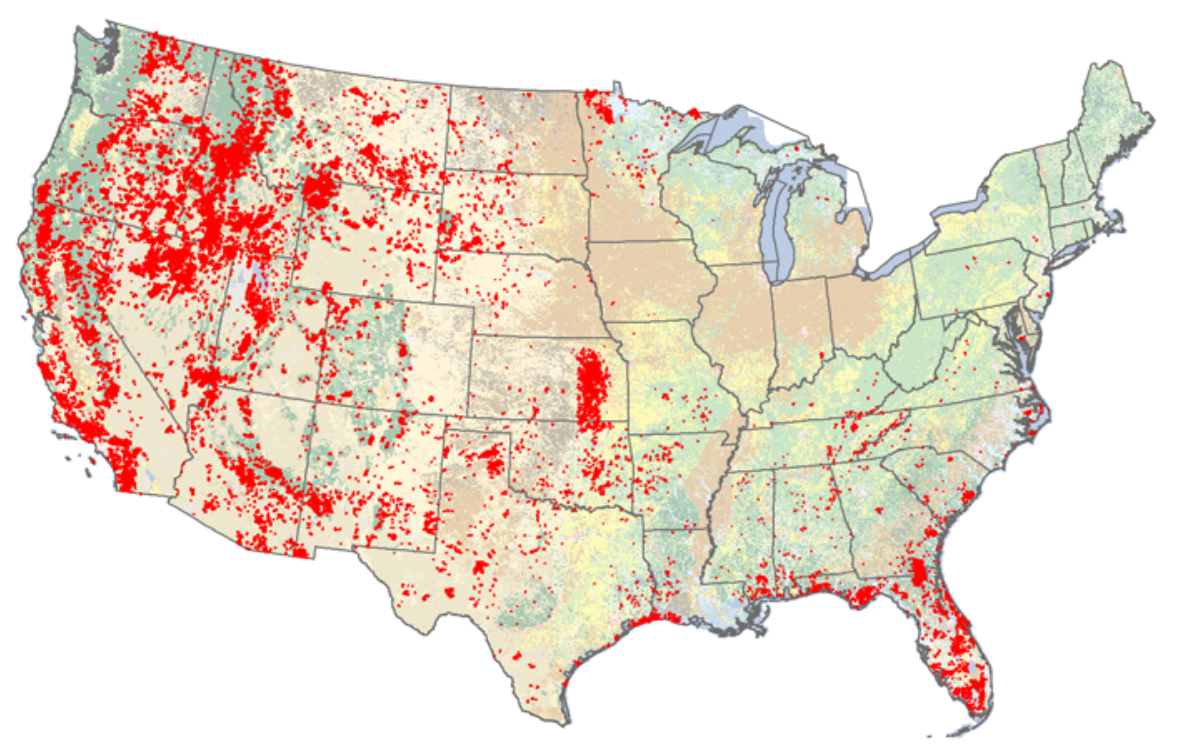

Figure 3. The graphic illustrates the number and extent of the fires (more than 13,000 ) assessed by the Monitoring Trends in Burn Severity project from 1984 to 2008 (northeast historical not yet complete).

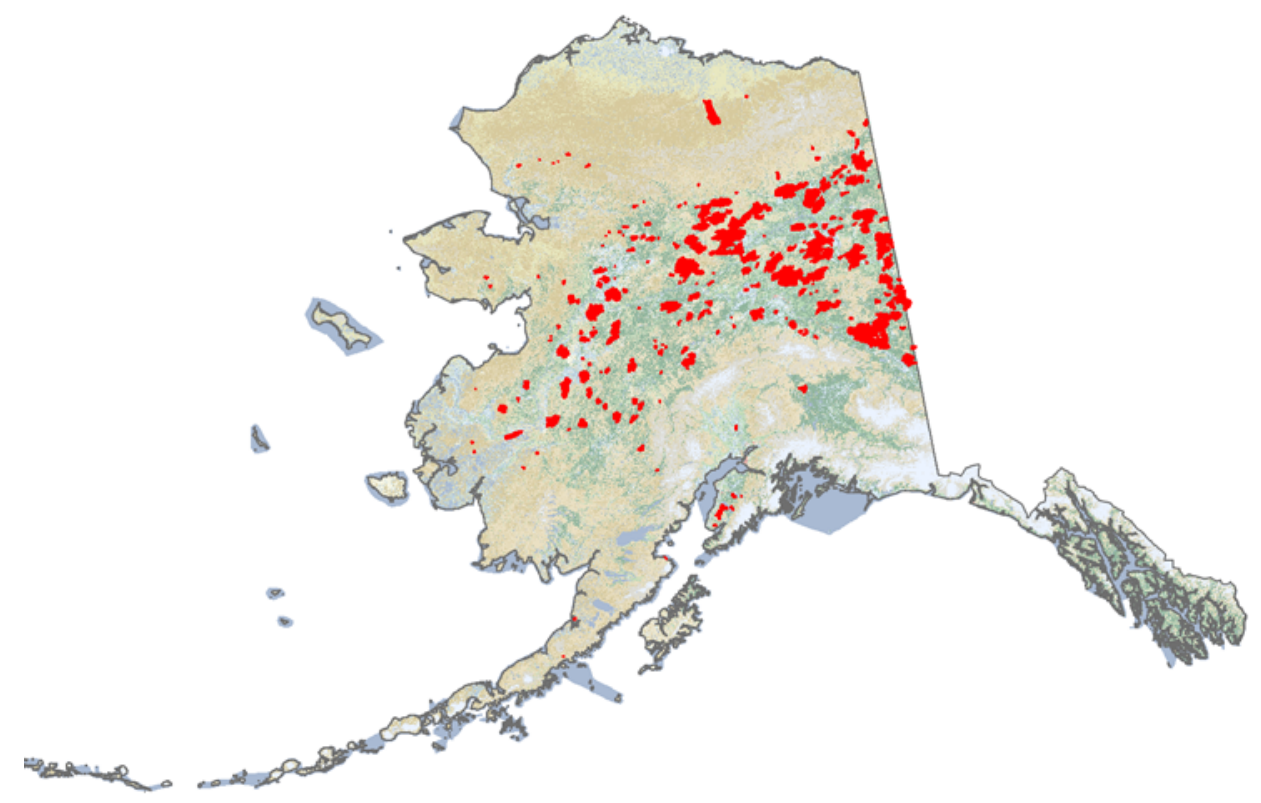

Figure 4. The graphic illustrates the number and extent of the fires (more than 900) in Alaska assessed by the Monitoring Trends in Burn Severity project from 1984 to 2003. Assessments of historical fires in Alaska, Hawaii, and the Northeast is scheduled to be completed by May 2011. 
the United States were assessed to flag fires that need a second look to confirm the suitability of image pairs, burn severity thresholds, and perimeters. For USGS, about 1,000 fires were flagged, reviewed, and revised as necessary. Similarly, a review of MTBS products created for the Southeast revealed that a change in assessment protocol was needed. Vegetation in the southeast grows so quickly that most fires require an "initial" assessment as soon as possible after the fire, rather than an "extended" assessment up to a year later. This change of strategy required that hundreds of previously mapped fires be revised. The free Landsat data policy makes revision economically feasible and new assessments more reliable.

A 5-year follow-on agreement was signed to continue MTBS activities until 2015 to include yearly updates of fire assessments and extending the satellite-derived historical fire record back to the early 1970s using Multispectral Scanner imagery from Landsats 1, 2, and 3. For further information, contact Stephen Howard, USGS EROS, smhoward@usgs.gov.

\section{Land Characterization and Trends}

The Land Characterization and Trends Team develops solutions for characterizing land cover at multiple temporal and spatial scales that enable subsequent analysis, monitoring, forecasting, and reporting of land cover processes. Key accomplishments are given in the following sections.

\section{The 2006 National Land Cover Database Reaches 80 Percent Completion}

The National Land Cover Database (NLCD) project provides consistent public domain information on the Nation's current and historical land cover characteristics that are applicable at national, regional, and local scales. Much of this work is accomplished through partnerships with Federal, State, and local government agencies, private industry, and nongovernmental organizations. NLCD represents three major land cover data releases including a 1992 conterminous U.S. land cover dataset (NLCD 1992); a 2001 land cover database for all 50 states with three thematic layers including land cover, percent imperviousness, and percent tree canopy (NLCD 2001); and a land cover change product that identifies land cover change between the two eras (NLCD 1992/2001 Retrofit Land Cover Change Product).

In FY 2010, production of NLCD 2006 (fig. 5) (updated land cover for the nominal year of 2006) continues for the conterminous United States. NLCD 2006 updates the 2001 land cover and percent imperviousness to the year 2006 and details the type
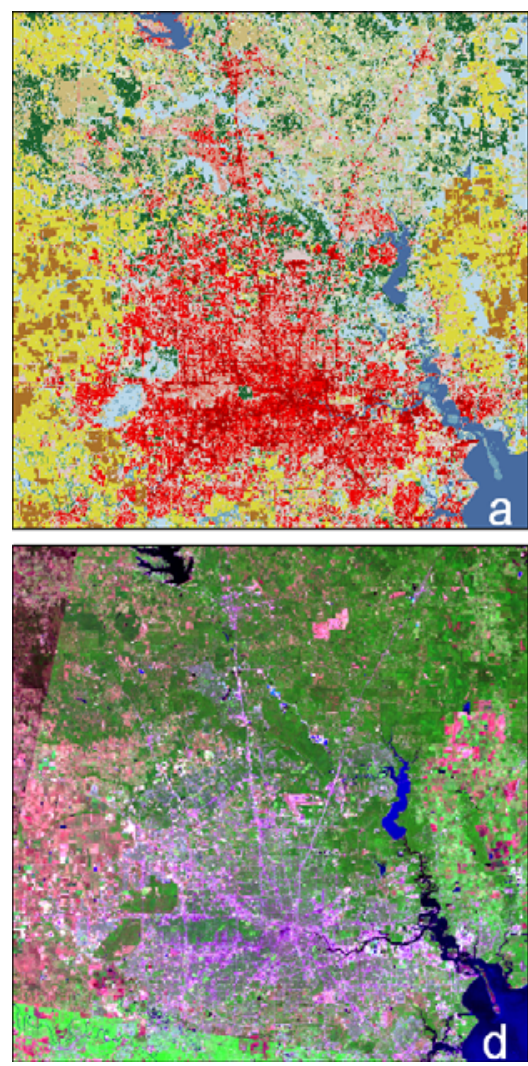
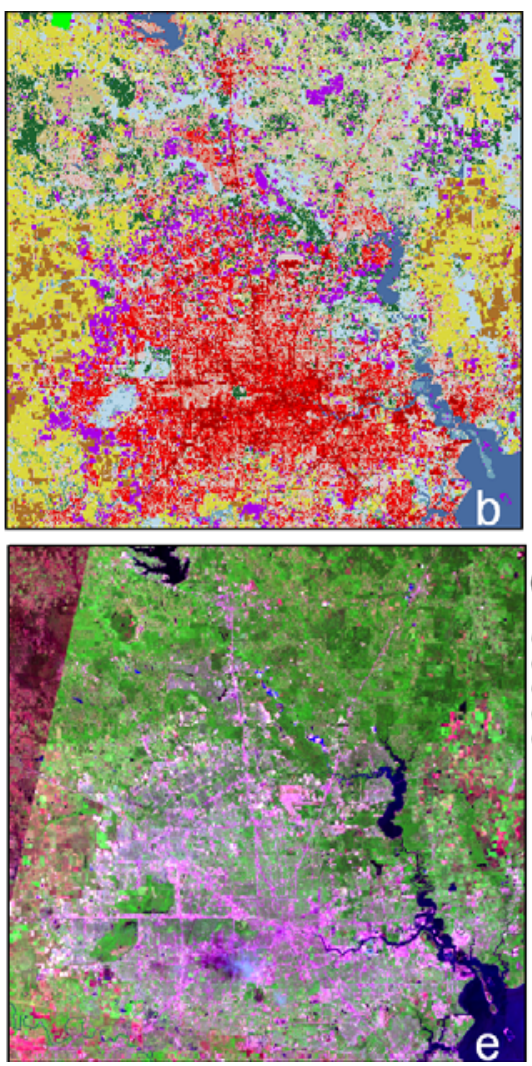
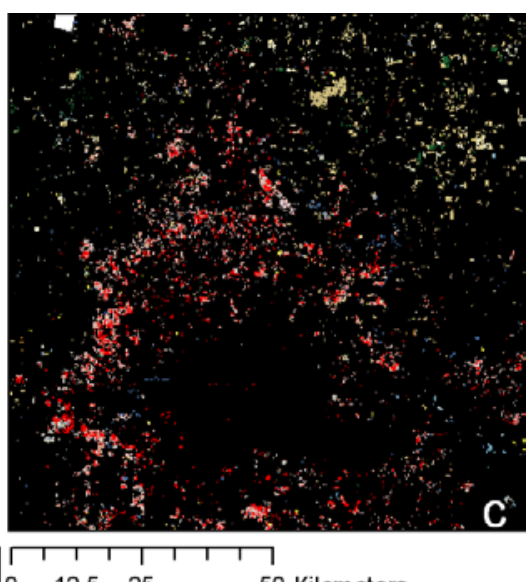

50 Kilometers

(a) NLCD 2001 Landcover

(b) NLCD 2001 Landcover with Change Overlay

(c) NLCD 2006 Change Pixels

(d) 2001 Landsat Imagery

e) 2006 Landsat Imagery

Land Cover Legend

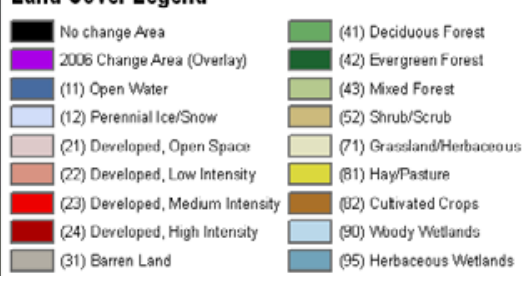

Figure 5. Example of NLCD 2006 and NLCD 2001 land cover change in Houston, Texas. 
and amount of land cover and imperviousness change between 2001 and 2006. During FY 2010, 80 percent of the conterminous United States has been completed. These comprehensive sets of scientifically credible land cover data layers are used to support thousands of applications in land management, environmental studies, and modeling and policy decisions. All NLCD products are web-enabled for download at the MRLC website at $h t t p: / / w w w . m r l c . g o v$. For further information, contact Collin Homer, USGS EROS,homer@usgs.gov.

\section{USGS Delivers New Sagebrush Characterization and Monitoring for Wyoming}

Sagebrush ecosystems in North America have experienced extensive degradation since European settlement and continue to degrade from a variety of factors. Understanding the distribution of system components such as shrub density, bare ground amounts, and grass and forb cover is critical for successful land management.

In Wyoming, widespread oil and gas development is exerting additional pressure on land managers to better understand the distribution of sagebrush habitats. Using three spatial scales of satellite remote sensing, the USGS developed new methods to characterize and monitor change of sagebrush system components (fig. 6). Four primary components (percent bare ground, percent herbaceous cover, percent litter, and percent shrub) and four secondary components (percent sagebrush, percent big sagebrush, percent Wyoming sagebrush, and shrub height) have been mapped with 30-meter pixels. These products are designed to provide maximum flexibility for a wide variety of ecosystem applications such as wildlife habitat and grazing and climate change assessments, and to provide a sagebrush monitoring database that is sensitive enough to discriminate significant change through time. For further information, contact Collin Homer, USGS EROS, homer@usgs.gov.

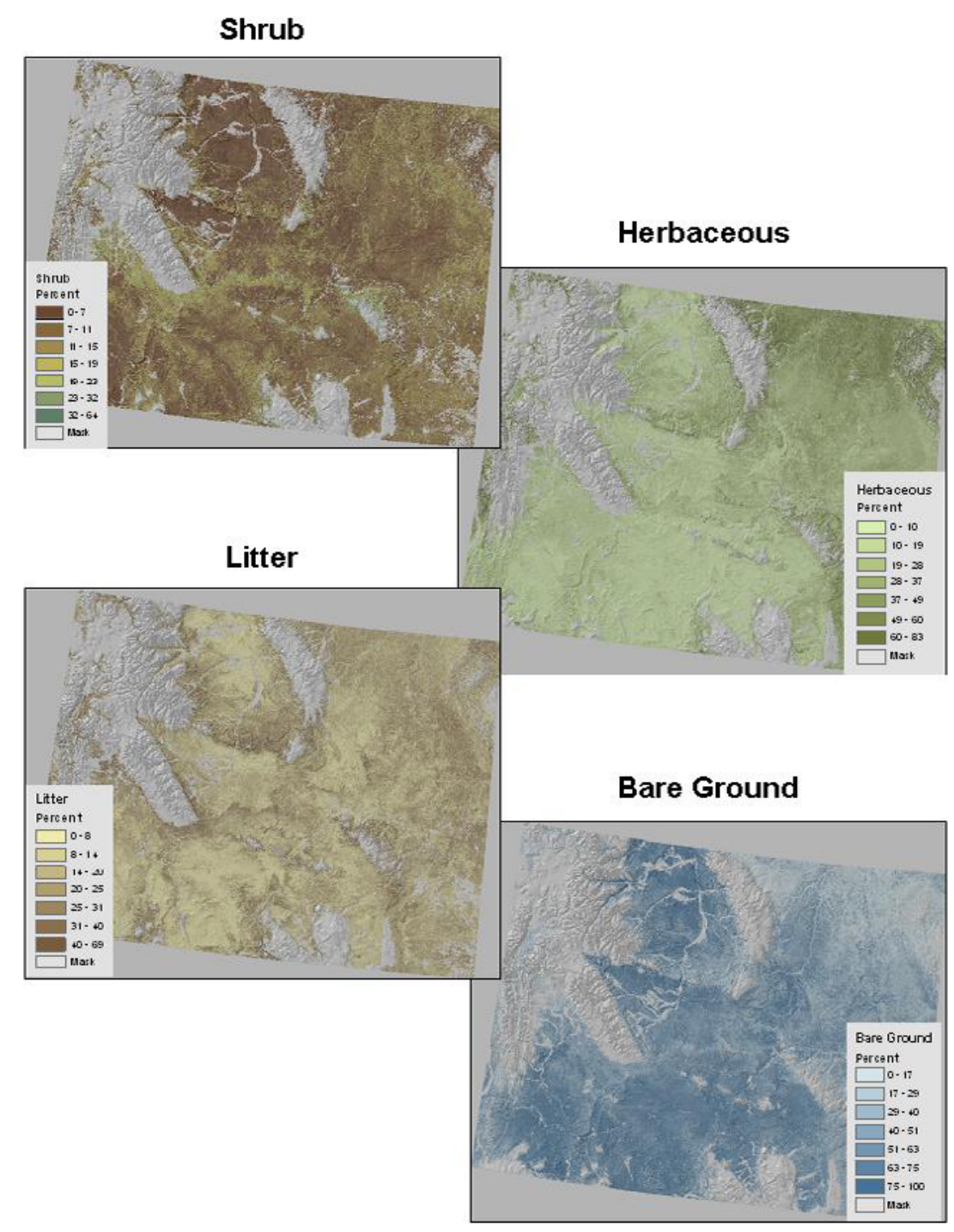

Figure 6. Example of four statewide primary components from combined Landsat and Advanced Wide Field Sensor predictions including percent estimates of shrub, herbaceous, litter, and bare ground for each 30-meter cell. 


\section{USGS Collaborates with Canada and Mexico to Produce the North American Land Change Monitoring System}

A digital database (and a paper map) of North American land cover, circa 2005, at a spatial resolution of 250 meters was completed and released (fig. 7). This product provides a harmonized view of the physical land cover across the continent. Nineteen land cover classes were defined using standard definitions from the Food and Agriculture Organization (FAO) of the United Nations by using monthly composites of 2005 Moderate Resolution Imaging Spectroradiometer satellite imagery. This product represents the first in a series of products that will be produced by the North American Land Change Monitoring System (NALCMS).

NALCMS is a collaborative initiative between Canada, Mexico, and the United States to monitor land cover and its change through time. Information provided by this land cover database can be used to address issues such as climate change, carbon sequestration, biodiversity loss, and changes in ecosystem structure and function through better understanding of the dynamics and continental-scale patterns of North America's changing land cover. For further information, contact Collin Homer, USGS EROS,homer@usgs.gov.

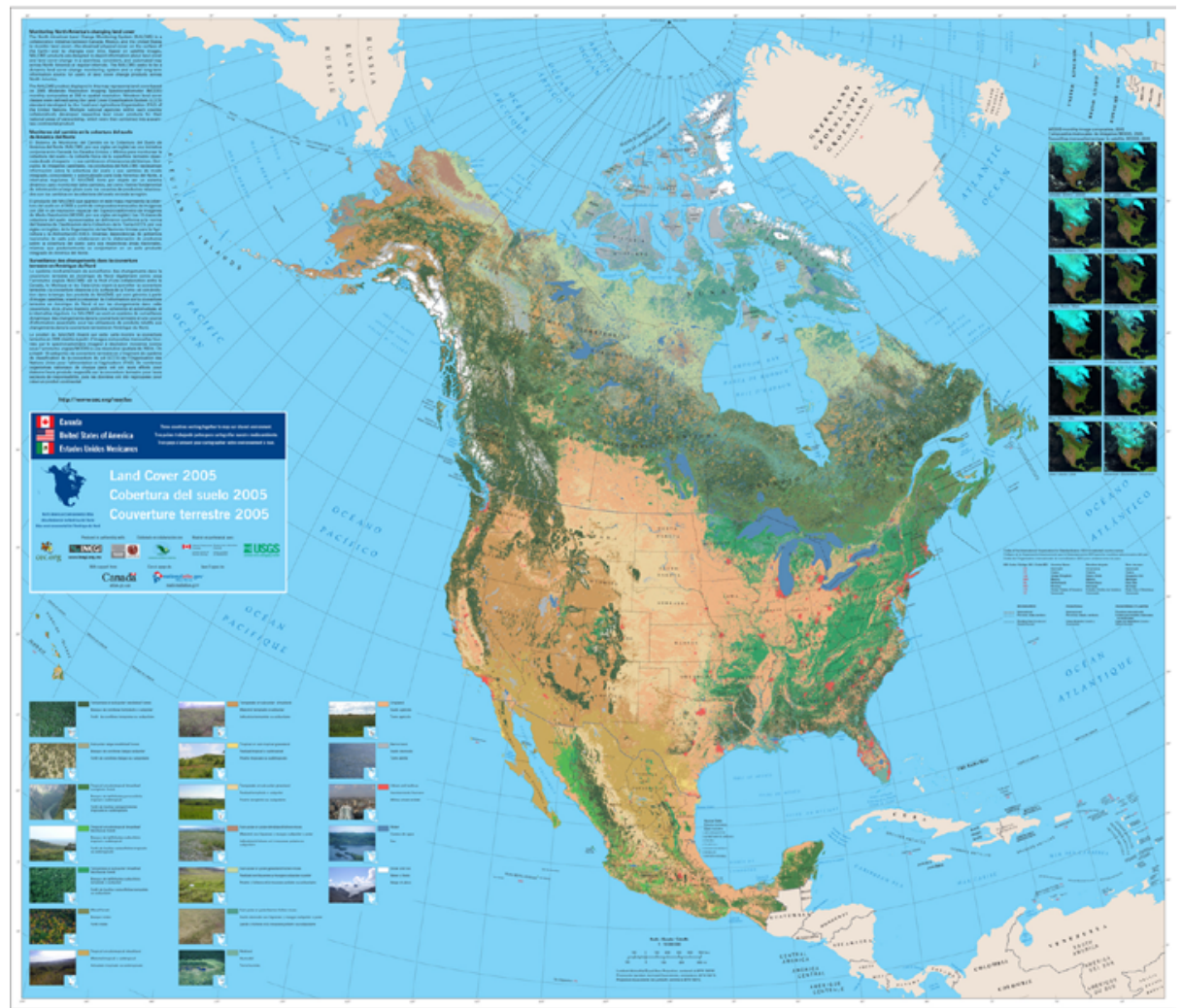

Figure 7. Completed 2005 land cover map produced for the North American Land Change Monitoring System.

\section{Land Cover Forecasting Methodology and Prototype Developed for Ecological Carbon Assessment}

A methodology for the development of realistic, scenario-based, land use and land cover (LULC) forecasts was developed to support a national assessment of ecological carbon sequestration and greenhouse gas flux mitigation. The methodology was developed in response to section 712 of the Energy Independence and Security Act (EISA) of 2007, which mandates the Department of the Interior to assess carbon sequestration and methane $\left(\mathrm{CH}_{4}\right)$ and nitrous oxide $\left(\mathrm{N}_{2} \mathrm{O}\right)$ emissions from ecosystems.

The LULC modeling team developed the methodology to support this work and tested it in two Environmental Protection Agency (EPA) Level III ecoregions in the southeastern United States (fig. 8). One reference scenario ("R" scenario) was developed to portray likely future LULC trajectories from 2010 to 2050 under the Intergovernmental Panel on Climate Change (IPCC) “A1B" scenario. A second scenario, portraying LULC mitigation strategies for sequestering additional carbon above and beyond the reference scenario "R" was also developed ("L" scenario). The reference scenario "R" is devoid of explicit carbon sequestration policy or mitigation actions and portrays the continuation of a dynamic forest industry with moderate urban expansion and little change in the fertile agricultural lands of the Mississippi Alluvial Plains. The "L" scenario portrayed multiple mitigation strategies to increase carbon sequestration, including significant wetland restoration in the Mississippi Alluvial Plains, 
reduced forest cutting, and increased forest rotation cycles. Spatially explicit forecasts of LULC change from 2010 to 2050 were developed for each scenario.

These scenarios were utilized by the Ecological Carbon Sequestration project's biogeochemical modeling team to assess impacts of LULC change under each scenario on carbon and other greenhouse gas fluxes. As mandated by EISA, a comprehensive methodology document was published which describes all components of the Ecological Carbon Sequestration project, including the LULC modeling component. Starting in FY 2011, the methodology will be utilized for a National assessment of carbon and greenhouse gas fluxes in support of EISA. For further information, contact Terry Sohl, USGS EROS, sohl@usgs.gov.
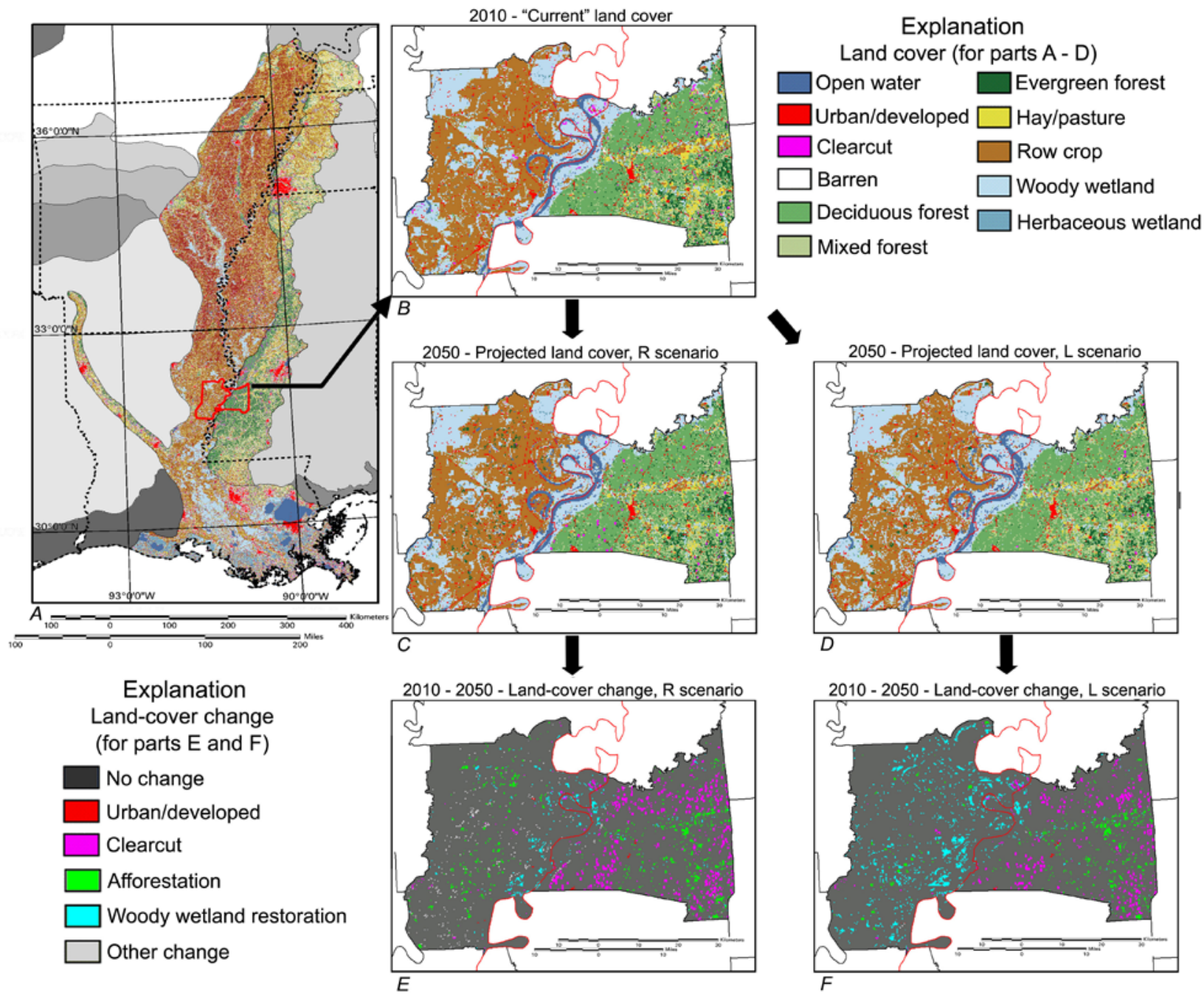

Figure 8. Land use and land cover modeling prototype results for the reference (R) and mitigation (L) scenarios for two Level III ecoregions, the Mississippi Valley Alluvial Plain and the Mississippi Valley Loess Plain. Obvious differences between the $R$ and $L$ scenarios are evident in the 2010 to 2050 land cover change images. The scenario-based LULC forecasts can be utilized to assess carbon sequestration and other greenhouse gas mitigation strategies on a regional basis.

\section{Historical Land Use and Land Cover Modeling in the Western High Plains}

In order to understand the impacts of future land use and land cover (LULC) change on issues such as biodiversity, water quality, carbon dynamics, and climate, it is often useful to examine past system response to LULC change. A spatially explicit and consistent LULC database such as the National Land Cover Database (NLCD) can be utilized to examine contemporary relations with LULC patterns, while the USGS Land Cover Trends database can be utilized to examine effects of historical (1973 to 2000) land use and land cover change. However, the Land Cover Trends database only goes back to 1973, is samplebased, and does not provide wall-to-wall LULC change data. Many applications require LULC data before 1973 or require 
wall-to-wall LULC data. This work is the first attempt to develop historical, wall-to-wall LULC databases consistent with the NLCD framework.

The Forecasting Scenarios (FORE-SCE) land cover model was utilized to provide a historical "backcast" of spatially explicit LULC for the western High Plains. A combination of sample-based Land Cover Trends data, historical county-level agricultural statistics, and historical census data was used to reconstruct county- or ecoregion-level proportions of specific land use and land cover classes back to 1955. The FORE-SCE model was then used to create spatially explicit LULC maps with a thematic resolution comparable to the NLCD. Continued development of historical backcast modeling of LULC provides a capability to recreate historical, spatially explicit, wall-to-wall LULC maps for a fraction of the cost of developing such databases through comprehensive mapping programs. These efforts also provide a rich source of data for applications requiring historical LULC data. For further information, contact Terry Sohl, USGS EROS, sohl@usgs.gov.

\section{National Assessment of Land Use and Land Cover Change}

Scientists from the U.S. Geological Survey completed the initial data collection for the first ever national assessment of land use and land cover (LULC) change. Geographers manually interpreted 429 100-kilometer (km) ${ }^{2}(10-\mathrm{km}$ by 10-km) blocks of up to 11 classes of LULC for 5 dates (1973, 1980, 1986, 1992, and 2000) of archived Landsat Multispectral Scanner (MSS), Thematic Mapper (TM), and Enhanced Thematic Mapper Plus (ETM+) satellite imagery. The block interpretations completed the collection of a stratified random sample of 2,756 blocks allocated across 84 U.S. EPA Level III ecoregions.

In addition to Landsat data, interpreters used historical aerial photographs, topographic maps, and various ancillary data sources to aid in image interpretation. Using a 60-meter minimum mapping unit, interpreters would use manual onscreen photo interpretation techniques to develop an initial baseline land cover map followed by forward and backward classifications of any changes seen in the Landsat images for the other core dates. Change matrix images, block interpretation notes, and time series animation of the land cover changes also were generated for each sample block. The LULC mapping effort yields five individual dates and four discrete periods for analysis. Change analysis uses post-classification comparison of the five dates of thematic LULC data for each sample block to generate estimates of LULC change for each ecoregion in the United States along with corresponding margins of error at an 85 percent confidence level.

This work was established in the early 2000s for the purpose of improving the understanding of the geographic variability and characteristics of 1973 to 2000 U.S. land cover change and for providing a scientific foundation for assessing the environmental consequences of past, present, and future land change. The assessment is based on an ecoregions framework and uses probability sampling and historical Landsat imagery to document the geographical variability of land change (fig. 9). Results from all 84 conterminous U.S. ecoregions show that the responses to various economic, policy, technological, and social driving forces differ substantially based on the unique environmental and socioeconomic factors shaping each ecoregion. Analysis and national synthesis of the data will be conducted in FY 2011. A full explanation of the Land Cover Trends project is provided at http://landcovertrends.usgs.gov. For further information, contact William Acevedo, USGS EROS, wacevedo@usgs.gov.

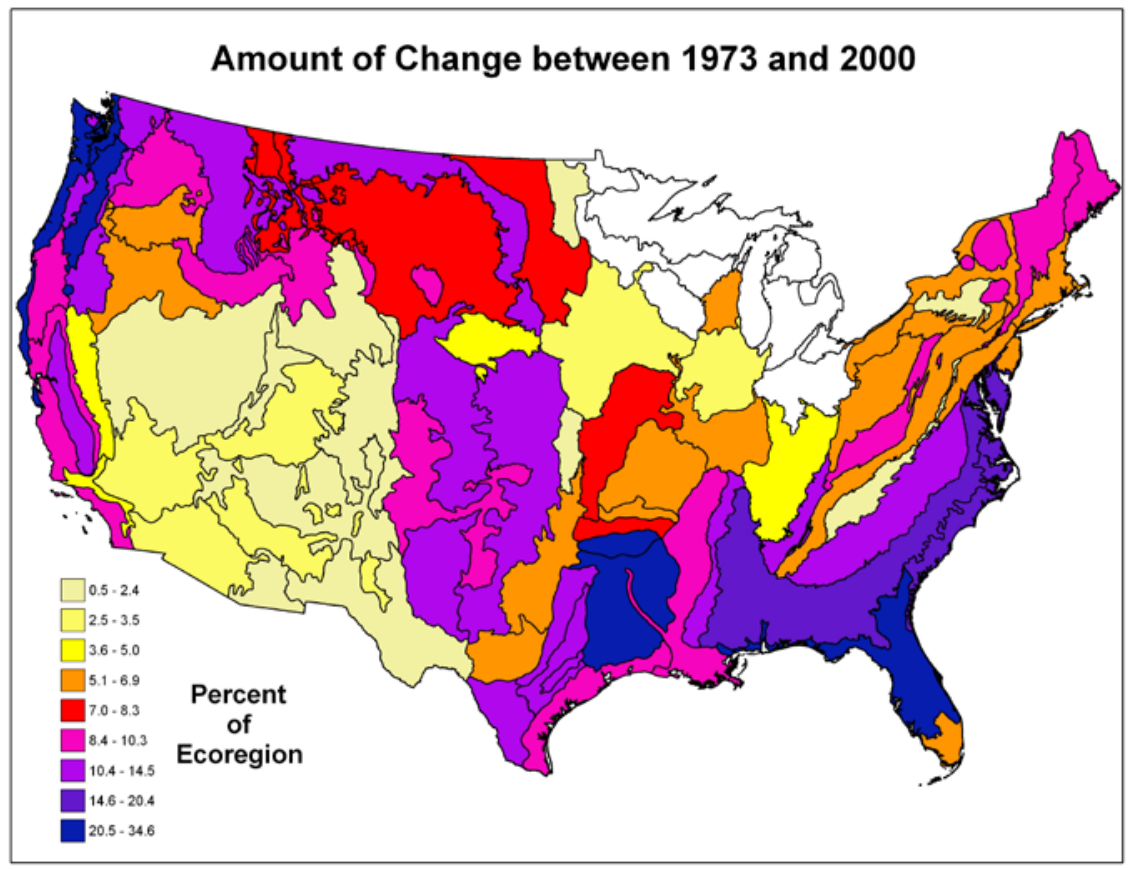

Figure 9. The amount of change between 1973 and 2000 as a percent of each ecoregion for the conterminous United States. Results show the variability in the amount of overall change across the United States and point out how responses to various economic, policy, technological, and social driving forces differ substantially based on the unique environmental and socioeconomic factors shaping each ecoregion. 


\section{Land Cover Applications and Global Change}

The Landscape Dynamics and Global Change Team integrates remote sensing resources with simulation models of natural and managed ecosystems to understand environmental change across landscape units, ecological systems, and multitemporal/ spatial scales in support of a sustainable Earth. Key accomplishments are given in the following sections.

\section{Ecosystem Performance Assessment for the Greater Platte River Basin: Applications on Optimal Land Uses for Bioenergy}

Bioenergy (biofuels) has been used recently and will grow substantially in the future as an energy alternative to fossil fuels. The environmental effects caused by the increase in biofuels development can be large and include increased soil and wind erosion, water quality impairment because of the greater usages of pesticide and fertilizer, and more demand for water for irrigation.

The objective of this study is to evaluate the effects of an expanded agricultural land use for biofuels with concurrent changes in climate on ecosystem sustainability across the Northern Great Plains. The initial focus was on the Greater Platte River Basin (GPRB) with the first study targeting the implementation of a dynamic monitoring of ecosystem performance for grasslands and croplands in the GPRB using nine-years (2000-2008) of satellite observations, climate data, and ecosystem models. The dynamic monitoring of ecosystem performance can identify low performing croplands or high performing grasslands which can be potentially converted to biofuels crops. Maps were generated of areas which may be suitable regions to be converted from grassland to biofuels feedstock in the GPRB (fig. 10). These resulting maps can be used by land managers, decision makers, and biogeochemical modelers for making optimal land uses decisions for biofuel development and sustainability.

Future plans for this project include performing dynamic ecosystem performance analysis for other land cover types (for example, shrub and forest) and identifying regions which may be suitable for biofuels development within the entire GPRB region; extending the study area and performing ecosystem performance analysis for the Northern Great Plains; evaluating the short-term and long-term environmental impacts on the local ecosystem because of the development of the biofuel product; and producing publications on the research results. For further information, contact Bruce Wylie, USGS EROS, wylie@usgs.gov.

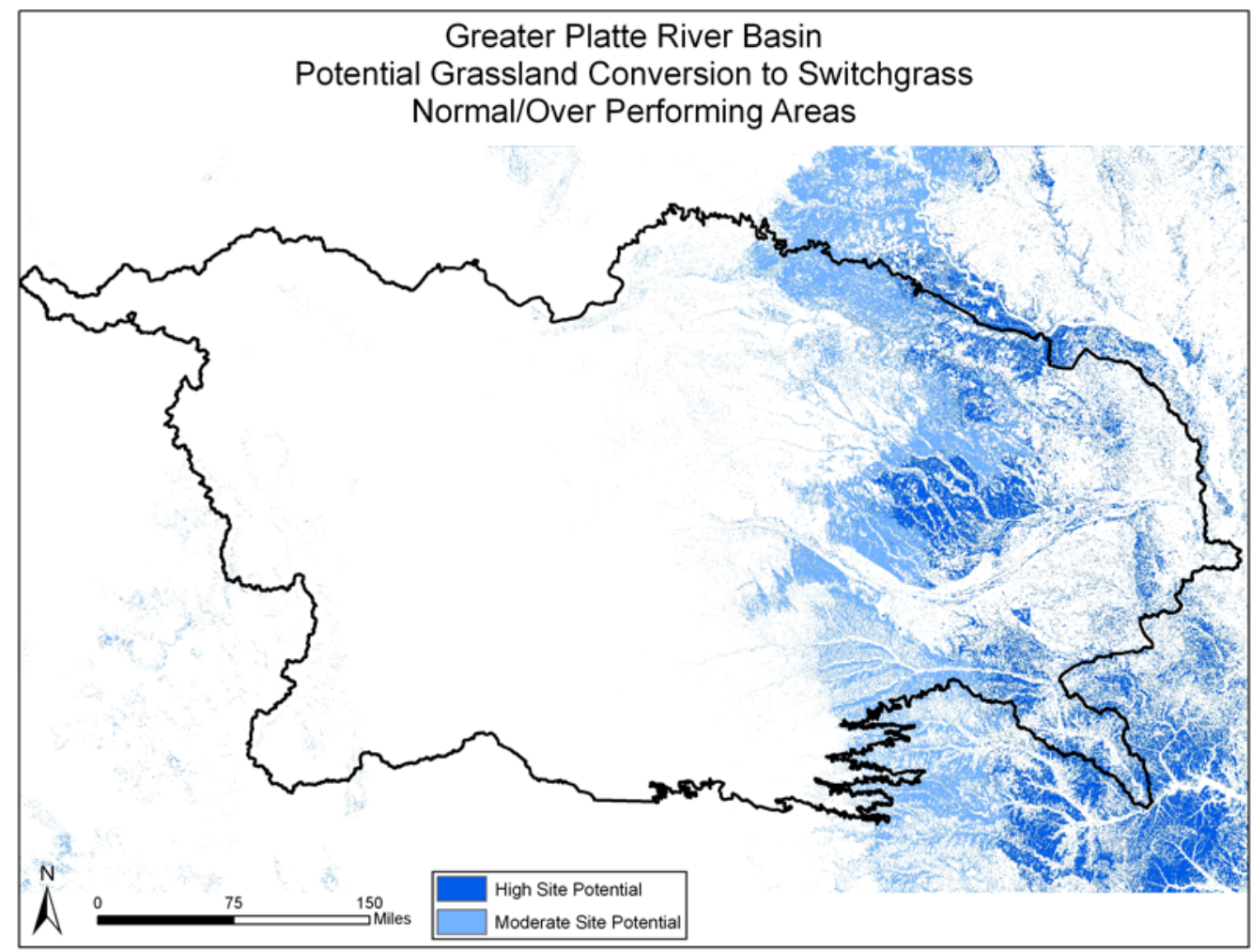

Figure 10. Site potential map for grassland in Greater Platte River Basin. The areas in blue represent pixels that either overperformed or normally performed for three of four years from 2005 to 2008. Overperforming and normal performing areas are where productivity is greater or similar to a weather-based estimate and represent good condition vegetation and fair condition vegetation. 


\section{Carbon Fluxes in the Great Plains}

Grasslands are among the most altered ecosystems in the world with large areas converted to cropland. A changing and more variable future climate will affect grasslands dramatically because they are responsive to prolonged periods of drought or wet conditions and illustrate major biodiversity and compositional changes along moisture gradients. Grasslands have lower aboveground carbon storage compared to forests but cover vast areas of the globe and store most of their carbon belowground. These grassland soil carbon stocks will reduce in areas which may experience future climatic drying and warming. Synoptic monitoring and comprehensive analysis of current and historical grassland carbon fluxes in the Great Plains provide information on interannual variability, expected drought responses, and regional grassland carbon sink and source magnitudes. Detailed light-temperature-vapor pressure deficit-response analysis of the Great Plains and other global flux tower datasets showed consistent patterns for gross photosynthesis, ecosystem respiration, photosynthetic capacity, quantum yield, and light-use efficiency.

Algorithms were derived for estimating these parameters annually and used to produce maps for the Great Plains (fig. 11, left). Daily flux tower net ecosystem exchange (NEE) from the flux tower analysis, synoptic weather data, synoptic photosynthetically active radiation, and other data were temporally summarized to correspond to "enhance" Moderate Resolution Imaging Spectrometer (eMODIS) Normalized Difference Vegetation Index (NDVI) seven-day composites at a spatial resolution of 250 meters. A regression tree model was developed to estimate grassland NEE weekly from 2000 to 2008 (fig. 11, right). Ecoregions within the Great Plains most affected by changing current carbon sinks were identified. For further information, contact Bruce Wylie, USGS EROS, wylie@usgs.gov.
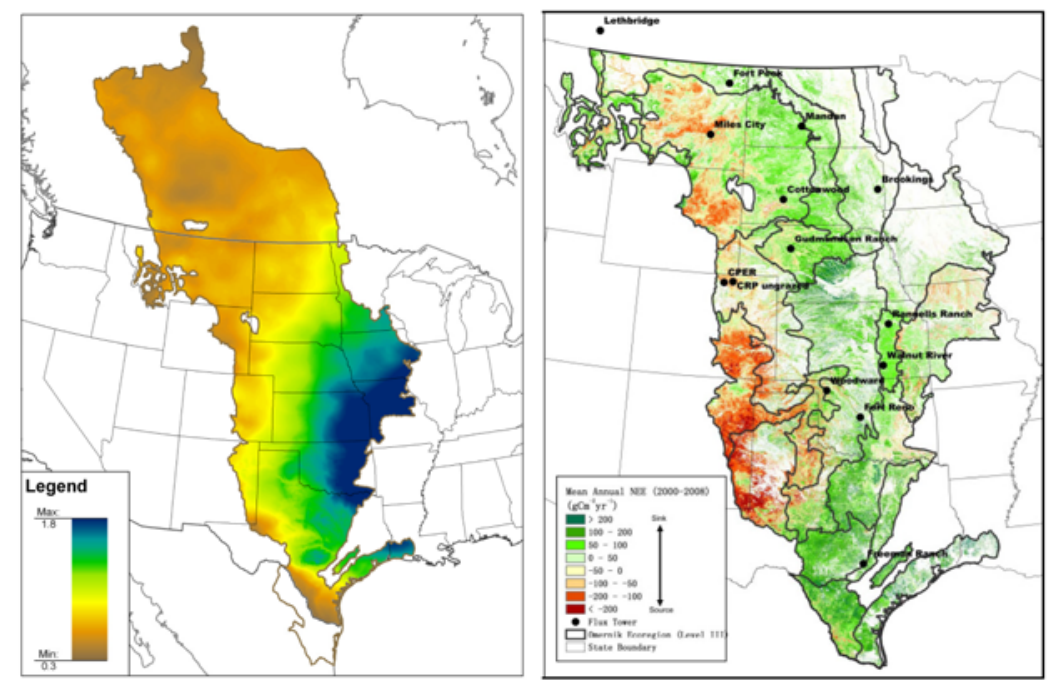

Figure 11. Photosynthetic capacity (Amax) for grassland systems (2000-2008) (left) and grassland mean annual ecosystem exchange (2000-2008) and flux tower locations (right).

\section{eMODIS: Useful MODIS Products for Alaskan Vegetation Studies}

In 2008, the U.S. Geological Survey prototyped Normalized Difference Vegetation Index (NDVI) products that combine the advantages of NASA's Moderate Resolution Imaging Spectroradiometer (MODIS) with user-specific processing options to enhance the use of MODIS data in the Alaskan vegetation monitoring community. As NASA's high-level MODIS products are constrained to programmatic standards that hinder their usability particularly in high-latitude regions, USGS eMODIS Alaska (fig. 12) offers timely 7-day composites projected to the Alaska Albers Equal Area mapping grid in Georeferenced Tagged Image File Format (GeoTIFF) files. These products enable researchers and monitoring agencies to utilize near-daily, 250-, 500-, or 1,000-meter MODIS observations to study short- and long-term changes without significant high-latitude geometric distortion (Ji and others, 2010) or the need for mosaicking, reprojecting, or reformatting in preparation for data application.

Through the USGS National Climate Effects Network (CEN), continued eMODIS Alaska production is supporting vegetation change research at the University of Alaska Fairbanks (Verbyla) and the USGS Alaska Field Office (Selkowitz, 2010). In collaboration with the Geographic Information Network of Alaska (GINA), use of eMODIS data also have operationalized the decision support activities of the Bureau of Land Management and the National Park Service to monitor and respond to vegetation related events such as fire and insect infestation. eMODIS data have likewise served USGS Carbon Cycle, Climate Change, and Geographic Analysis and Monitoring Program activities in the conterminous United States with the addition of near-real time NDVI products for the lower 48 states. For further information, contact Bruce Wylie, USGS EROS, wylie@usgs.gov. 


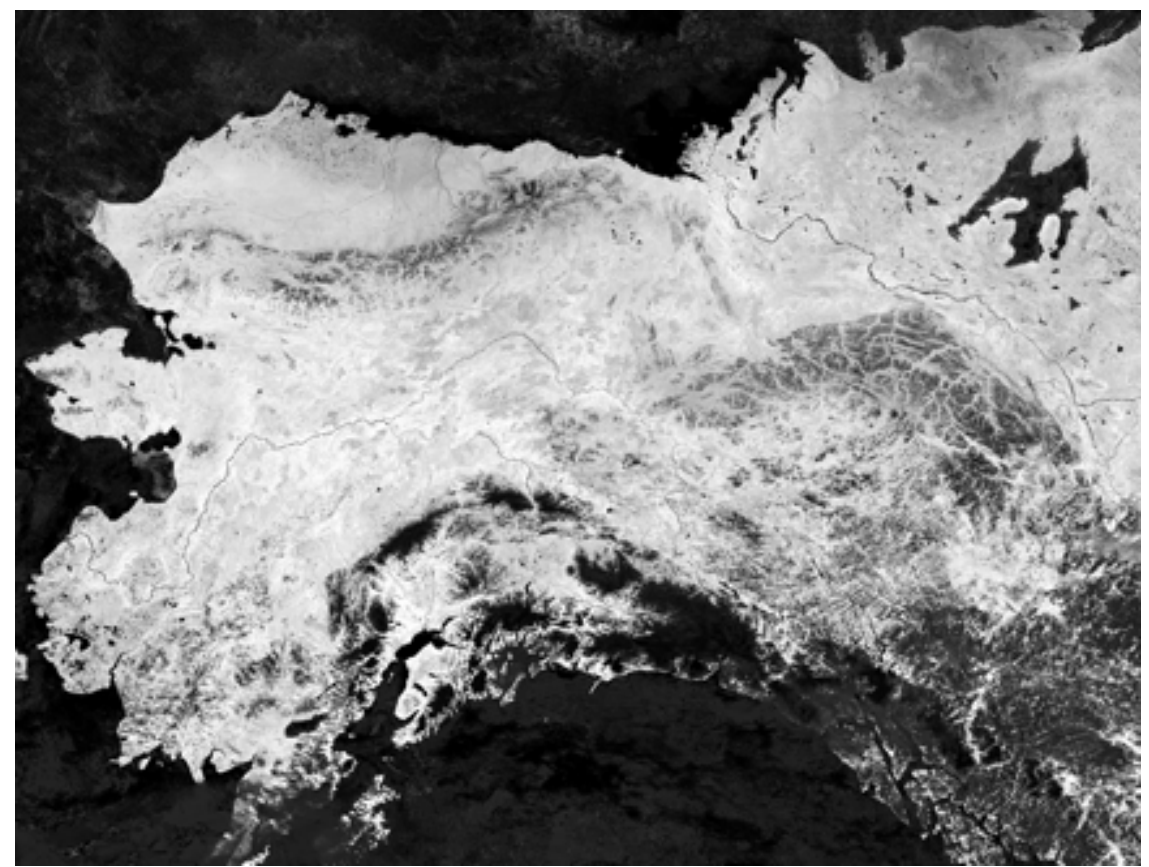

Figure 12. Grayscaled 250-meter Normalized Difference Vegetation Index calculated from Terra MODIS data acquired August 20-26, 2007, over Alaska and the adjacent Canadian Yukon River Basin.

\section{Mapping Aboveground Biomass for the Yukon Flats using Landsat Images, Ancillary Data, and Field Measurements}

Terrestrial plant biomass is a key biophysical parameter in the studies of Alaskan ecological and environmental systems. In this study, a preliminary map was generated of 30-meter aboveground biomass for the Yukon Flats, Alaska area based on Landsat images, Digital Elevation Model (DEM) data, and field measurements. The ground biomass (including tree, shrub, and herbaceous biomass) data were collected during August 28-September 9, 2009, by a field team.

A multiple regression model was created based on the ground-measured biomass, spectral variables derived from the Landsat data acquired on September 3, 2009 and DEM data. The model, with $\mathrm{R}^{2}=0.61$, uses the normalized difference vegetation index (NDVI), normalized difference infrared index (NDII), land surface temperature (LST), and elevation as predictor variables. To map the biomass for the entire Yukon Flats, six cloud-free Landsat 5 images were selected from August 21-September 1, 2008, and generated into a mosaicked Landsat image. By applying the regression model to the Landsat mosaic and the DEM data, a 30-meter total aboveground biomass map (fig. 13) was produced. The ongoing studies include estimation of live and dead biomass and accuracy assessment of the biomass map using a Lidar-derived biomass product. For more information, contact Bruce Wylie, USGS EROS, wylie@usgs.gov.
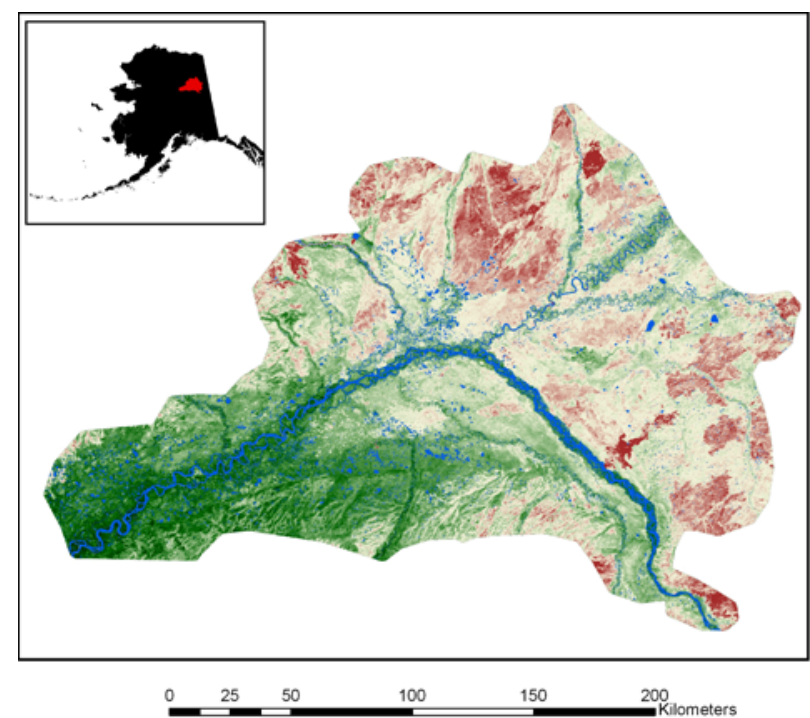

Biomass

$\left(\mathrm{g} / \mathrm{m}^{2}\right)$

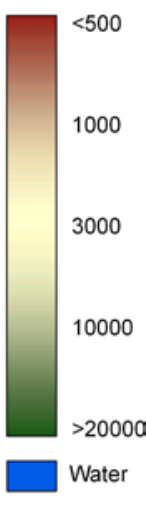

Water
Figure 13. The map of 30-meter resolution aboveground biomass for the Yukon Flats, Alaska. 


\section{Lidar-Derived Biomass in the Yukon River Basin}

Biomass levels in the Yukon River Basin (YRB) are being assessed both on the ground and through remote sensing techniques. Lidar data over the YRB were acquired in the fall of 2009 as were an initial set of field sampling data. Additional field data were collected during two 2010 field campaigns. Using the canopy height data derived from the lidar dataset and a set of height-based biomass equations (Yarie and others, 2007), a preliminary map of biomass (fig. 14) was generated for the YRB study area.

The allometric biomass equations published in Yarie and others (2007) are species-specific, so a cover type map provided by the LANDFIRE Project was used to divide the landscape as the most appropriate biomass equation for a given location. Additional work is being done to refine the lidar-derived biomass product. In particular, the biomass map will need to be validated using field-based estimates of biomass. Furthermore, additional metrics will be derived from the lidar dataset to be used as independent variables in a plot-level, regression-based effort to predict biomass for the sampled areas within the YRB. The information obtained through that exercise can then be used to develop a new biomass map for the YRB study area from the complete lidar dataset. Lidar digital elevation model (DEM) derivatives (catchments, compound terrain index, flow direction, shaded relief) were also generated and shared with National Resources Conservation Service, Yukon Flats National Wildlife Refuge, and fellow scientists. For further information, contact Bruce Wylie, USGS EROS, wylie@usgs.gov.

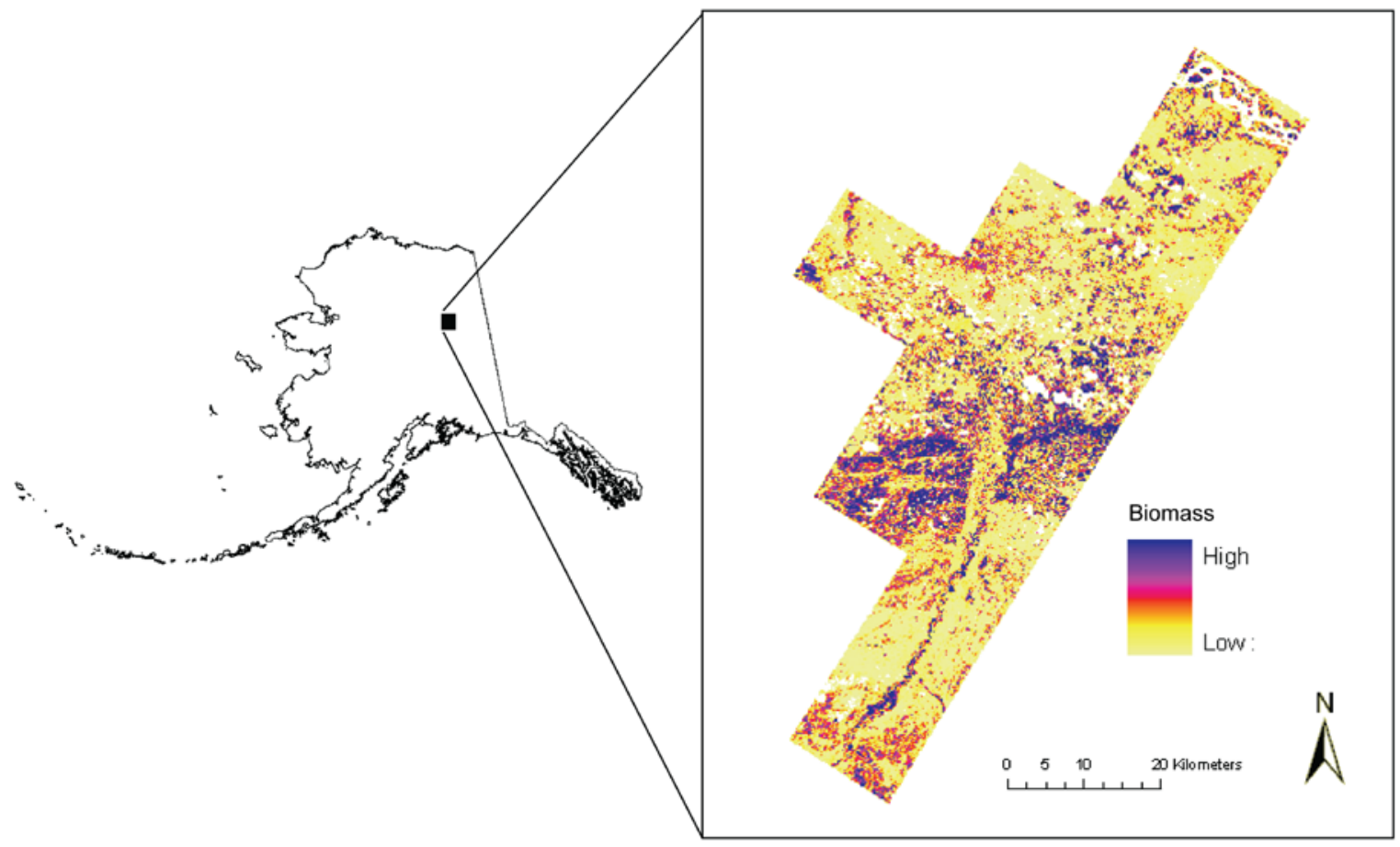

Figure 14. Location of lidar data acquisition within the Yukon River Basin study area and preliminary biomass product generated from lidar canopy height data and height-based allometric biomass equations.

\section{Estimating Big Sagebrush Productivity Decline in the Owyhee Uplands}

The Big Sagebrush ecosystem is critical for many species' survival in the Owyhee Uplands (Oregon, Idaho, and Nevada) because it provides them with winter forage and essential cover from predators and for reproductive activities. However, a changing climate is expected to affect Big Sagebrush productivity. A regression-tree model was used to estimate Big Sagebrush productivity based on site potential, where site potential is understood as a measure of an ecosystem's inherent productivity, and seasonal historical and current weather, and a projected moderate emissions near-future climate scenario.

A time-series cluster analysis was performed to delineate ten classes of low to high Big Sagebrush productivity. The technique estimates that the six most productive Big Sagebrush areas in the Owyhee Uplands will experience declining productivity between the present time (2010) and the year 2040 (fig. 15). Overall, average Big Sagebrush productivity for this area from the present time to 2040 will decline about 20 percent. In the figure, productivity points derived from the weather-related models are 
shown, and lines that were fit to the data points display the mean productivity trend for the landscape through time. Projecting future productivity of Big Sagebrush in the Owyhee Uplands and being able to compare that productivity to past levels can be tools used to formulate adaptive range, wildlife and watershed management strategies. For further information, contact Bruce Wylie, USGS EROS, wylie@usgs.gov.

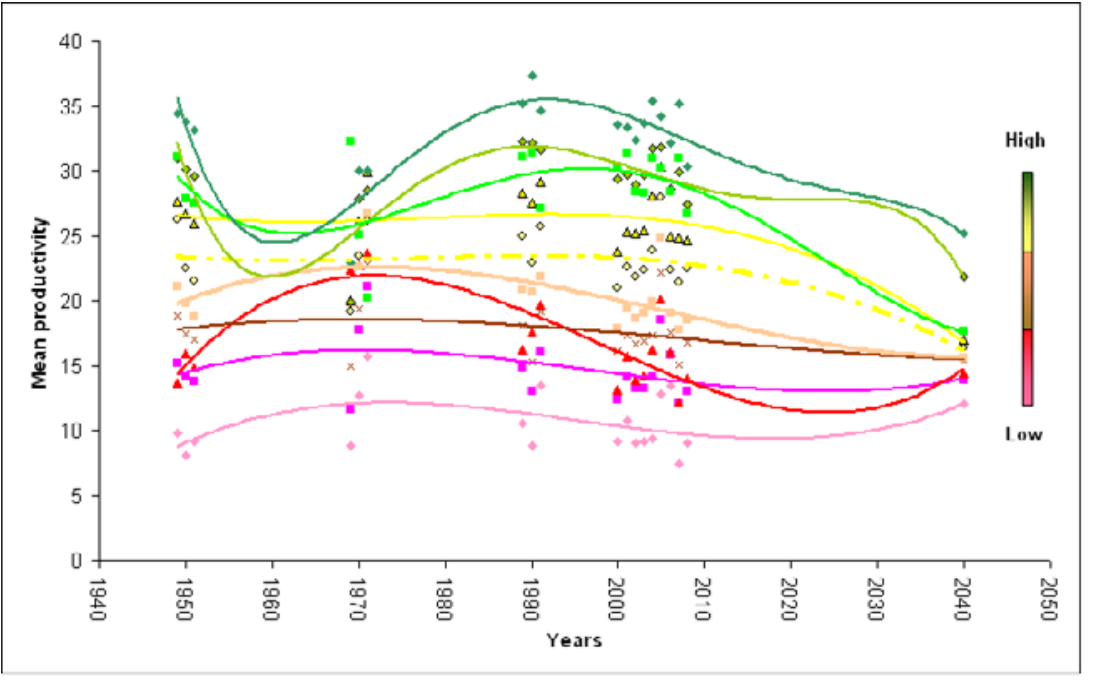

Figure 15. The time-series cluster analysis reveals a long-term decline of higher producing Big Sagebrush areas, especially from the present time (2010) to 2040. Trends of similar or slightly increased productivity levels were predicted for the lowest producing areas. Areas of moderate productivity trended downward or remained at similar productivity levels.

\section{Ecosystem Performance Anomalies in the Owyhee Uplands}

Ecosystem performance monitoring using remote sensing, geospatial analyses, and modeling technologies provide a valuable tool for researchers and land managers, especially when they are faced with a changing global climate that presents new threats to ecosystem stability. The monitoring of ecosystem performance can be difficult to interpret and put into an appropriate context if management decisions and disturbances cannot be separated from an ecosystem's climate. Ecosystem performance anomaly (EPA) studies conducted in the Owyhee Uplands do separate effects of climate from effects of management decisions and disturbances like overgrazing and fire.

The Bureau of Land Management (BLM) is responsible for the sustainable management for most of the Owyhee Uplands, a shrub-steppe environment located in the Great Basin of the western United States, and USGS EROS provided the BLM with results from EPA studies for this area for the years 2000-2008. Products delivered to the BLM include annual maps of ecosystem performance anomalies and areas of persistent ecosystem overperformance and underperformance. These areas of persistent anomalies are shown in the map (fig. 16). The annual and persistent anomaly maps from these studies can assist the BLM by identifying areas for field visits and possible range interventions, helping to maximize the effectiveness of limited resources. For further information, contact Bruce Wylie, USGS EROS, wylie@usgs.gov.

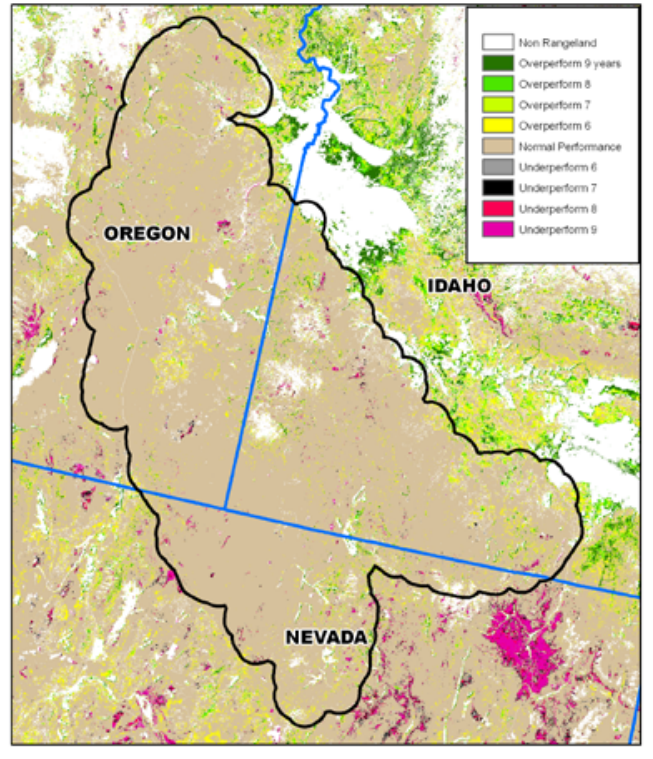

Figure 16. The persistent anomaly map displays areas that overperformed or underperformed at least 6 of 9 years studied. Areas on the map in shades of red or gray show areas of possible concern for land managers. 


\section{Dynamic Monitoring of Ecosystem Performance for Upper Colorado River Basin}

Ecosystem performance (a surrogate for ecosystem productivity) provides important information to decision makers for land management. Currently, the growing season-integrated Normalized Difference Vegetation Index (NDVI) derived from satellite observations is used as a proxy for ecosystem performance. Interpreting ecosystem performance variation is complex because of the effects of weather, site potential, natural disaster, and anthropogenic effects. For moisture-limited rangelands, the interannual variation in vegetation productivity is substantially related to the local weather conditions, management, and disturbances. The approach is to separate weather- and nonweather-related variations in growing season NDVI (for example, annual ecosystem performance) and make historical trend maps in weather- and nonweather-related variations. Identification and quantification of areas with long-term persistent ecosystem performance anomaly (EPA) within the Upper Colorado River Basin based on satellite observations, weather data, and ecosystem models is shown in figure 17. The EPA maps were validated using "percentage of bare soil" ground observations. The validation results at comparable site potential indicated that regions identified as persistently underperforming (over-performance) tended to have a higher (lower) percentage of bare soil, suggesting that our EPA maps agree with ground-based observations. The resulting EPA maps can be used by the Bureau of Land Management and other land managers for making optimal land management decisions.

Future work for this study includes generating 10-year (2001-2010) EPA maps within the Upper Colorado River Basin using 10-year satellite observations, climate data, and ecosystem models, and identifying long-term (that is, 10-year) persistent EPA areas and trends as well as weather-based variations in vegetation production. Investigation of ecosystem performance anomalies for the other vegetation cover types (for example, black sagebrush, mixed desert shrub, per the request of BLM and other land managers) are also planned for the future. For further information, contact Bruce Wylie, USGS EROS, wylie@usgs. gov.

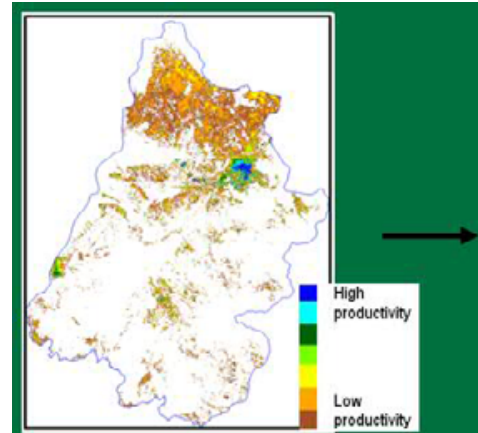

Site potential

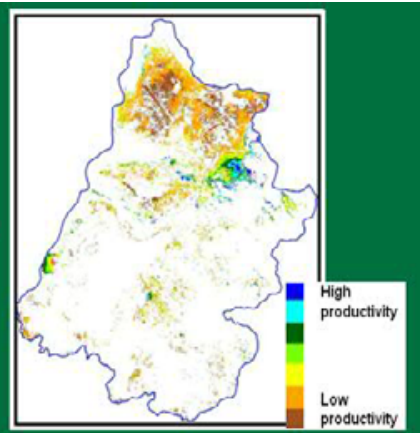

Expected ecosystem performance

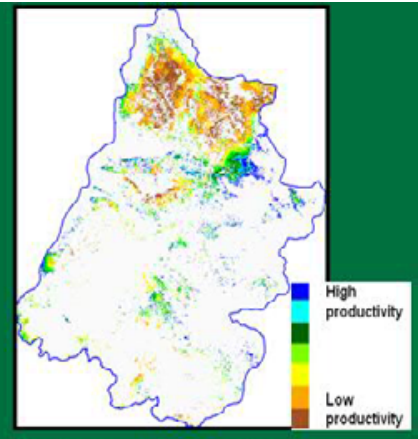

Real ecosystem performance
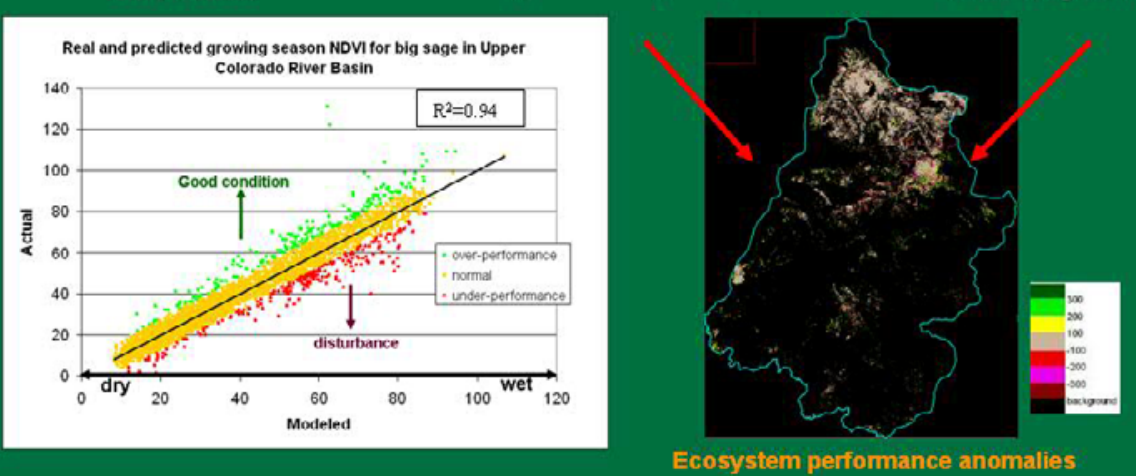

Ecosystem performance anomalies

Figure 17. Example

Ecosystem Performance for Big Sagebrush in the Upper Colorado River Basin (2006).

\section{Climate Change: Are High Latitude Lakes Drying?}

Several recent studies report that changing climate at high latitudes impacts lakes, causing an increase in lake drying. If permafrost continues degrading in a warming climate, researchers expect many lakes to decrease in size until they eventually disappear. This decrease in the number of lakes may have a negative effect on wildlife. To aid in predicting future water levels and the locations of drying lakes under multiple climate scenarios, measurements of recent surface water changes are needed. The results will provide information for land managers.

Many of the recent studies that documented decreases in surface water were based on temporally and seasonally limited remotely sensed measurements. The measurements of the lakes occurred on only two or three dates and compared aerial photos and satellite data from different sensors. Since many lakes and wetlands have high seasonal or annual variability, measurements 
were made of the surface water on 20 dates from a single source, Landsat. The 20 Landsat scenes capture surface water throughout the growing season during a 30-year period, from 1979 to 2009. Indications were that during this 30-year period, more than 96 percent of lakes did not significantly change in size (fig. 18). Only 2.5 percent of lakes significantly decreased in size (fig.

19) while just less than 1 percent significantly increased in size. This results in a net decrease of 1.6 percent. After future climate scenarios are integrated, estimations will be presented of when each of the drying lakes will disappear and the amount of carbon that could be exposed from each drying lake's sediments. For further information, contact Bruce Wylie, USGS EROS, wylie@ usgs.gov.
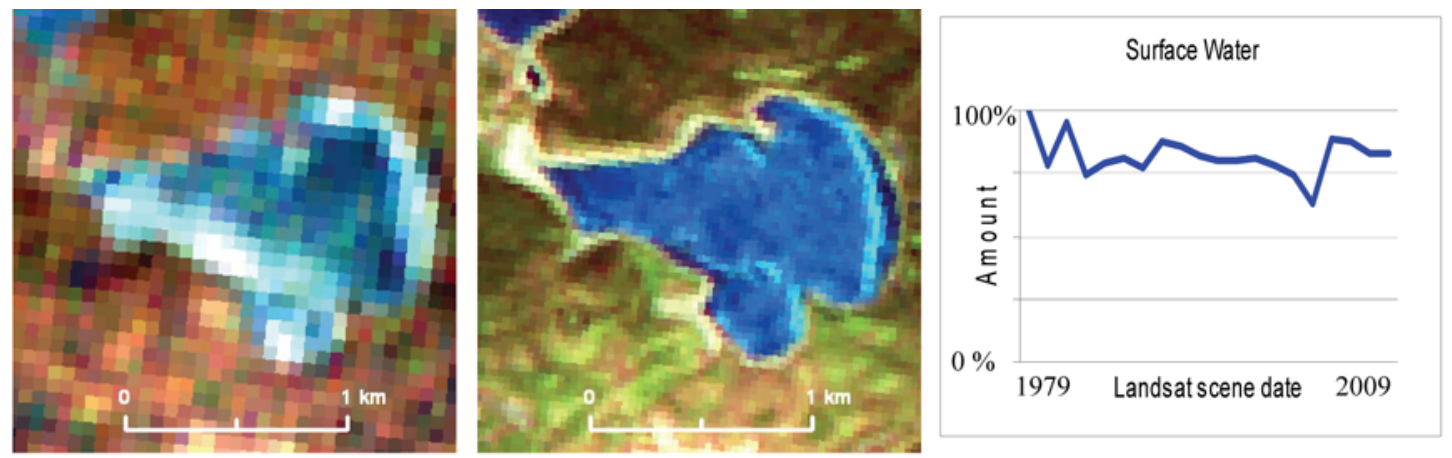

Figure 18. An example of a lake (name unknown, Yukon Flats, Alaska) with no significant surface water change between May 1979 and May 2009.
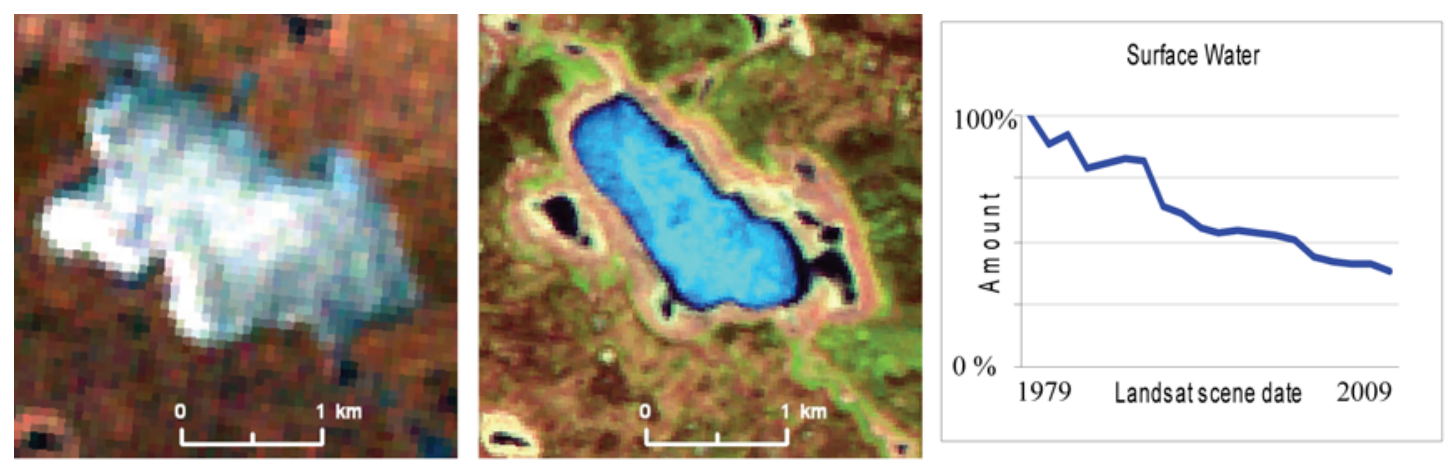

Figure 19. An example of a lake (Twelve Mile Lake, Yukon Flats, Alaska) with significant drying between May 1979 and May 2009.

\section{Boreal Forest Performance Anomalies in the Yukon River Basin}

Climate change impacts in high northern latitudes are greater than other areas of the globe and have resulted in record fire years as well as insect infestations and permafrost degradation. High latitude soils in the Yukon River Basin hold large amounts of organic matter in both the surface organic layer and in permafrost. Organic carbon in these layers may be vulnerable to emission into the atmosphere in a changing climate.

The growing season Normalized Difference Vegetation Index (GS NDVI) was used as a proxy for boreal forest production or the performance of the boreal ecosystem. Interannual variations in GS NDVI are affected by variations in weather conditions and disturbances. Because weather affects GS NDVI, weather was accounted for with regression tree models that predict GS NDVI. The residuals of this model provide weather de-trend GS NDVI anomalies. The model residuals were mapped annually from 2000 to 2008 and represent ecosystem performance anomalies where a site is either underperforming relative to its weather-based potential, responding normally to its weather-based potential (normal or within the 90 percent confidence intervals), or overperforming relative to its weather-based potential.

Time series analysis was used to effectively identify disturbance and weather-related variations. Linear time series analysis of the performance anomalies (disturbances) clearly identified known disturbances such as fires which occurred late in the study period while nonlinear analysis identified disturbance date and post disturbance recovery rates (fig. 20). This approach provides a useful method for monitoring and understanding burned and unburned boreal systems responses to a variable and changing climate. For more information, contact Bruce Wylie, USGS EROS, wylie@usgs.gov. 


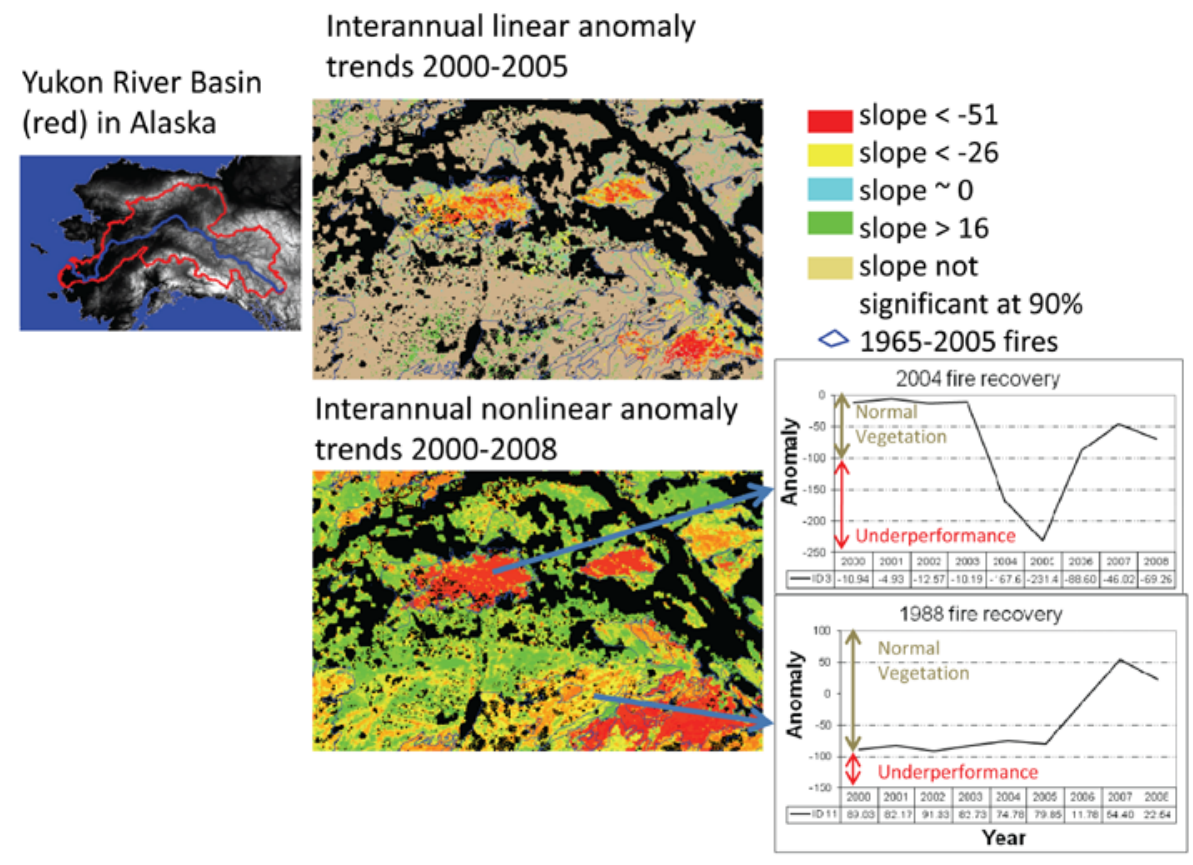

Figure 20. Time series analysis of boreal forest performance anomalies to identify linear and nonlinear trends.

\section{Adapting to Climate Change by Re-Greening Landscapes in West Africa's Sahel}

The Sahel, the semiarid strip of land along the southern fringe of the Sahara, is known for its harsh environment. Low annual rainfall, poor soils, locusts, and drought are all problems faced by millions of farmers who strive to produce enough food to feed a growing population. Throughout the past 30 years, however, hundreds of thousands of farmers in Burkina Faso and Niger have transformed large swaths of the region's arid lands into a greener landscape, improving food security for about 3 million people (fig. 21). Once-degraded and denuded landscapes are now transformed into open tree parklands that provide a much improved environment for crops, livestock, and people. Sahelian farmers achieved their success through innovations that modify traditional agroforestry, water, and soil management practices. Having lived through the terrible droughts of the 1970s and 1980 s, farmers are adapting to climate change by taking new approaches to farming, encouraging natural regeneration of on-farm tree cover, and diversifying production (fig. 22).

With support from the U.S. Agency for International Development, USGS EROS scientists have teamed up with African and European geographers and ecologists to document and study the re-greening of the Sahel's landscapes. The EROS team used time-series, high-resolution remote sensing and field studies to map the extent and impact of the agro-environmental transformation, including increases in biomass, carbon, biodiversity, and food and fodder production (fig. 23). The team's findings suggest a human and environmental success story at a scale not seen anywhere else in Africa.

In the coming year, the EROS team will continue to work with African and European partners and the World Agroforestry Center to better understand the driving factors of re-greening, and to seek ways of promoting the adoption of these practices into other regions still plagued by land degradation. This is part of a new vision for agricultural landscapes across Africa, conservation farming that integrates trees with annual food crops. This combination of practices is now referred to as Evergreen Agriculture. The objective is to build a healthy soil and environment to enhance food crop production, increase household income, increase on-farm biomass and carbon, and increase resilience of agricultural communities to climate change. EROS expertise in remote sensing and other geospatial tools will play an increasingly vital role in monitoring the extent and impacts of Evergreen Agriculture, and for effective targeting of investments to expand it. Two recent publications on this work include:

Reij, C., Tappan, G.G., and Smale, M., 2009, Agroenvironmental transformation in the Sahel-another kind of "Green Revolution”: Discussion Paper, 914, 52 p. (Also available online at http://www.ifpri.org/book-5826/millionsfed/pubs).

Reij, C., Tappan, G.G., and Smale, M., 2009, Re-Greening the Sahel-farmer-led innovation in Burkina Faso and Niger, chap. 7 in Spielman, D.J., and Pandya-Lorch, R., eds., Millions fed-proven successes in agricultural development: Washington, D.C., International Food Policy Research Institute, p. 53-58. (Also available online at http://www.ifpri.org/book-5826/millionsfed/ pubs).

For further information, contact Gray Tappan, USGS EROS, tappan@usgs.gov. 

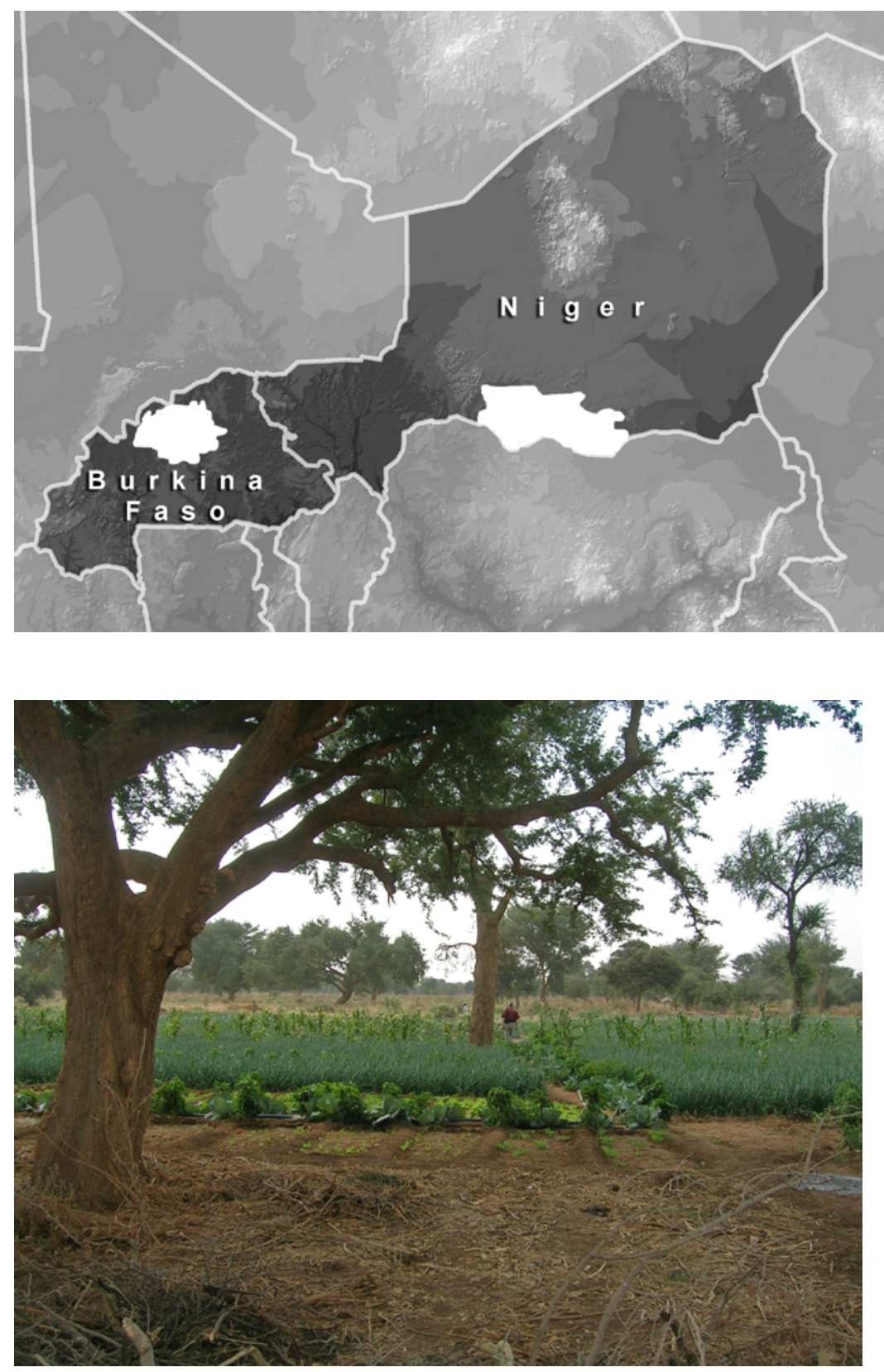

Figure 21. General location (white areas) of landscape regreening, where farmers have adopted practices that have substantially improved environmental and agricultural conditions.
Figure 22. Hand-irrigated vegetable cultivation surrounded by dense tree parkland dominated by the winter thorn tree (Faidherbia albida). Tree parklands have increased in density and extent across 5 million hectares of southern Niger. The winter thorn tree provides many benefits, including boosting crop yields by fixing nitrogen in the soil, and providing fodder for livestock. Adouna Valley, Niger. Photograph: C. Reij.
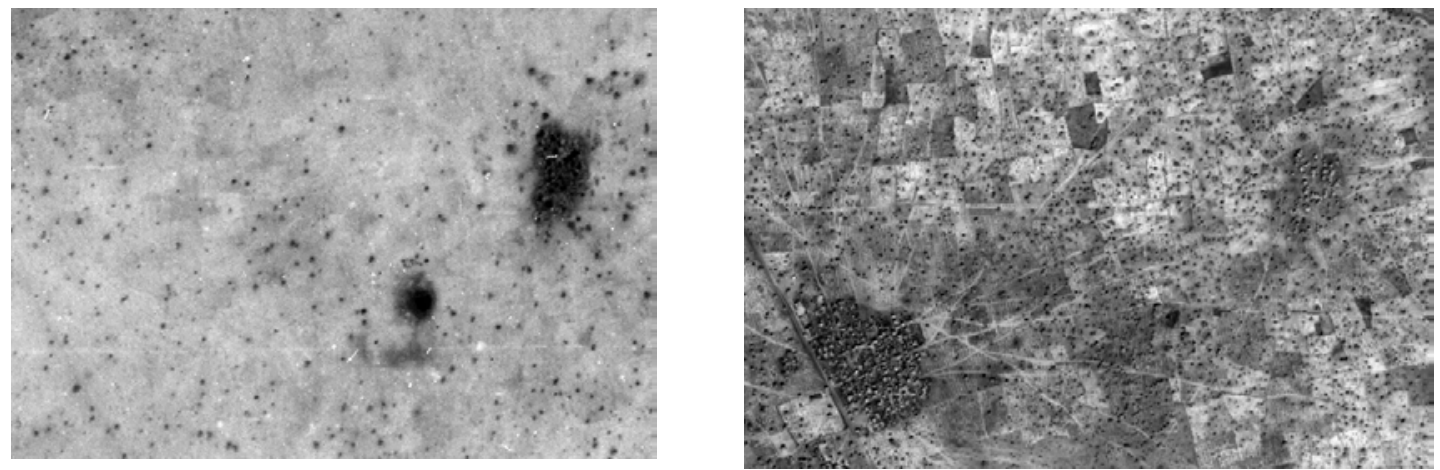

Figure 23. Comparison of an aerial photograph (left, 1975) and a QuickBird satellite image (right, 2005) showing the much increased tree cover of agricultural landscapes in southern Niger. Note that the large village in the 2005 image did not yet exist when the 1975 photograph was taken. 


\section{Monitoring Biodiverse Forests and Protected Areas in West Africa's Upper Guinean Forest Ecoregion}

The Upper Guinean Forest Ecosystem is a priority for biodiversity conservation (fig. 24). It is also a region of strategic importance in terms of peace building, extractive industries, and as a source of valuable ecosystem services and products. The forests are fundamental to the welfare of West African societies, have great cultural importance, and have considerable value for mitigating climate change. This unique, fragile block of forest is contained within Guinea, Sierra Leone, Liberia, and Côte d'Ivoire. Several USGS EROS scientists are working closely with partners in the four countries to monitor land cover, biodiversity, deforestation, and a variety of land management practices that aim to strengthen natural resource management and sustainable livelihoods. Funding for this activity is from USAID/Guinea and USAID/West Africa. The project targets biodiverse habitats within protected and nonprotected transboundary areas along country borders. Major partners include the existing government initiatives such as the Mano River Union, national forestry departments, the U.S. Forest Service, the World Agroforestry Center, the Wild Chimpanzee Foundation, and the PAGE Project (Promoting Agriculture, Governance, and the Environment, Sierra Leone).

Throughout the past year, the EROS team provided satellite imagery, produced land cover and forest maps, and provided landscape assessments to:

- Map and quantify the remaining dense forest cover in Sierra Leone (fig. 25);

- Provide scientific support for establishment of wildlife migration corridors between the Taï Forest and Sapo Forests of Cote d'Ivoire and Liberia;

- Provide scientific support for creation of a network of protected areas along the Guinea-Sierra Leone border;

- Provide training on assessing land cover with satellite imagery;

- Provide land use and land cover data for sustainable land and forest management plans and implementing activities in forestry, agroforestry, protected area management, and biodiversity conservation within communities along the GuineaSierra Leone border; and

- Provide image-maps of a large part of Sierra Leone in support of the PAGE Project's work with communities to engage in forest management (fig. 26).

For further information, contact Gray Tappan, USGS EROS, tappan@usgs.gov.

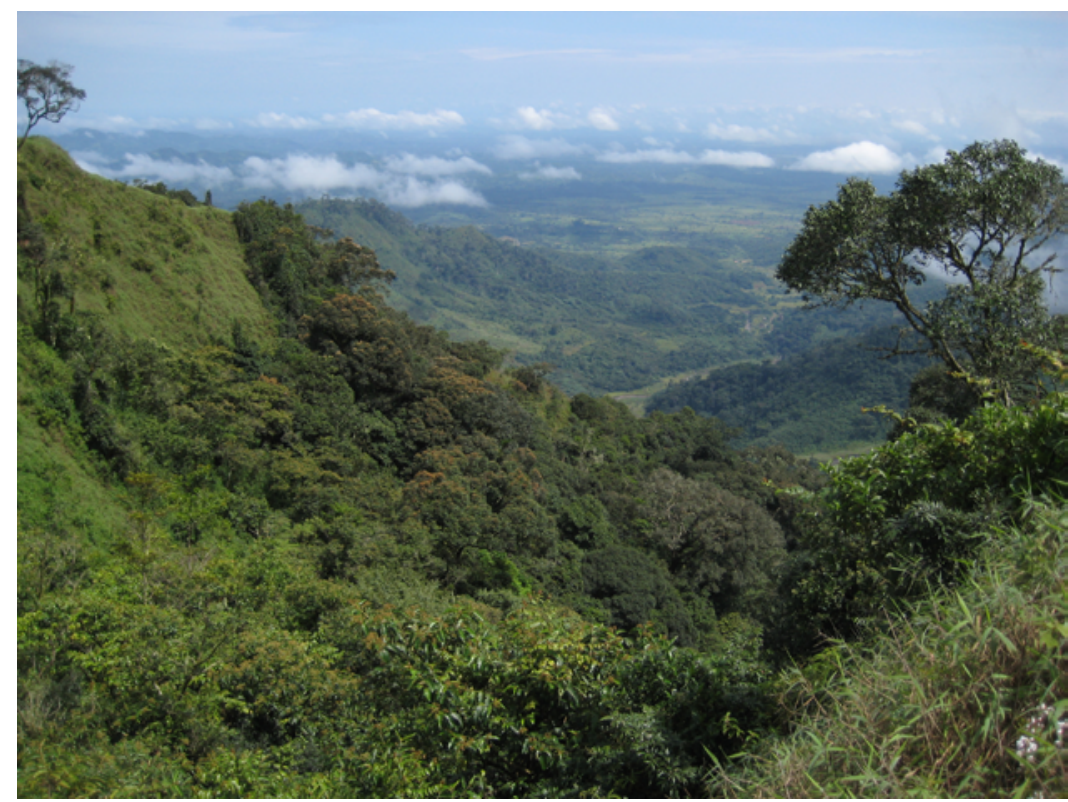

Figure 24. A view of the cloud forest near the top of Mount Nimba. The Mount Nimba range is a transboundary reserve located on the border between Guinea, Cote d'Ivoire, and Liberia. It preserves unusually rich flora and fauna including a number of endemic species. It is one of the hotspots in the Upper Guinea Forest Ecoregion. 

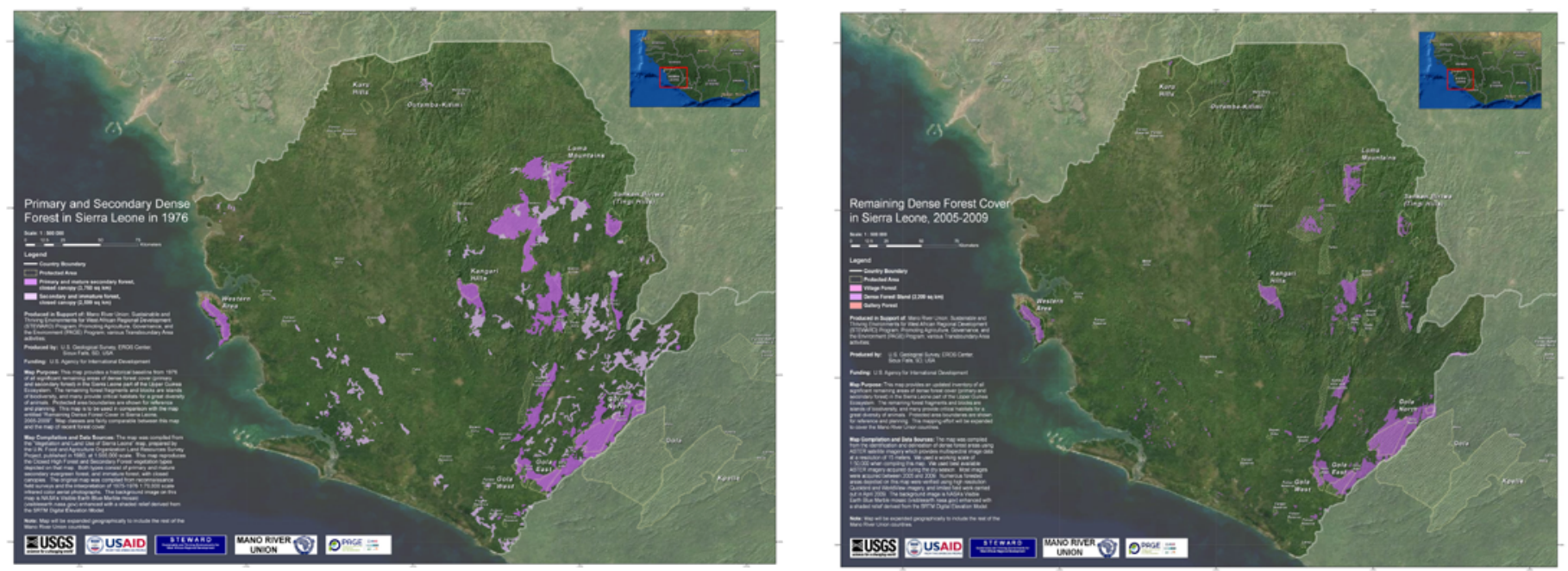

Figure 25. This pair of maps compares primary and secondary dense forest cover in Sierra Leone from 1976 (left) to 2005-2009 (right). The remaining forest fragments and blocks are islands of biodiversity. Forest cover during this period declined from about 6 percent to just more than 2 percent of the national land area. Forest cover was mapped using Landsat and Advanced Spaceborne Thermal Emission and Reflection Radiometer (ASTER) imagery.

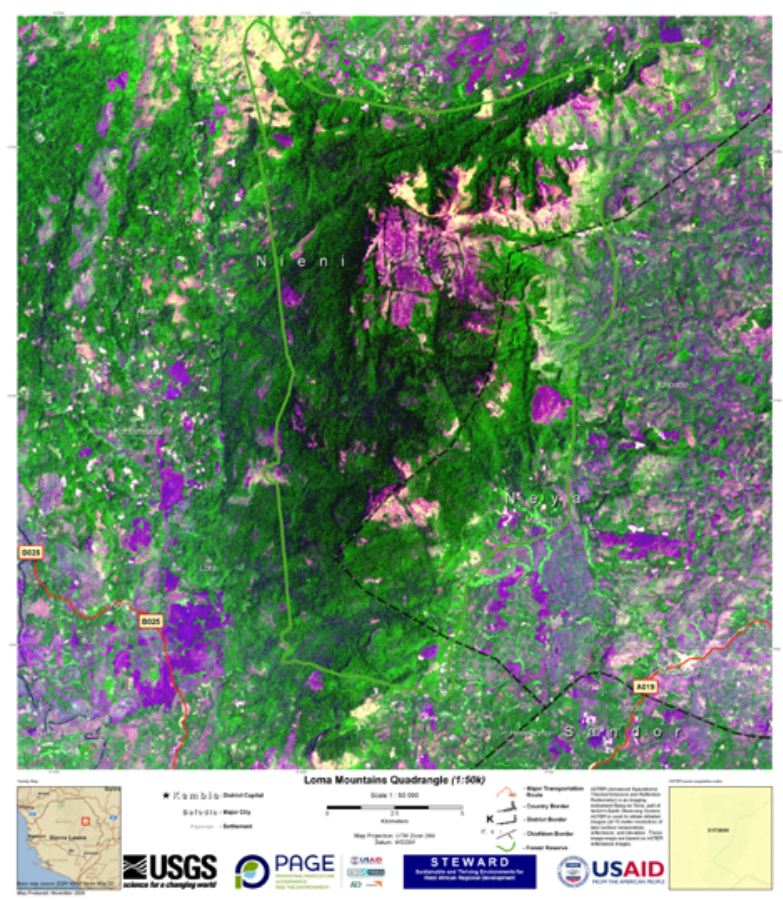

Figure 26. One of 13 ASTER-based image maps produced of eastern Sierra Leone where existing maps are 30 years out-of-date. The maps are being used by the PAGE Project in support of formulating land use and forest management plans with local communities.

\section{Assessing Human Impacts on Critical Environments in Senegal}

USGS EROS geographers are working with Senegal's Center for Ecological Monitoring (CSE) to monitor, map, and assess the extent and condition of the country's ecosystems, including critical biodiverse hotspots, deforestation, and rapid land use change. The team is building on a rich experience of work in Senegal since 1982, using remote sensing and GIS to provide unique information to resource managers, development practitioners, wildlife conservationists, and ecotourists. A number of geographic products will allow them to "see" the land resources, both in their current state and through time.

During the past year, the team focused on the Kedougou Region of southeastern Senegal. The region stands out for its relatively pristine landscapes - the last major refuge for wildlife and unbroken expanses of Sudanian zone vegetation. Some of Senegal's most critical and biodiverse habitats are found there. It also includes the large Niokolo-Koba National Park, established in 1951 and more recently classified as both a biosphere reserve and as a World Heritage for Humanity site. Throughout 
the past three decades, the biological resources of this enclave have been buffeted by degradation that threatens this fragile ecosystem (fig. 27). The region is experiencing a gold rush, with an influx of major international mining companies. Pristine areas are being opened up by new roads. There is an urgent need to balance economic exploitation with preserving ecosystem services and wildlife conservation.

The EROS/CSE team has nearly completed a detailed land cover map of the Kedougou Region using Landsat, Advanced Spaceborne Thermal Emission and Reflection Radiometer (ASTER), and high-resolution imagery (fig. 28). Several derived maps are being prepared, including a relative wildness map important for identifying undisturbed areas and wildlife corridors, a biodiversity hotspot map, and an ecotourism map of Niokolo Koba National Park. EROS is working with a number of partners in Senegal who will use the geographic products for numerous applications, including:

- Work with chimpanzee conservation groups to map areas of five known chimpanzee populations and assess the threat of habitat fragmentation from farming and logging; prepare maps for ecotourism;

- Work with the Directorate of Mines to help them monitor the impact of industrial mining on the environment, including deforestation and downstream pollution;

- Work with the Forest Department and rural community governments to produce forest management plans for unprotected community forests;

- Work with the National Directorate of Parks to promote development of the Niokolo Koba National Park and to promote ecotourism; and

- Work with the National Directorate of Parks and local authorities to assist in the creation of a new protected area-the Dindefelo Nature Reserve.

For further information, contact Gray Tappan, USGS EROS, tappan@usgs.gov.

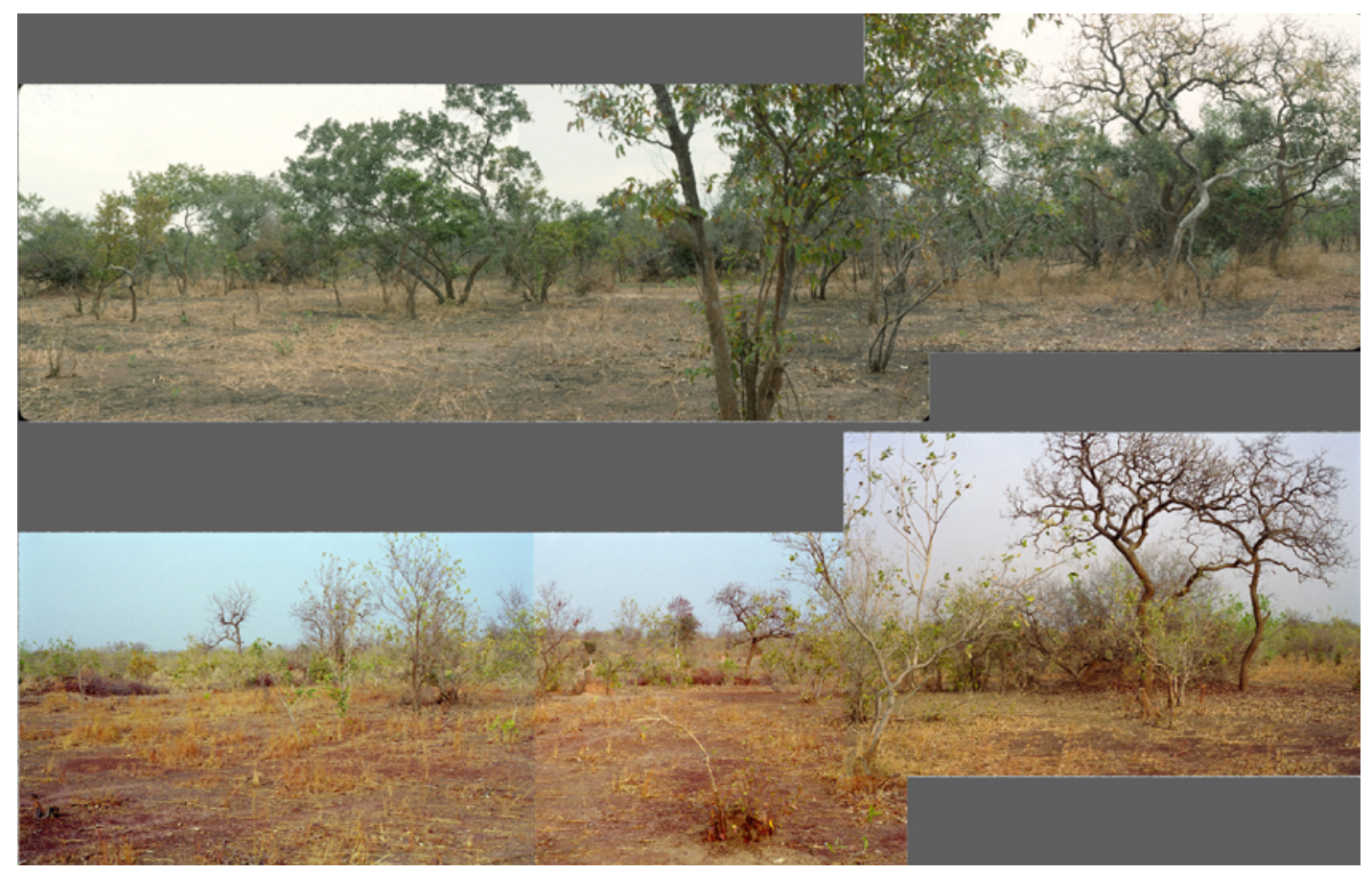

Figure 27. EROS environmental scientists and their counterparts from CSE are monitoring vegetation structure and biodiversity changes at hundreds of ground sites across Senegal, including sites like this one in southeast Senegal. This photograph pair compares the same landscape in 1995 (top) and 2006 (bottom). Woody species inventories show significant decline in biodiversity and habitat quality. The team is revisiting sites they originally established in 1983. 


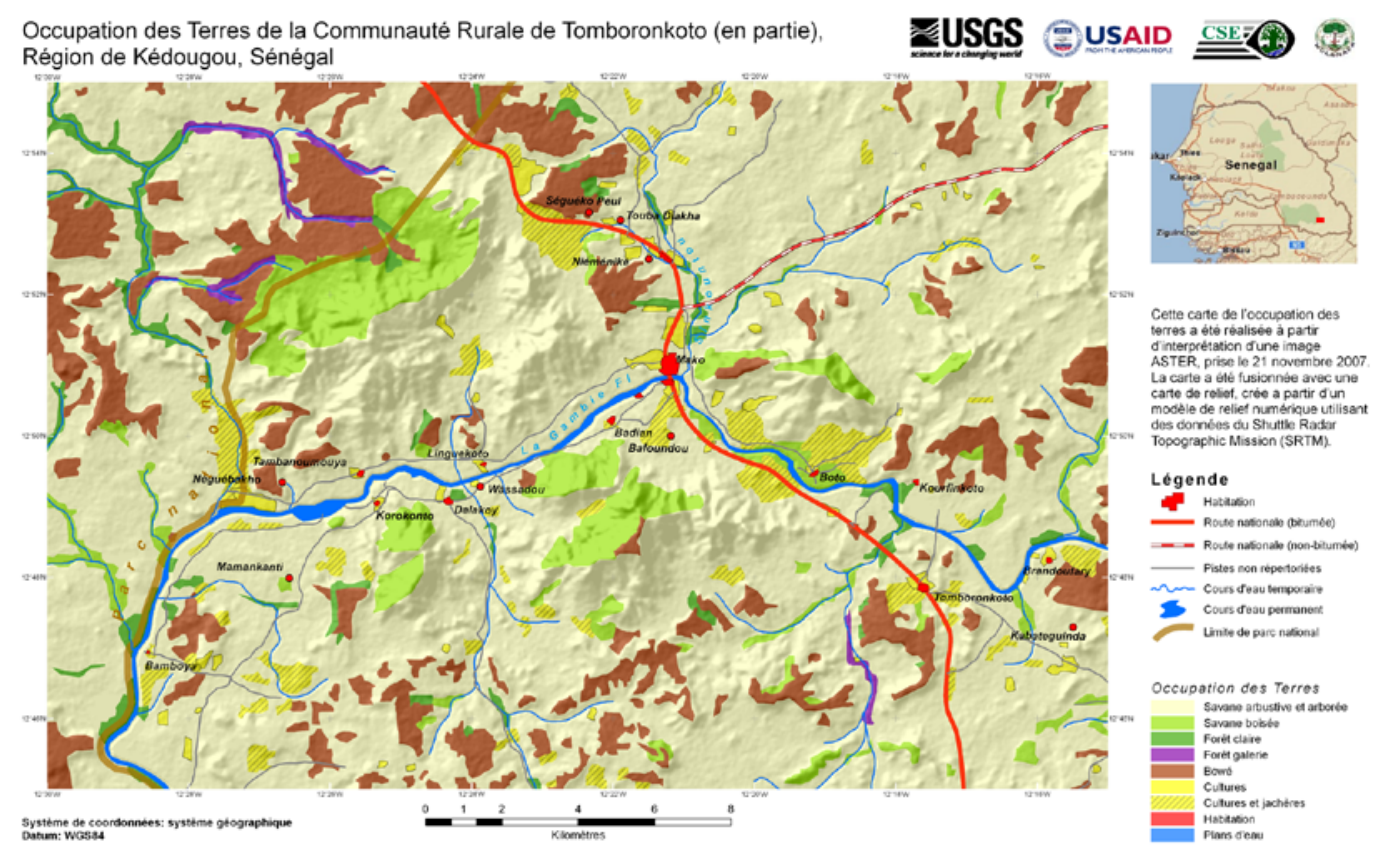

Figure 28. This map is a small portion of a Land Cover Map of the Kedougou Region of Senegal. The map is being prepared from ASTER and Landsat imagery. The map and supporting field work will be used to produce several derivative themes, including a Relative Wildness Map and a Biodiversity Hotspot Map.

\section{Mapping Land Cover through the Decades in East Africa}

EROS scientists teamed up with counterparts from the Regional Centre for Mapping of Resources for Development (RCMRD) in Nairobi, Kenya to bring the experience of time-series land cover mapping from West Africa to East Africa. The primary goal is to build capacity among environmental institutions in East Africa to use Landsat and other imagery to map and monitor land cover through time. Monitoring trends in land cover also is an important goal of SERVIR-Africa, which integrates geographic data from many sources to provide decision makers with a synthesized view of their regions. SERVIR is the Regional Visualization and Monitoring System for environmental management and disaster response. This effort culminated in a workshop facilitated by two EROS geographers at RCMRD in May 2010 (fig. 29). National Aeronautics and Space Administration's SERVIR-Africa Program funded this activity. RCMRD is one of three regional remote sensing and mapping centers in sub-Saharan Africa and has a long history of collaboration with EROS. The workshop provided an opportunity to share the experiences and approach of time-series mapping that EROS developed and used for mapping a vast area of West Africa. Twelve participants from five countries (Kenya, Uganda, Rwanda, Ethiopia, and Tanzania) attended the training, along with RCMRD staff.

EROS facilitators introduced the Rapid Land Cover Mapper tool. Participants used it to produce time-series maps of two areas in Kenya. The resulting land cover maps were checked and validated during a short field trip (fig. 30). The Rapid Land Cover Mapper provides a unique and practical way of mapping land cover over large areas through time. It is particularly wellsuited to incorporating a wide variety of image sources, ranging from digital multispectral imagery to analog panchromatic photography. Users can reach back in time to map land cover in the 1940s and 1950s with aerial photography, and potentially worldwide in the 1960s using Corona satellite photography. The conceptually simple

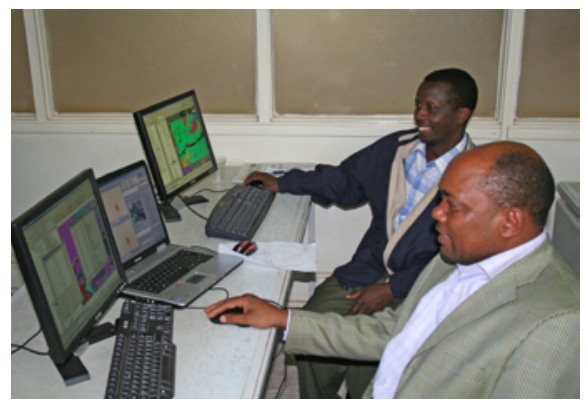
approach produces raster format land cover maps that can easily be compared to assess change. There is much interest on the part of RCMRD and the participating institutions in completing time-series land cover maps for their respective countries. For further information, contact Gray Tappan, USGS EROS, tappan@usgs.gov.

Figure 29. Participants from five East African countries attended the workshop in time-series land cover mapping at the Regional Centre for Mapping of Resources for Development, Nairobi, May 2010. 


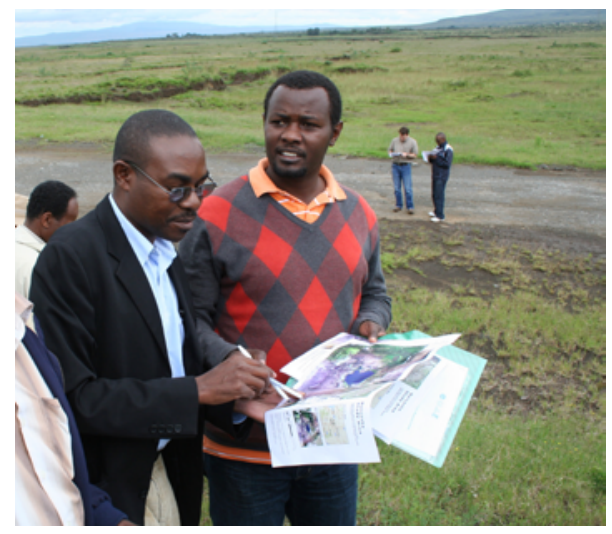

Figure 30. Participants field-checked their draft land cover maps at a study area near Lake Naivasha, in Kenya's Rift Valley.

\section{Topographic Processing Service for South America - Andean Development Bank GeoSUR Program}

The USGS collaborated with the Andean Development Bank (CAF) GeoSUR program and released a web service tool that provides access to Shuttle Radar Topography Mission (SRTM) 30-meter resolution elevation derivative products for the continent of South America. Designed and implemented at the USGS EROS Center, this tool allows these countries to securely access SRTM's full 1-arc-second (30-meter) resolution digital elevation model (DEM) via the Internet to produce elevationderived products. These higher resolution products allow users to extract detailed information allowing better natural disaster prevention and mitigation, natural resource management, and local and international infrastructure development.

The GeoSUR program optimized access to and the use of the derivative products by developing a dynamic geoprocessing web service that allows users to dynamically request derivative products from restricted SRTM source data in a secure environment, evaluated and approved by the National Geospatial-Intelligence Agency (NGA). Labeled as the Topographic Processing Service (TPS), it initially offers tools (models) to allow users to request slope, aspect, shaded relief (hillshade), and an elevation reclassification from a gap-filled SRTM 30-meter data source (fig. 31).

The USGS EROS Center is hosting the service for GeoSUR in order to meet the security requirements defined by NGA and has implemented the Environmental Systems Research Institute's (ESRI's) ArcGIS Server for handling geoprocessing requests. By using the ArcGIS Server, the program can offer multiple methods of accessing the derivative tools. Not only can users request data products from the web-mapping interface (fig. 32), they can access the same tool through ESRI's ArcGIS desktop products or from the ArcGIS JavaScript application programming interface, allowing users to build custom tools and web application. For further information, contact Larry Tieszen, USGS EROS, tieszen@usgs.gov.

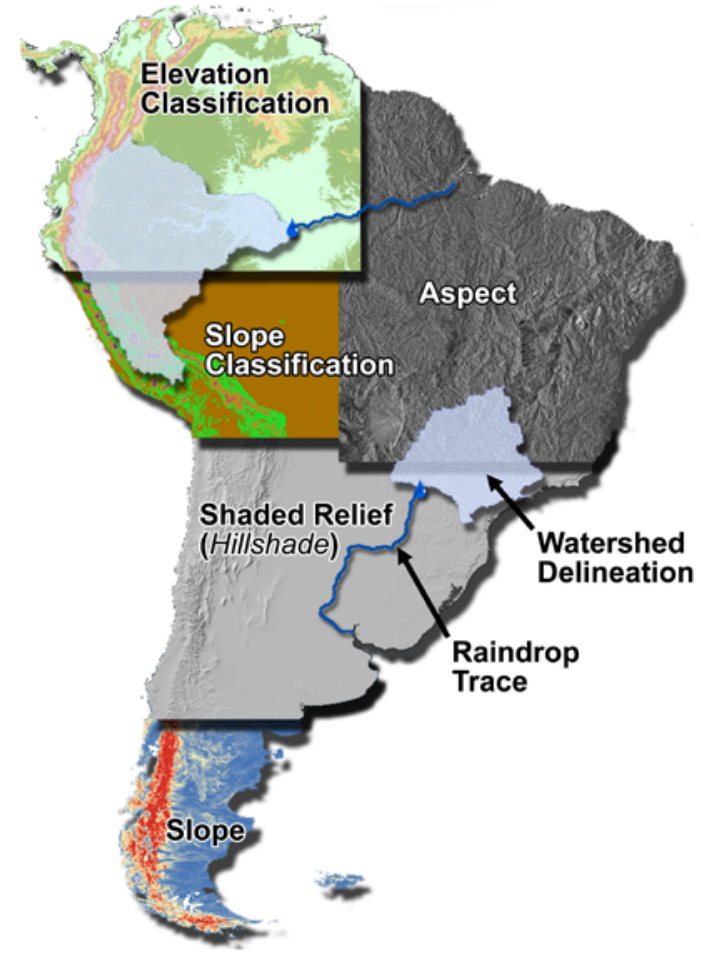

Figure 31. Composite image of Topographic Processing Services available as digital elevation model derivative products. 


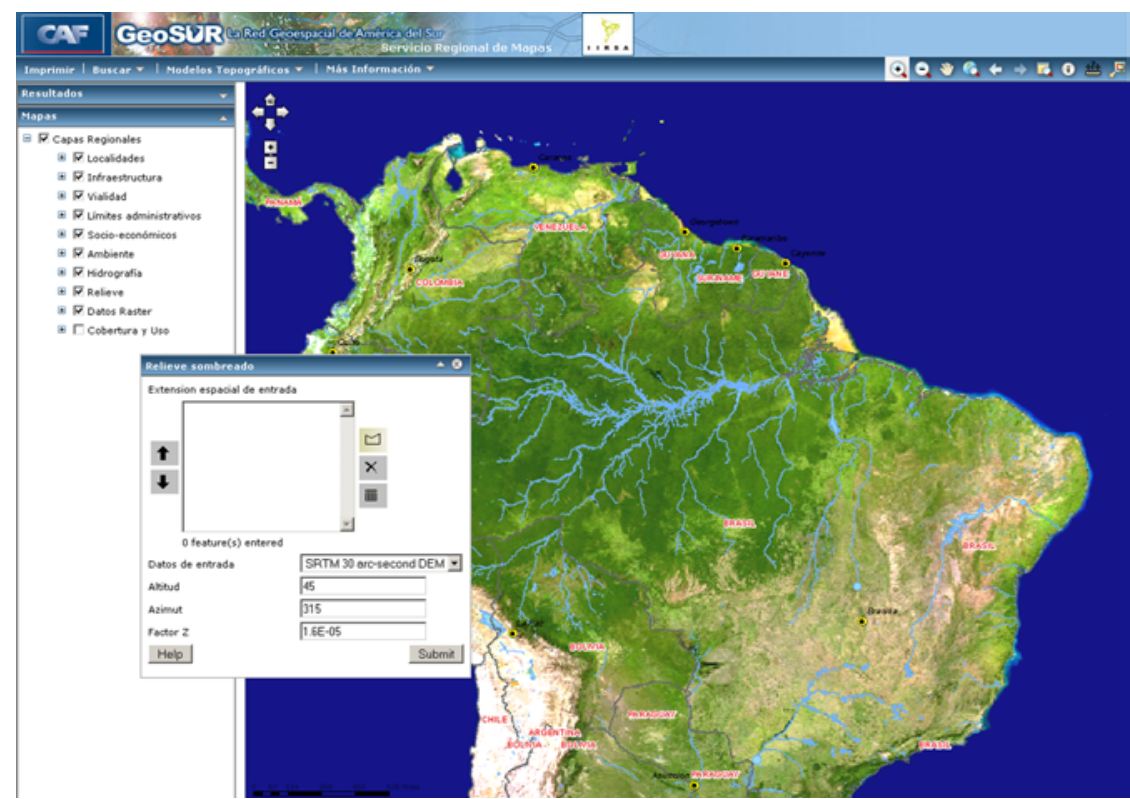

Figure 32. GeoSUR geoprocessing web interface.

\section{EcoServ: An Integrated Web-Services-Based Ecosystem Services Modeling System}

Many people are interested in natural resources management. The consequences of related policy decisions are multidimensional and often conflicting. A scenario "optimized" to one group might be a "risk" to another; therefore, models are needed that simultaneously quantify the impacts of management practices, policies, and climate change on diverse ecosystem services. EcoServ is such a modeling system; it was developed using data and model sharing technology and web services to accommodate a variety of users and purposes. EcoServ simulates more than 12 major ecosystem services related to water resources, wildlife, plants, soils, and greenhouse gas (GHG) emissions. It takes advantage of existing databases and disciplinary models by sharing them on the Internet. Scenarios of land cover and land use can be created easily in EcoServ by using the online Land Cover Editor. This feature allows users to simulate and analyze the impacts of management activities on ecosystem services under different climate change scenarios. EcoServ is especially suited for evaluating, understanding, diagnosing, monitoring, and forecasting changes of multiple ecosystem services in response to future changes in policy, climate, and land use (for example, biofuel production). EcoServ is being developed and applied in the Prairie Pothole Region (fig. 33) of the United States to quantify the impacts of U.S. Department of Agriculture's programs (for example, Conservation Reserve Program and Wetland Reserve Program) and practices (for example, perennial grass, contour buffer strips, critical plantings, grassed waterways, biofuel production) on a wide range of ecosystem services. For further information, contact Shuguang Liu, USGS EROS, sliu@usgs.gov.

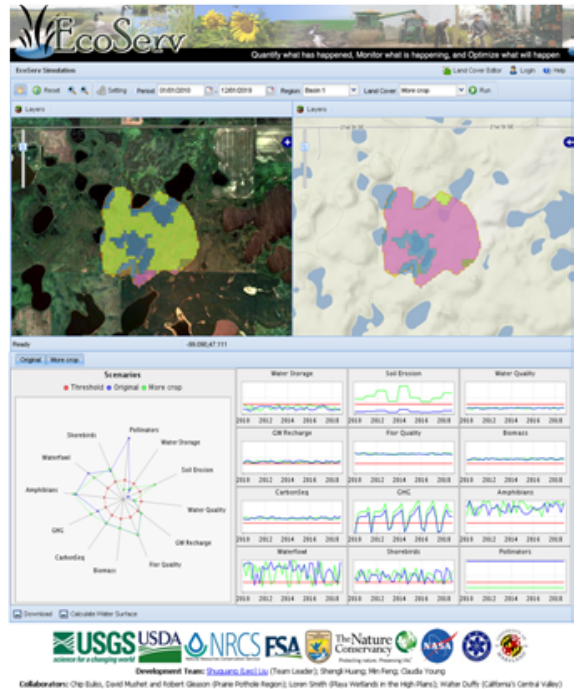

Figure 33. EcoServ Online Modeling System in a pilot study area of the Prairie Pothole Region. 


\section{Collateral Effects of Carbon Sequestration on Ecosystem Services}

Many participants are involved in ecosystem management simultaneously affecting a myriad of Ecosystem Services (ES). However, a "good" option from the perspective of one user may be "bad" for another. Therefore, single land use evaluations may be misleading if the overall impact on the ecosystem is not evaluated. In Tensas Parish, Louisiana, and Claiborne County, Mississippi, 10 ecosystem services were simultaneously evaluated and compared under two management scenarios of R and $\mathrm{L}$ where $\mathrm{R}$ was a reference scenario, and $\mathrm{L}$ was an optimized land use scenario to enhance carbon sequestration for mitigating global warming. The major differences between $\mathrm{R}$ and $\mathrm{L}$ were with the land use, land cover, and land management (for example, wetland restoration, forest clear cutting). The outputs of these two scenarios were compared to the baseline (2001-2010). Since different ES have different definitions, ranges, and meanings, a ES Change Indicator (ESCI) was used to normalize all ES and made them comparable:

$$
E S C I=\left(E S-E S_{0}\right) / E S_{0}
$$

where $E S$ refers to the output value of a selected $E S$, and $E S_{0}$ is the corresponding baseline value of 2001-2010. However, to those $E S$ where a higher $E S C I$ value indicates a reduction in $E S$, “-1" was multiplied. Results determined the optimized L scenario improves the ecosystem carbon storage; however, it also shows reductions in grain and timber production, and increased $\mathrm{CH}_{4}$ emissions (fig. 34). This leaves the policy makers with two questions. Will the increased $\mathrm{CH}_{4}$ emissions, which are almost 25 times that of $\mathrm{CO}_{2}$ in the greenhouse warming effect, offset efforts to mitigate global warming through carbon sequestration? Will this "optimized" scenario be acceptable by timber and agricultural stakeholders? Hence, a broader perspective and context with social and economic analysis is needed to evaluate and understand the concurrent effects of the optimized carbon sequestration on other ES. For further information, contact Shuguang Liu, USGS EROS, sliu@usgs.gov.
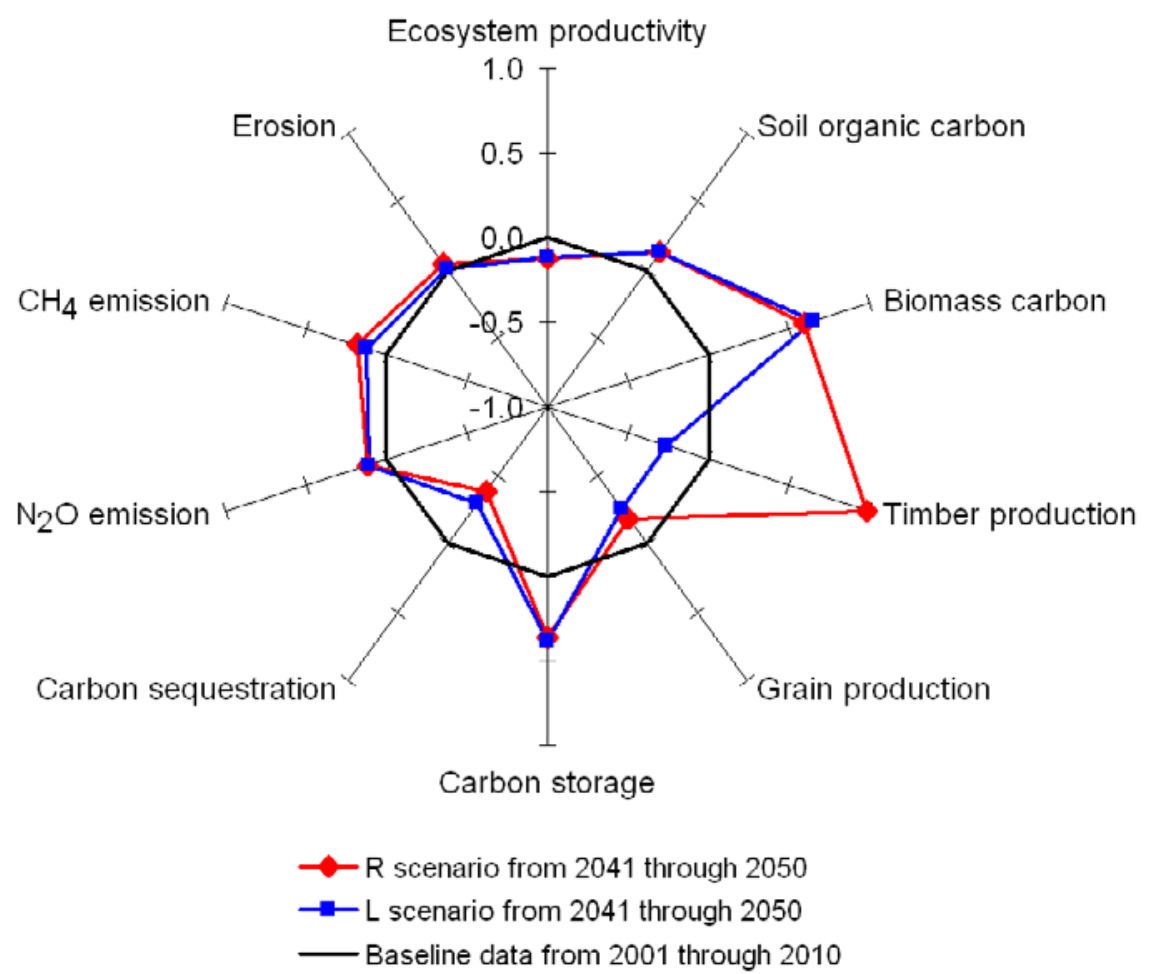

Figure 34. Ecosystem Services Change Indicator of the reference and optimized scenarios compared to the baseline.

\section{Quantifying Water Storage Capacity of Topographic Depressions in the Prairie Pothole Region from Lidar and National Wetland Inventory Datasets}

Recent flood events in the Prairie Pothole Region of North America have stimulated interest in modeling water storage capacities of wetlands and surrounding catchments to facilitate flood mitigation efforts. Accurate measurements of basin storage capacities have been hampered by a lack of high-resolution elevation data. A 0.5-meter bare earth model was developed from lidar data in combination with National Wetlands Inventory data. These data were used to delineate wetland catchments and spilling points within a 196-square-kilometer study area. 
From the delineated catchments and spill points, the water storage capacity of individual basins was calculated; and since wetlands could be merged to create a larger wetland through "spill and overflow," wetland connectivity also was modeled. However, storage capacity of basins does not fully translate into floodwater regulation because some wetlands are easily filled and overflow while others may never overflow. Therefore, the Basin Floodwater Regulation Index (BFRI) was calculated as the division of volume and catchment area. Based on the BFRI, the absolute and relative water that could be held by the wetlands over a landscape could be modeled if the water level before a flood was available, which was demonstrated with the water condition of May 17, 2008 (fig. 35). Being able to estimate the water holding capacity of the Prairie Pothole Region basins will aid efforts in quantifying the role that these basins play in mitigating downstream flooding.

This work is in collaboration with the USGS Northern Prairie Wildlife Research Center. For further information, contact Shuguang Liu, USGS EROS, sliu@usgs.gov.
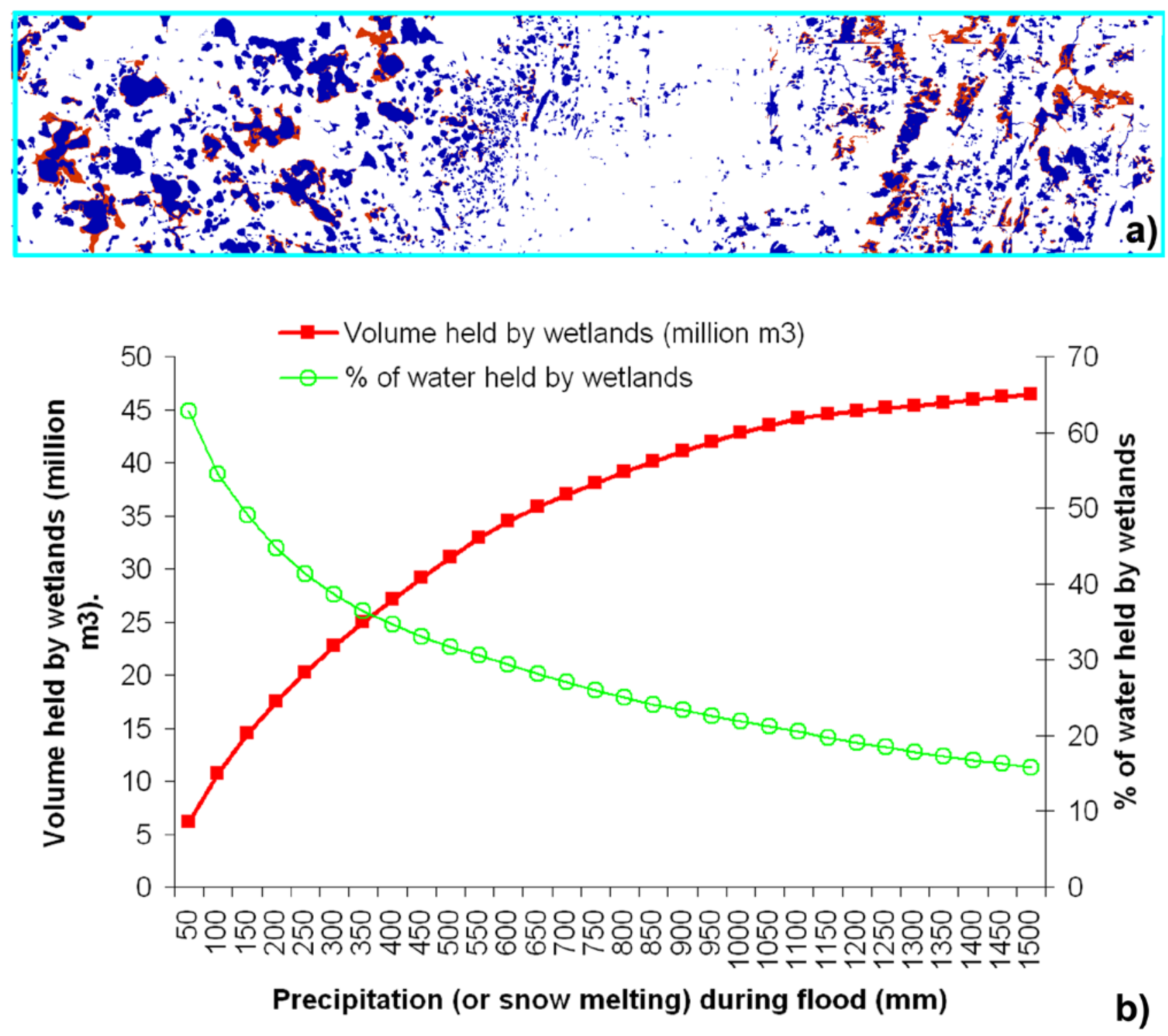

Figure 35. Prairie Pothole storage capacity and the capability of floodwater regulation. a) Floodwater potential distribution. Blue indicates the water when individual and isolated wetlands are full. Red indicates extended water when the wetland connectivity is considered. b) With the water level of May 17, 2008, before the flood event, the absolute and relative floodwater regulation under different precipitation events was modeled. 


\section{The Methodology Development for the USGS Land Carbon Project}

The 2007 Energy Independence and Security Act mandated that the USGS develop a methodology for assessing the nation's ecosystem capacity for carbon sequestration and mitigation of greenhouse gas (GHG) fluxes, including carbon dioxide $\left(\mathrm{CO}_{2}\right), \mathrm{CH}_{4}$, and $\mathrm{N}_{2} \mathrm{O}$. The USGS Land Carbon Project, created from this mandate, developed a methodology document describing the outline and necessary approaches for conducting this national assessment. Major components of the methodology framework include scenario development, land use and land cover change modeling, terrestrial and aquatic carbon and GHG modeling, uncertainty assessment, and analysis of management activities and ramifications.

The General Ensemble biogeochemical Modeling System (GEMS) plays a key role in the Land Carbon Project. The GEMS group has concentrated on the writing of Section 3.3.4 (Carbon Stocks, Carbon Sequestration, and GHG Fluxes of Terrestrial Ecosystems) and Appendix D (Methods for Carbon Stock, Carbon Sequestration, and GHG Fluxes of Terrestrial Ecosystems). The flowchart of GEMS is shown in figure 36. For more information, contact Shuguang Liu, USGS EROS, sliu@usgs.gov.

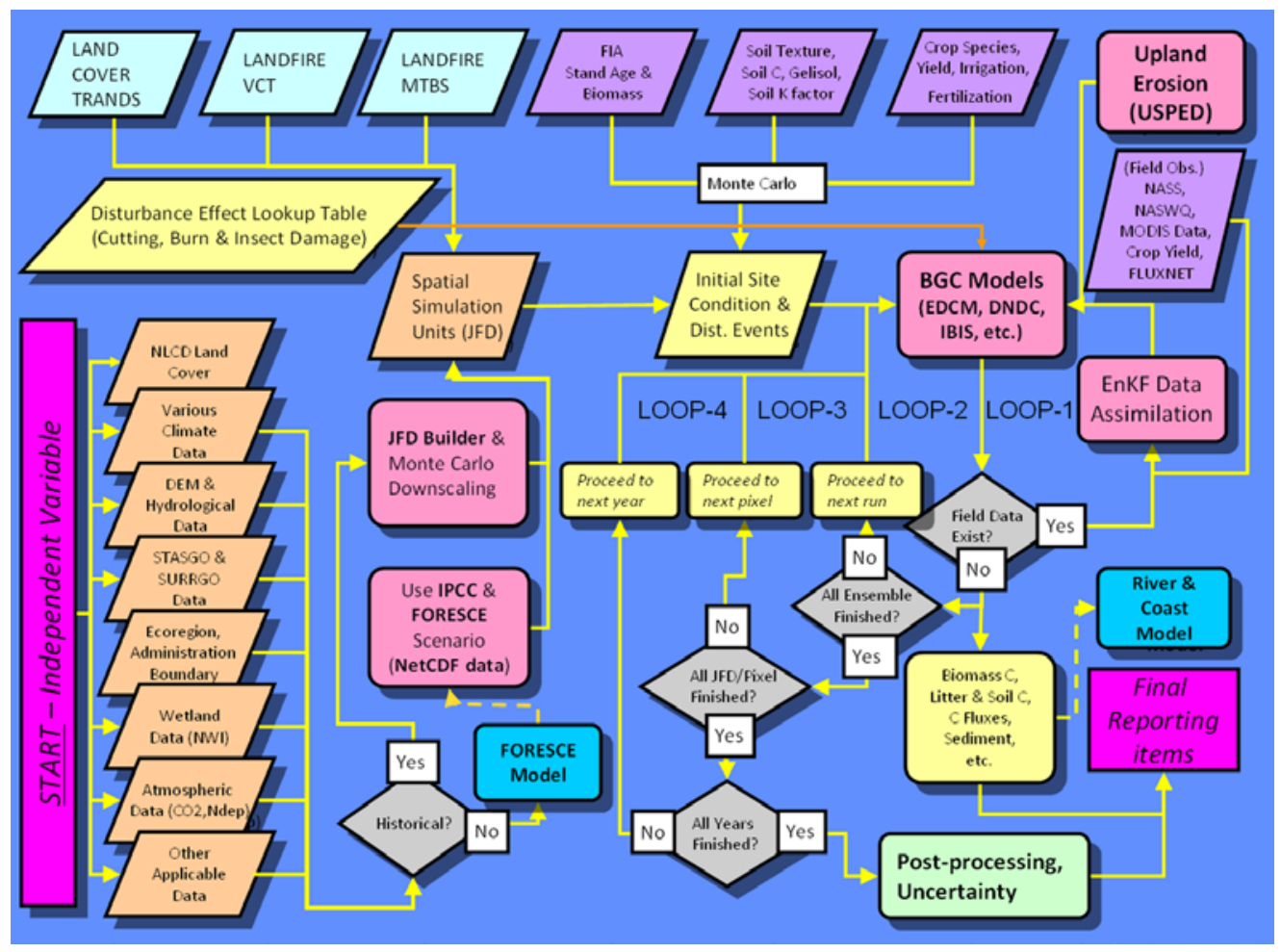

Figure 36. Flow chart of the GEMS. LANDFIRE, Landscape Fire and Resource Management Planning Tools Project; VCT, vegetation change tracker; MTBS, Monitoring Trends in Burn Severity Project; FIA, Forest Inventory and Analysis Program (U.S. Forest Service); C, carbon; K, potassium; USPED, unit stream power-based erosion and deposition; NASS, National Agricultural Statistics Service; NASWO, National Action Plan for Salinity and Water Quality; MODIS, moderate resolution imaging spectroradiometer; JDF, joint frequency distribution; BGC, biogeochemical; EDCM, erosion deposition carbon model; DNDC, denitrification-decomposition; IBIS, integrated biosphere simulator; EnKF, ensemble Kalman filter; NetCDF, network common data form; NLCD, national land cover database; DEM, digital elevation model; STATSGO, U.S. general soil map; SSURGO, soil survey geographic database; NWI, national wetland inventory; $\mathrm{CO}_{2}$, carbon dioxide; Ndep, nitrogen deposition.

\section{GEMS Simulation Results for the Land Carbon Pilot Study Area}

Estimating ecosystem carbon sequestration and greenhouse gas (GHG) emissions under various scenarios of future land cover and land use change is one of the key focuses of the Land Carbon Project. A pilot study area was chosen in the Land Carbon Project, which includes Tensas Parish, Louisiana, and Claiborne County, Mississippi. Three biogeochemical modeling methods (GEMS-spreadsheet, GEMS-CENTURY, and GEMS-EDCM) were used to estimate carbon change under future land use and land cover change scenarios, which were generated by the FORE-SCE model at 250-meter resolution from 2001 to 2050. 
As an example, the spatial distribution of total ecosystem carbon stock simulated by GEMS-CENTURY is shown in figure 37. Regional biomass carbon change simulated by the three biogeochemical models is summarized in figure 38 . The model intercomparison provides a way to quantify modeling uncertainty. For more information, contact Shuguang Liu, USGS EROS, sliu@ usgs.gov.

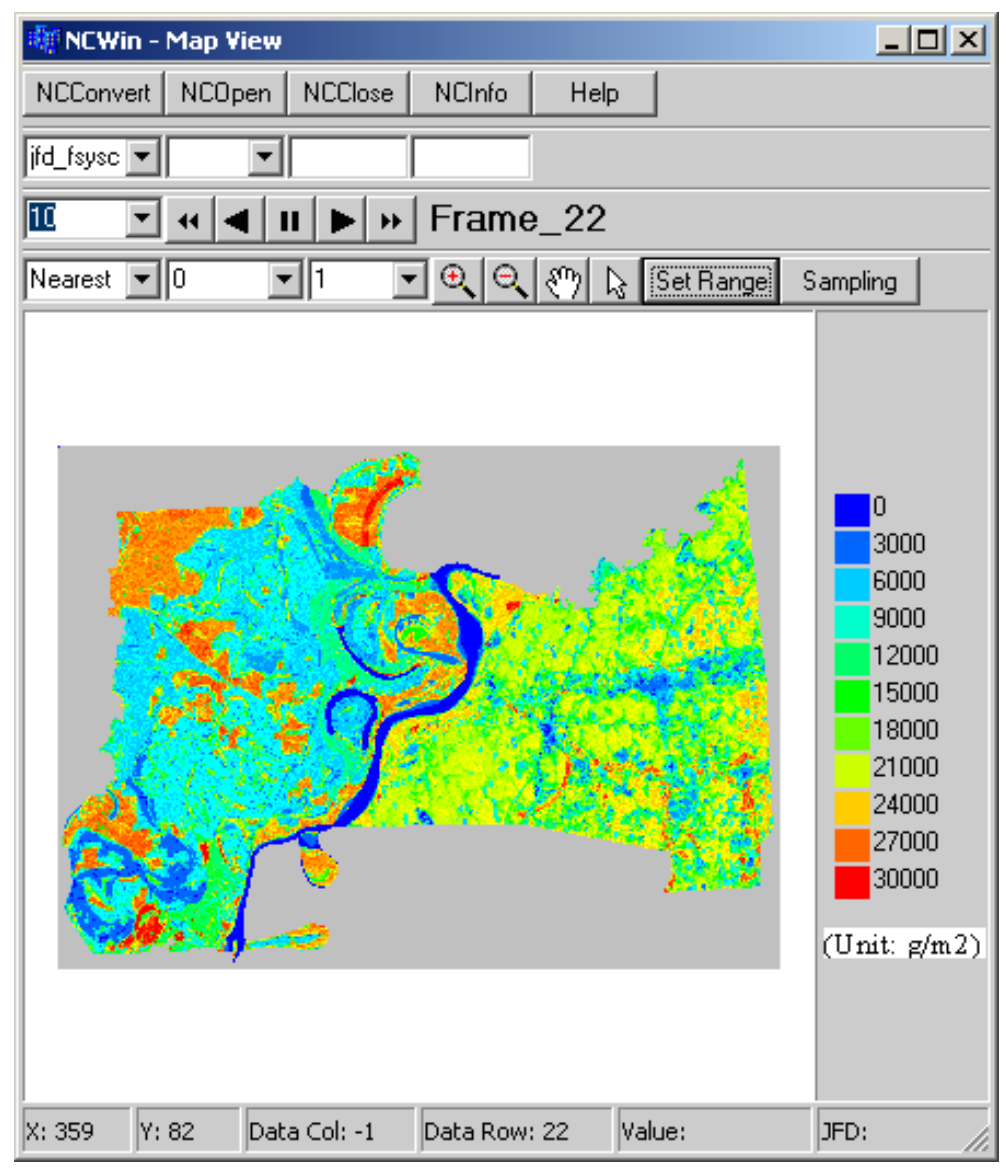

Figure 37. Total ecosystem carbon stock simulated by GEMS-CENTURY in the pilot study area.

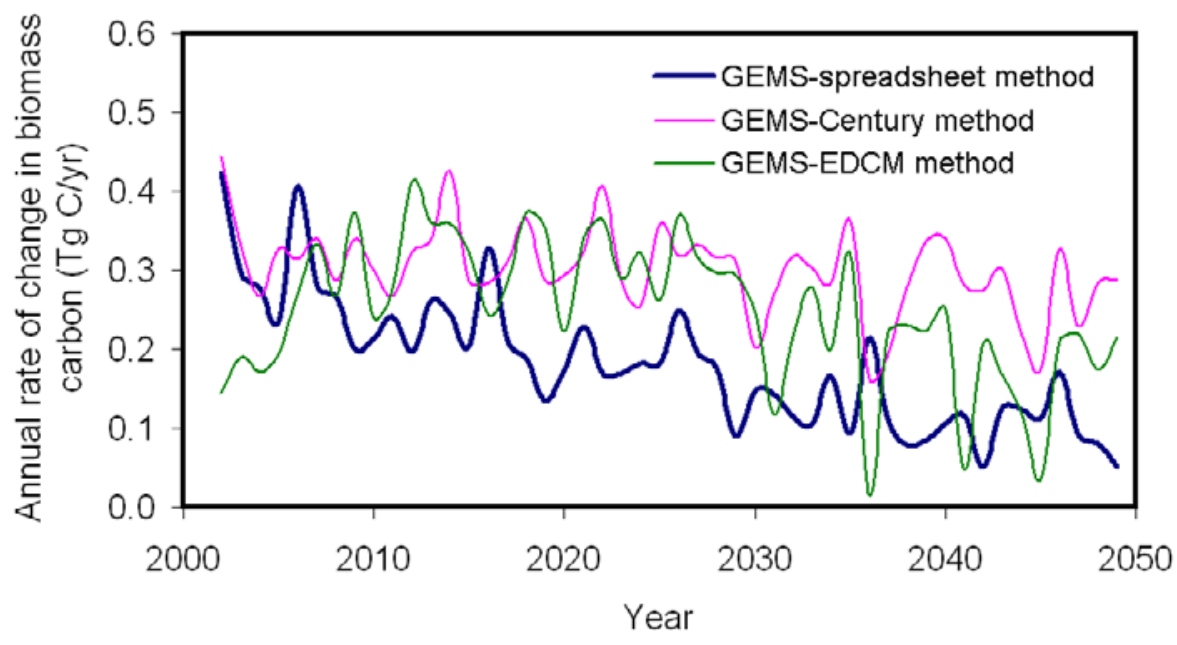

Figure 38. Comparisons of annual carbon sequestration rates of biomass carbon stock among three methods (GEMS-spreadsheet, GEMS-CENTURY, and GEMS-EDCM) using the "enhanced land use and land cover with reference land management" (L) scenario for the whole pilot study area from 2001 to 2050. Comparison made using the same models and the "reference land use, land cover, and land management" (R) scenario yielded similar results. $\mathrm{Tg} \mathrm{C} / \mathrm{yr}$, teragrams of carbon per year. 


\section{Simulation of Lateral Movement of Soil and Carbon on Landscape}

Lateral movement of ecosystem carbon across landscape and changes in vertical soil profile are important aspects in ecosystem carbon accounting; however, few biogeochemical carbon cycle models are capable of simulating carbon changes related to soil erosion. The USGS Land Carbon Project is attempting to link the Unit Stream Power-based Soil Erosion and Deposition model (USPED) with the Erosion-Deposition-Carbon-Model (EDCM) to make more detailed carbon estimates at watershed to regional levels. The soil erosion and deposition map created by USPED for the Mississippi Alluvial Plain Ecoregion and the Mississippi Valley Loess Plains Ecoregion is shown in figure 39. Results indicate that the 50-year trend of soil and carbon erosion is affected by land use activities. Decreased forest cutting and increased wetland restoration reduced soil erosion by approximately 20,000 tons per year. The next step is applying USPED and EDCM to dynamically update vertical soil profile and soil carbon content for the conterminous United States. For more information, contact Shuguang Liu, USGS EROS, sliu@usgs. gov.

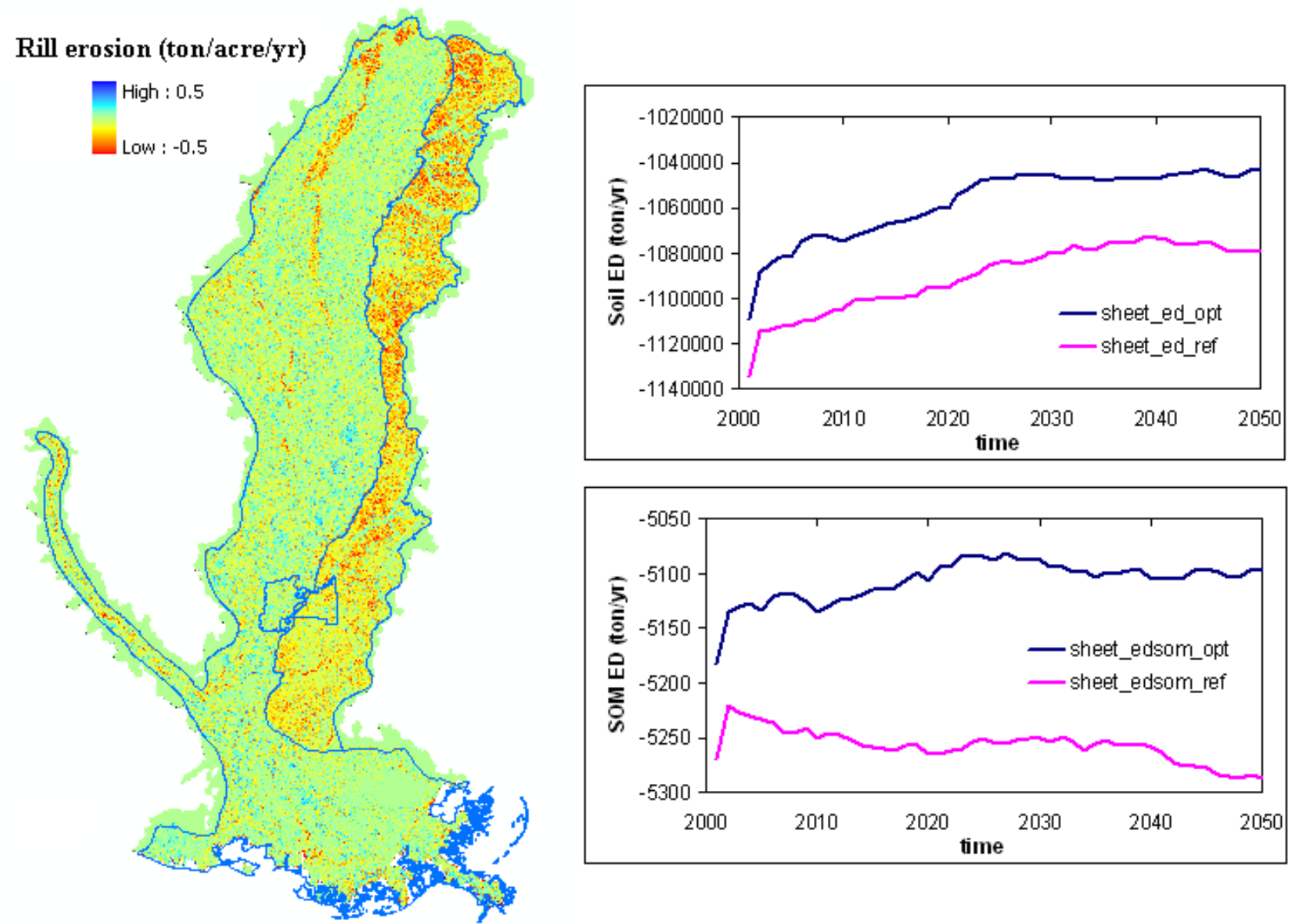

Figure 39. Spatial distribution of soil erosion and deposition is shown on the left. Trends of total soil erosion are shown on the right with blue lines indicating business as usual and purple lines indicating reduced forest cutting and increased wetland restoration. 


\section{Contemporary Carbon Dynamics in U.S. Eastern Terrestrial Ecosystems}

Carbon sequestration in terrestrial ecosystems is an important part of an overall carbon management strategy to help reduce $\mathrm{CO}_{2}$ concentrations in the atmosphere. U.S. terrestrial ecosystems may contribute substantially to global carbon sequestration; however, the magnitude, locations, underlying mechanisms, and temporal trends of terrestrial carbon sinks are highly uncertain. In order to resolve these challenging issues, the U.S. Carbon Trends Project at USGS quantifies the spatial and temporal changes of carbon sources and sinks in the conterminous United States from the 1970s to the 2000s using the General Ensemble Biogeochemical Modeling System (GEMS) developed at EROS.

GEMS uses Monte Carlo sampling and ensemble Kalman filter techniques to incorporate land use and land cover change, climate variation, soil variability, and land management practices into a biogeochemical model. In this study, simulations were carried out in sample blocks (10x10 km or 20x20 km) from the USGS Land Cover Trends Project.

Panel A (fig. 40) shows the Ridge and Valley ecoregion removed $\mathrm{CO}_{2}$ from the atmosphere from 1973 to 2000 at a rate of about 97 grams of carbon per square meter per year $\left(\mathrm{g} \mathrm{C} \mathrm{m}^{-2} \mathrm{yr}^{-1}\right)$ with a strong interannual variability. Soils were a small carbon sink, and the sink strength was not sensitive to the interannual variability of disturbances and climate. Panel B (fig. 40) shows that ignoring land cover change leads to overestimation of net ecosystem exchange (NEE) or the strength of carbon sinks. For further information, contact Shuguang Liu, USGS EROS, sliu@usgs.gov.
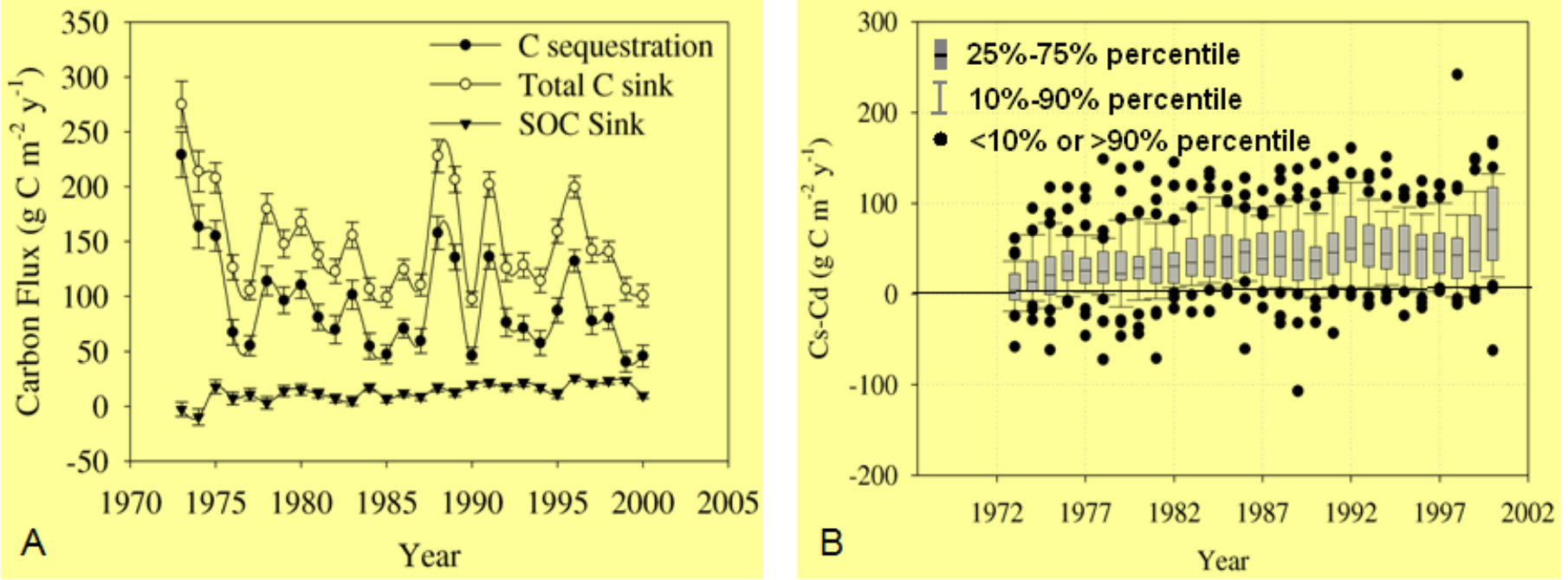

Figure 40. Panel A displays the annual variation of carbon fluxes in the Ridge and Valley ecoregion from 1973 to 2000, where total carbon sink refers to the net carbon uptake by terrestrial ecosystems (that is, increase of plant biomass carbon and soil organic carbon (SOC), and harvest carbon in grain and wood). Panel B shows the impact of land cover change on net ecosystem exchange (NEE) in 40 sample blocks each year, where $\mathrm{Cs}$ and $\mathrm{Cd}$ denotes NEE under static and dynamic land covers, respectively.

\section{Spatiotemporal Dynamics of Water Loss because of Evapotranspiration in the Great Plains}

Evapotranspiration (ET), one of the major components of the water cycle, accounts for about 70 percent of precipitation in the United States. Though ET is expected to alter because of climate change, its intensity and spatial patterns will depend upon local variables and forcings. An energy balance modeling approach was used to quantify the spatial and temporal distribution of ET for the 2001 growing season with Landsat (path 28, row 31) images. Temporal progression of ET captured the phenological stages during the crop growing season (fig. 41). During 2001, in general, crops had higher ET during July and August, and lower ET with maturity in September and harvest in October. Spatial distribution of ET showed lower ET from urban settlement (lower middle part) and barren land (lower left part) than from crop and grasslands. Results were validated with eddy covariance measurements. ET at an irrigated continuous maize site was estimated with a standard error of 0.7 millimeter $(\mathrm{mm})$ day-1 $\left(\mathrm{R}^{2}=0.93\right)$, while ET at a rain-fed maize-soybean rotation site was estimated with a standard error of $0.6 \mathrm{~mm}$ day $-1\left(\mathrm{R}^{2}=0.89\right)$. For further information, contact Shuguang Liu, USGS EROS, sliu@usgs.gov. 

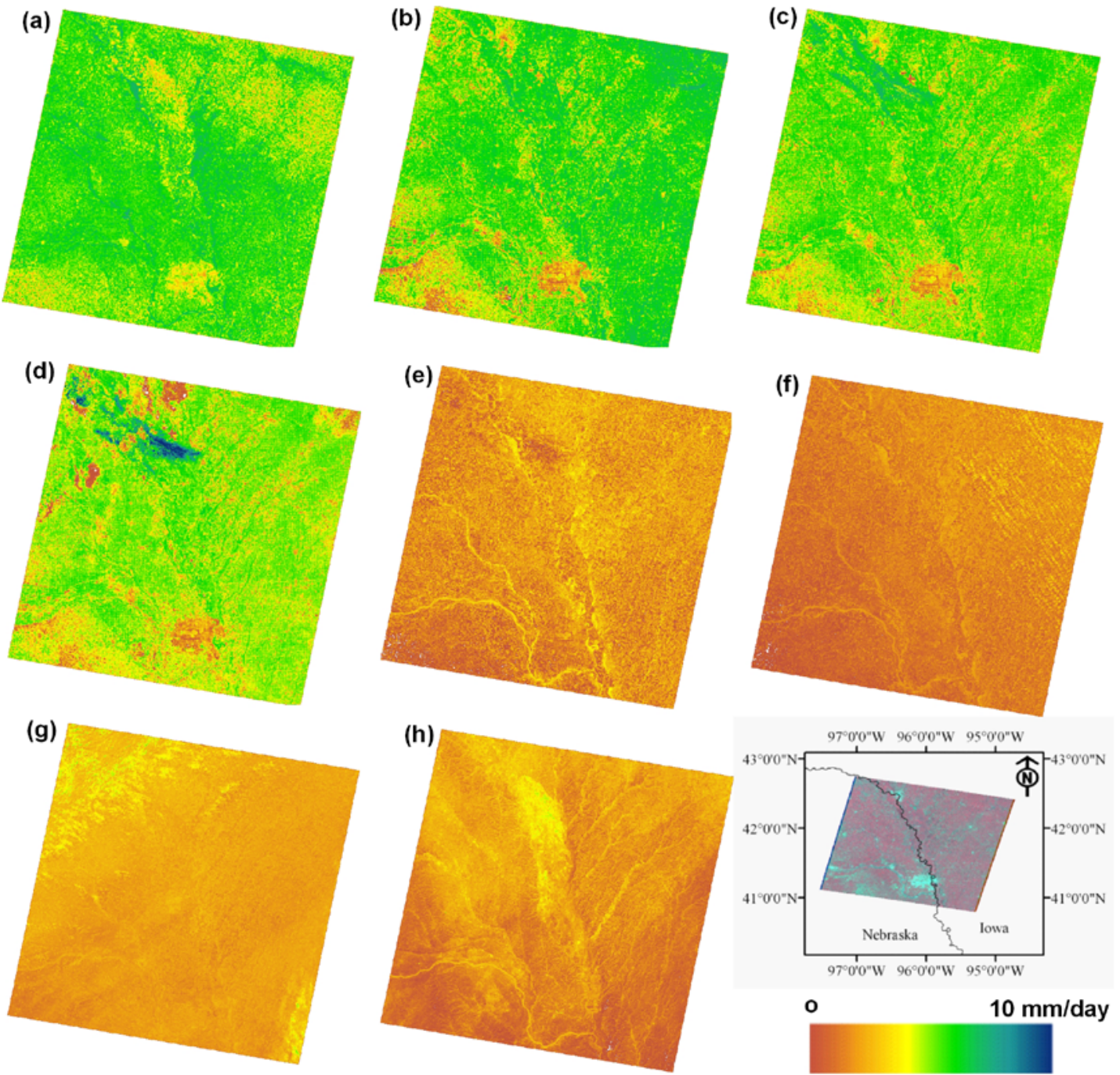

Figure 41. Evapotranspiration maps showing the water loss because of evapotranspiration on (a) July 4, (b) August 5, (c) August 13, (d) August 29, (e) September 30, (f) October 16, (g) October 24, and (h) December 11, 2001. Location of the study area and legend for evapotranspiration maps are shown in the lower-right corner.

\section{Modeling Gross Primary Productivity in the Mid-Continent Intensive Campaign Region of the North American Carbon Program}

Primary production is the process of synthesis and storage of organic molecules during the growth and reproduction of photosynthetic organisms. Better understanding of primary productivity is important for sustainable ecosystems at regional and global scales because all forms of life on Earth depend on it. This study was carried out using the Eddy Covariance-Light Use Efficiency (EC-LUE) model for estimating gross primary productivity (GPP) in the Mid-Continent Intensive campaign region. The EC-LUE model was selected because of its ability to compute GPP across the biomes. Landsat images from Nebraska (path 28, row 31), Illinois (path 23, row 31), and Wisconsin (path 25, row 28) were used for this study. Spatial and temporal progression of GPP depicted the dynamics of primary productivity in the region. GPP dynamics for the Nebraska site are shown in figure 42. Validation of GPP estimates with eddy covariance estimated GPP indicated that more than 90 percent of the variability can be explained. For further information, contact Shuguang Liu, USGS EROS, sliu@usgs.gov. 


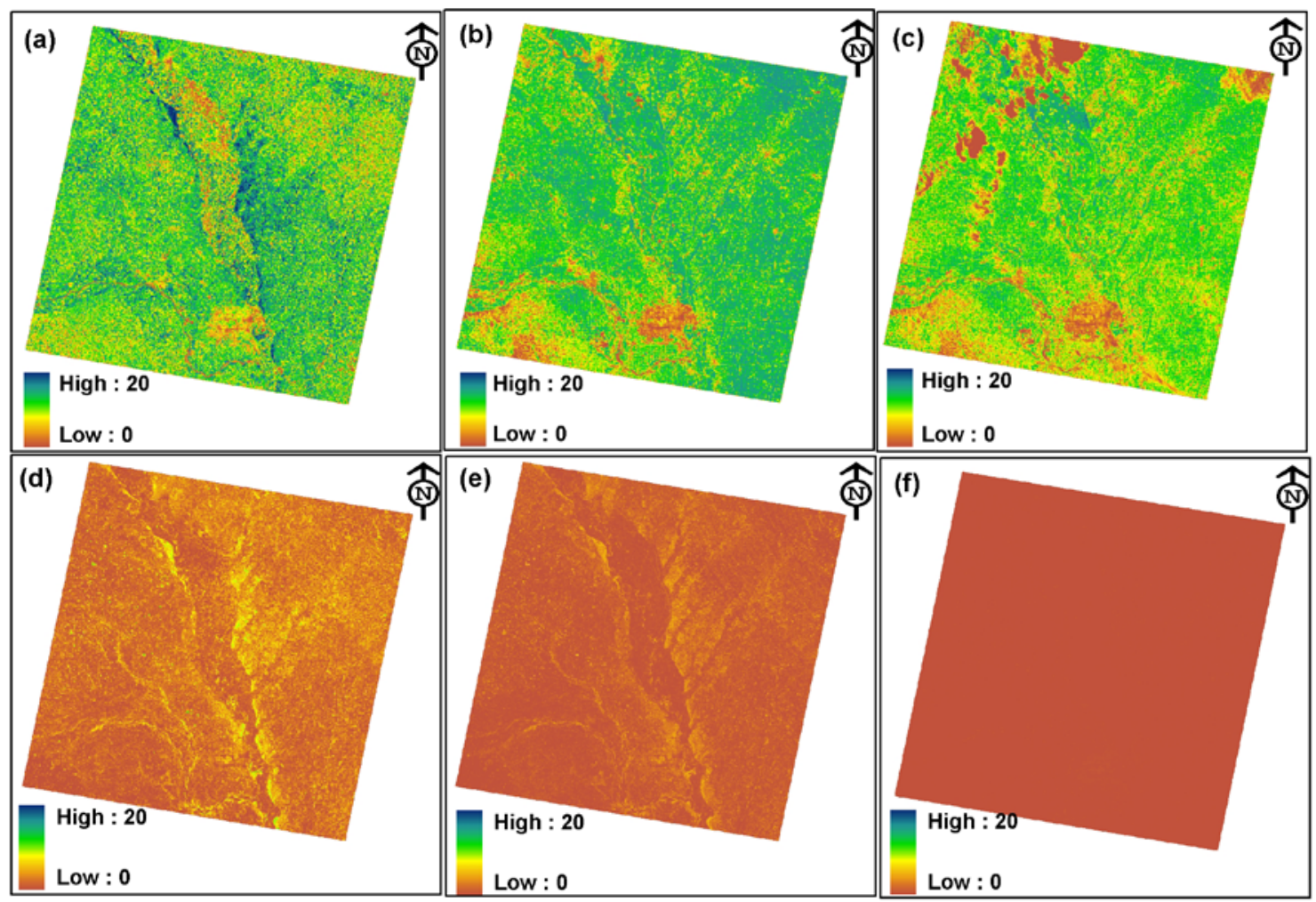

Figure 42. Gross primary productivity maps derived from Landsat (path 28, row 31) for (a) July 4, (b) August 5, (c) August 29, (d) September 30, (e) October 16, and (f) December 11, 2001. The GPP values are in grams of carbon per square meter per day $\left(\mathrm{g} \mathrm{C} \mathrm{m}^{-2}\right.$ day $\left.^{-1}\right)$.

\section{Computing Seasonal Evapotranspiration in the Great Plains Using Satellite Images}

Evapotranspiration (ET) plays an important role in water balance studies at local, regional, and global scales. Estimates of seasonal ET have many applications in water resources planning and management, including hydrological and ecological modeling. However, computing seasonal ET from temporal satellite images is very challenging because of either limited availability of cloud-free images or long repeat cycle of satellite overpass. This study was conducted to determine the suitability of three different methods (cubic spline, fixed, and linear interpolation) for estimating seasonal ET from temporally sparse Landsat images (path 28, row 31). All three methods resulted in a similar pattern of seasonal ET distribution (fig. 43). However, the density plot of seasonal ET indicated that the linear method was in closer agreement with the fixed method than the cubic spline (fig. 44).

Seasonal ET estimated using cubic spline was in better agreement with the eddy covariance measured seasonal ET, particularly if no or only one image per month was available. However, the fixed and linear methods resulted in comparable performance when two or more images per month were available. Validation of seasonal ET using eddy covariance tower measurements indicated that all three methods resulted in higher (18 percent) seasonal ET. For further information, contact Shuguang Liu, USGSEROS,sliu@usgs.gov. 

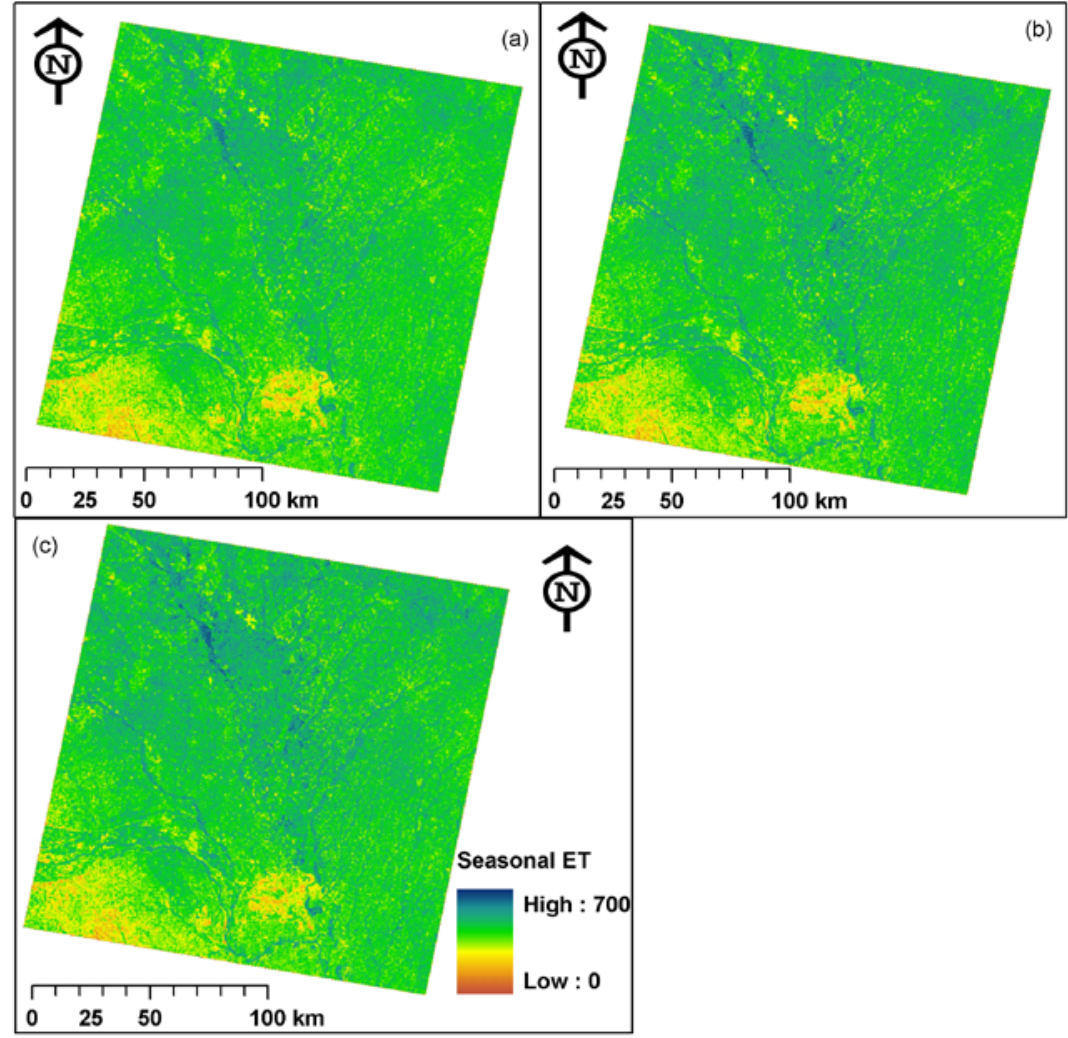

Figure 43. Cumulative seasonal evapotranspiration (July-December) for 2001 growing season using (a) cubic, (b) fixed, and (c) linear methods.
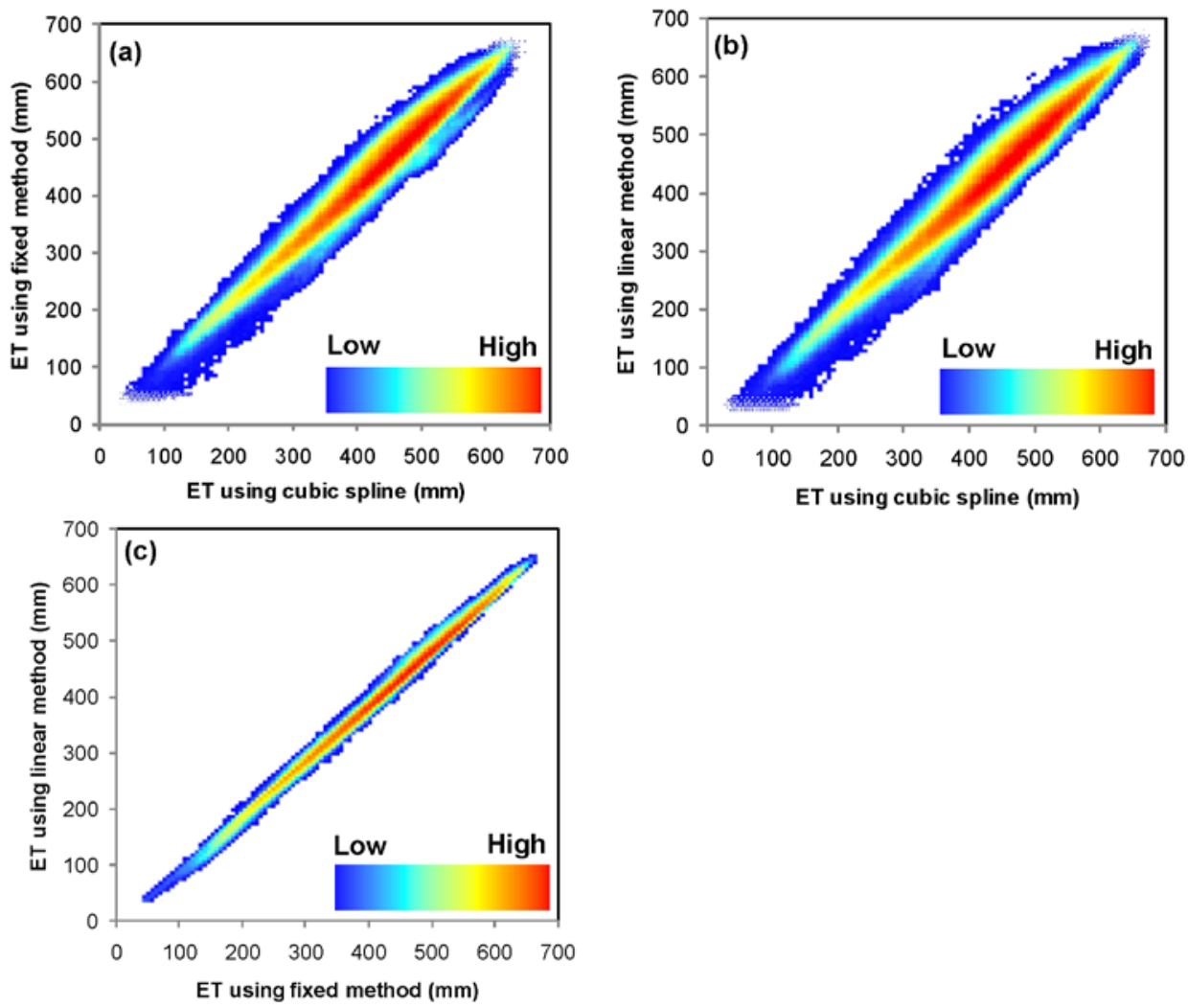

Figure 44. Density plot of seasonal evapotranspiration for (a) cubic and fixed methods, (b) cubic and linear methods, and (c) fixed and linear methods. 


\section{Effects of Spatial Resolution of Satellite Sensors on Seasonal Evapotranspiration Estimates}

Seasonal evapotranspiration (ET) was estimated in the Great Plains using 30-meter Landsat (path 28, row 31) and 1-kilometer MODIS images. These images were acquired on July 4, August 5, August 13, August 29, September 30, October 16, October 24, and December 11, 2001. Daily ET on the days of the satellite overpass was computed using an energy balance approach, and seasonal ET was computed using cubic spline interpolation of daily ET. The spatial resolutions of Landsat and MODIS data affected the seasonal ET distribution and magnitude as shown in figure 45.

The mean seasonal ET from July to December was 422 millimeters and 431 millimeters using MODIS and Landsat images, respectively. Though the mean seasonal ET using Landsat images was close to the ET using MODIS images, the spatial distribution was quite different (fig. 46). The higher spatial resolution of Landsat shows the variation of ET even at field scale, which cannot be seen from MODIS-estimated ET. For further information, contact Shuguang Liu, USGS EROS, sliu@usgs.gov.

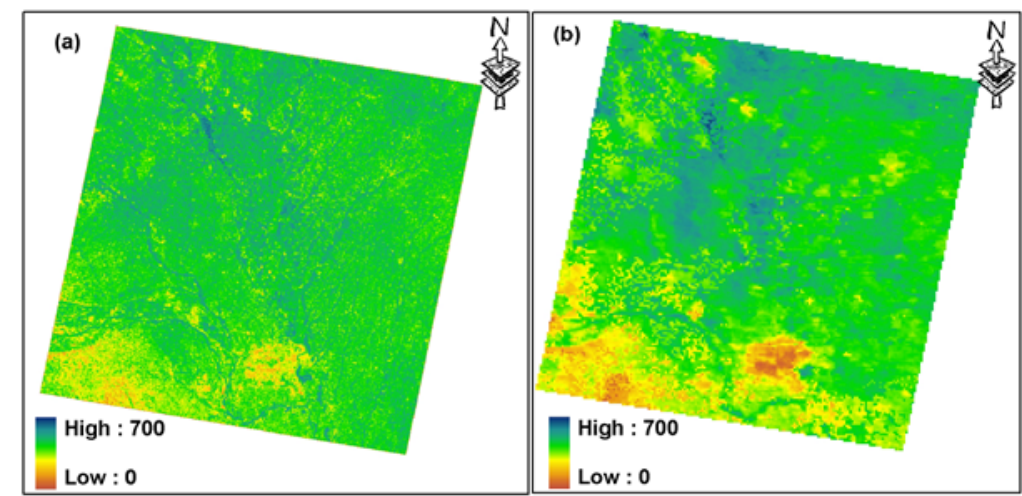

Figure 45. Seasonal evapotranspiration (millimeters) from July to December 2001 growing season using (a) Landsat and (b) MODIS images.

\section{Sensitivity of Hydrological Processes to Climate Change in the Upper Mississippi River Basin}

Global warming has become more apparent in recent decades, as evident from observations of increasing global average air and ocean temperatures, widespread melting of snow and ice, and rising global sea levels. Future warming because of increasing anthropogenic releases of $\mathrm{CO}_{2}$ is projected to alter potential evapotranspiration (ET) with the most immediate effect being an increase in the ability of air to absorb water as temperature rises. Therefore, potential consequences of an elevated atmospheric $\mathrm{CO}_{2}$ concentration may change the temporal and spatial distribution of precipitation.

Sensitivity studies of temperature and precipitation variations can provide important information regarding the responses and vulnerabilities of different hydrologic systems to climate change. Using the Soil and Water Assessment Tool (SWAT), the hydrological responses to changing climate variables (for example, $\mathrm{CO}_{2}$, precipitation, and temperature) in the Upper Mississippi River Basin were estimated. Eight model setups were used to test model sensitivities. The study results show that water yield changed linearly with precipitation (fig. 47 and table 1). However, water yield and soil water content decreased dramatically when temperature increased, while simulated ET remained proportional to the temperature rise. For further information, conta Shuguang Liu, USGS EROS, sliu@usgs.gov.

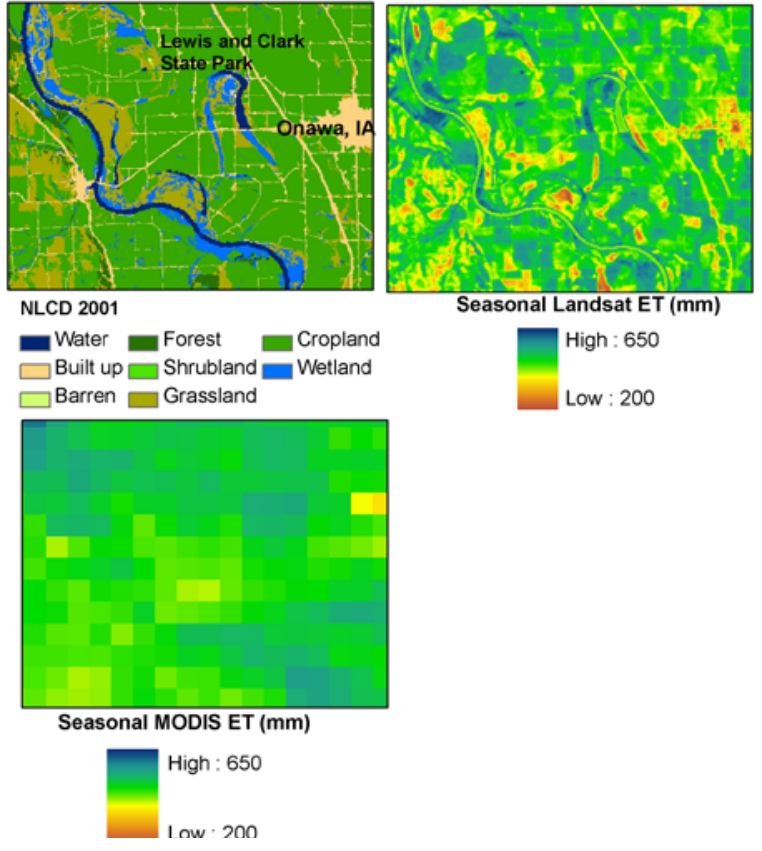

Figure 46. Effect of spatial resolution on estimated seasonal evapotranspiration. 

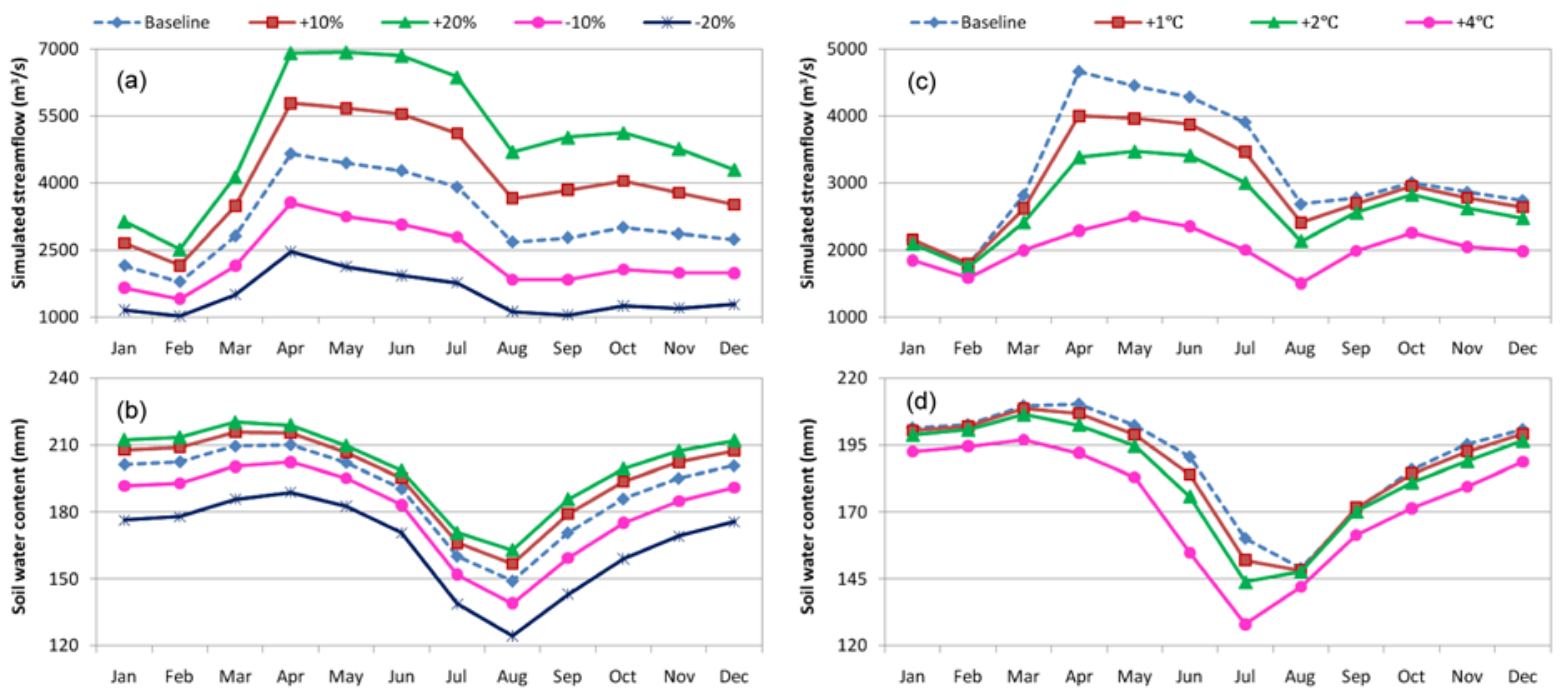

Figure 47. Comparison of simulated streamflow and soil water content under changing precipitation and temperature scenarios.

Table 1. Predicted relative changes in annual average hydrological components for the climate change sensitivity simulations.

$\left[\mathrm{CO}^{2}\right.$, carbon dioxide; $\%$, percent; ${ }^{\circ} \mathrm{C}$, celsius $]$

\begin{tabular}{|c|c|c|c|c|c|c|c|c|c|}
\hline \multirow{4}{*}{$\begin{array}{l}\text { Hydrological } \\
\text { components }\end{array}$} & \multirow{4}{*}{$\begin{array}{c}\text { Reference } \\
\text { (mm/yr) }\end{array}$} & \multicolumn{8}{|c|}{ Climate sensitivity simulations } \\
\hline & & \multirow{2}{*}{$\begin{array}{l}\mathrm{CO}_{2} \\
600\end{array}$} & \multicolumn{4}{|c|}{ Precipitation } & \multicolumn{3}{|c|}{ Air tempurature } \\
\hline & & & $+10 \%$ & $+20 \%$ & $+30 \%$ & $+40 \%$ & $+1^{\circ} \mathrm{C}$ & $+2^{\circ} \mathrm{C}$ & $+4^{\circ} \mathrm{C}$ \\
\hline & & \multicolumn{8}{|c|}{ Percentage change } \\
\hline Water yield & 244 & 23 & 28 & 57 & -26 & -50 & -7 & -14 & -33 \\
\hline Evapotranspiration & 561 & -11 & 2 & 4 & -3 & -6 & 3 & 7 & 15 \\
\hline Soil water content & $190 *$ & 7 & 3 & 6 & -5 & -13 & -1 & -3 & -9 \\
\hline Groundwater recharge & 129 & 31 & 25 & 50 & -25 & -49 & -5 & -12 & -35 \\
\hline
\end{tabular}

"Unit of soil water content is millimeters.

\section{Hydrological Responses to Rising Atmospheric Carbon Dioxide $\left(\mathrm{CO}_{2}\right)$ Concentration in the Upper Mississippi River Basin}

Increased atmospheric $\mathrm{CO}_{2}$ concentration and future climate change will have significant impacts on hydrological systems. Quantifying and understanding the hydrological responses to an elevated ambient $\mathrm{CO}_{2}$ and climate change is critical for formulating adaptive strategies to manage water resources. This study examined the impacts of increased $\mathrm{CO}_{2}$ in the Upper Mississippi River Basin using a modified Soil and Water Assessment Tool (SWAT). To adequately estimate the impacts of increased $\mathrm{CO}_{2}$ in past decades, the constant $\mathrm{CO}_{2}$ in the original SWAT was replaced with historical monthly $\mathrm{CO}_{2}$ concentration observations. Vegetation responses to elevated $\mathrm{CO}_{2}$ such as vegetation-specific stomatal conductance reduction and leaf area increase have been implemented in the revised model.

The results indicate that streamflow has increased by 1 to 8 millimeters per year ( 1 to 4 percent) from 1987 to 2008 because of $\mathrm{CO}_{2}$ increase (fig. 48). A strong relation between the increase in streamflow and the increase in $\mathrm{CO}_{2}$ concentration is shown in figure 49. Specifically, a doubling of current $\mathrm{CO}_{2}$ concentration may lead to an increase of about 50 millimeters in streamflow under current climate conditions in this Basin. For further information, contact Shuguang Liu, USGS EROS, sliu@usgs.gov. 


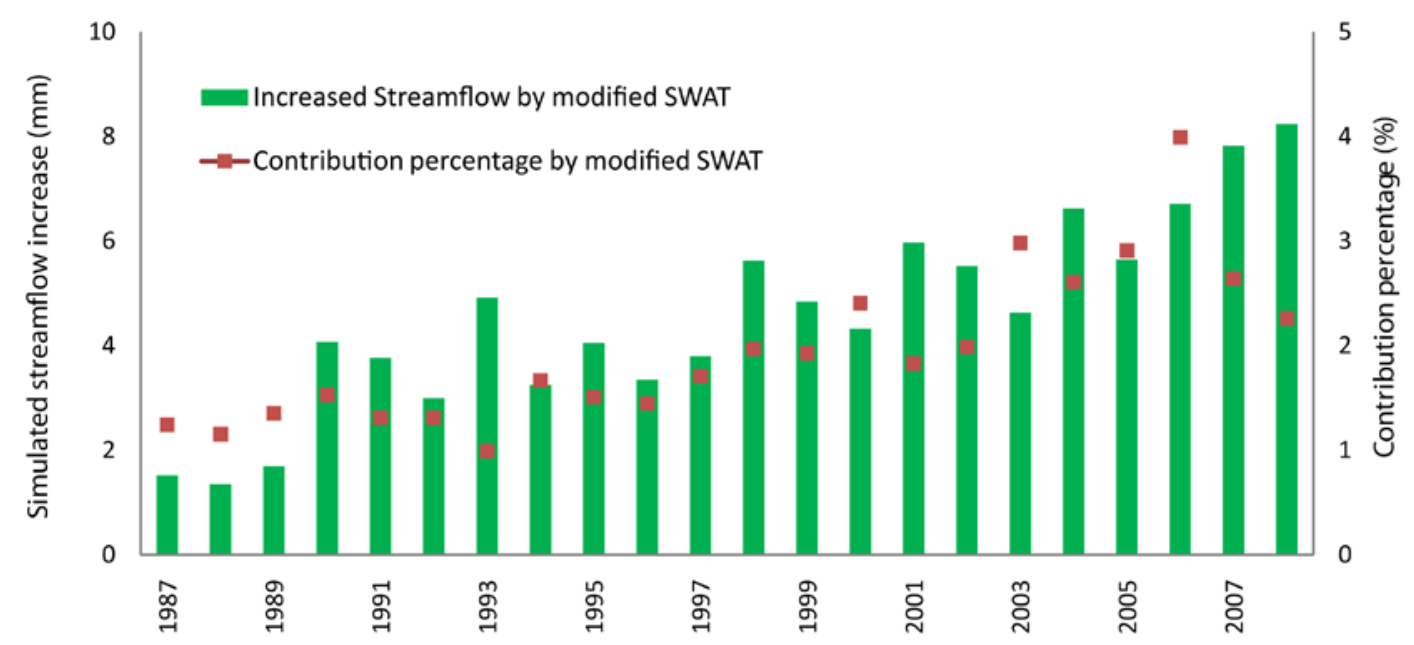

Figure 48. Simulation of streamflow increase because of the elevated atmospheric carbon dioxide concentration and contribution percentage since 1987.

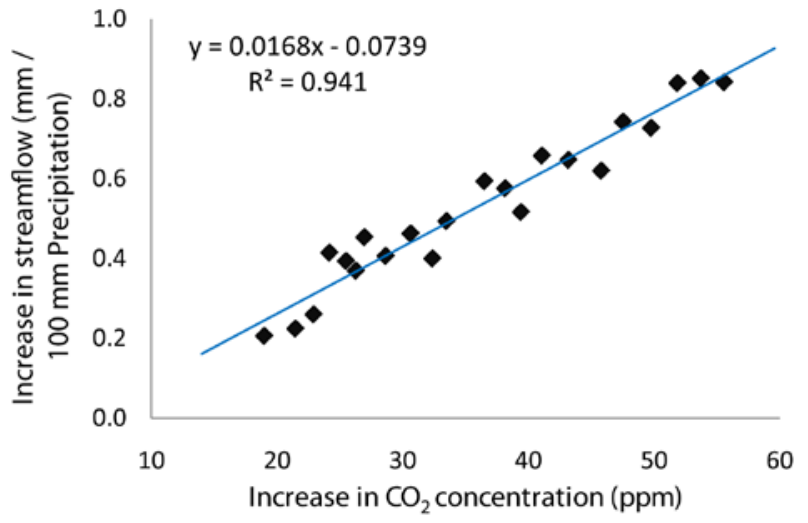

Figure 49. Relation between the increase in streamflow per unit precipitation and the increase in carbon dioxide concentration.

\section{Grazing Affects DOI Land Carbon Dynamics, but with High Uncertainty}

Twenty-five percent of the Nation's lands are managed by the Department of Interior (DOI). DOI lands store a large amount of carbon, but no systematic research has been performed on carbon status and trends. To study the current carbon status and address the impacts of different management practices on these public lands, USGS EROS is using the General Ensemble Biogeochemical Modeling System (GEMS) and existing regional databases (such as land cover, soil, and climate) to quantify ecosystem carbon dynamics for historical, current, and future carbon stocks in vegetation and soils.

For example, the carbon status of the Green River Basin (GRB) in Wyoming, which is largely managed by the Bureau of Land Management (BLM) in DOI, was studied. Grazing management is a dominant driving force affecting carbon dynamics in GRB. To evaluate the impacts of different grazing management practices, we used GEMS to simulate the ecosystem carbon sequestration under different scenarios. The simulated vegetation production agreed with MODIS vegetation production and U.S. Department of Agriculture census hay production from pasture lands.

The spatial distribution of ecosystem carbon sinks (carbon gain) and sources (carbon loss) in GRB is shown in figure 50. As a whole, GRB was a weak carbon sink of $6 \mathrm{~g} \mathrm{C} \mathrm{m}^{-2} \mathrm{yr}^{-1}$ from 1970 to 2000. Model simulations indicated grazing intensity had different impacts on production and ecosystem carbon dynamics in this area, but the uncertainty of the impacts was high mainly because of the lack of grazing information (such as location, time period, and animal type). For further information, contact Shuguang Liu, USGS EROS, sliu@usgs.gov. 


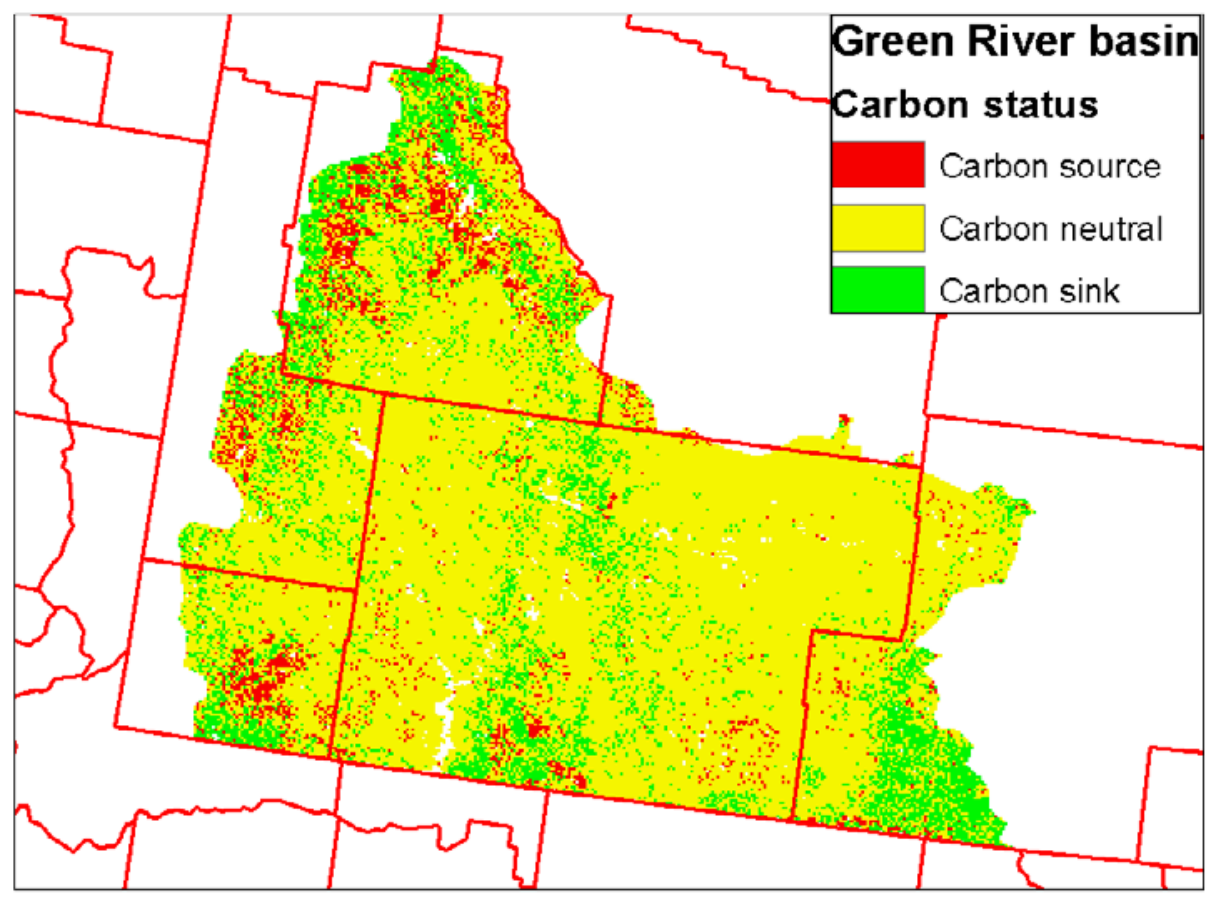

Figure 50. Spatial distribution of carbon sinks and sources in the Green River Basin simulated by General Ensemble Biogeochemical Modeling System from 1970 to 2000.

\section{General Ensemble Biogeochemic al Modeling System (GEMS) Development}

Ecosystem carbon sequestration has been recognized by international communities as a major means of reducing atmospheric $\mathrm{CO}_{2}$ concentration. Estimating the impacts of changes on land use, land cover, and climate on carbon sequestration, while important to decision and policy makers, is challenging. To quantify carbon sequestration over large areas, we have developed and successfully applied GEMS in multiple terrestrial ecosystems (such as forest, cropland, and grassland) around the world (fig. 51).

GEMS has been selected by the USGS Land Carbon Project as the backbone biogeochemical modeling system for assessing the Nation's ecosystem capacity for carbon sequestration and reduction of greenhouse gas emissions $\left(\mathrm{CH}_{4}\right.$ and $\left.\mathrm{N}_{2} \mathrm{O}\right)$. Further development of GEMS in areas such as parallel computing, model integration, model ensemble, data assimilation, and webservices-based application will substantially help to fulfill the USGS Land Carbon Project's missions. For further information, contact Shuguang Liu, USGS EROS, sliu@usgs.gov.

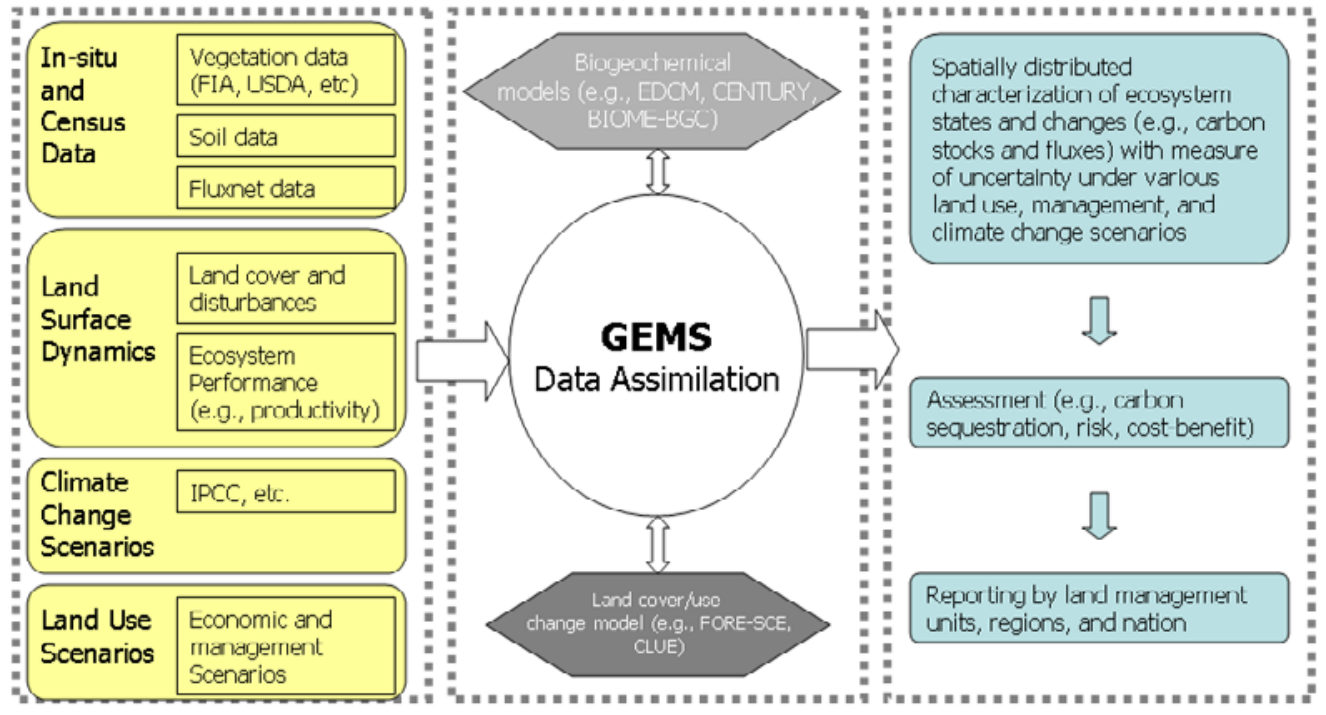

Figure 51. Structure of the General Ensemble Biogeochemical Modeling System. 


\section{Impacts of Management Practices on Cropland Carbon Sequestration in Mid-Continent Intensive Region}

Large discrepancies usually exist between atmospheric and ecosystem model results in quantifying carbon fluxes over vast areas. As part of the North American Carbon Program, the Mid-Continent Intensive (MCI) Campaign compares and reconciles regional carbon flux estimates by "top-down" atmospheric models and "bottom-up" ecosystem models to identify the dominant mechanism of regional carbon flux. Collaborative work activities occurred with scientists from universities and other agencies to provide ecosystem carbon flux estimations with uncertainties in the MCI region using the General Ensemble Biogeochemical Modeling System (GEMS).

Cropland soil carbon changes under different tillage management scenarios is shown in figure 52. This research will not only improve scientific understanding of carbon dynamics in MCI but also will benefit land resource managers in choosing proper management practices to enhance the cropland carbon sequestration in the region. For further information, contact Shuguang Liu, USGSEROS, sliu@usgs.gov.

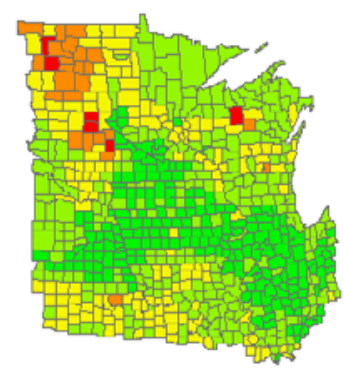

No-till

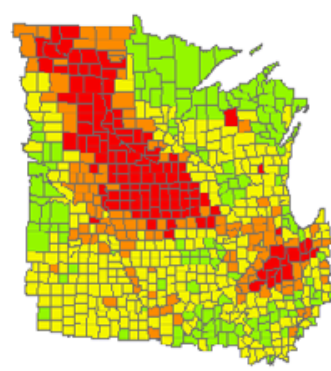

Continuous tillage

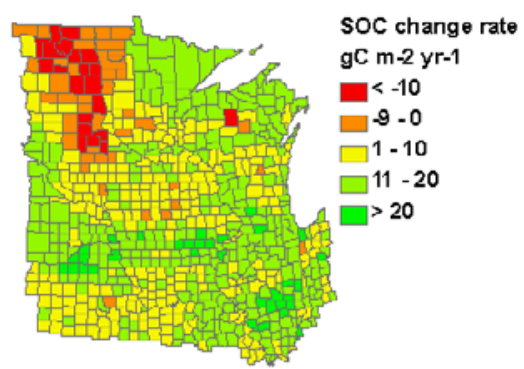

Historical tillage

Figure 52. Annual soil organic carbon $(\mathrm{SOC})$ changes in the top 20 centimeters between 2000 and 2007 per county in the Mid-Continent Intensive region for three tillage scenarios.

\section{Will Climate Change Stimulate Greenhouse Gas Fluxes in Wetlands? Greenhouse Gas Research in the Prairie Pothole Region}

The Prairie Pothole Region (PPR) contains a large number of freshwater wetlands. Greenhouse gas (GHG) emissions of $\mathrm{CO}_{2}, \mathrm{CH}_{4}$, and $\mathrm{N}_{2} \mathrm{O}$ from these wetlands are poorly understood and quantified. Work is ongoing in cooperation with the USGS Northern Prairie Wildlife Research Center (NPWRC) to simulate GHG emissions from wetland catchments for estimating spatial and temporal global warming potential in the PPR. This research will not only help to quantify the wetland contributions to global warming but also will help to understand climate change impacts on GHG emissions. The results can provide valuable information for resource managers and government agencies to apply proper management practices to reduce the GHG emissions from wetlands in the PPR.

The NPWRC collected GHG emissions data in more than 130 wetland catchments across the PPR region. Focusing on wetlands dominated by grass in upland catchments, scientists integrated MODIS Gross Primary Production data into a process-

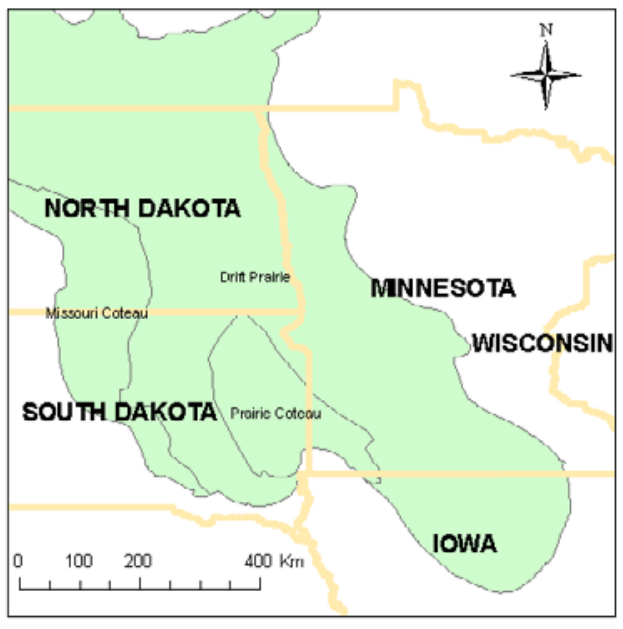
based biogeochemical model DNDC (Denitrification-Decomposition) to simulate the GHG emissions. Simulation results agreed with field measurements and explained seasonal changes in GHG emissions (fig. 53). This research indicates that the seasonal GHG emissions from PPR wetland catchments were determined by the upland vegetation growth and wetland hydrological conditions. For further information, contact Shuguang Liu, USGS EROS, sliu@usgs.gov.

Figure 53. Green indicates the location of the Prairie Pothole Region. 


\section{Evaluating Ecosystem Sustainability under Biofuel Pressure}

The demand for agricultural biomass for energy is expanding cropland into grassland-dominated systems, altering traditional crop rotations, and exploiting grassland and Conservation Reserve Program (CRP) systems. The societal need for renewable energy from the agricultural sector offers new opportunities and challenges. This project is designed to evaluate impacts of current land use and projected biofuel production scenarios on ecosystem services and sustainability across the Northern Great Plains by developing a modeling system to integrate GEMS, FORE-SCE, and economic models.

Model simulation results are shown in figure 54 for a 260-square-kilometer Prairie Pothole area in North Dakota: (1) annual ecosystem carbon fluxes and soil carbon budgets were mainly regulated by land use and management practices; and (2) the rate of soil carbon stock change was dependent mainly on the soil carbon stock level. Ecosystem sustainability mainly depends on land use and biomass removal intensity. Simulation results suggest that the current modeling system is capable of evaluating changes of ecosystem goods and services related to land use activities for biofuel production. For more information, contact Shuguang Liu, USGS EROS, sliu@usgs.gov.
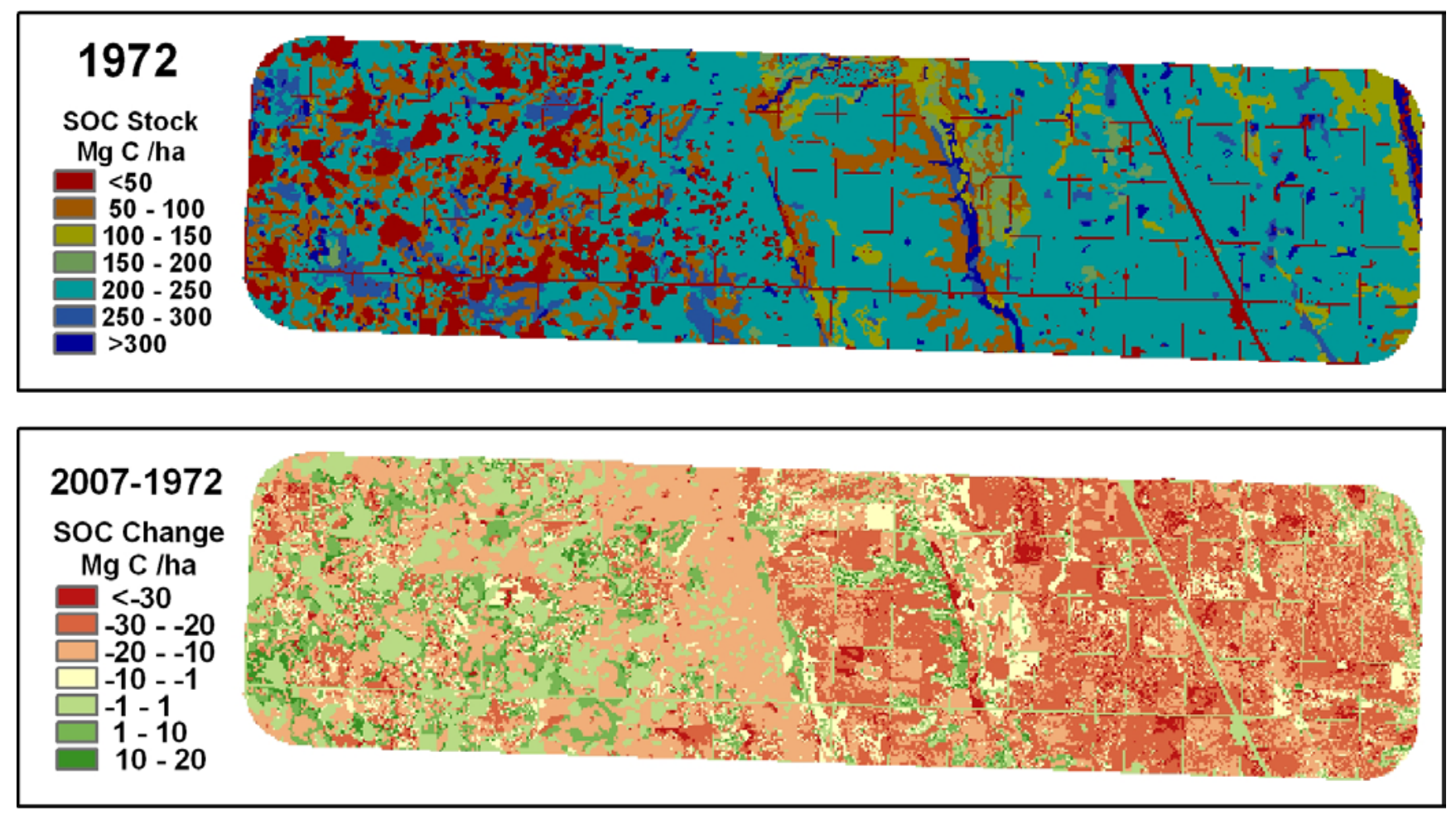

Figure 54. Top: Soil organic carbon (SOC) stock in 1972. Bottom: Total change in soil organic carbon (SOC) from 1972 to 2007.

\section{A New Approach for Estimating Global Evapotranspiration and Gross Primary Production}

To quantify and assess how climate change affects carbon, energy, and water budgets, a light use efficiency model, called EC-LUE, was developed and driven by MODIS Normalized Difference Vegetation Index (NDVI), photosynthetically active radiation, air temperature, and the Bowen ratio. The impacts of precipitation seasonality on evapotranspiration (ET) and Gross Primary Production (GPP) was examined using 54 towers' eddy covariance observations worldwide from 2000 to 2003 . Results showed that the estimates of ET and GPP agreed with those from other global models, with the highest ET and GPP over tropical forests and the lowest values in dry and high latitude areas (fig. 55). Results also imply the importance of seasonal variations of precipitation in regulating annual ET and the dependency of ET on ecosystem types. The EC-LUE, along with the revised Remote Sensing Penman-Monteith model, will provide an alternative approach to map ET and GPP over large areas. For more information, contact Shuguang Liu, USGS EROS, sliu@usgs.gov. 

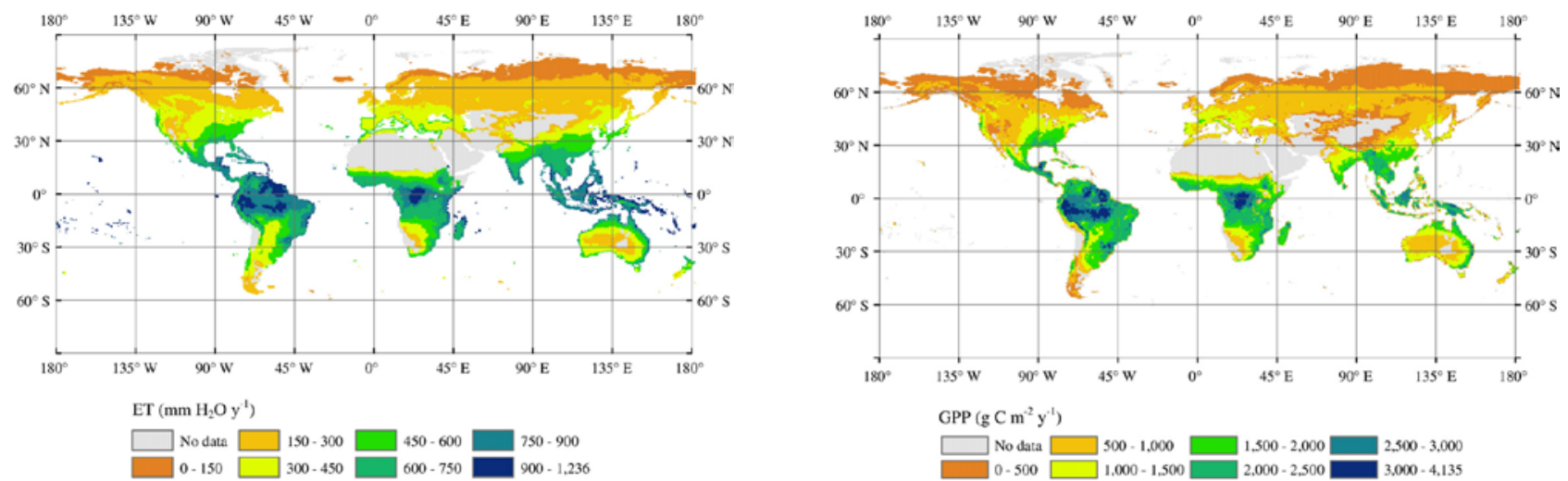

Figure 55. Left: Simulated global evapotranspiration (ET) pattern. Right: Simulated global Gross Primary Production (GPP) distribution.

\section{Improving Biogeochemical Simulations with Data Assimilation in the Yukon River Basin}

Adequate quantification of the behavior of model parameters and the assessment of model output uncertainty are challenging in regional carbon cycle modeling efforts. To address these challenges, parameter optimization and data assimilation algorithms (SEnKF) were integrated into the General Ensemble Biogeochemical Model System (GEMS). Some results at a boreal forest eddy covariance site within the Alaskan Yukon River Basin are presented in figure 56. GEMS predictions of net ecosystem exchange (NEE) can be improved by adjusting model parameters dynamically and/or updating system states using data assimilation. Predicted NEE uncertainties stemming from errors of parameters, input, and model structure can also be reduced. The new knowledge gained from data assimilation on parameter behavior can be used to evaluate errors in GEMS structure and representations of fundamental biogeochemical processes. For more information, contact Shuguang Liu, USGS EROS, sliu@usgs.gov.

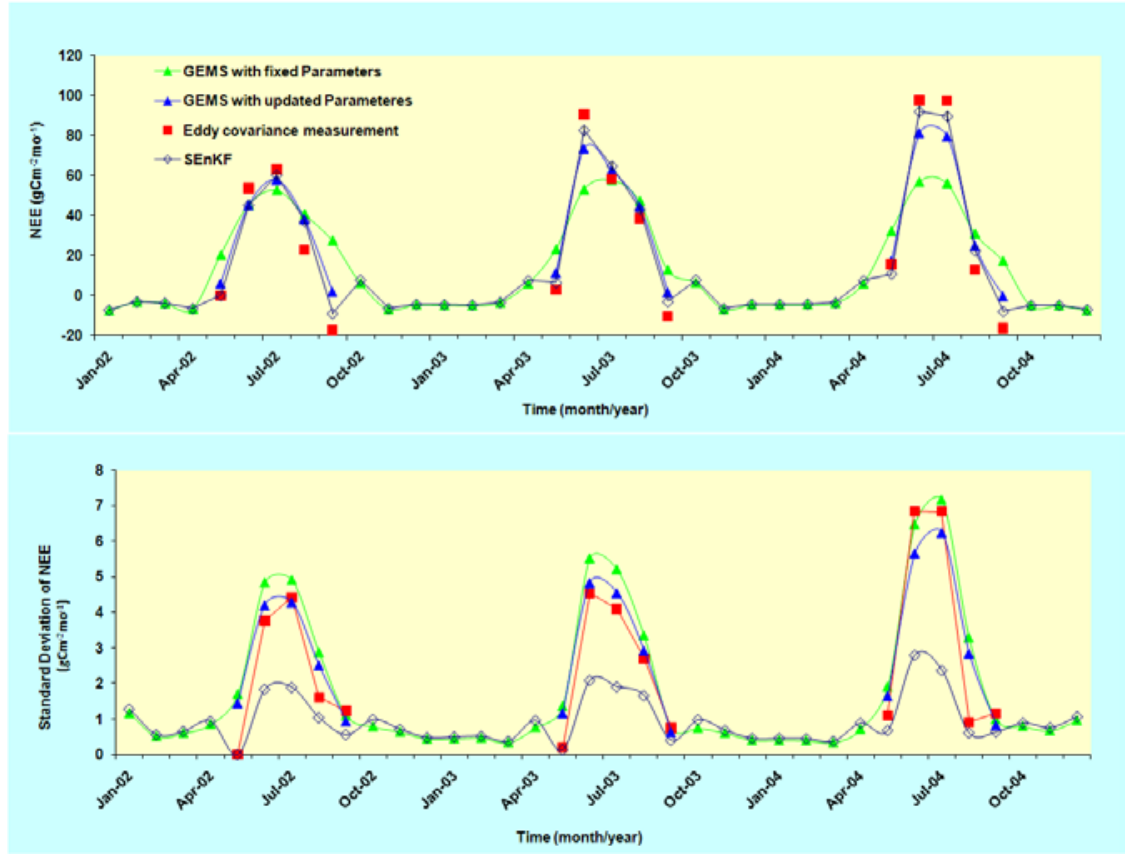

Figure 56. Upper panel shows comparisons of net ecosystem exchange (NEE) simulated by data assimilation (that is, SEnKF) (blue diamond) and by GEMS alone (green triangle: with pre-determined parameters, blue triangle: with parameters adjusted by data assimilation) against eddy covariance measurements (red square) at a boreal forest tower site in Alaska. Lower panel shows comparisons of corresponding ensemble-based standard deviations of NEE against errors of eddy covariance measurements. 


\section{Topographic Science, Elevation, and Lidar}

The Topographic Science, Elevation, and Light Detection and Ranging (lidar) Team establishes partnerships and conducts research, technique development, dataset development, and applications focused on the study of the topographic land surface. Key accomplishments are given in the following sections.

\section{The Global Multi-Resolution Terrain Elevation Data (GMTED2010) Model}

Many of the fundamental geophysical processes active at the Earth's surface are controlled or strongly affected by topography, thus the critical need for high-quality terrain data. The USGS and the National Geospatial-Intelligence Agency (NGA) have collaborated on the development of a notably enhanced global elevation model named the Global Multi-resolution Terrain Elevation Data 2010 (GMTED2010) that replaces GTOPO30 as the elevation dataset of choice for global and continental scale applications. This new dataset will be useful in many hydrological, climatological, and geomorphological applications at both the regional and global scales. The new model is complete and has been generated at three separate resolutions (horizontal post spacings) of 30 arc-seconds (1 kilometer), 15 arc-seconds (500 meters), and 7.5 arc-seconds ( 250 meters) from the best available higher resolution data sources. The GMTED2010 product resolutions also match the resolutions of the Land Processes Distributed Active Archive Center (LP DAAC) Moderate-resolution Imaging Spectroradiometer (MODIS) data products. This new global elevation product suite will provide global coverage from $83^{\circ} \mathrm{N}$ to $90^{\circ} \mathrm{S}$. The primary data source for this project is the voidfilled 1 arc-second Shuttle Radar Topography Mission (SRTM) dataset. In addition to providing a multiresolution data structure, seven new products have been generated at each resolution $(7.5,15$, and 30 arc-seconds). The following elevation products have been produced: minimum, maximum, mean, median, standard deviation, systematic subsample, and breakline emphasis. Detailed spatially referenced metadata have been produced for all the data sources that constitute GMTED2010.

Project accomplishments in FY 2010 included the completion of the GMTED2010 (fig. 57) data suite with products delivered to NGA for final review and acceptance. In addition, a final spatially referenced metadata dataset was completed that documents the input data sources used in the global model (fig. 58). Furthermore, a final accuracy assessment was completed that evaluated the GMTED2010 products against a global set of absolute photogrammetric control points provided to the USGS by NGA. Currently, final project documentation was delivered to NGA in October and the GMTED2010 products were released December 31, 2010. GMTED2010 has no redistribution restrictions and will be publicly available. For further information, contact Jeff Danielson, USGS EROS, daniels@usgs.gov.

\section{Global Multi-resolution Terrain Elevation Data 2010 (GMTED2010)}

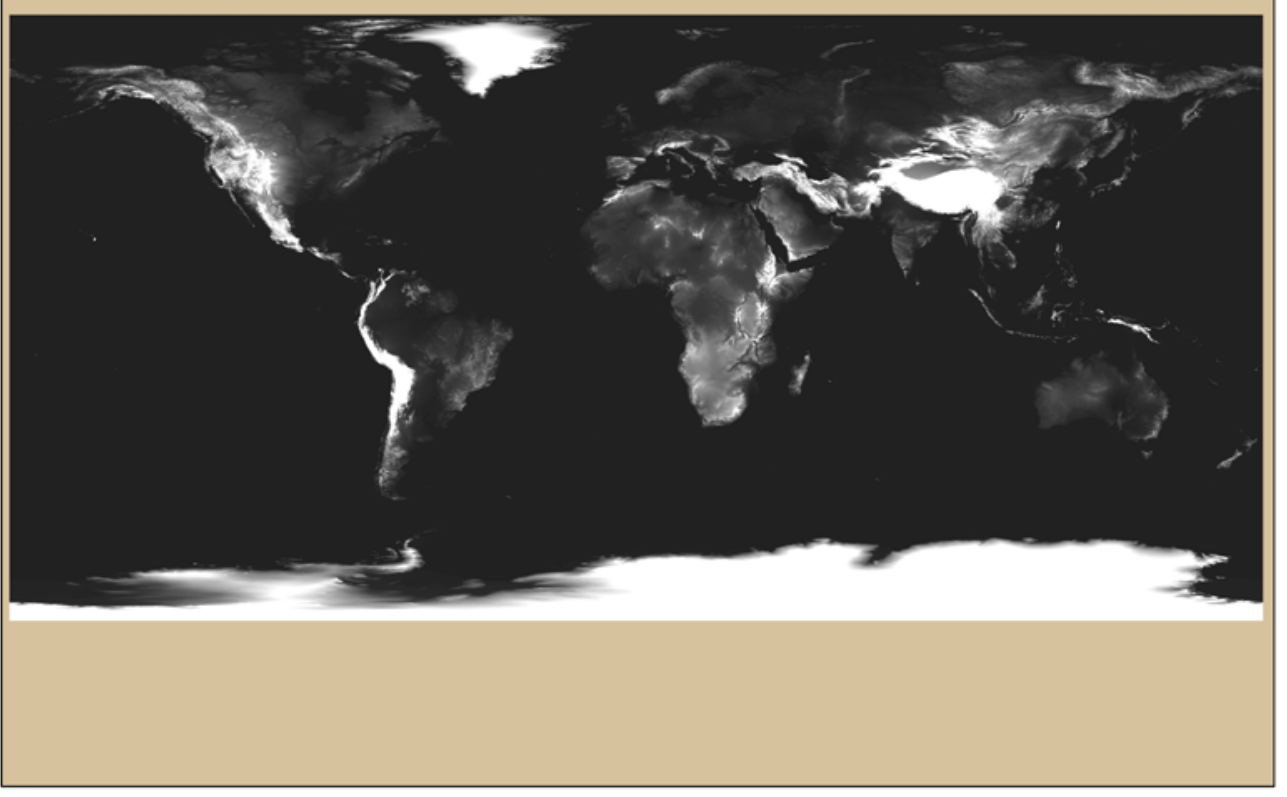

Figure 57. The Global Multi-resolution Terrain Elevation Data 2010 (GMTED2010) replaces GTOPO30 as the elevation dataset of choice for global and continental scale applications. 


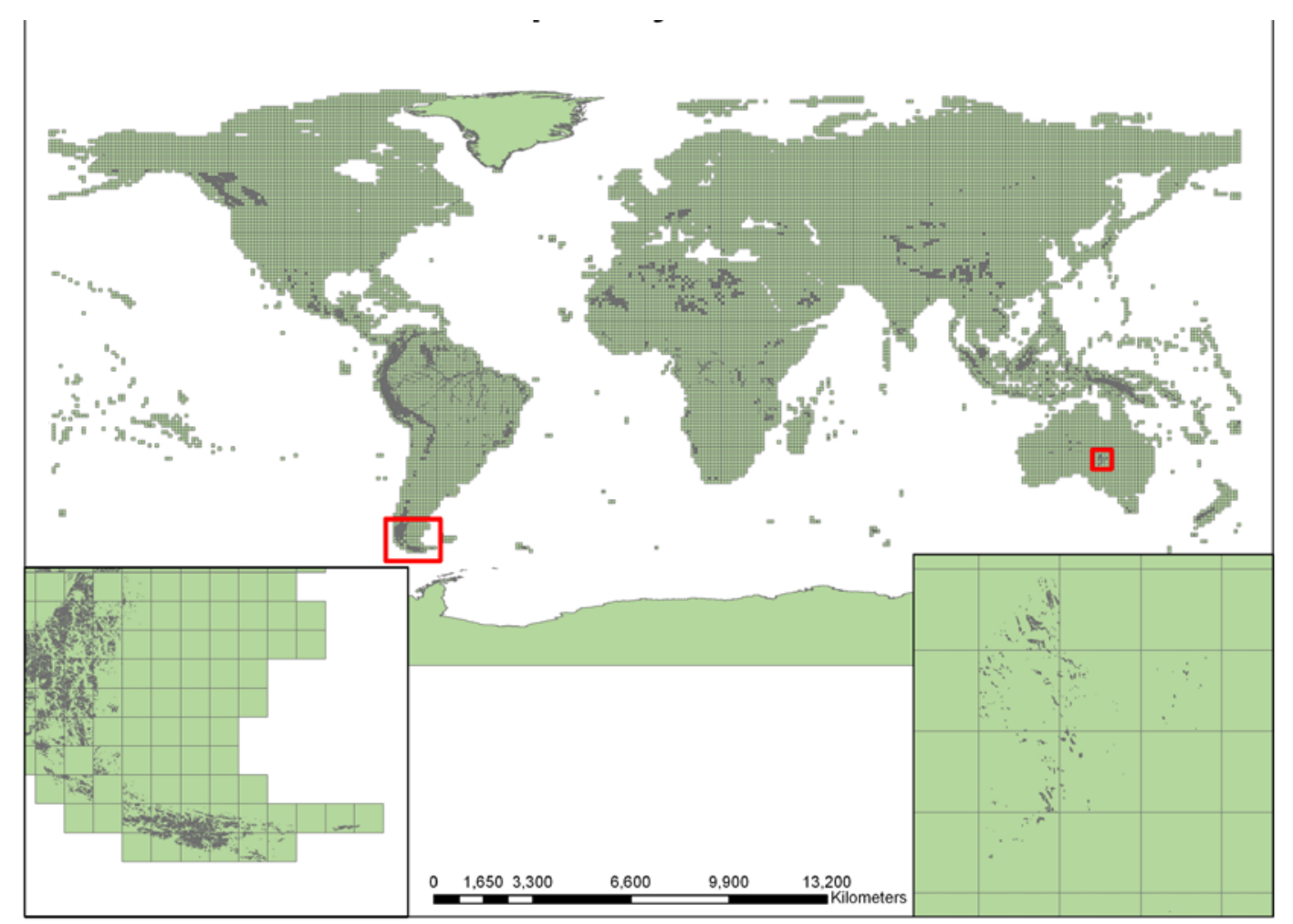

Figure 58. GMTED2010 Spatially Referenced Metadata.

\section{Hydrologic Derivatives Extracted from High-Resolution Lidar Elevation Data: USGS Scientific Investigations Report 2010-5059}

As the need for flood hazard mapping and emergency response intensifies, more accurate hydrologic information is essential to improve the understanding of surface water movements, drainage patterns, flood inundation, and coastal erosion. Highresolution, high-vertical accuracy bare earth digital elevation models (DEMs) generated from light detection and ranging (lidar) data have become instrumental in extracting this valuable hydrologic derivative information.

As lidar data become more prevalent for generating highly detailed DEMs, there is an increasing demand for lidar-derived hydrologic information. Because of lidar's fine-scale ability to represent the surface of the Earth, a vast amount of detail is captured in the lidar-DEM. Although this detail is desirable for incorporating the best available elevation data into the National Elevation Dataset, extracting hydrologic information from high-resolution, high-vertical accuracy lidar-DEMs presents some challenges.

Because lidar-DEMs are complex elevation surfaces, geographic features such as elevation data representing bridges, railroads, roads, or other elevated surfaces, are more prominent in lidar-DEMs than they are in coarse (30-meter) resolution elevation data. These geographic features result in obstructed hydrologic information that misrepresents the true surface flow on the landscape. Although the methods to extract hydrologic information from coarse (30-meter) DEMs are well documented in the scientific community, the methods to extract hydrologic information from high-resolution, high-vertical accuracy lidar-DEMs are less documented and are more complex.

To accommodate the increasing need for hydrologic information extracted from high-resolution, high-vertical accuracy lidar-DEMs, the U.S. Geological Survey has ongoing research to develop selective drainage methods. These methods provide the capability to extract valuable and integrated hydrologic information from lidar-DEMs. The selective drainage methods have been developed and tested in Minnehaha County, South Dakota (fig. 59) and are published in a USGS Scientific Investigations Report (fig. 60). For further information, contact Sandra Poppenga, USGS EROS, spoppenga@usgs.gov. 


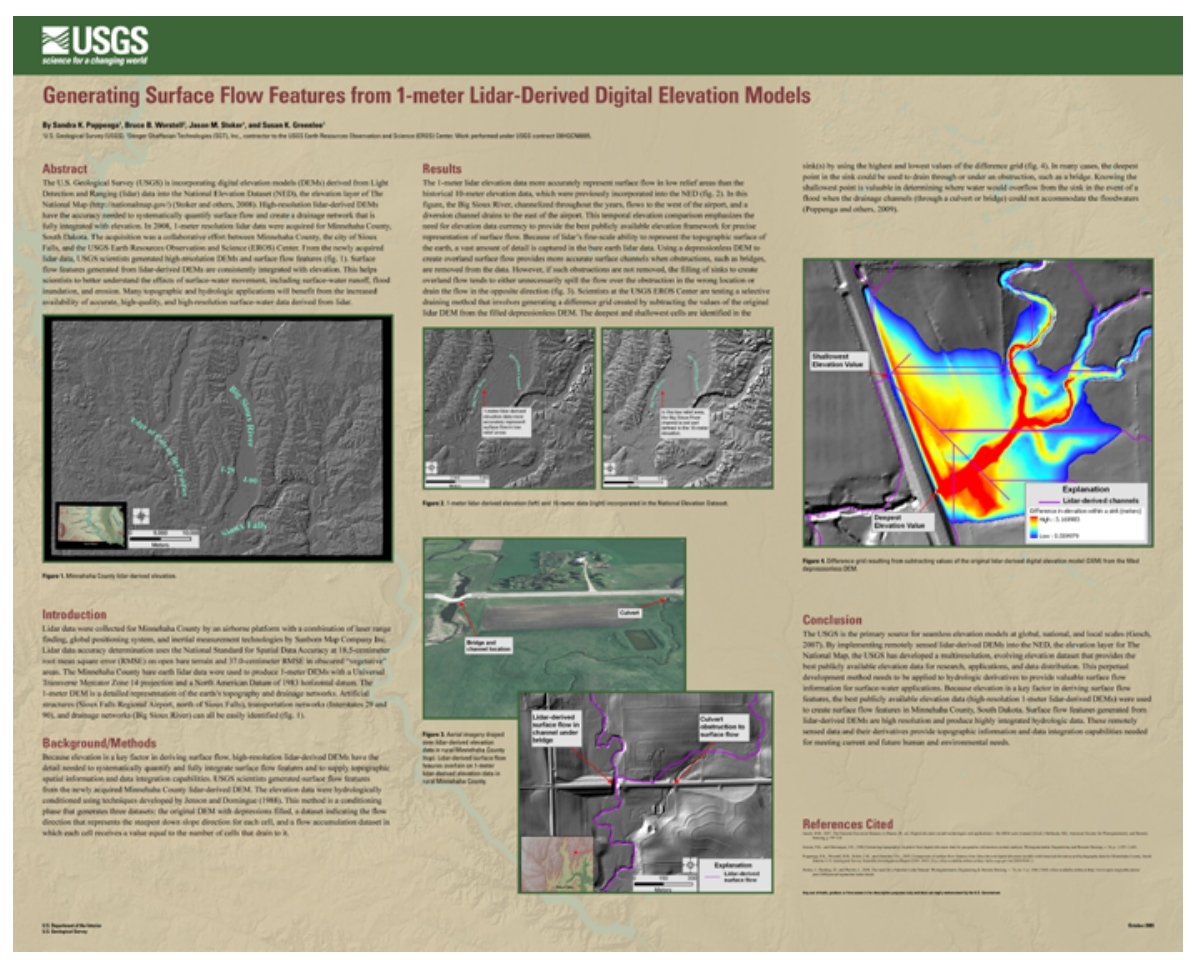

Figure 59. The U.S. Geological Survey developed selective drainage methods to extract hydrologic information from high-resolution, high-vertical accuracy light detection and ranging (lidar) digital elevation models in Minnehaha County, South Dakota.

\section{¿USGS}

Using Selective Drainage Methods to Extract Continuous Surface Flow from 1-Meter Lidar-Derived Digital Elevation Data

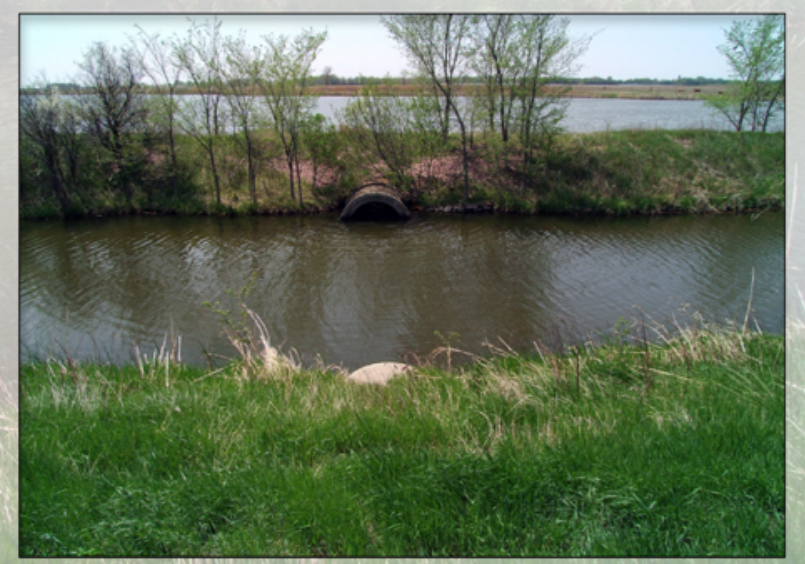

Scientific Investigations Report 2010-5059

U.S. Department of the Interio

U.S. Geological Survey
Figure 60. Cover of U.S. Geological Survey Scientific Investigations Report 2010-5059 “Using Selective Drainage Methods to Extract Continuous Surface Flow From 1-Meter Lidar-Derived Digital Elevation Data." The selective drainage methods that the U.S. Geological Survey tested and developed for Minnehaha County, South Dakota, are published in this Scientific Investigations Report. 


\section{Geographic Information System Tools for Estimating Post-Wildfire Debris Flow Inundation}

Terrain and land surface conditions after wildfire events can create ideal conditions for rainfall-induced debris flow events that endanger lives and property. The USGS has ongoing research in southern California to understand the probability and magnitude of debris flow events; however, no tools were available for mapping the inundation extent of debris flow estimates. To address this shortcoming, LAHARZ, a menu-driven software function that runs within a Geographic Information System (GIS) that is used for estimating inundation from volcanic lahars, or debris flow, has been modified for use in post-wildfire areas. Digital Elevation Model (DEM) data available from the USGS Topographic Science Project and from local partners are necessary to operate the tool.

The debris flow inundation tool provides an important mapping capability needed to visually communicate the model results to municipal and emergency response planners (fig. 61). The tool is also valuable to researchers because it allows examination of the spatial extent of modeling results and makes comparisons with historical debris flow inundations needed to revise and improve the models. For further information, contact Vivian Queija, USGS EROS, vqueija@usgs.gov.

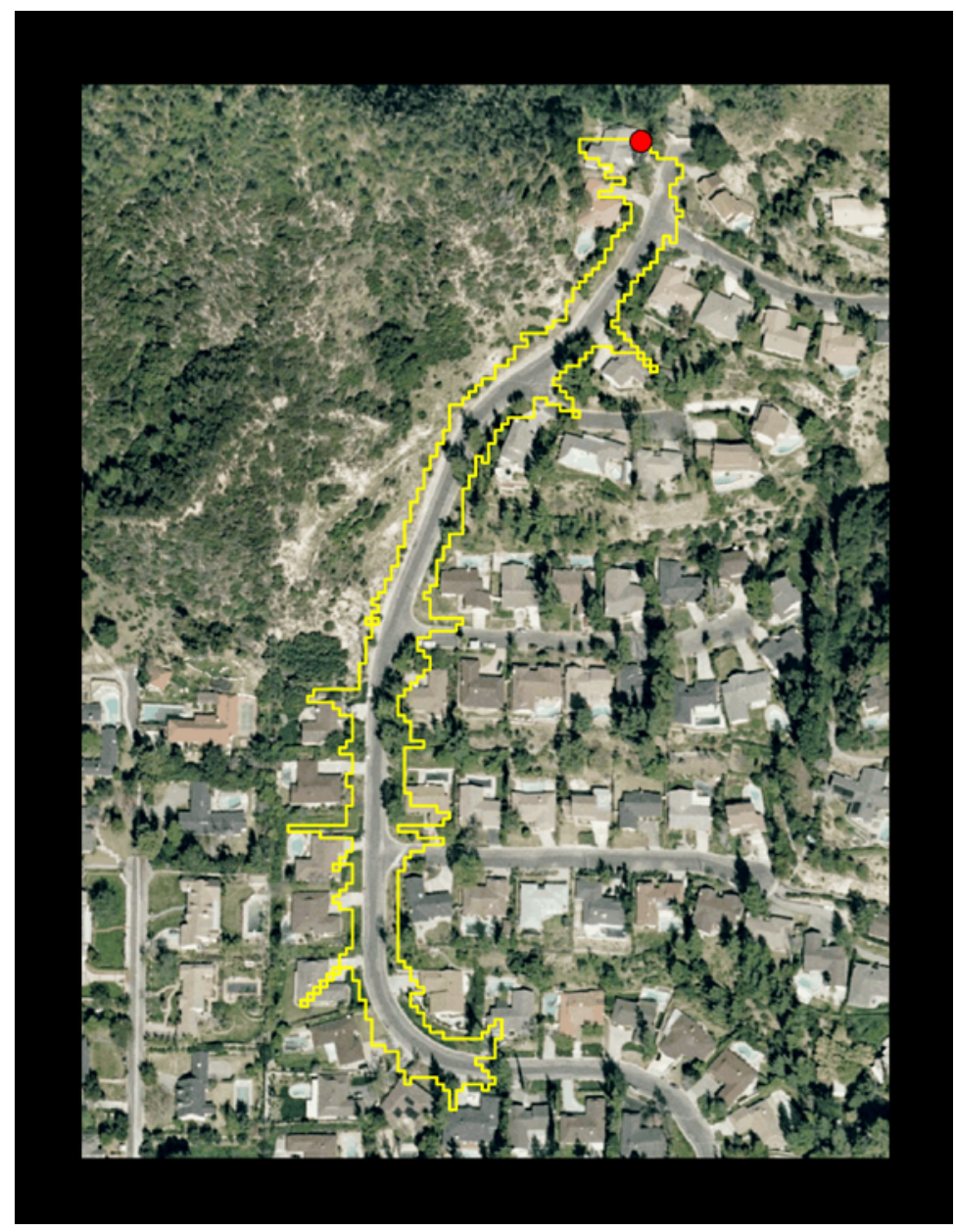

Figure 61. This aerial view is an example of an inundation zone for 10,000-cubic-meter debris flow volume produced using the LAHARZ tool. Zones like these are typically compiled as a series to show a range of magnitudes for conveying risk to decision makers.

\section{National Atlas Million Scale Mapping}

The National Atlas of the United States has a goal to develop 1:1,000,000-scale cartographic frameworks for use in new National Atlas products and to submit as the U.S. contribution to Global Map, an international effort to develop seamless million scale datasets. In FY 2010, the top priority for National Atlas work at EROS was the review and edit of 1:1,000,000-scale waterbodies data that were developed by staff at the USGS Texas Water Science Center. By July 1, 2010, the task was completed for the western half of the conterminous United States, or about 7,950 waterbodies (fig. 62). For further information, contact John Hutchinson, USGS EROS, hutch@usgs.gov. 


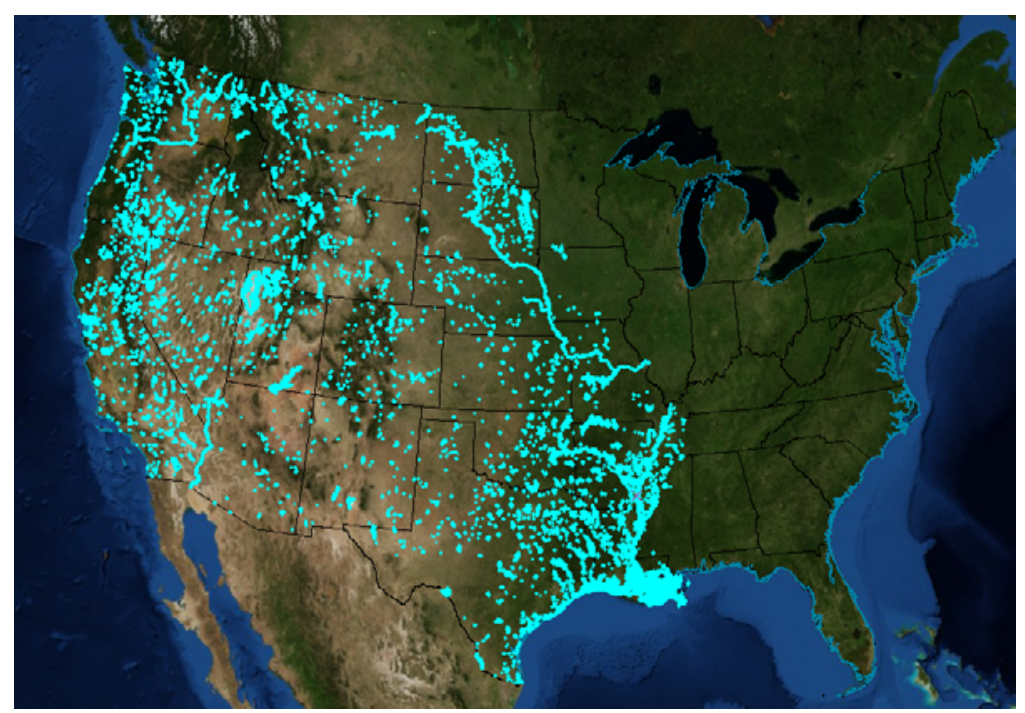

Figure 62. The image shows mapping that has been completed for the western half of the conterminous United States, or about 7,950 waterbodies.

\section{The National Elevation Dataset: Lidar for Science}

The National Elevation Dataset (NED) is a science-ready multiresolution elevation dataset that serves as the elevation layer of The National Map. The resolution of NED data has improved as production methods have evolved and new technologies have been developed. In FY 2010, lidar has been the main data source and is the source for an additional 111,200 square miles of high-quality and high-resolution bare-earth elevation data. This brings the total area of the NED 1/9-arc-second collection to 338,153 square miles. Lidar datasets are collected from a variety of providers, including Federal, State, local governments and the private sector. The lidar data are received and assessed for quality and merged into a common projection, datum, and vertical units. Lidar data provide basic elevation information for earth science studies and mapping applications in the United States (fig. 63). Scientists and resource managers use lidar-derived NED data for global change research, hydrologic modeling, resource monitoring, mapping and visualization, and many other applications.

The American Recovery and Reinvestment Act (ARRA) Stimulus funds, in addition to Survey Investigation and Research (SIR) funds, have enabled data collection via multiple funding mechanisms, larger area acquisitions, interdisciplinary partnerships, and newer and better data. Both ARRA and SIR funds have been awarded to acquire elevation, lidar in particular, emphasizing those areas that support USGS Science Strategy and DOI program activities (such as coastal watersheds, USGS Multi-Hazards Program, and DOI Healthy Lands) and other priority areas around the Nation. The resulting data will improve the resolution, quality, consistency, and coverage of existing data assets. The funded acquisitions will add to the 1/9-arc-second elevation data coverage in the NED, and, in turn, revise and improve the 1/3- and 1-arc-second elevation layer of the NED.

Although lidar is a priority, there is also work being done to improve areas which only have 30-meter source data. The standard 10-meter Digital Elevation Models (DEMs) are being developed through cartographic contours and mapped hydrography. By the end of calendar year 2011, the source data of the conterminous NED multiresolution layers are projected to be of 10-meter or better resolution. This activity supports contour generation and hydrographic integration. An additional 250,732 square miles were added to the NED 1- and 1/3-arc-second layers in FY 2010 either by migration of the NED 1/9-arc-second source or standard 10-meter DEM production.

The U.S. Geological Survey (USGS)-National Geospatial Program (NGP) Lidar Guidelines and Base Specification has been written and extensively reviewed in an effort to assist the elevation community in establishing a consistent and reliable lidar source dataset. Topics addressed in this document include collection criteria, data processing and data handling, and deliverables. This specification is also being used as the basis for the Federal Emergency Management Agency and Natural Resources Conservation Service's new Guidelines, as well as the American Society for Photogrammetry and Remote Sensing Best Practices for the lidar profession. Final editing and formal USGS publication is expected in FY 2011.

Several lidar workshops, presentations, and panel discussions were led during FY 2010 in support of the lidar specification, lidar processing, and status of lidar datasets destined for the NED collection. EROS also hosted the Elevation Business Process Reengineering meeting last February and continues to respond to the resulting action items. The NED team is always looking for new and better ways to provide the nation with the best available science-ready digital elevation data. For further information, contact Gayla Evans, USGS EROS,gevans@usgs.gov. 


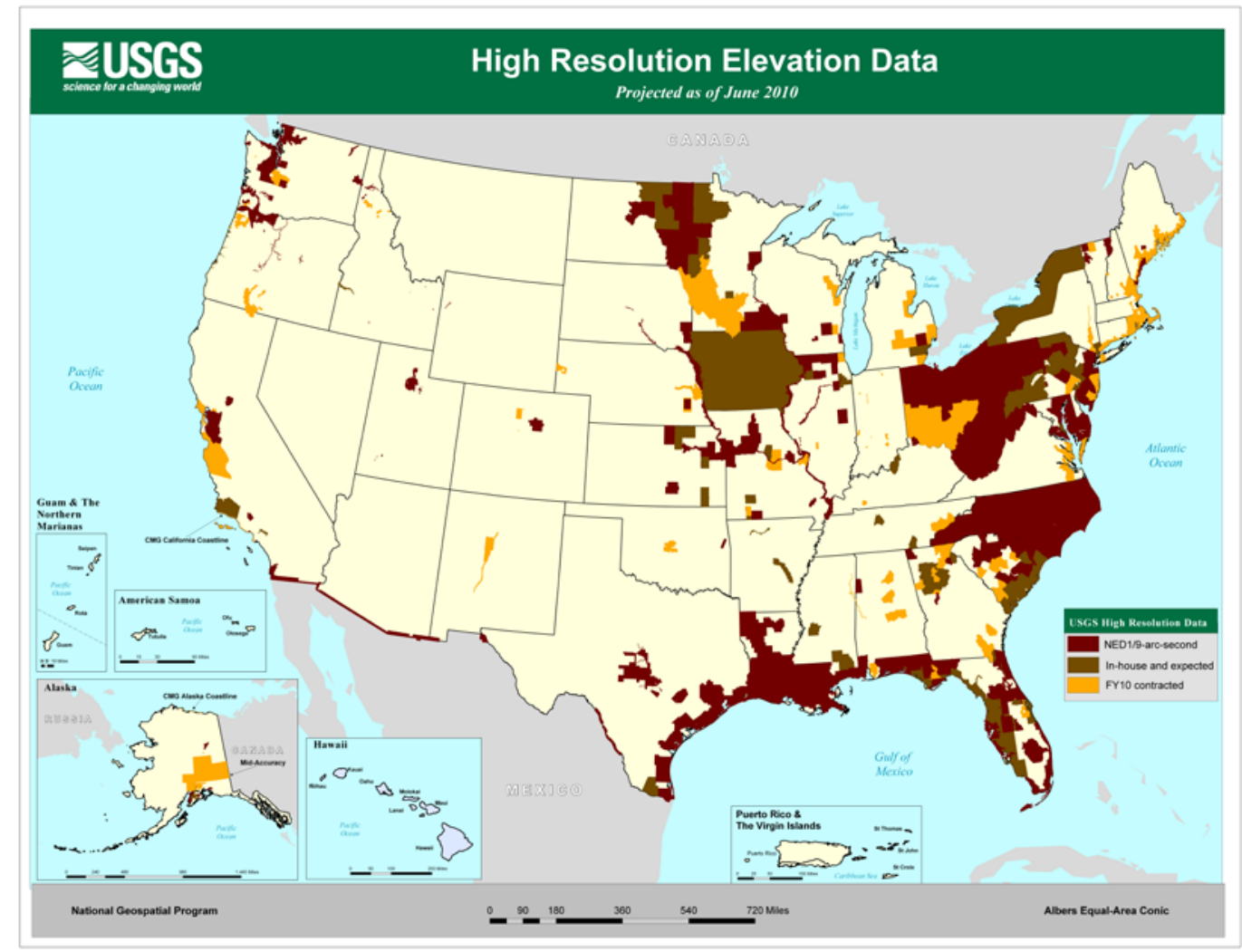

Figure 63. Fiscal year 2011 holds great promise for the amount of available high-resolution lidar data to be added to the National Elevation Dataset collection.

\section{CLICK Passes a One-Trillion Milestone}

The USGS Center for Lidar Information Coordination and Knowledge (CLICK) passed the trillion lidar point mark in FY 2010 by housing approximately 1.1-trillion lidar points across the United States - that is more than 1,100,000,000,000 threedimensional georeferenced coordinate records that describe parts of the United States in 3-D. Trees, buildings, volcanoes, fault lines, bridges, power lines, bare earth are among the features represented by a 3-D point cloud in CLICK (fig. 64). Currently, CLICK is providing more than 25 terabytes of 3-D data from lidar for approximately 7 percent of the United States. Also, since its inception in 2006, the CLICK bulletin board, which provides lidar information to users across the world, has been viewed more than 2.7 million times and has 1,400 registered members. For further information, contact Jason Stoker, USGS EROS, jstoker@usgs.gov.

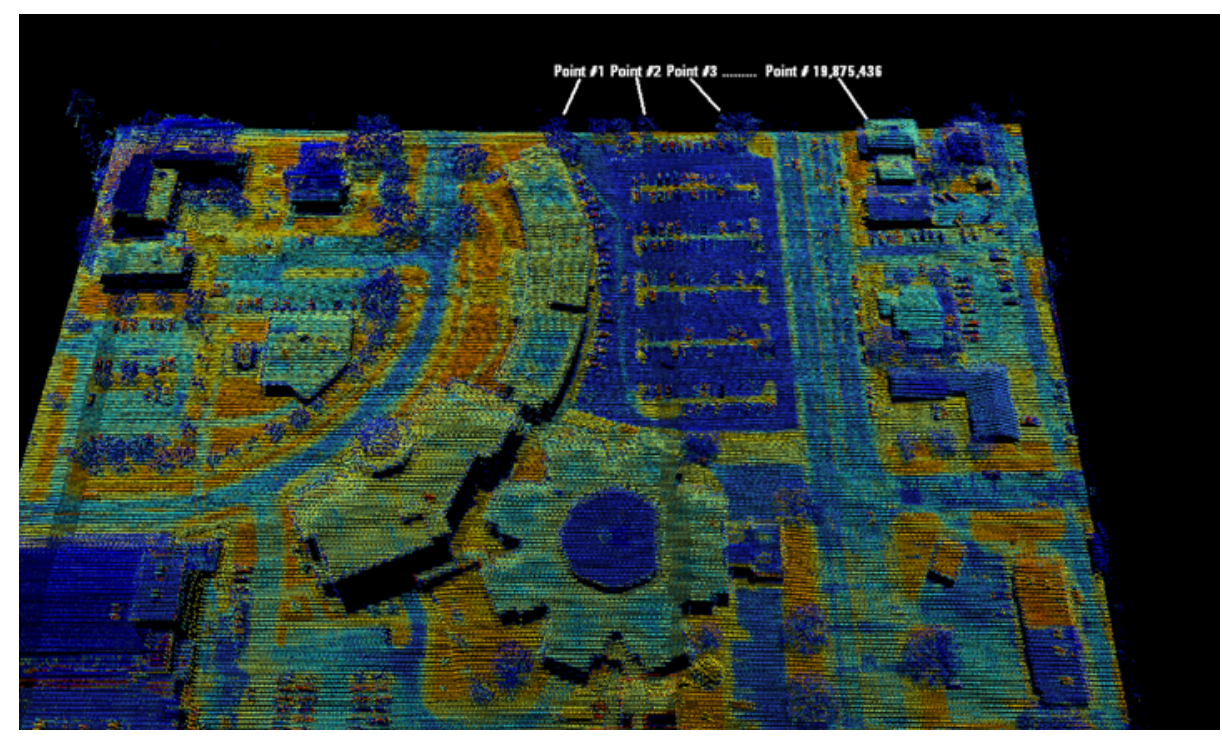

Figure 64. The image depicts approximately 20,000 lidar points in downtown Sioux Falls, South Dakota. 


\section{Lidar Research Highlighted in Prestigious Industry Journal}

Light detection and ranging (lidar) research at EROS was highlighted in an article and on the cover of the journal Photogrammetric Engineering and Remote Sensing (PE\&RS) in FY 2010. Jason Stoker, author of the paper, has developed a new and novel approach to processing, representing, and modeling lidar data. The March 2010 journal article, "Making Lidar More Photogenic: Creating Band Combinations from Lidar Information," documented a new technique that could have very strong implications on how lidar is used, manipulated, and fused with other data for classification, analysis, and modeling.

The methodology demonstrates how to use lidar point cloud information and develop a multiband image stack similar to Landsat bands. By creating bands from information such as slope, elevation, laser intensity, and other lidar properties inherent in the data, users can now visualize and classify lidar data using the same software, algorithms, and methodology used for passive optical data. Users can directly fuse spectral information from instruments such as Landsat with lidar-derived information into a single file, which provides the opportunity to perform classifications and models on imagery with aided by the vertical dimension provided by lidar. The significant findings from this research have been recognized by Lidar News: http://www.lidarnews. com.

The February 2010 PE\&RS cover (fig. 65) featured a lidar dataset of Mount Rainier, Washington, thus continuing attention on EROS lidar activities first shown by the September 2008 PE\&RS cover of downtown Sioux Falls, South Dakota. For further information, contact Jason Stoker, USGS EROS, jstoker@usgs.gov.
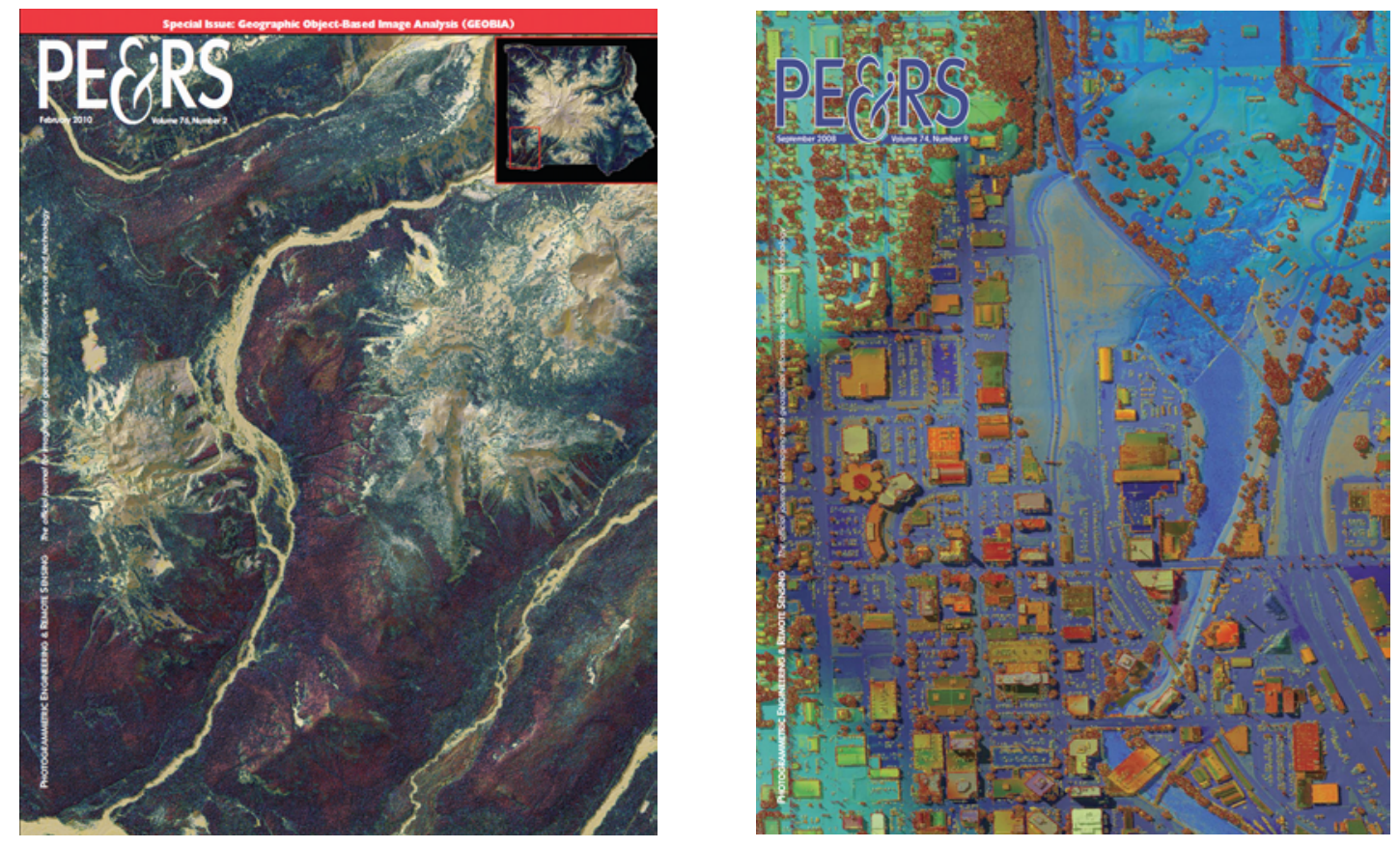

Figure 65. Lidar featured on PE\&RS covers depicting Mount Rainier, Washington, (left) and Falls Park in Sioux Falls, South Dakota (right). 


\section{Early Warning, Environmental Monitoring, and Hazards Management}

The Early Warning, Environmental Monitoring, and Hazards Mitigation Team conducts research on and implements new approaches for monitoring environmental hazards and mitigating their impact through creative applications of geographic analysis and modeling of Earth processes. Key accomplishments are given in the following sections.

\section{Global Environmental Alert Service}

The United Nation Environmental Program's (UNEP) Global Environmental Alert Service (GEAS) continuously scans the scientific literature and analyzes results of earth observations and other data sources to produce widely distributed alerts, focusing on policy relevant Environmental Hotspots, Environmental Science, and Near Real-Time Environmental Event Alerts in an easily understandable format. GEAS monitors the planet and enhances UNEP's ability to provide regular, science-based updates to its member states and the international community on the status and trends of the global environment.

The staff at UNEP Global Resource Information Database (GRID) - Sioux Falls produced 5 environmental Hotspot Alerts, 5 Environmental Science Alerts, and 4 Near-Real Time Environmental Event Alerts, which included the most current issues such as the Deepwater Horizon oil spill, wildland fires in Russia, and Pakistan flooding. At the same time, the GEAS website (http://www.na.unep.net/geas) was redesigned with state-of-the-art technologies engaging the popular social tools to provide this invaluable information in the most interesting way (fig. 66). For further information, contact Charles Trautwein, USGS EROS, trautwein@usgs.gov.

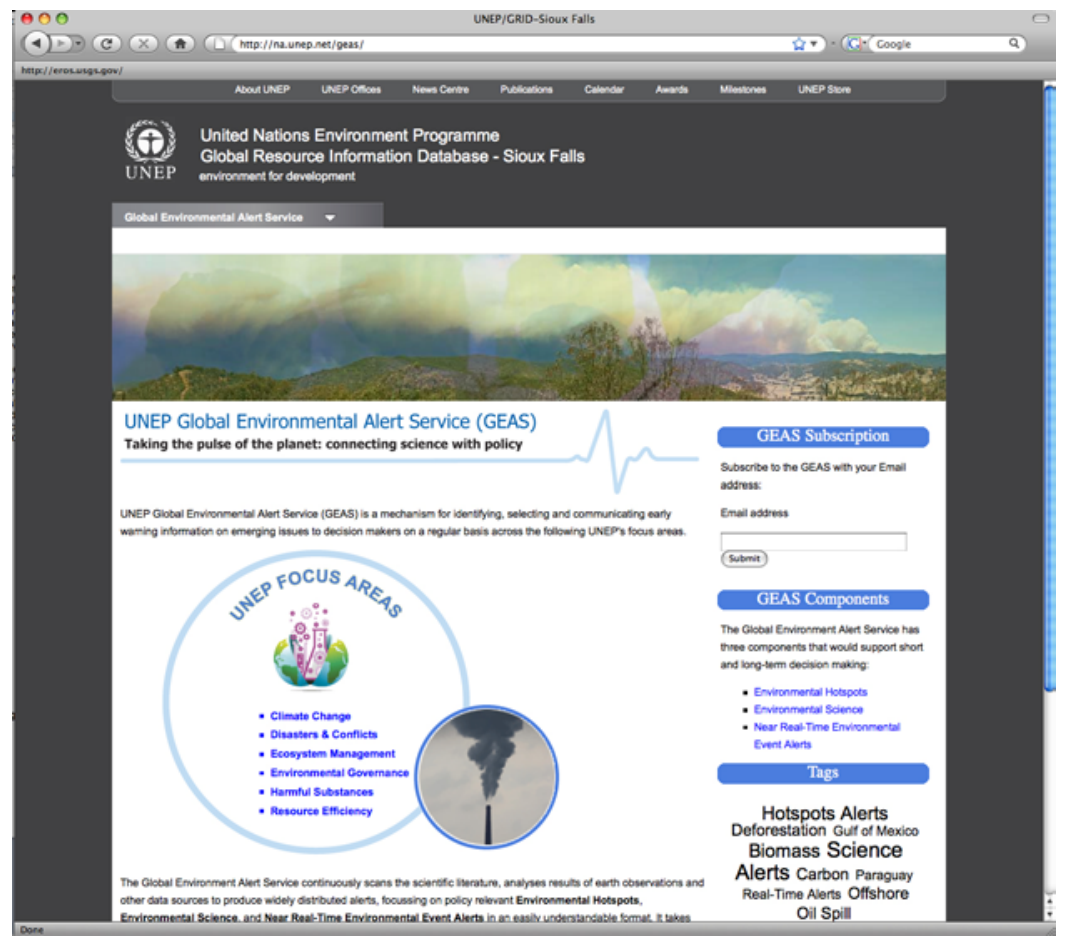

Figure 66. Screenshot of the Global Environmental Alert Service website (http://www. na.unep.net/geas).

\section{Africa Water Atlas}

At the request of the African Ministers' Council on Water, the team at UNEP GRID Sioux Falls published the Africa Water Atlas in late 2010.

The Africa Water Atlas provides decision makers, interested readers, and others who care about the future of the continent with invaluable information concerning the state of water resources through illustration with more than 100 satellite images, 225 maps, 500 graphics, 250 ground photographs, and a brief profile of the water situation in every country (fig. 67). In addition, the Atlas provides reason for optimism about addressing water issues - although the population is challenged by the presence of "hot" spots where rain-fed agriculture is constrained and food security is tenuous. The Atlas highlights Africa's many "hope" spots where long-practiced water-harvesting coping strategies can be expanded and new practices adopted, especially in light of the changing climate. The Atlas vividly illustrates the importance of Africa's water towers in supplying millions of people with 
life-giving water and in supporting activities that are crucial to our ecosystems and economies.

This Atlas balances the many challenges Africa faces in dealing with water problems by stressing the opportunities to improve the quantity, quality, and use of water resources. One example is the huge opportunity to develop untapped water resources for electricity, irrigation, industry, and tourism. There are also opportunities to support exciting innovations, such as revolutionizing toilets to conserve water, investing in small-scale hydropower projects and fostering the greening of the Sahel. For further information, contact Charles Trautwein, USGS EROS, trautwein@usgs.gov.

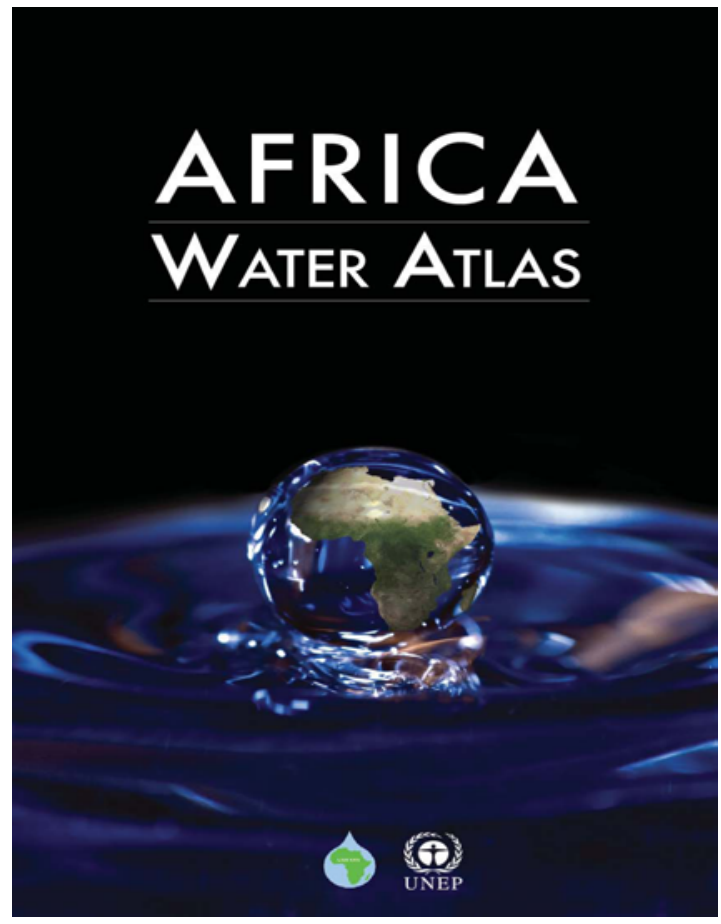

Figure 67. Cover of the Africa Water Atlas.

\section{Radar Applications Development}

Supported by the USGS Land Remote Sensing Program, this project focuses on the development of state-of-the-art synthetic aperture radar (SAR), interferometric SAR (InSAR) technologies and the transfer of satellite radar remote sensing into bureau-wide applications. Project members actively collaborate with USGS scientists on monitoring natural and man-made hazards, and imaging landscape characteristics with all-weather radar and InSAR imagery. Project activities provide funda-

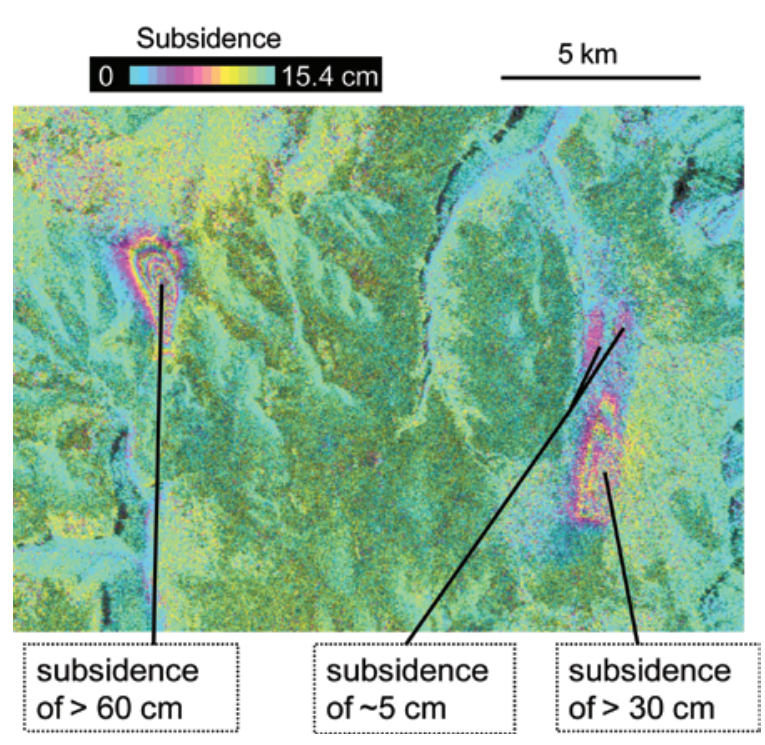
mental research and technologies on mapping and monitoring the Nation's ecosystem function, water availability, natural hazards, and climate changes of USGS science in the coming decade. Project scientists have authored and co-authored several manuscripts on volcano deformation monitoring, wetland and flood mapping, InSAR technique development, radar remote sensing of natural hazards, and land subsidence mapping (fig. 68). Staff members have developed and refined a website for the Center for Radar Information Coordination and Knowledge et al (CRICKet) - a USGS Center for SAR technology that seeks to expand the application and use of satellite radar technology by scientists and managers within the USGS and other DOI agencies. Project scientists have given support and guidance to scientists from USGS and other Federal agencies on exploring SAR and InSAR technologies, and provided support to the LRS Program on radar related activities. For further information, contact Zhong Lu, USGS EROS, lu@usgs.gov.

Figure 68. InSAR image of Dec 6, 2006-June 8, 2007, showing land surface subsidence because of mining activity over Utah. 


\section{Mapping Irrigated Agriculture across the Country}

Accurate, detailed, and timely geospatial information on the extent of irrigated lands improves understanding of national agricultural water use, local land surface processes, conservation or depletion of water resources, and climate conditions. It is an important component for modeling the hydrologic budget. A new method for mapping in a geospatial modeling framework assimilates three data sources to produce a national map of irrigated agriculture at a 250 -meter resolution across the entire conterminous United States.

The geospatial model, referred to as the Moderate Resolution Imaging Spectroradiometer (MODIS) Irrigated Agriculture Dataset (MIrAD-US), ingests federal irrigation statistics from the U.S. Department of Agriculture (USDA), a satellite-based variable describing peak vegetation vigor, and agricultural land cover from the 2001 National Land Cover Database to identify the location of irrigated agriculture. The model was run for 2002 (fig. 69) and 2007, corresponding to the USDA's Census of Agriculture publication years. Consistent field data to ground reference irrigation are not readily available across the whole country. Two existing data sources were used to assess MIrAD-US accuracy: field-level land use surveyed by the California Department of Water Resources and Great Plains field points collected for irrigated and nonirrigated fields by the University of North Dakota in 2006. Model results for 2002 MIrAD-US identified irrigated lands with reasonable accuracy in California and Great Plains states with overall accuracies of 92 percent and 75 percent and kappa statistics of 0.75 and 0.51 , respectively. The lower statistics for the Great Plains may be a result of the temporal mismatch of the field dataset.

The MIrAD-US modeling approach enables consistent wall-to-wall mapping and regular updates for irrigated lands and should lead to better understanding of spatial trends in irrigated lands across the conterminous United States. For further information, contact Jesslyn Brown, USGS EROS, jfbrown@usgs.gov.

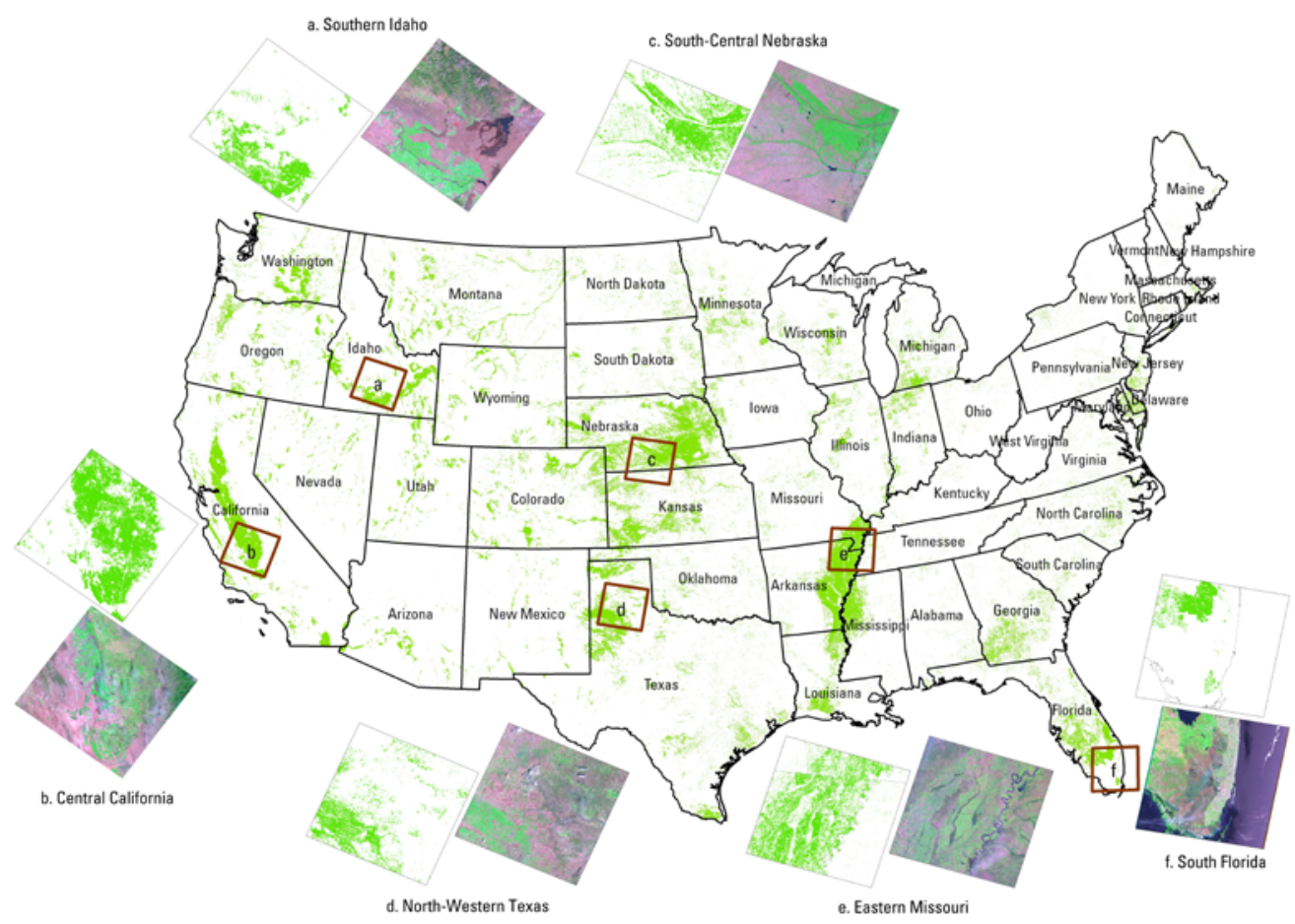

Figure 69. The 2002 irrigated agriculture results from the MIrAD-US model. The six inset boxes show MIrAD-US model results next to 2002 mid-summer Landsat scenes.

\section{U.S. Evapotranspiration Project}

The Evapotranspiration (ET) Project at USGS EROS covers diverse geographic areas around the world. The USGS EROS developed the Simplified Surface Energy Balance (SSEB) model to estimate landscape ET for various applications. Since ET is a critical component of the hydrologic cycle and the most difficult to measure, remote-sensing-based techniques such as the SSEB have become very important. For early warning applications, ET provides crop performance and drought monitoring information. For hydrological applications, ET is used to estimate groundwater recharge and withdrawal rates. Water management 
personnel use ET information for estimating irrigation water requirements and use.

The SSEB ET model was run using a combination of MODIS datasets (thermal, NDVI, and albedo) and weather datasets such as radiation, air temperature, wind speed, relative humidity, and air pressure for the continental United States, the Euphrates and Tigris region in Iraq, and northeast Africa. The model produced 1-kilometer resolution ET on 8-day, monthly, seasonal, and annual time scales for the various study regions from March 2000 to December 2009. The annual ET total distribution for 2009 at the three study sites is shown in figure 70 .

The U.S. ET Project was funded by the USGS Groundwater Resources Program in collaboration with various water science centers such as the California, Nevada, New Mexico, Oregon, and Washington Water Science Centers. The Northeast Africa ET Project was funded by the Famine Early Warning System Network (FEWS NET) of the U.S. Agency for International Development. The Department of Defense funded the Iraq ET Project. For further information, contact Gabriel Senay, senay@usgs.gov.

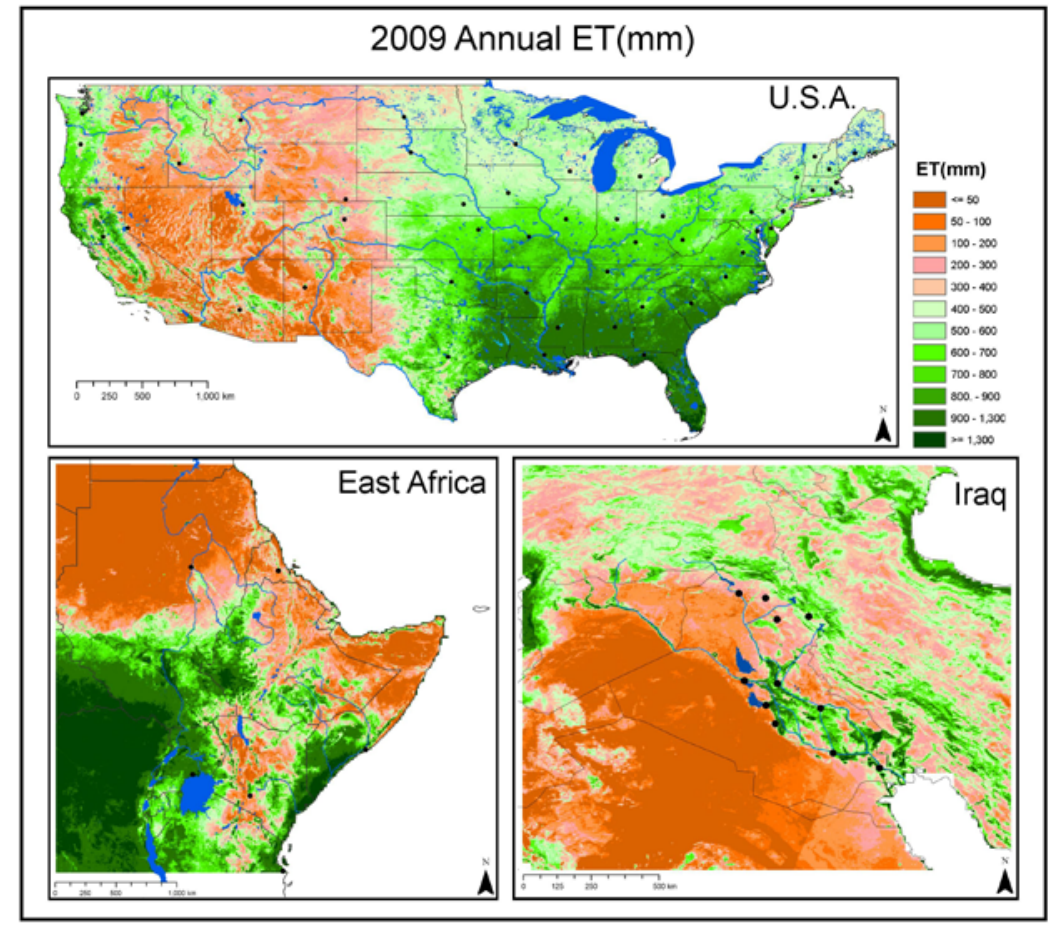

Figure 70. Annual evapotranspiration for three study regions showing spatial distribution of vegetation water use across different landscapes in the United States, northeast Africa, Iraq, and surrounding regions. Green indicates high water use in high rainfall and irrigated regions. Brown indicates low water use in arid and semiarid regions.

\section{eMODIS Normalized Difference Vegetation Index for Food Security Monitoring}

Famine Early Warning Systems Network (FEWS NET) uses a variety of remotely sensed data products and modeled outputs to support food aid decision making. One of the products that FEWS NET has utilized throughout its 25-year history is the Normalized Difference Vegetation Index (NDVI), used primarily for monitoring vegetation conditions. NDVI data from the Advanced Very High Resolution Radiometer (AVHRR) sensor have provided a long time series for monitoring cropland and pasture conditions, initially supporting FEWS NET efforts in Africa. In recent years, monitoring efforts have expanded to include Haiti, Central America, and Afghanistan and are now becoming more global. As the number of areas monitored continues to grow, so does the need for obtaining new and improved datasets.

The Moderate Resolution Imaging Spectroradiometer (MODIS) sensor flown on the Terra satellite provides a good source of NDVI data at higher spatial resolution and greater geometric accuracy than AVHRR. USGS EROS began using these data as an alternative NDVI data source in 2002. The data have proven to be invaluable for a number of applications, including support to crop and food supply assessment missions in multiple countries, maize production estimation in Zimbabwe, drought monitoring in Afghanistan, and pastoral/agro-pastoral analysis in Niger.

The standard MODIS NDVI data, however, have limited capabilities when it comes to the type of operational monitoring that is required by FEWS NET. The 16-day composite period is lengthy for early warning applications, variable degrees of product latency hamper efforts for quick response, and the numerous reprocessing iterations have limited the ability to collect a consistently processed time series. For these reasons, USGS EROS has pursued an alternative MODIS-based NDVI resource.

The eMODIS (expedited MODIS) capabilities developed by the Land Processes Distributed Active Archive Center (LP DAAC) at EROS in 2007 provided a viable option. The system relies on direct access to daily swath surface reflectance data from MODIS for calculating NDVI. The eMODIS production system provides the ability to customize compositing and to pro- 
vide timely data delivery (24 hours expedited; 3-5 days nonexpedited), minimized re-sampling, user-friendly file formats, and improved spatial resolution (fig. 71).

In FY 2010, FEWS NET initiated the near-real time production of 250-meter eMODIS NDVI data for Central America, the Caribbean (including Haiti), and Africa. The Central America/Caribbean dataset is complete throughout the Terra MODIS history and is being used in an operational manner for monitoring these areas. The Africa eMODIS data are operational in the near-real time production mode (fig. 72) but were historically incomplete at the end of FY 2010. FEWS NET will begin to use these data operationally as soon as comparison with a historical dataset is done fiscal year 2011. For further information, contact James Verdin, USGS EROS, verdin@usgs.gov.
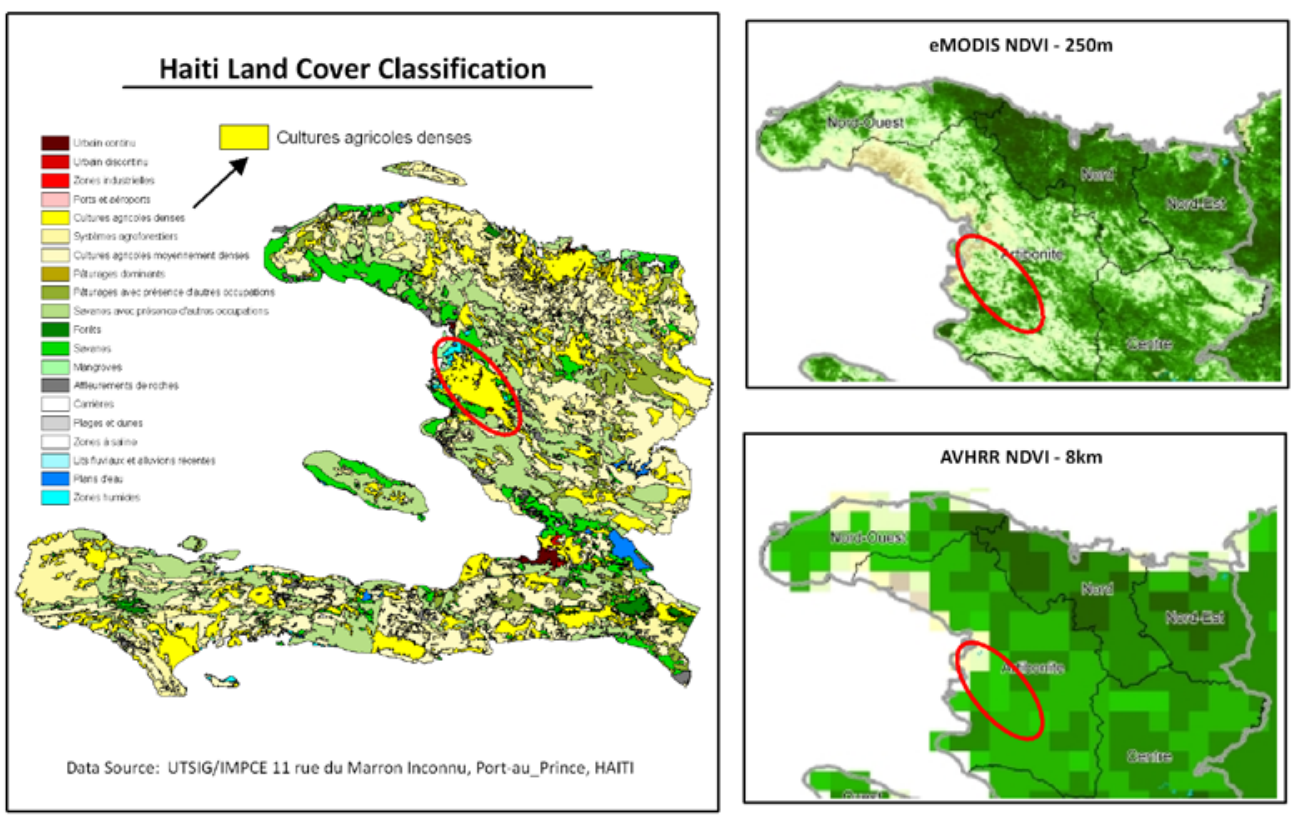

Figure 71. An example of the improvement in spatial resolution with the expedited MODIS (eMODIS) Normalized Difference Vegetation Index (NDVI) (upper right) compared to coarse resolution Advanced Very High Resolution Radiometer data (lower right). The Haiti land cover map (left) shows an area of dense agriculture along the

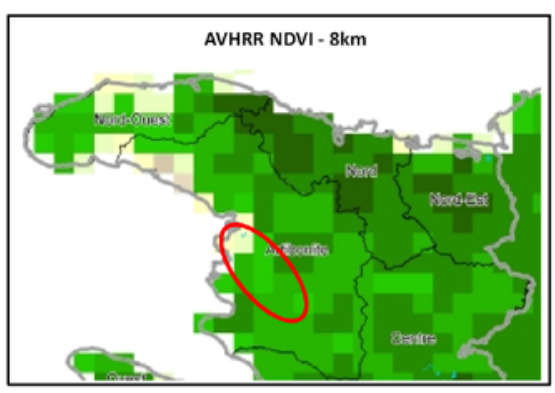
west central coast that, when compared to the NDVI maps, illustrates the benefits that eMODIS quality and resolution will provide for improved agricultural monitoring in current Famine Early Warning Systems Network countries and other remote monitoring locales.

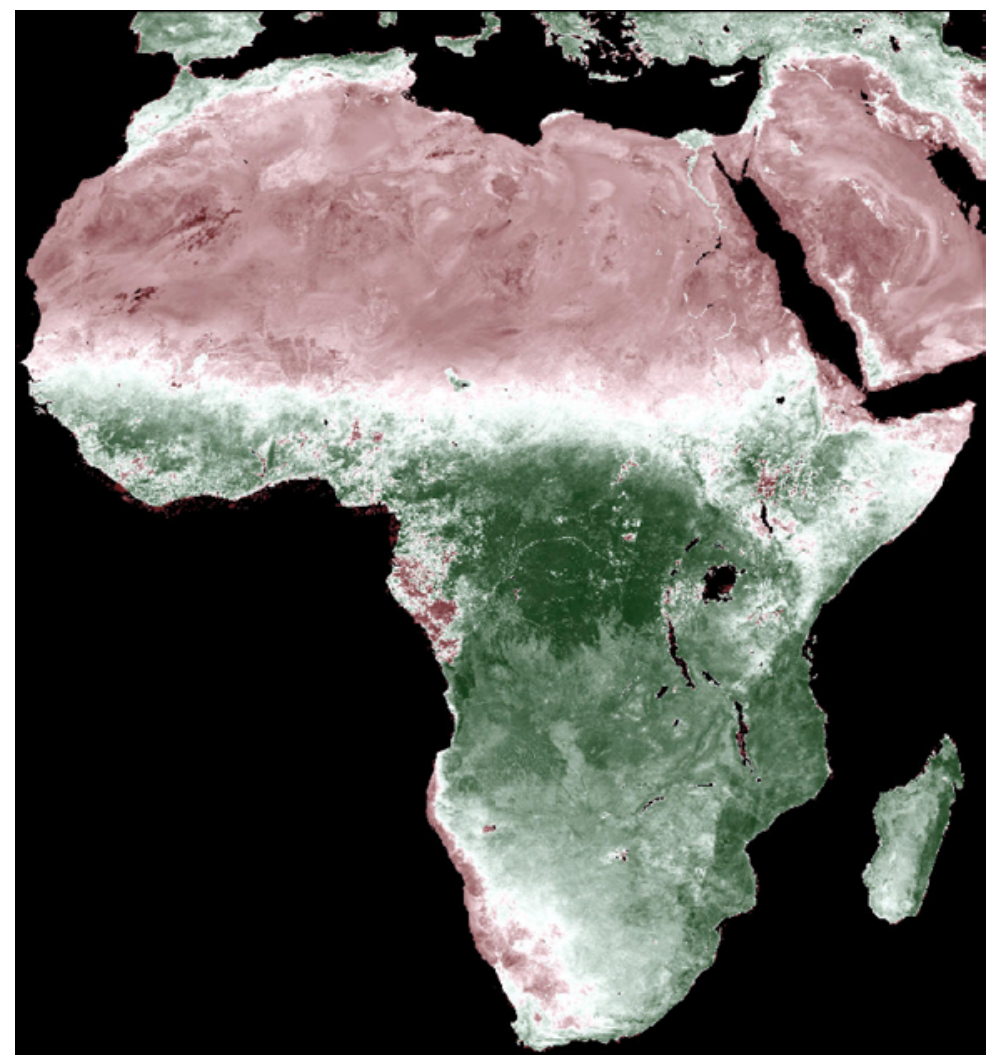

Figure 72. A 10-day eMODIS Normalized Difference Vegetation Index composite of Africa at 250-meter resolution. 


\section{The USGS FEWS NET Informing Climate Adaptation Series}

Whether related to natural internal variations of the climate system or anthropogenic changes related to greenhouse gas emissions, low frequency climate trends can have serious impacts on food insecure nations. To support the information needs of food security and development specialists, the USGS and FEWS NET have created a new "Informing Climate Change Adaptation" series of reports. These brief reports have a standard format, comprised of the following elements: (1) a callout box listing key climate trends, impacts, and affected populations, (2) a climate "hotspots" map showing observed and projected changes in key rainfall and contour lines, (3) a plot of observed and potential rainfall and/or temperature changes between the 1960-1989 and 2010-2039 time periods, (4) a qualitative evaluation of the likelihood that the observed trend may continue, and (5) a discussion of affected populations and agricultural production centers. If relevant, additional analyses may also be presented. An example of these reports for Kenya is available online as a USGS Fact Sheet (Funk and others, 2010).

The first "hotspot" graphic combines long-term climate mean fields and gridded trend fields in a unique way (fig. 73). First, visualization of the data and knowledge of crop requirements for the region are used to identify meaningful rainfall thresholds. For example, a 500-millimeter-per-season rainfall threshold typically provides a reasonable delineation between productive and marginal cropping areas. Almost all cultivated areas in eastern Africa and the Sahel receive, on average, more than this amount of rainfall during the main growing season. The $30^{\circ} \mathrm{C}$ temperature contour line tends to play a similar role, delineating hot-dry regions and cool-wet seasons during the main crop growing periods. The 1960-1989 mean fields may be used to derive 19601989 contour lines. By combining the mean and trend fields, observed contours for the 1980-2009 time period may be produced. Assuming stationarity of the trend through the 2010-2039 era allows for a third contour to be created.

In research (2003-2010) looking into African rainfall trends (table 2), results suggest that the drying in parts of eastern Africa, Kenya, and Sudan is related to a $\sim 1^{\circ} \mathrm{C}$ warming in the Indian Ocean. This warming is consistent and persistent through the 1950-present era, correlates strongly with global air temperature through the 1900-2009 era, and shows up as a pronounced "hockey stick" in related proxy data (coral and station air temperature data). It is also uniformly reproduced by all the IPCC climate models and many additional datasets (Williams and Funk, 2010). Indian Ocean sea surface temperatures and Kenyan, Ethiopian, and Sudanese rainfall and temperature trends exhibit considerable levels of persistence on decadal timescales. Thus, even in the absence of greenhouse gas forcings, momentum in the climate system seems likely to cause persistence of these trends for at least the next 10-15 years.

The second figure of the FEWS NET climate adaptation report combines 1960-2009 observations with an assumption of trend persistence to produce a composite climate shock assessment (fig. 74): the best estimated change in rainfall or air temperature between 1975 and 2025. Note that the bulk (70 percent) of this change assessment relies upon observations (35 years spanning the 1975-2009 era), and the 15 years until 2025 are projected using the observed trend.

For Kenya, the food security implications of this change can be visualized in rainfall patterns by plotting the 500-millimeter rainfall contour lines for the observed 1960-1989, observed 1980-2009, and projected 2010-2039 contour lines, overlain on major food surplus areas for long rains maize production (fig. 73). The 500-millimeter lines are significant, as they represent areas which, on average, receive enough long-season rainfall to support cropping. Throughout the 1960-1989 period, mean rainfall extended well to the east and north of the central highlands but now is much closer, contracting by about 15 kilometers per decade. This recession has already impacted the densely populated areas to the south, east, north, and northeast of Nairobi (Funk and Verdin, 2009). Some of these districts are major food surplus areas for long rains maize production. The 1975 to 2025 warming will generally represent more than a $1^{\circ} \mathrm{C}$ increase in temperature for Kenya, a substantial change in the country's underlying climate. This $1^{\circ} \mathrm{C}$ warming value can be compared to the typical interannual standard deviation of March through June station temperatures, about $0.6^{\circ} \mathrm{C}$; the long-term warming signal is therefore substantially more than half a standard deviation. This warming has likely exacerbated the impact of the observed drying tendencies, which coincide with densely populated, food insecurity, and agriculturally important areas of the central highlands.

The resulting USGS FEWS NET Climate Change reports are being used to inform climate adaptation. For example, recent discussions at the USAID mission in Nairobi helped differentiate areas of increasing climate vulnerability and areas of stable climatic resilience. This information can help guide agricultural development along sustainable and productive pathways. USGS Fact Sheets for Ethiopia and Sudan are under final preparation, and FY 2011 activities should produce special reports targeting temperature ET impacts, links between crop phenology and warming temperatures, recent drying trends in India, and the interaction between land cover and climate change in Ethiopia. For further information, contact Chris Funk, USGS EROS, cfunk@, usgs.gov. 


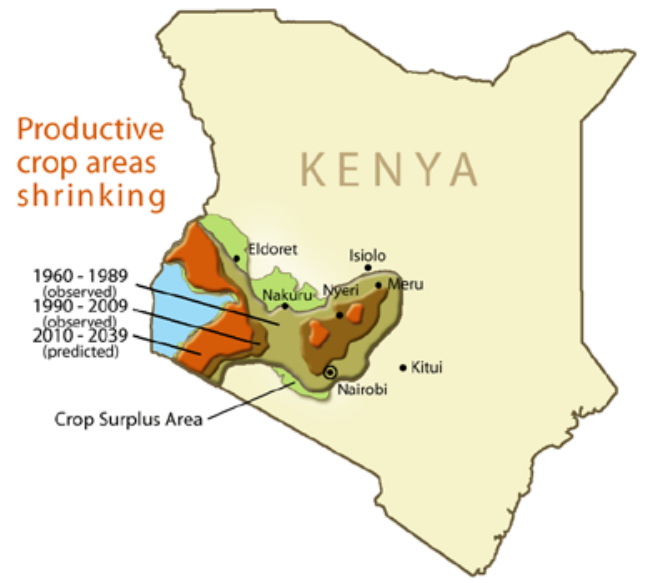

Figure 73. Suitable crop growing areas shrink in central Kenya. The backdrop image (light green) shows key crop surplus and crop deficit areas. The three overlain polygons show areas typically receiving enough rain to support a healthy crop (areas receiving, on average, more than 500 millimeters of rainfall) during 1960-1989 (tan), 1990-2009 (brown), and 2010-2039 (orange).
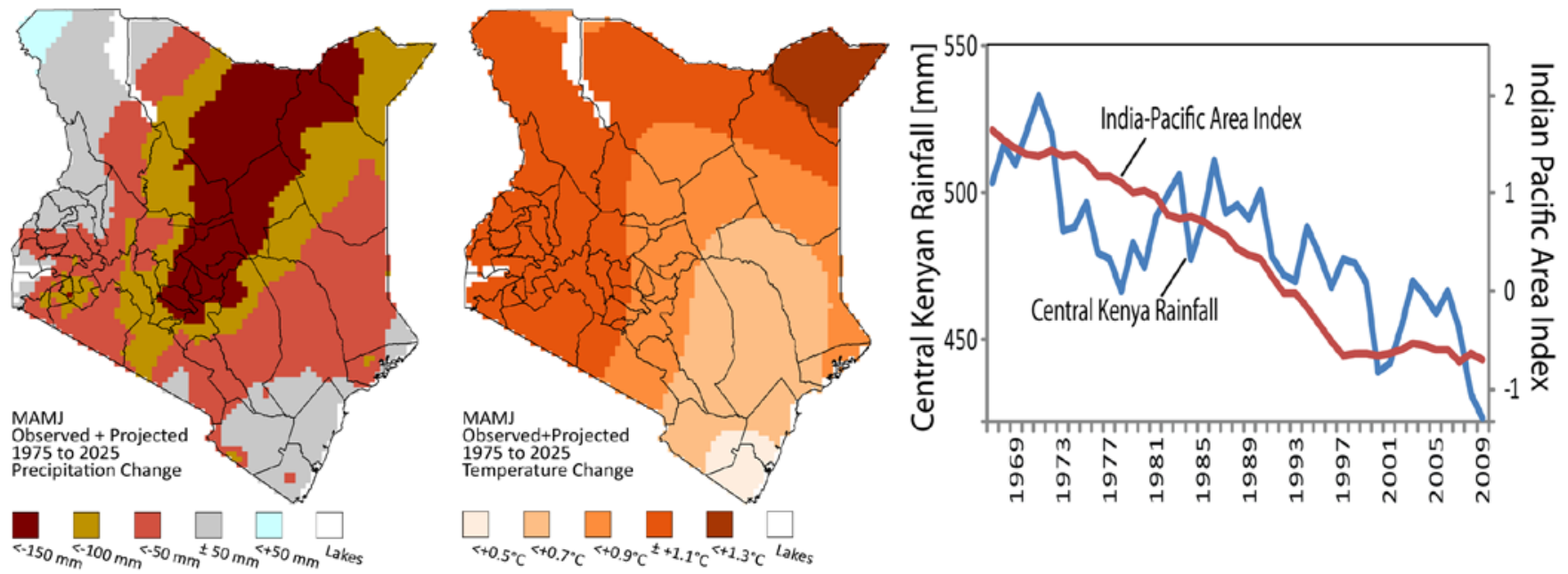

Figure 74. Observed and projected change in rainfall and temperature (left), together with smoothed central Kenyan rainfall and a smoothed version of the Indian-Pacific-Area climate index (right).

\section{Past research and relevant reports}

Funk, C., Michaelsen, J., Verdin, J., Artan, G., Husak, G., Senay, G., Gadain, H., and Magadzire, T., 2003, The Collaborative Historical African Rainfall Model—Description and Evaluation: International Journal of Climatology, v. 23, p. 47-66. (Also available online at ftp://chg.geog.ucsb.edu/pub/pubs/CHARM_IJOC_article.pdf).

Funk, C., and Michaelsen, J., 2004, A simplified diagnostic model of orographic rainfall for enhancing satellite-based rainfall estimates in data poor regions: Journal of Applied Meteorology, v. 43, p. 1366-1378. (Also available online at ftp://chg.geog. ucsb.edu/pub/pubs/VDELB.pdf).

Funk, C., Asfaw, A., Steffen, P., Senay, G., Rowland, J., and Verdin, J., 2003, Estimating Meher Crop Production Using Rainfall in the 'Long Cycle' Region of Ethiopia: FEWS NET Special Report available online at http://earlywarning.usgs.gov/adds/ pubs/EthProductionOutlook.pdf.

Funk, C., Senay, G., Asfaw, A., Verdin, J., Rowland, J., Michaelsen, J., Eilerts, G., Korecha, D., and Choularton, R., 2005, Recent Drought Tendencies in Ethiopia and equatorial-subtropical eastern Africa: FEWS NET Special Report available online at http://earlywarning.usgs.gov/adds/pubs/RecentDroughtTendenciesInEthiopia.pdf.

Verdin J., Funk C., Senay, G., and Choularton, R., 2005, Climate Science and Famine Early Warning: Philosophical Transactions of the Royal Society B, v. 360, p. 2,155-2,168. (Also available online at ftp://chg.geog.ucsb.edu/pub/pubs/RoyalSociety_2005.pdf). 
Funk, C., and Brown, M., 2005, A maximum-to-minimum technique for making projections of NDVI in semi-arid Africa for food security early warning: Remote Sensing of Environment, v. 101, p. 249-256. (Also available online at http://earlywarning.usgs.gov/adds/pubs/ndvi_projections.pdf).

Funk C., Dettinger M., Michaelsen J.C., Verdin J.P., Brown M.E., Barlow M., and Hoell A., 2008, Warming of the Indian Ocean threatens eastern and southern African food security but could be mitigated by agricultural development: Proceedings of the National Academy, v. 105, p. 11,081-11,086. (Also available online at http://earlywarning.usgs.gov/adds/pubs/WarmingInTheIndianOceanThreatensEasternAndSouthernAfrica.pdf).

Brown, M.E., and Funk, C., 2008, Food Security under Climate Change: Science, v. 319, p. 580-581. (Also available online at http://earlywarning.usgs.gov/adds/pubs/PerspectivesPiece_and_Letter.pdf).

Funk, C., and Brown M., 2009, Declining Global Per Capita Agricultural Capacity Production and Warming Oceans Threaten Food Security: Food Security, v. 1, no. 3, p. 271-289, DOI: 10.1007/s12571-009-0026-y. (Also available online at ftp://chg. geog.ucsb.edu/pub/pubs/FoodSecurity_2009.pdf).

Funk C., and Verdin, J., 2009, Real-time decision support systems - the Famine Early Warning System Network, chap. 17 in Gebremichael, M. and Hossain, F., eds., Satellite rainfall applications for surface hydrology: New York, Springer, p. 295-320. (Also available online at ftp://chg.geog.ucsb.edu/pub/pubs/RealtimeDSS_for_FEWS_NET_wfigs_v5.pdf).

Jury M., and Funk C., 2010, Climate change over Ethiopia-local signals and regional drivers: International Journal of Climatology (under review).

\section{Crop Area Estimation for Haiti with Very High Resolution Satellite Imagery}

Food security assessment in developing countries is a multidisciplinary activity that must take into account a wide range of socioeconomic and agro-climatic variables. The Famine Early Warning Systems Network (FEWS NET) performs this service for the Office of Food for Peace (FFP) of the U.S. Agency for International Development, which provides \$2-3 billion in food aid worldwide each year. The goal of FFP is "to ensure that appropriate... emergency food aid is provided to the right people in the right places at the right time and in the right way." USGS EROS has been a FEWS NET implementing partner since 1985, applying its expertise in remote sensing to support food aid decision making at FFP.

A key variable in food security assessment is the amount of food produced within a country, which is compared with the population's food requirement. Estimation of national crop production requires, in turn, knowledge of the crop area harvested in the country. Unfortunately, in some countries the available data on crop area are ambiguous at best because of weak data collection methods, lack of timeliness, or inconsistent figures from more than one government agency. In the face of this uncertainty for a key variable needed in the design of food aid programs, FFP asked USGS EROS to develop objective and repeatable methods for estimating crop area from satellite imagery.

In partnership with the Geography Department at the University of California, Santa Barbara, an approach has been developed that combines interpretation of very high resolution commercial satellite imagery and area-frame sampling statistical methods. It has been applied in several priority countries for the last few years, including Ethiopia, Zimbabwe, Niger, Afghanistan, and Guatemala. In FY 2010, the method was applied in Haiti, a country whose chronic food insecurity was seriously exacerbated by the devastating earthquake of January 12, 2010.

With the assistance of the National Geospatial-intelligence Agency (NGA), imagery from OrbView and WorldView, with resolution of 1 meter or better, was acquired between August and November 2009 for Haiti. Coverage of 30 percent of the national territory was achieved. A 0.5-kilometer dot grid was defined to create a systematic sample of 32,225 points for interpretation of the presence or absence of a crop at each of these locations (fig. 75). These image interpretations were supplemented by other datasets having full national coverage: gridded mean seasonal rainfall, general land cover types, slope, erosion risk, and demographic variables at the commune level. Using the dot grid interpretations of the very high resolution imagery, a logistic regression statistical model was trained to estimate percent crop area nationwide based on the values of the nationally continuous datasets.

Results for Haiti as a whole, as well as its 10 Departments, were calculated using the statistical estimator. They are presented in table 2. These figures were used by FEWS NET and the United Nations to design a Crop and Food Supply Assessment Mission for Haiti in July 2010. They cited the lack of any other up-to-date and authoritative figures. Thus, remote sensing was able to fill a critical information gap needed to assess the food security of Haiti and design appropriate international food aid programs. For further information, contact James Verdin, verdin@usgs.gov. 


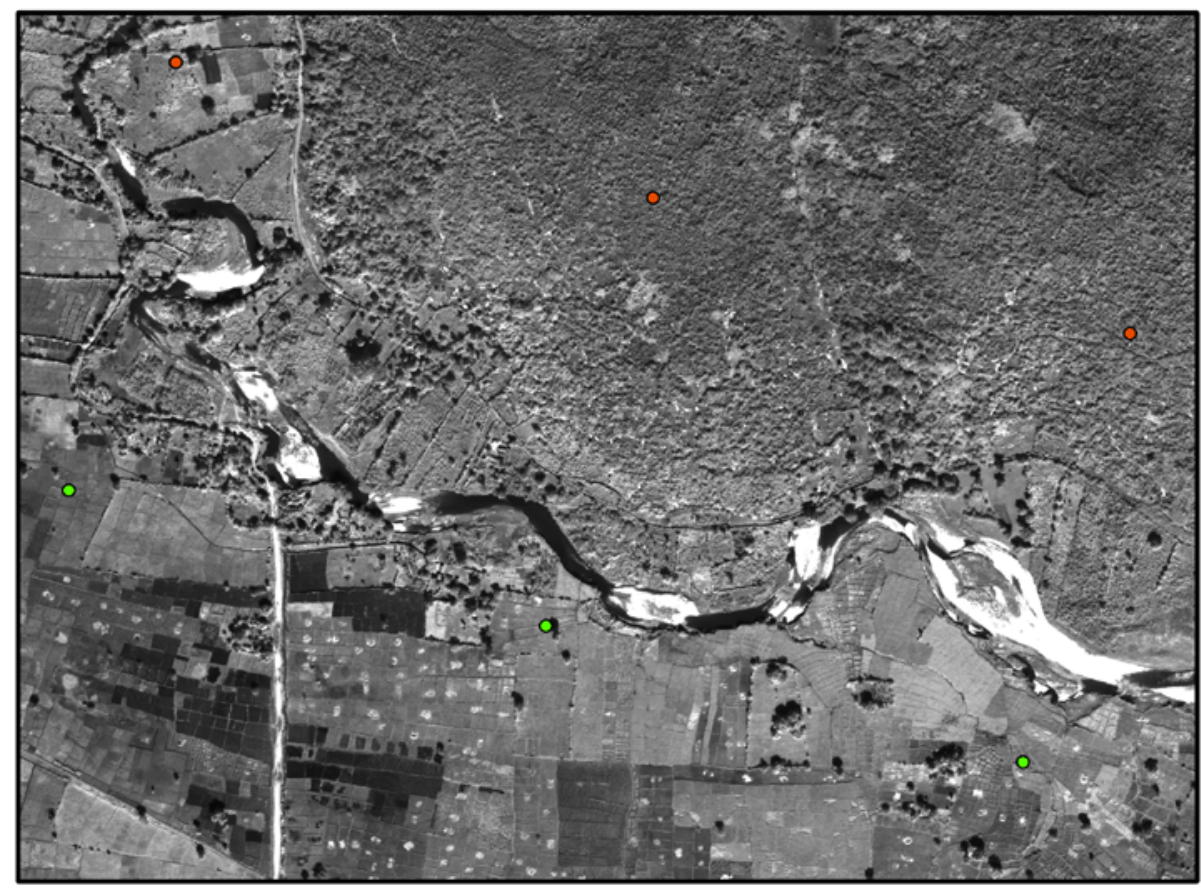

Figure 75. WorldView panchromatic image of Central Haiti, L'Artibonite Department from November 23, 2009. This image captures agricultural areas (green points) and nonagricultural areas (orange points) as interpreted by expert image analysts in the region.

Table 2. Cropped area estimates for all of Haiti and broken down by Department. Area estimates are in thousands of hectares.

\begin{tabular}{lccccc}
\hline & $\begin{array}{c}\text { Coverage by } \\
\text { imagery } \\
\text { (percent) }\end{array}$ & Total area & $\begin{array}{c}\text { Cropped } \\
\text { area } \\
\text { estimate }\end{array}$ & $\begin{array}{c}\text { Standard } \\
\text { error }\end{array}$ & $\begin{array}{c}\text { Cropped area } \\
\text { (percent) }\end{array}$ \\
\hline Haiti & $30 \%$ & $2,688.30$ & 549.9 & 27.5 & $21 \%$ \\
\hline Centre & $47 \%$ & 324.2 & 59.4 & 5.9 & $18 \%$ \\
Grand'Anse & $3 \%$ & 187.7 & 36.2 & 4 & $19 \%$ \\
L'Artibonite & $47 \%$ & 441.1 & 81.7 & 6.5 & $19 \%$ \\
Nippes & $1 \%$ & 126.7 & 25.7 & 3.3 & $20 \%$ \\
Nord & $18 \%$ & 197.4 & 60.9 & 6.1 & $31 \%$ \\
Nord-Est & $25 \%$ & 158.4 & 55.1 & 5.5 & $35 \%$ \\
Nord-Ouest & $32 \%$ & 248.6 & 60.9 & 6.1 & $24 \%$ \\
Ouest & $33 \%$ & 509.4 & 63.9 & 5.1 & $13 \%$ \\
Sud & $9 \%$ & 287.6 & 72.6 & 5.8 & $25 \%$ \\
Sud-Est & $29 \%$ & 207.2 & 33.4 & 3.7 & $16 \%$ \\
\hline
\end{tabular}

\section{Remote Sensing Activities}

The USGS EROS Center's remote sensing activities are framed around excellence in science, data management, infrastructure, and facilities devoted to evaluation and assessment of land changes and their impact on society. Core to the EROS mission is the continuity of remote sensing of the Earth's land surfaces at all scales to ensure availability of historical and current observations. Although EROS is well known as the USGS receiving station for Landsat satellite images, data from many other satellites and other remote sensing platforms are also archived and distributed by EROS. Receiving, calibrating and validating, 
processing, archiving, and distributing these data are primary tasks performed at EROS. In addition, EROS is defining requirements and specifications for future instruments, developing and implementing ground systems for future Earth observing missions, and developing national and international partnerships.

\section{Landsat Program}

The Landsat Program is a joint effort of the USGS and NASA to gather Earth resource data using a series of land observing satellites. Whereas NASA's role is the development and launch of Earth observing instruments and spacecraft, the USGS is responsible for flight operations, maintenance, and management of all ground data reception, processing, archiving, product generation, and distribution for the Landsat series of Earth observation missions. A primary objective of the Landsat Program is to ensure a collection of consistently calibrated Earth imagery.

Today, the Landsat Project at EROS manages two active satellites, Landsat 5 and Landsat 7, and the historical archive of data collected since 1972-more than 2.4 million images. In FY 2009, a change in data policy (no charge, web-enabled data) transformed the distribution of Landsat data for scientists and operational users worldwide; as a result, more than 3 million Landsat images have been delivered to customers! As of FY 2010, Landsat 5 reached 26 years in orbit, and Landsat 7 reached 11 years in orbit. With the respective design life of 3 years and 5 years, both of these satellites continue to provide essential data to scientists well beyond their expected lifespan. The Landsat team is continually working to extend the longevity of the satellites in orbit, enhance Landsat data quality, improve systems at EROS used to archive, process, and access Landsat data, and is leading the design and development of the ground system for the Landsat Data Continuity Mission.

\section{Survey of Landsat Users Demonstrates Value of Landsat Data}

To better understand the users, uses, and societal benefits of Landsat imagery, USGS conducted a survey of approximately 1,400 U.S.-based professional users of this imagery in the fall of 2009. This surveying effort sought to answer the following questions:

How is Landsat imagery used?

- At multiple scales, from local to global, in locations around the world.

- In a variety of sectors, from academic institutions to all levels of government, as well as private businesses and nonprofit organizations.

- In many applications areas including ecological monitoring, emergency/disaster relief, agricultural management, rural and urban planning and development, climate science, and water resource management.

How important is Landsat imagery?

- More than 80 percent of respondents find Landsat important to their current work.

- More than 80 percent will increase or maintain their use of Landsat in the next 5 years.

- 40 percent rely exclusively on Landsat for their work.

Does the imagery meet the needs of users?

- Key features of Landsat are important to respondents when they choose which kind of imagery to use for their work.

- Respondents are satisfied with these features of Landsat.

What are the impacts if Landsat imagery were no longer available?

- Negative impacts to respondents include:

- More than 50 percent would discontinue some to all of their work.

- 65 percent would likely incur increased overall project costs.

- 33 percent would experience a decrease in revenues or funding.

What are the effects of Landsat imagery becoming available at no charge?

- Respondents acquired twice as many Landsat scenes from 2008 to 2009.

- Respondents spent 80 percent less on Landsat imagery from 2008 to 2009. 
Some of the preliminary information from the survey indicates that Landsat data are very important and valuable to a broad user community (fig. 76). The USGS is compiling the complete results in an upcoming report.

The survey, funded by the Land Remote Sensing Program, was conducted by USGS Biological Resources Discipline, USGS Policy Analysis and Science Assistance Branch, Fort Collins, Colorado. For further information, contact Kristi Kline, USGS EROS, kkline@usgs.gov or Thomas Loveland, USGS EROS, loveland@usgs.gov.

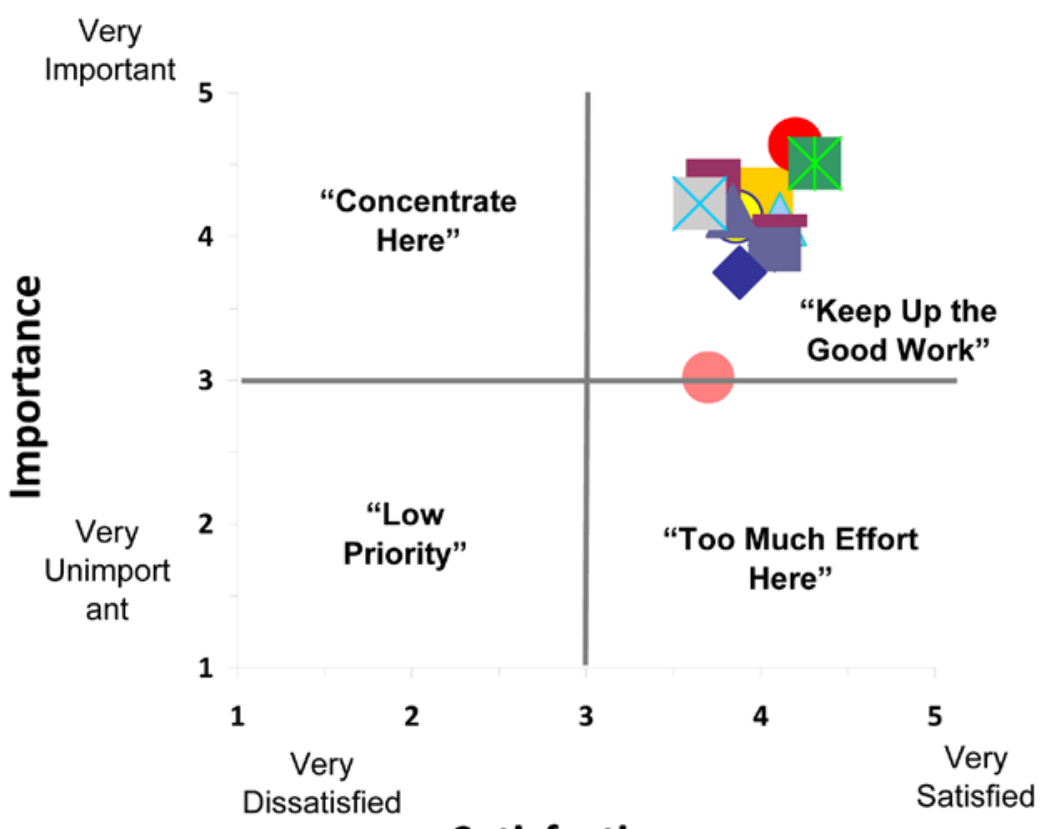

\author{
$\diamond$ Accessibility \\ $\triangle$ Area/footprint of individual scene \\ 亶 Cost \\ Delivery time \\ - Global coverage \\ Spatial resolution \\ $\triangle$ Temporal resolution/frequency of coverage
}

\author{
Archive/continuity \\ - Availability \\ O Data quality assessments \\ - Ease of use \\ - Licensing/distribution restrictions \\ $\Delta$ Spectral resolution
}

Figure 76. Preliminary survey information shown by this scatter diagram indicates that Landsat data are very important and valuable to a broad user community.

\title{
Landsat Users Break Records-More than 2.4 Million Images Delivered
}

In FY 2009, Landsat users downloaded an astounding 1.1 million images from the EROS Center. That number pales in comparison to the downloads in FY 2010-More than 2.4 million!

The USGS previously charged nominal fees for Landsat data, but in FY 2008 a policy change enabled Landsat data to be distributed at no charge via the Internet. Before the policy change, the highest year of distribution was in FY 2001 when approximately 25,000 scenes were delivered. Today, the Landsat Project can distribute in just a few days what once took an entire year (fig. 77).

Providing free data has improved capability in the Earth observation research community. For instance, in perpetually cloudy areas, researchers struggled to find the best images at an affordable cost resulting in less than ideal data coverage of the study area. The images below highlight the impact of the free archive on science results. In figure 78, in the first image, scientists purchased the best available data (104 images for $\$ 83,200)$. In the second image, 3 to 5 images were added per path/row area to reduce cloud cover. However, that was once cost prohibitive (416 images for $\$ 332,800$ ). It is clear in the third image that additional Landsat scenes can improve the forest cover mapping in a cloudy region. For further information, contact Kristi Kline, USGS EROS, kkline@usgs.gov. 

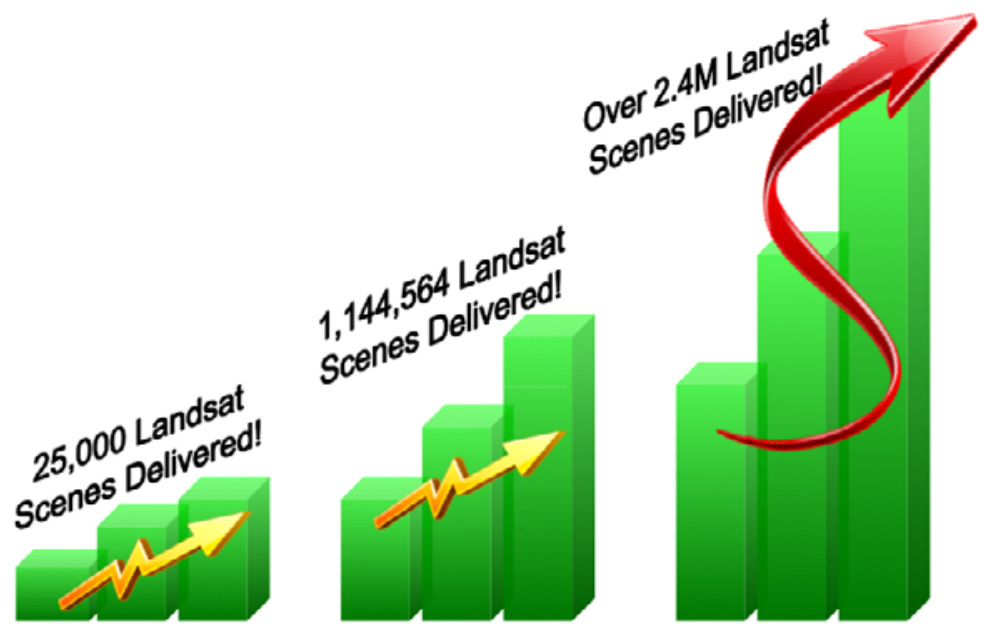

Figure 77. Increased data delivery into fiscal year 2010.
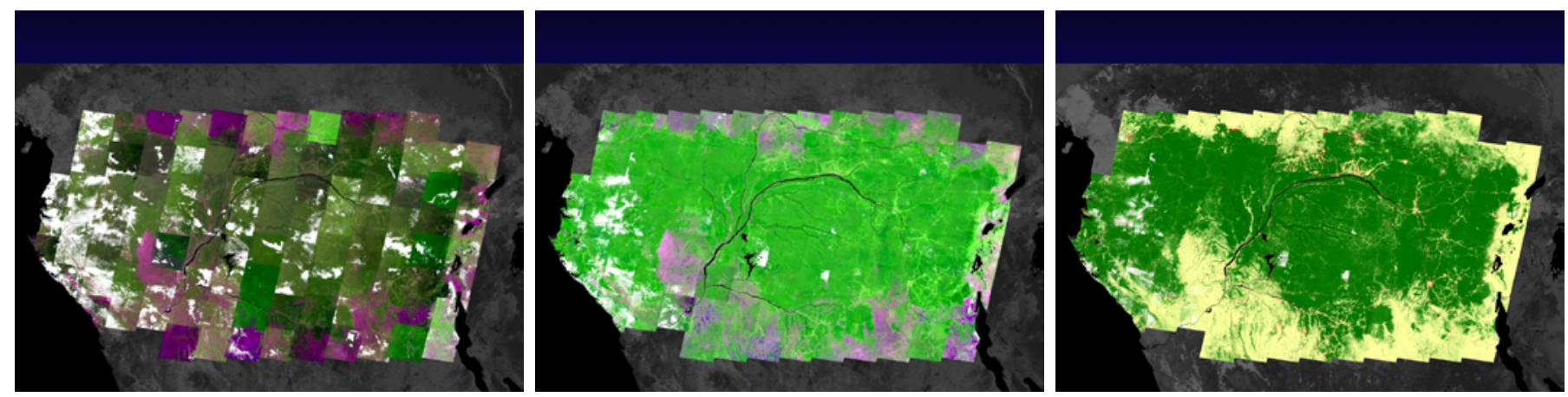

Figure 78. Landsat scenes (left to right) illustrate improved research capabilities with increased availability and use of free data (Hansen and others, 2008).

\section{Landsat Data Revival—Multispectral Scanner Data Improvements}

Landsat 1, known initially as Earth Resources Technology Satellite 1 (ERTS-1), was launched on July 23, 1972. The first five Landsat missions included an instrument to collect multispectral data called the Multispectral Scanner (MSS). MSS data were collected from 1972 through 1992. The oldest data on the early Landsat satellites have undergone many changes since inception. From significant technological advances in computing capability to migration of the data from many media sources, the ability to process and utilize these data has dramatically changed.

In FY 2010, the Landsat Project completed an effort to migrate processing of MSS data from a legacy system to a single

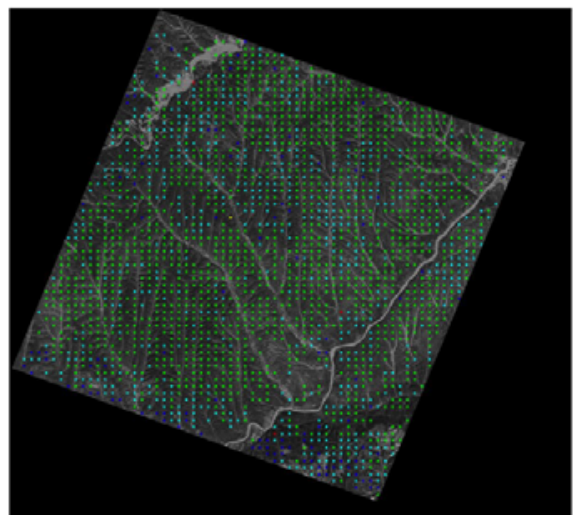
system used for other instruments from later Landsats. As part of this recent change, the project upgraded the MSS capability. Included in this upgrade are significant improvements to data calibration, faster automated processing of data, and

Path/Row : 128/18 (WRS-1) Legend:

Green - RMSE $<=0.5$ pixel Cyan - $0.5<$ RMSE $<=1$ pix Blue - $1<$ RMSE $<=2$ pixel
Yellow $-2<$ RMSE $<=3$ pixel Red - RMSE $>3$ pixel

GVERIFY_RMSE : 0.57 pixels increased geometrical accuracy of most products. Each MSS image includes a JPEG (fig. 79) of geometric accuracy. Past processing of MSS images was slow and cumbersome, and image accuracy often constrained use of the products. For further information, contact Kristi Kline, USGS EROS, kkline@ usgs.gov.

Figure 79. Example Multispectral Scanner image includes a JPEG of geometrical accuracy. 


\section{Landsat Saves the Orphans}

In addition to significant processing improvements for MSS data, the Landsat Project discovered old MSS data that were unable to be processed (fig. 80). In the early years of operations, data were collected on Wide Band Video Tape (WBVT) media with the necessary spacecraft telemetry metadata stored on 9-track computer tapes. As part of a data rescue effort, older collections stored by other Federal agencies were sent to EROS. However, unreadable or misplaced 9-track computer tapes resulted in "orphan" data. These data were once considered to be unable to be processed. The Landsat Project is implementing an innovative method to recover these images. The recovery systems have been built and tested, and rescue will commence in FY 2011. For further information, contact Kristi Kline, USGS EROS, kkline@usgs.gov.

Figure 80. Example of a recovered image (Landsat 2 , path 40 , row 35 , June 27,1978 ) not previously archived at EROS, but processed using the updated MSS processing software.

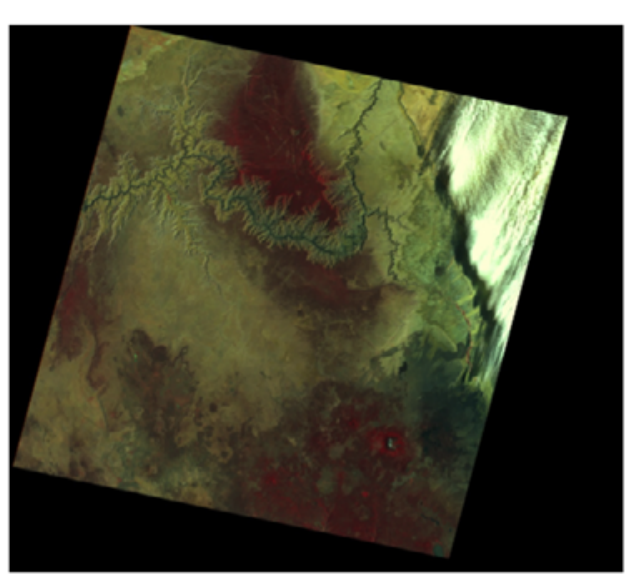

- Landsat 2 Image

- Path 40, Row 35

6-27-1978

\section{Landsat Global Archive Consolidation-The World at EROS}

The Landsat Global Archive Consolidation (LGAC) effort will bring more of the world to EROS. Pre-Landsat 7 missions did not have onboard data recorders like the one on Landsat 7. Instead, data were downlinked to ground stations around the world. These stations collected, archived, and distributed these data to customers. Initial estimates show that the global stations have nearly 5 million Landsat images in their archives. With approximately 2.4 million images in the U.S. archive today, bringing the world to EROS would triple the Landsat data holdings in the USGS archive.

Although in some cases these data have been in foreign archives for decades, collecting the Landsat holdings in the U.S. archive is increasingly critical. Many stations have unique data, unique systems, and unique data formats. Scientists have long desired to have Landsat data in common formats with standard processing methods applied. Additionally, data in the archives of many stations are already at risk with aging media and are unable to be processed by the station that originally received the data.

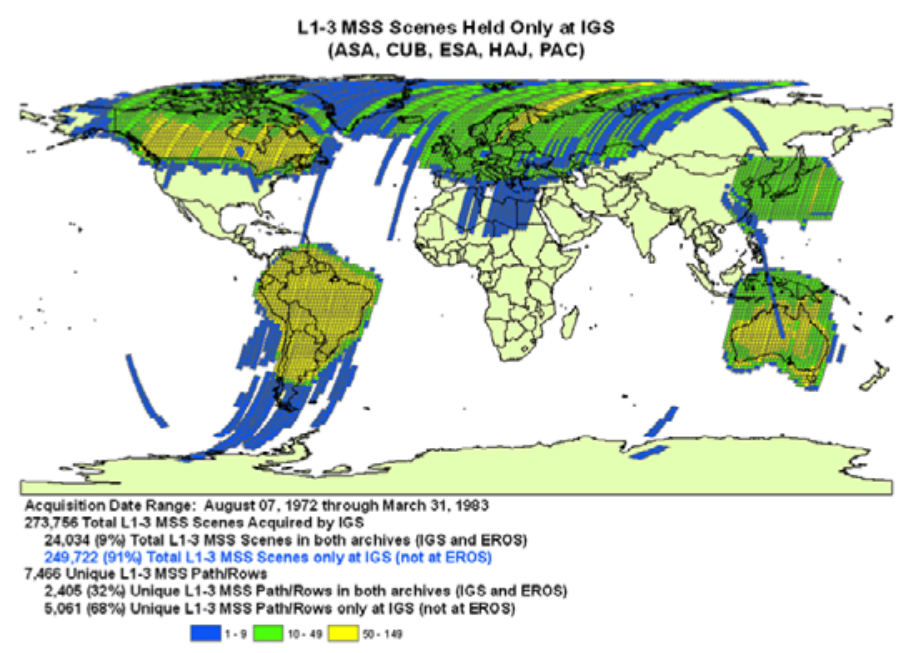

Data successfully recovered from global archives will be archived and made available to the science community. Landsat is a key dataset used to perform long-term studies for global change research. Stations collecting data in the early years with Landsats 1,2 , and 3 have nearly 250,000 unique images in their archives (fig. 81). Approximately 3.5 million additional unique Landsat images are housed in the archives of other non-U.S. stations.

The Landsat project is currently working with international stations to compile the complete picture of Landsat data holdings globally. Sample data are being assessed to determine the technical requirements of consolidating all Landsat data at EROS. Many international stations are eager to work with the Landsat project, and arrangements are in work to begin collection of data. For further information, contact Kristi Kline, USGS EROS, kkline@usgs.gov.

Figure 81. Graphic of unique Landsat 1-3 image data held at international ground stations (IGS). 


\section{New Missions}

The USGS and the EROS Center are continually seeking opportunities to collaborate in the development and operations of Earth observing remote sensing missions to satisfy the needs of the Nation's land imaging data requirements. The New Missions activities facilitate the communication and definition of USGS LRS Program requirements to the EROS Center. These activities are focused on developing partnerships to collect, archive, process, and distribute remotely sensed data in response to the evolving needs of scientific research, operational applications, decision makers, and educators. Toward these ends, teams are established to develop project plans, define and document requirements, perform systems engineering analysis, and implement technical solutions.

\section{LDCM Ground Network Element Critical Design Review}

The Landsat Data Continuity Mission (LDCM) Ground Network Element (GNE) is responsible for communicating telemetry and commands between the mission operations center (MOC) and the spacecraft, as well as receiving mission data which are subsequently sent to the Data Processing and Archive System (DPAS) for processing, archive, and distribution. The GNE is composed of LDCM ground network (LGN) stations located at Gilmore Creek, Alaska ("GLC," in partnership with National Oceanic and Atmospheric Administration) and at USGS EROS in Sioux Falls, South Dakota ("LGS," in partnership with the Landsat 5/7 program), and the Data Collection and Routing Subsystem (DCRS), which is a new development for LDCM. A diagram of the high-level Ground Network Element architecture is shown in figure 82.

The GNE critical design review was held on February 9, 2010, covering the final details of the design implementation of the GNE and the analysis showing predicted performance. Two minor requests for action (RFAs) and three advisories were received during the review. In preparation for the review, peer reviews were held for the LGN design and the DCRS development effort, which reviewed documentation to ensure that the element was at the maturity needed for the Critical Design Review (CDR). For further information, contact Grant Mah, USGS EROS, mah@usgs.gov.

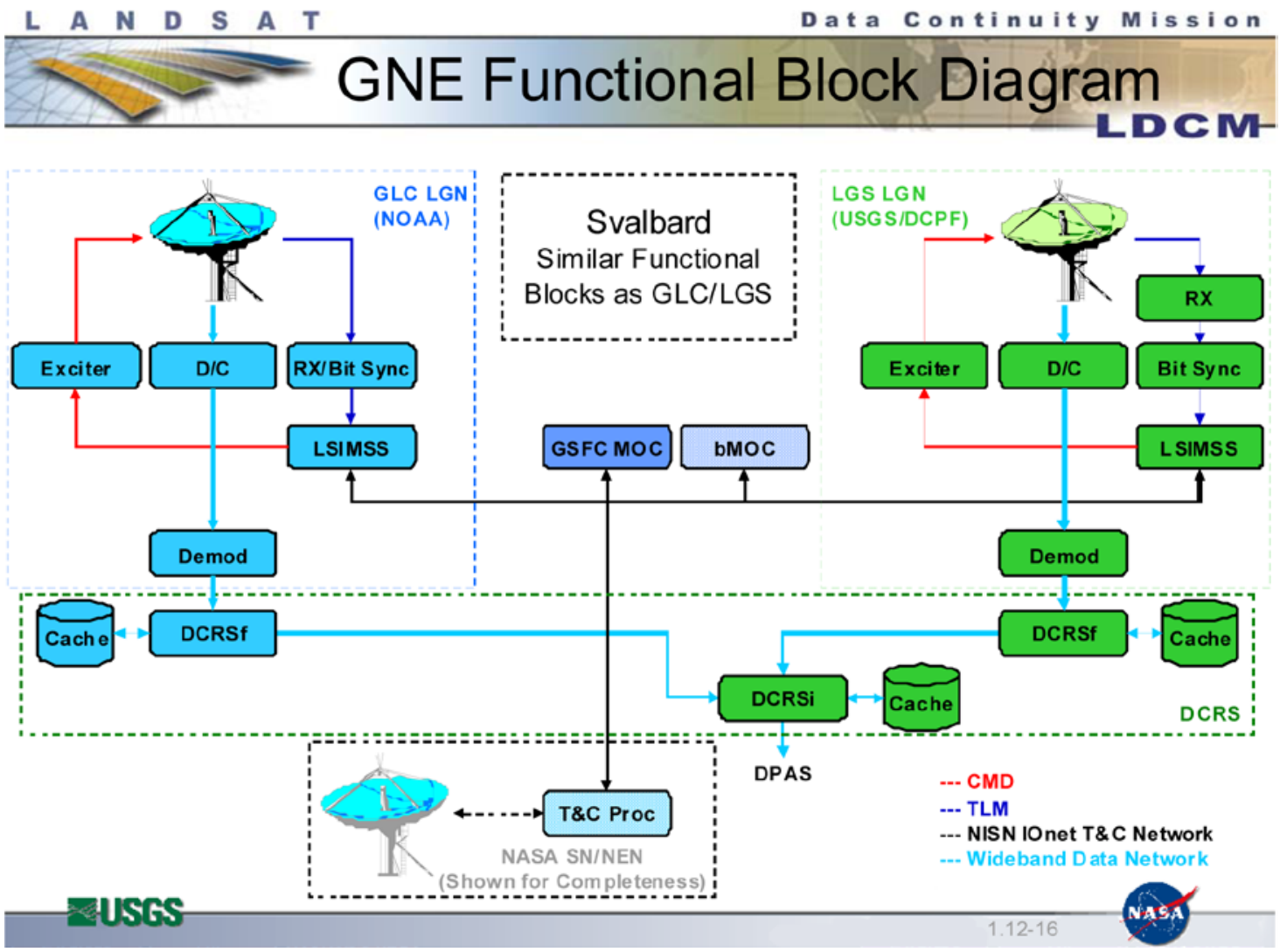

Figure 82. Illustration of the equipment used in the June 2010 test (image courtesy of Orbital Sciences Corporation). 


\section{LDCM Ground Network Element (GNE) Testing with Spacecraft Engineering Model (EM) Hardware}

During the weeks of February 8 and June 14, 2010, tests were conducted using the spacecraft engineering model (EM) communications and command and data handling $(\mathrm{C} \& \mathrm{DH})$ subsystems to send data to ground system equipment. In the February test, a demod similar to the operational unit was tested to measure bit error rate (BER) and implementation loss performance, and in the June test, operational Ground Network Element (GNE) equipment (demod, downconverter, Data Collection and Routing Subsystem server, and network switch) were used. Both tests were highly successful, demonstrating that the end-to-end link performance will easily meet the 10e-12 BER and $3 \mathrm{~dB}$ implementation loss requirements. Test data were consistent between both sets of testing and with tests run for GNE Level 4/5 testing at the USGS/EROS ground station. Moreover, the June test also demonstrated the capability of the ground system to receive and process the Consultative Committee on Space Data Systems (CCSDS) File Data Protocol (CFDP) data files that were generated and formatted by the EM C\&DH. This demonstrated, with ample margin, that the system works end-to-end at the levels of performance needed for LDCM to deliver 400 scenes/day to the ground system for processing, archive, and distribution. These results have led to the recommendation to retire the LDCM system level risks for BER performance and CFDP compatibility between the spacecraft and the ground system. Image of the equipment used in the June test is shown in figure 83 (image courtesy of Orbital Sciences Corporation).

LDCM is the first operational flight mission to use Low Density Parity Check (LDPC) forward error correction (FEC), which is more spectrally efficient than the current convolutional coding FEC currently used by most missions. Moreover, the LDCM BER requirements are orders of magnitude higher than is typically required by a space mission (LDCM requires 10e-12 BER, most space missions are typically specified in the range of $10 \mathrm{e}-6$ to 10e-9), which is further compounded by the exceptionally high data rates used for LDCM (384 Mbits/sec). The successful end-to-end testing is a major accomplishment in both the overall LDCM development effort and in demonstrating new technology that operates at a substantially higher level of performance than anything that is currently flying or in development. For further information, contact Grant Mah, USGS EROS, mah@usgs.gov.

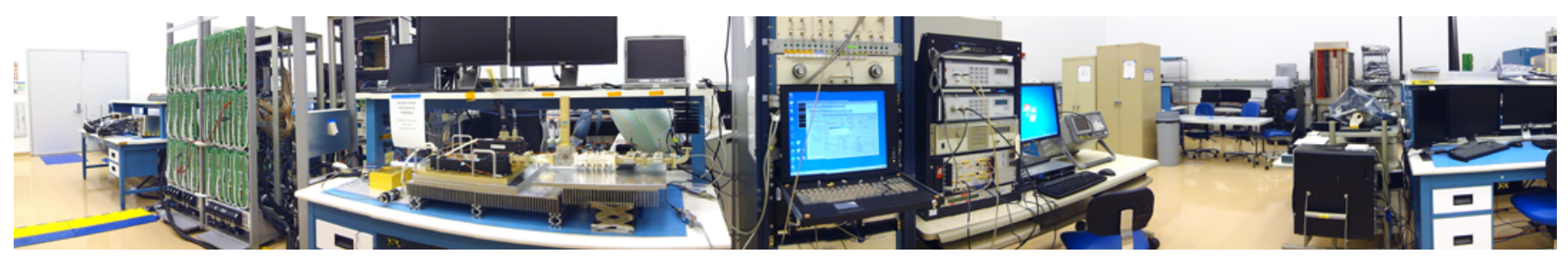

Figure 83. Illustration of the equipment used in the June 2010 test (image courtesy of Orbital Sciences Corporation).

\section{LDCM Collection Activity Planning Development Element}

In January 2010, the Landsat Data Continuity Mission (LDCM) Development Team released the first version of the Collection Activity Planning Development Element (CAPE) that contains the ability to generate the high level instrument imaging mission schedules. The bulk of the imaging is done to satisfy the requirements established in the Long Term Acquisition Plan 8 (LTAP-8) controlled by the LDCM Science Office. The policies governing data collection scheduling are implemented in the CAPE and provided to the Mission Operations Center to be transmitted to the orbiting satellite. For further information, contact Rodney Pater, USGS EROS, pater@usgs.gov.

\section{Landsat Science Team Activities}

The Landsat Science Team comprises 18 scientists from industry, academia, and government selected by the U.S. Geological Survey through an open competition to provide technical and scientific input to the USGS and NASA in support of Landsats 1-7 and the Landsat Data Continuity Mission (LDCM). The Landsat Science Team is completing its fourth year out of a 5-year contract period, and the team has sustained a regular schedule of meetings every January and June since its inception in Fiscal Year 2007.

In addition to the two meetings in FY 2010, the team held an additional meeting to address Landsat processing topics. The special meeting was hosted by Boston University in October 2009. During the meeting, the team reviewed state-of-the-science algorithms used to detect and map clouds and shadows, for atmospheric correction, and to calculate surface temperature and reflectance. The meeting concluded with plans to further test selected approaches for generating advanced Landsat science products that might be distributed by the USGS in the future. 
The need for higher level science products was the theme for the January 2010 meeting held in Mountain View, California, and hosted by NASA Ames. The team concluded that producing a Landsat surface temperature and reflectance time series from 1972 forward is a priority and the development of derived datasets based on Essential Climate Variable concepts should also be pursued.

The June 2010 meeting was hosted in Boise, Idaho by the University of Idaho and Idaho Department of Water Resources. The meeting included reviews of the status of Landsat 5 and 7, LDCM, and the recently completed Landsat user survey. In addition, each science team member gave a detailed presentation on their research and applications involving Landsat. The presentations highlighted the rapid advances resulting from the availability of web-enabled Landsat data (fig. 84).

In addition to these meetings, during the past year the Landsat Science Team contributed to a USGS congressional briefing on Landsat and provided periodic evaluations of issues facing the USGS and NASA. For example, the team provided input on Landsat 5 acquisition options, methods for processing Landsat thermal imagery, and priorities for improving the USGS global Landsat archive. For further information, contact Thomas Loveland, USGS EROS, loveland@usgs.gov.
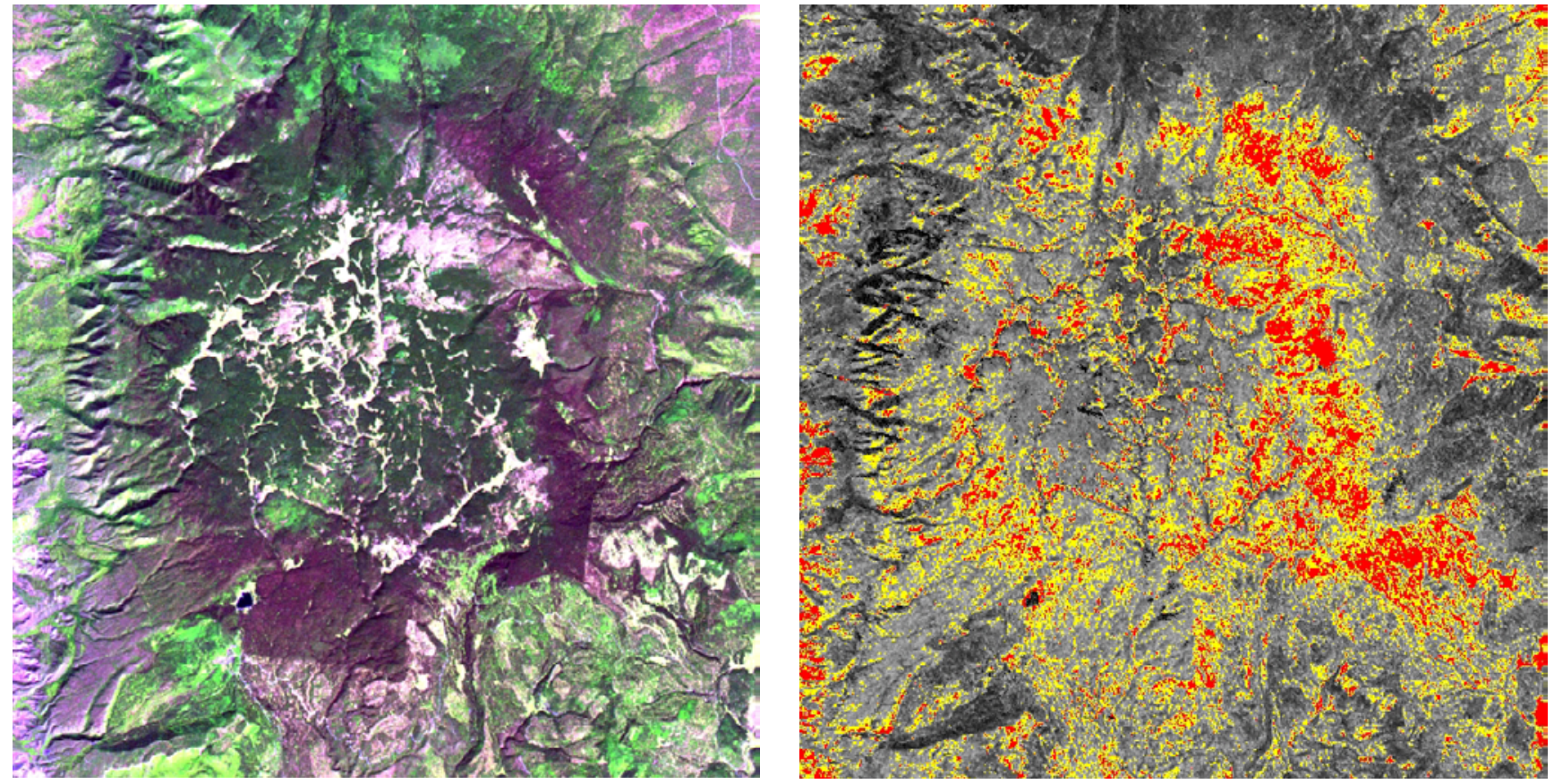

Figure 84. No-charge Landsat time series datasets contribute to natural resources management by providing an affordable means to detect threats to resources. The images show areas of forest change associated with western spruce budworm (yellow and red) at San Pedro Peaks, New Mexico and was produced by Landsat Science Team member Jim Vogelmann (USGS). The two images represent a 1998 Landsat 5 image (left) and a 1998 to 2008 land change map (right).

\section{Data Processing and Archive System Critical Design Review}

The Data Processing and Archive System (DPAS) is responsible for receiving Landsat Data Continuity Mission data from the Ground Network Element (GNE), archiving the data for safekeeping, calibrating the performance of the science instruments, and generating products for the user community (fig. 85).

The DPAS engineering team presented its Critical Design Review (CDR) to a review panel of veteran USGS and NASA engineers on February 23-24, 2010. This review was the culmination of a year's worth of difficult work that started with a ground-up re-architecture of the entire system in early 2009. The new architecture required the team to revisit its System Requirements Review in July 2009 and present a new Preliminary Design Review in September 2009. The DPAS CDR was a very successful review, resulting in only two formal Requests For Action throughout two full days of very detailed design material review. The panel characterized the review as fully successful, and the panel chairman noted in his report that the team "provided a comprehensive presentation of the entire final design" and "is to be commended on a well thought out design." This review puts the DPAS team on very solid ground as it moves forward into implementation and testing. For further information, contact Chris Engebretson, USGS EROS, engebret@usgs.gov. 


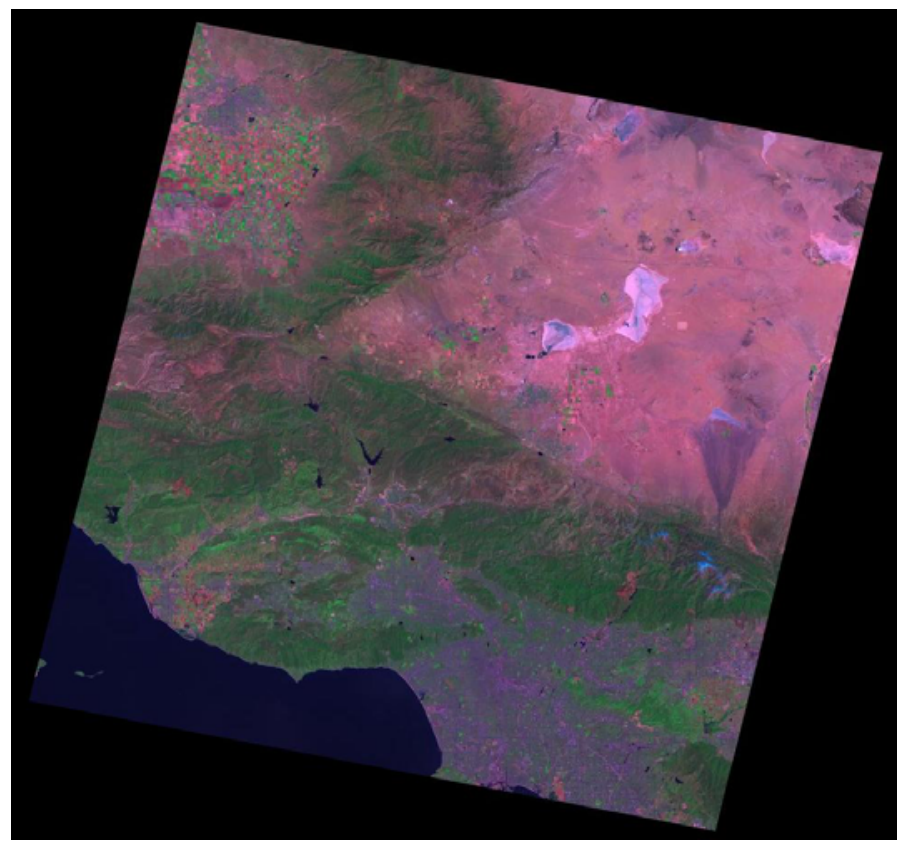

Figure 85. Browse image of a sample Level 1 user product.

\section{Landsat Data Continuity Mission Ground System Critical Design Review}

The Landsat Data Continuity Mission (LDCM) project completed critical design of the Ground System (fig. 86) this fiscal year, culminating in a Critical Design Review (CDR) in March 2010. The USGS, with mission partner NASA, presented the Ground System design to an independent review panel, receiving approval to proceed with implementation, integration, and test. The panel issued only three Requests for Action, which were addressed following the conclusion of the design review. For further information, contact Dave Hair, USGS EROS, hair@usgs.gov.

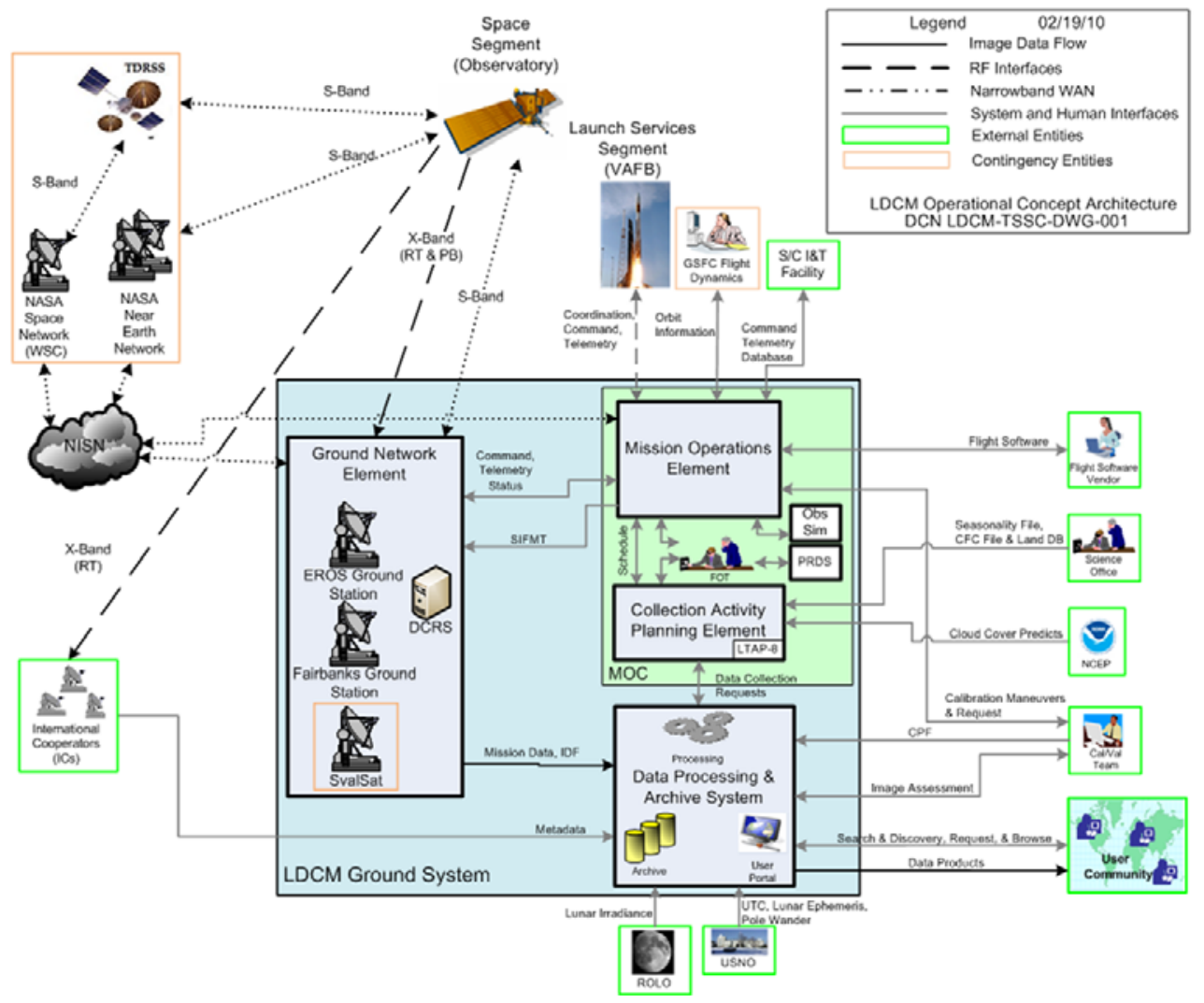

Figure 86. High-level architectural diagram of the Landsat Data Continuity Mission Ground System. 


\section{EROS LDCM Test Infrastructure}

The EROS Landsat Data Continuity Mission (LDCM) is entering the early test phases. The infrastructure to support formal qualification testing of the Data Processing and Archive System (DPAS) has been acquired and installed. The infrastructure needed to support testing includes the operational test room, four racks of computer equipment, and network improvements (fig. 87). When completed, the DPAS will archive satellite image data and process it to a format suitable for scientific and civilian purposes. Future plans include procuring the LDCM production string of hardware at EROS and augmenting the capabilities at two other remote ground stations. For further information, contact Chris Torbert, USGS EROS, ctorbert@usgs.gov.

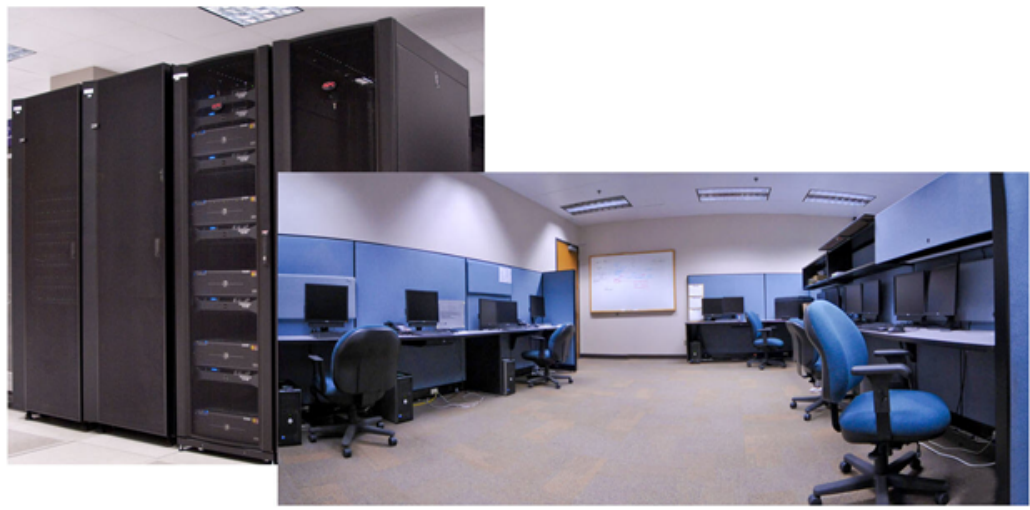

Figure 87. LDCM Data Processing and Archive System housed in a secure, climate controlled equipment room. Computer operators will test the system from the operations room adjacent to the computer room.

\section{EROS LDCM Ground Readiness Tests}

The EROS Landsat Data Continuity Mission (LDCM) is taking delivery of the first of many components needed for the completion of the ground system. The integration of those components is currently being performed at EROS and Goddard Space Flight Center, where Ground Readiness Testing (fig. 88) will occur. Ground Readiness Testing is a collaborative effort between USGS and NASA personnel to demonstrate that the ground system meets documented requirements. The tests will be conducted in phases and began in July 2010 when the commanding, reception of telemetry and imagery, and ground communication systems were evaluated. Future tests in 2011 and 2012 will include a capstone of nominal operational scenarios, contingency scenarios, and the calibration and processing of the LDCM imagery. For further information, contact Chris Torbert, USGS EROS, ctorbert@usgs.gov.

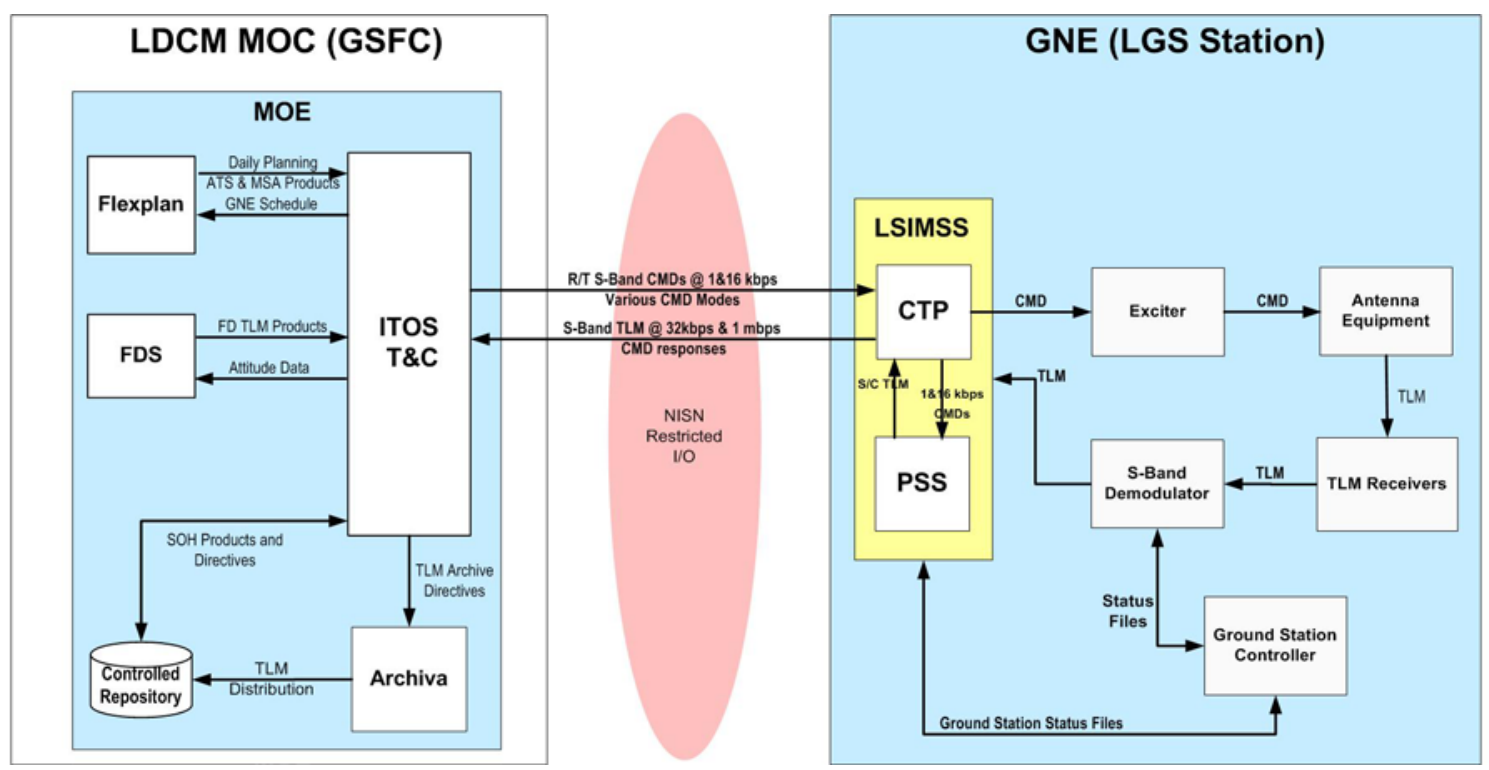

Figure 88. This is a graphical representation of the configuration needed for Ground Readiness Test 1, where the Mission Operation Center will generate commands that the EROS Ground Station will transmit to a spacecraft simulator. Simulated telemetry will be received and verified as valid responses by the flight operation team. 


\section{Calibration and Validation Technical Interchange Meetings}

The Landsat Data Continuity Mission (LDCM) continues the long heritage of consistent, high-quality data collected with all the previous Landsat missions. The LDCM Calibration and Validation Team (CVT) ensures LDCM data are accurate and consistent throughout the life of the mission. The CVT consists of groups within the U.S. Geological Survey (USGS) at the EROS Center and NASA Goddard Space Flight Center (GSFC), as well as remote sensing groups at South Dakota State University (SDSU), University of Arizona (UA), and Rochester Institute of Technology (RIT). The CVT works closely with organizations across the country ranging from the instrument and spacecraft providers to the scientists relying on the imagery. Calibration and Validation Technical Interchange Meetings (TIM), held quarterly, provide the opportunity to discuss instrument and spacecraft development, ground system development, algorithm development, and calibration and validation methodologies, with the end goal of high-quality LDCM imagery in the hands of the science community.

The first calibration and validation TIM of 2010 occurred April 6-7, 2010, at NASA GSFC. John Schott from the Rochester Institute of Technology (RIT) was on hand to provide an overview of the Digital Imaging and Remote Sensing Image Generation (DIRSIG) model, which is a software package used to simulate remotely sensed imagery. The Thermal Infrared Sensor (TIRS) team presented the development status of the sensor along with some initial analysis of their functional performance model (the precursor to the TIRS flight instrument). Additional analysis of TIRS dark data was presented by CVT members from GSFC. A lengthy discussion of the development status of the Operational Land Imager (OLI) was led by Jeff Pedelty of the Landsat Project Science Office (LPSO), who is stationed at Ball Aerospace and Technologies Corporation (BATC) (fig. 89). BATC presented their data acquisition plans for the OLI Engineering Development Unit (EDU) and OLI flight unit. Additional presentations and discussions revolved around the algorithm development and ground system development occurring at the USGS EROS Center.

The second calibration and validation TIM was held August 10-12, 2010. Updates from the second phase of the TIRS functional performance model testing and results of the OLI EDU thermal vacuum testing were among the topics of discussion. The second phase of the TIRS functional performance model testing is intended to prepare the test equipment and build the software needed to test the TIRS flight unit. Similarly, the OLI EDU thermal vacuum testing is intended as a dry-run of the test equipment and analysis software needed to test the OLI flight unit. While neither the OLI EDU nor the TIRS functional performance model are going to be operational, they are similar enough to the flight units that algorithms needed for requirements verification and image product generation can be built and tested. During the TIM in August 2010, substantial time was spent on the analysis of the OLI EDU and TIRS functional performance model test data that was collected and allow for collaboration between elements of the CVT. For further information, contact John Dwyer, USGS EROS,dwyer@usgs.gov.

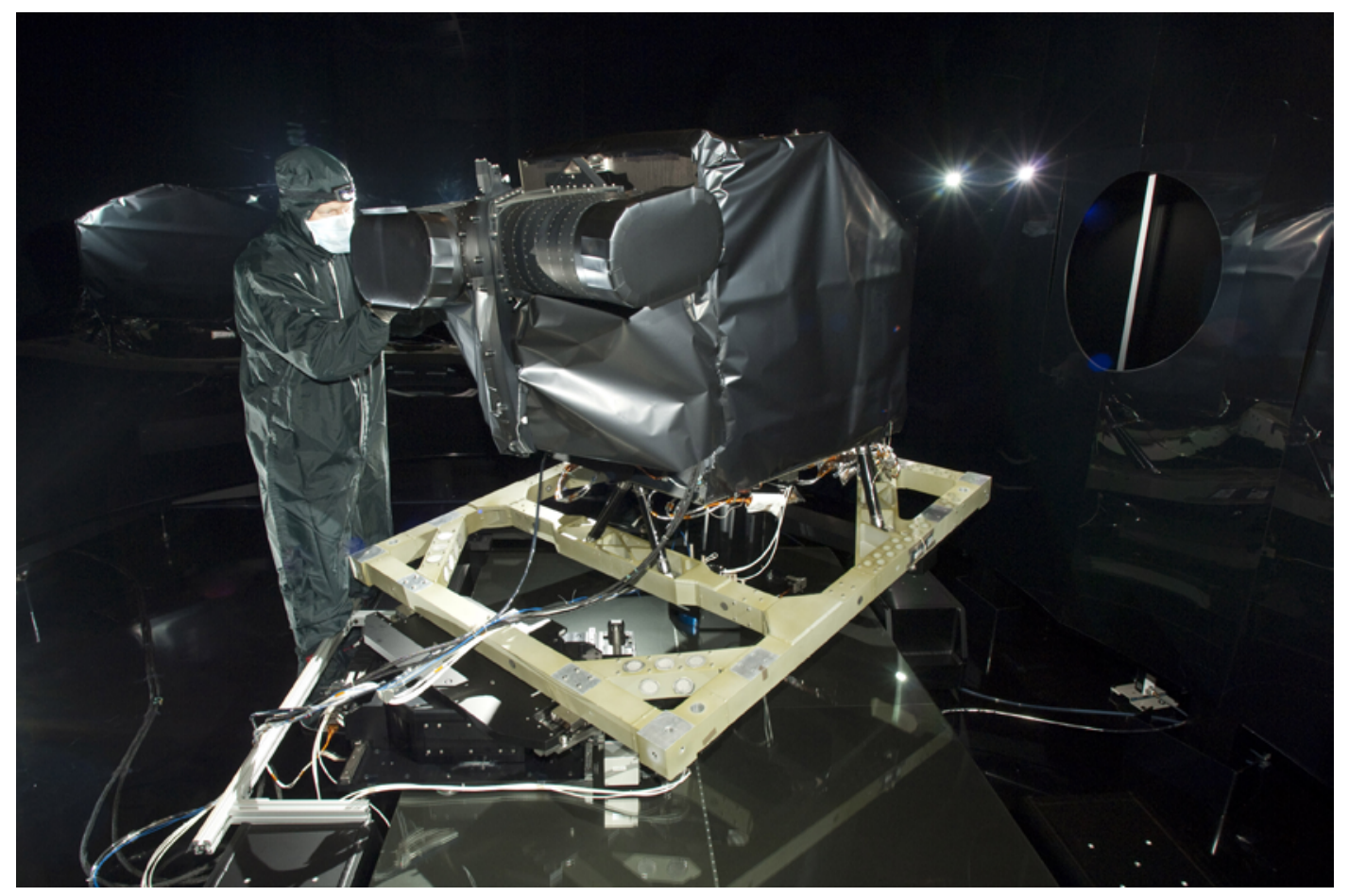

Figure 89. The Operational Land Imager design concept by Ball Aerospace and Technology Corporation. 


\section{Phase 2 Algorithms for Operational Land Imager and Thermal Infrared Sensor Delivered to Development}

The Calibration and Validation Team's (CVT) major accomplishment in 2010 was the delivery of all the phase 2 algorithms to the Data Processing and Archive Segment (DPAS) in the Landsat Data Continuity Mission (LDCM) project. The last of the phase 2 deliveries were delivered by the CVT to DPAS developers in May 2010. The phase 1 algorithm deliveries included only basic information, such as inputs, outputs, dependencies, and background. The DPAS developers used this information to define processing flows and interfaces for their preliminary design review. The phase 2 algorithms build upon the phase 1 content, adding the detailed algorithm procedures needed to support the DPAS critical design review (fig. 90). Phase 2 also enables the developers to begin implementing the algorithms shortly after critical design review. These deliveries are less mature than the phase 3 algorithms; however, they provide the development team with a good platform to build schedules and identify some of the problems that may come up during the phase 3 work. Since the phase 3 algorithm maturity level is what the final image processing and image assessment system code will be built upon, including prototype code, verification methods, and test data, it is imperative that the phase 2 deliveries are well researched and the methodologies are clearly defined.

The LDCM instruments will not be completed until the later portion of phase 3; therefore, the algorithm updates, and possibly new algorithms, will be delivered if found to be needed as the instrument is built. Changes are likely before the instruments' preship reviews. After the instrument preship reviews, a final phase 3 delivery will occur, with expectations of no significant changes at that point. The follow-on phase 4 will contain updates determined once the instrument is in orbit as real-time data are collected, especially during the on-orbit check-out period. The responsibility for researching and delivering phase 2 algorithms were members of the CVT at the NASA Goddard Space Flight Center and at the USGS EROS. The collaboration between these two groups along with external researchers at South Dakota State University, Rochester Institute of Technology, and the instrument vendors at Ball Aerospace and Technology Corporation, and NASA Goddard, were essential to these phase 2 algorithm deliveries. For further information, contact John Dwyer, USGS EROS, dwyer@usgs.gov.

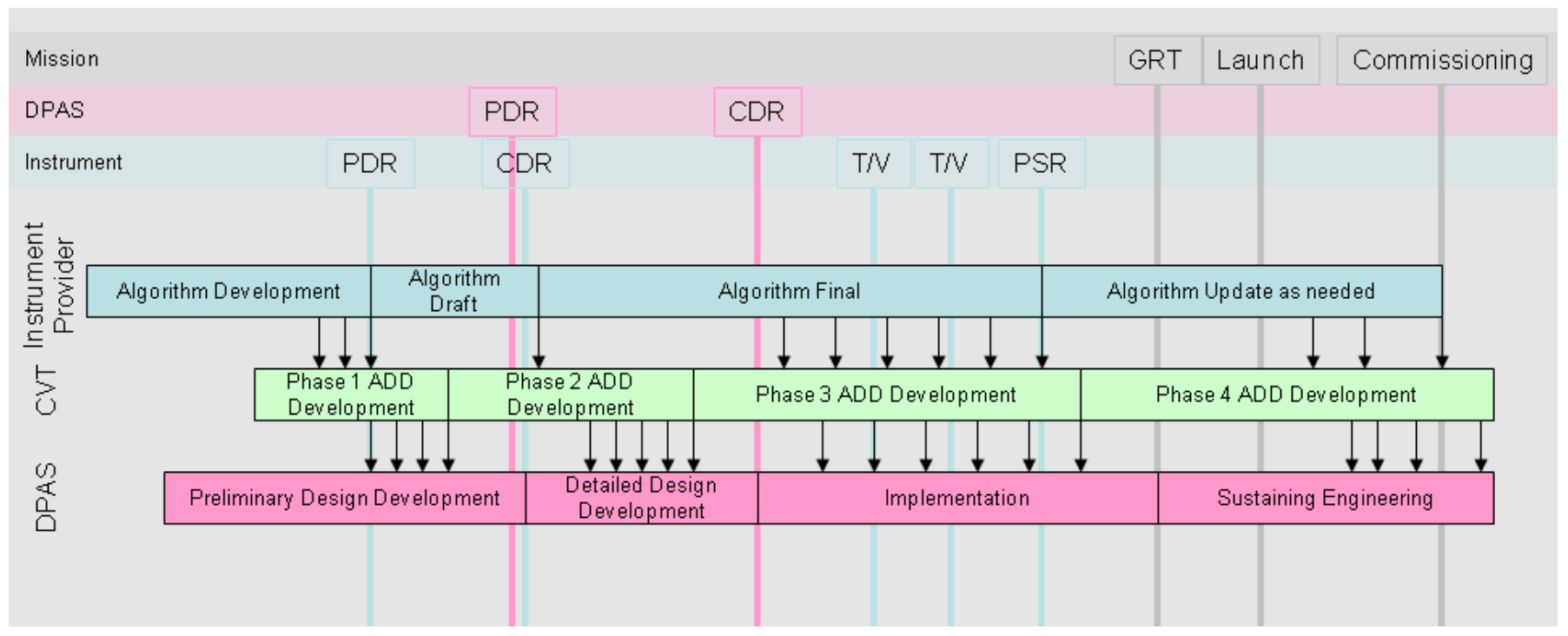

Figure 90. The algorithm maturity level is mapped from the instrument provider to the Calibration and Validation Team for algorithm design to Data Processing and Archive Segment development. The green box (across center of diagram) identifies the phase of development along with interfaces and a rough event synchronization.'

\section{International Cooperator Meeting: 38th Landsat Ground Station Operators Working Group}

The 38th Landsat Ground Station Operators Working Group (LGSOWG \#38) meeting was held in Berlin, Germany, September 28-October 5, 2009. The meeting was jointly organized by the USGS and NASA and was hosted by the German Aerospace Center (DLR). Participants from 11 countries (fig. 91) represented 14 international ground stations who discussed a wide range of programmatic and technical topics.

Presentations included Landsat 5 and Landsat 7 mission status, the Landsat Project's web-enabled product distribution statistics, Landsat 4 Thematic Mapper (TM) and Landsat 1-5 Multispectral Scanner (MSS) product development progress, the Global Land Survey Projects, the Landsat Global Archive Consolidation initiative, proposed data validation and exchange modi- 
fications, and future development plans. LDCM-related presentations included project and ground system status, ground system and downlink overview, data processing flow, and the LDCM Ground System-to-International Cooperator interface, including the International Cooperator Web Portal. Additionally, the USGS Land Remote Sensing Program provided the attendees with an overview of the future land remote sensing satellite data downlink framework agreement, along with the National Land Imaging initiative's international vision and goals. A Landsat Science Team update was also presented, providing an update on its working group activities and several key research projects.

Each International Cooperator briefed the group on the status of their systems, addressed their future satellite mission(s) and ground system plans, and provided an overview of their data distribution statistics and business model impacts since the introduction of Landsat web-enabled data. Finally, a representative from the Australian Department of Climate Change capped the meeting with a briefing on the Group on Earth Observation (GEO) Forest Carbon Tracking (FCT) initiative.

International Cooperators in attendance included representatives from the following countries and organizations:

- Australia (GA-NEO)

- Brazil (INPE)

- Canada (CCRS)

- China (CEODE)

- Europe (ESA)

- Germany (DLR)

- Indonesia (LAPAN)

- Japan (RESTEC)

- Mexico (CONABIO)

- Sweden (SSC)

- Thailand (GISTDA)

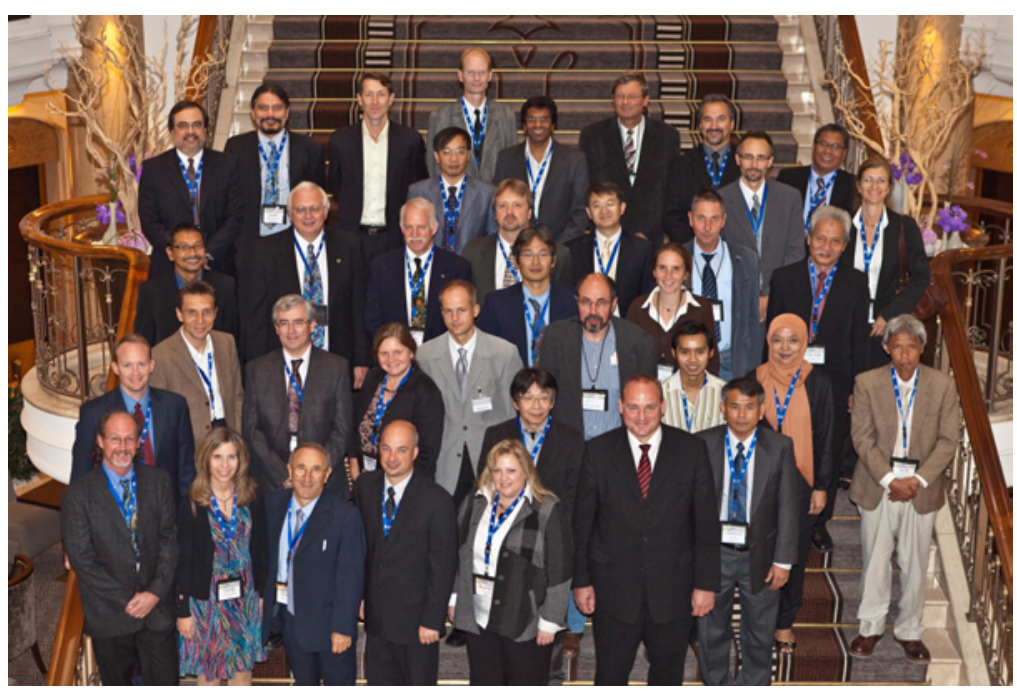

For further information, contact Steve Labahn, USGS EROS, labahn@usgs.gov.

Figure 91. Group photograph from the 38th Landsat Ground Station Operators Working Group (LGSOWG \#38) meeting held in Berlin, Germany, September 28-0ctober 5, 2009.

\section{International Cooperator Meeting: 19th Landsat Technical Working Group}

The 19th Landsat Technical Working Group (LTWG \#19) meeting was held in Phuket, Thailand, March 22-26, 2010. The meeting was jointly organized by the U.S. Geological Survey (USGS) and NASA and was hosted by the Thailand Geo-Informatics and Space Technology Development Agency (GISTDA). Participants from nine countries (fig. 92), including members of the USGS Landsat and Landsat Data Continuity Mission (LDCM) Projects, represented 14 international ground stations who discussed a wide range of Landsat technical topics.

Landsat Project presentations included Landsat 5 and Landsat 7 mission statuses as well as the latest Landsat 5 Traveling Wave Tube Amplifier testing results, Landsat 1-5 Multispectral Scanner product development progress, Global Land Survey status, the Landsat Global Archive Consolidation initiative, and Data Validation and Exchange enhancements. With the LDCM Ground System undergoing a major re-architecture activity throughout the last year, this was also a primary area for discussion. LDCM presentations included Project and Ground System status including plans and timelines for LDCM Ground System processing software availability, Science Data Reception, Science Data Processing, LDCM Ground System-to-International Cooperator interface, including the International Cooperator Web Portal, and a discussion on LDCM Data Validation and Exchange. A Landsat Science Team update was also presented, providing information on its working group activities and several key research projects.

Each International Cooperator briefed the group on the status of their systems; presented their future satellite mission(s), ground system plans, and Landsat Metadata Initiative (LMI) implementation status; and provided an overview of their data distribution statistics. Finally, a representative from the European Space Agency (ESA) capped the meeting with a briefing on the Sentinel-2 mission.

- International Cooperators in attendance included representatives from the following countries and organizations: 
- Australia (GA-NEO)

- Brazil (INPE)

- China (CEODE)

- Europe (ESA)

- Indonesia (LAPAN)

- Japan (RESTEC)

- Russia (ScanEx)

- Sweden (SSC)

- Thailand (GISTDA)

For further information, contact Steve Labahn, USGS EROS,labahn@usgs.gov.

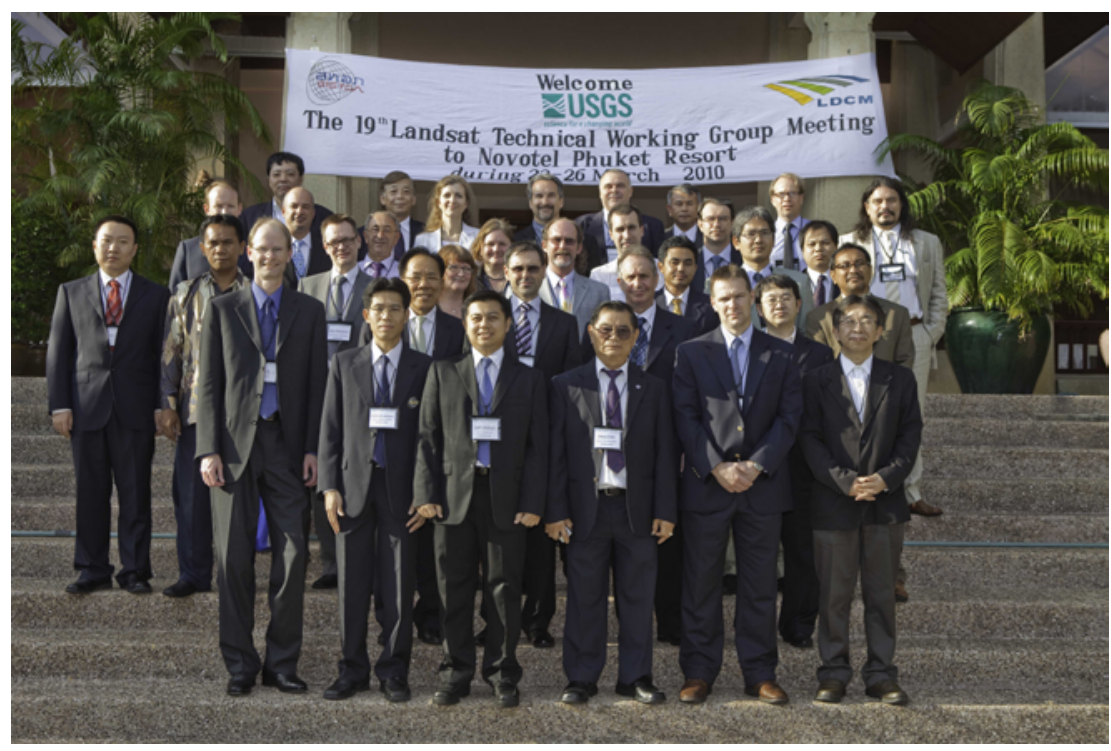

Figure 92. Group photograph from the 19th Landsat Technical Working Group Meeting held in Phuket, Thailand, March 22-26, 2010.

\section{Land Satellites Data System Consolidated Exhibit 300}

In January 2010, the Office of Management and Budget approved a proposal by the U.S. Geological Survey to consolidate the Landsat Operations and Landsat Data Continuity Mission investments into the Land Satellites Data System (LSDS) investment. LSDS is an umbrella program, composed of several projects, that supports and ensures coordinated planning and management of these inter-related efforts. The projects and Department of the Interior's Project Management Office have worked well together in implementing this new approach, developing common management plans wherever possible, and completing the required budget year FY 2012 capital planning exhibit 300 by the September 2010 deadline. For further information, contact David Hair, USGS EROS, hair@usgs.gov.

\section{Data Management and Distribution}

The USGS EROS Center manages a variety of data collections acquired from a wide array of current and historical sources, and distributes them to a broad range of global and niche user communities in science, applications, and operations. Data sources range from active satellite missions that are operated by EROS and others, historical aerial and satellite sources, as well as information about elevation, land cover, and other aspects of the Earth's land surfaces and data that are maintained in EROS' archives. The archives include film and digital systems developed commercially, in-house, and by and with other collaborators such as NASA. Access to the data is via a number of web-enabled user interfaces tailored to the collaborators' and users' needs, from simple websites to fully featured data discovery tools. In addition to managing the data as bits, EROS maintains the data via a data calibration and validation function, as well as science-based collection appraisals, and works with NASA and academia to ensure the integrity and value of the data. EROS uses this broad range of capabilities in collaboration with a number of partners to more effectively meet USGS strategic objectives.

\section{Image Server/ArcGIS Server Now Providing NAIP Web Mapping Service and Downloads}

The National Agriculture Imagery Program (NAIP) consists of data acquired by the U.S. Department of Agriculture, with contributions from other Federal agencies, such as the U.S. Geological Survey. The data are utilized by the U.S. Geological Survey (USGS) as an Orthoimagery layer within The National Map. The data are a consistent 1-meter resolution, natural color or 4 band, leaf on, and cover the conterminous 48 states (fig. 93). The previous layer was distributed for web mapping services and online downloads via ArcIMS and using the ESRI Spatial Database Engine (SDE). With the release of the new The National Map interface, EROS was tasked to transition the NAIP imagery to ESRI Image Server and ArcGIS server technology. The transition consisted of loading NAIP imagery to a Storage Area Network (SAN) and creation of service overviews. The data were added to a single layer web mapping service and made available for downloads. The move from SDE to Image Server/ArcGIS 
technology for NAIP is the first phase of transition. The next phase will be to transition the most current high resolution Orthoimagery. For further information, contact S. Jean Paulson, Paulson@usgs.gov.

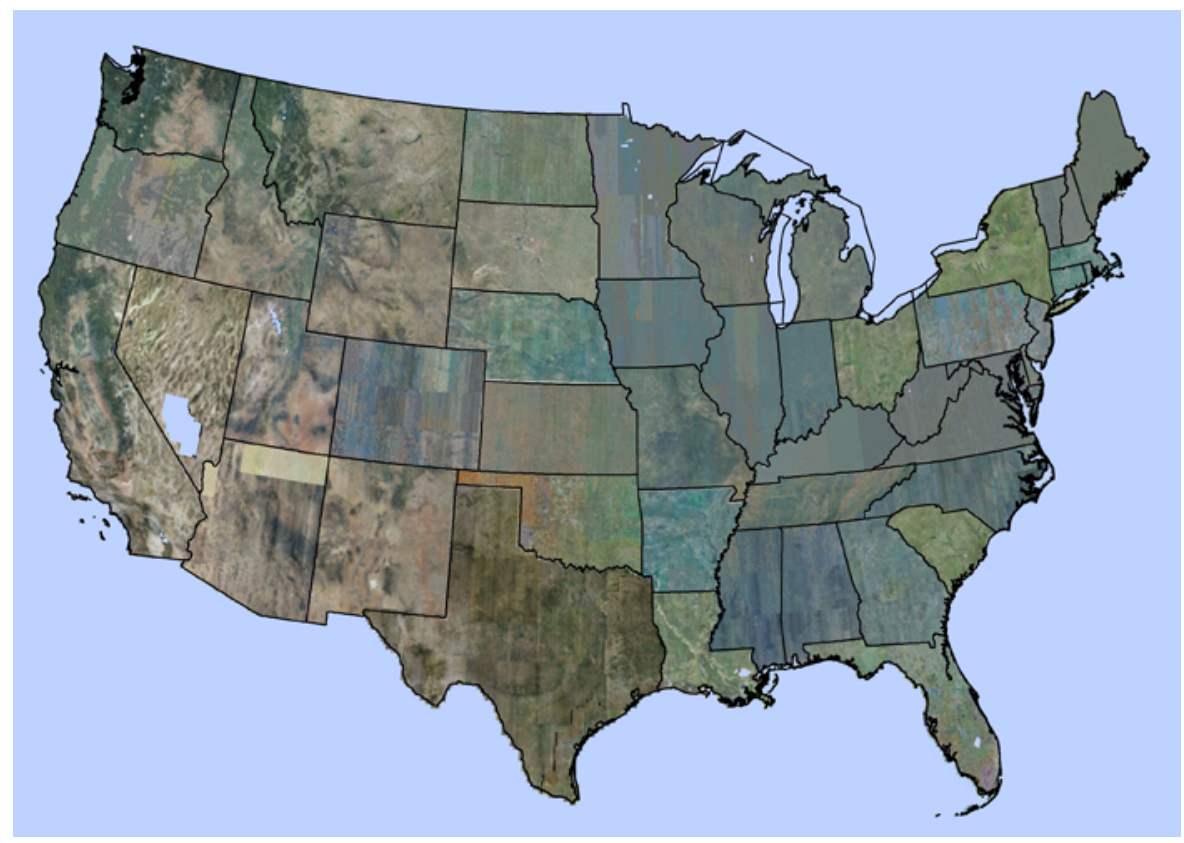

Figure 93. The map illustrates the coverage area in the continental 48 states of National Agriculture Imagery Program imagery.

\section{DATA.gov: Access to High Resolution Orthoimagery}

DATA.gov is an official website of the U.S. Government. The website allows users to query for many kinds of data available for public consumption. The USGS was tasked to populate the DATA.gov website with metadata records representing observational science records. As part of the task, EROS registered 72,000+ High Resolution Orthoimagery (HRO) files, and

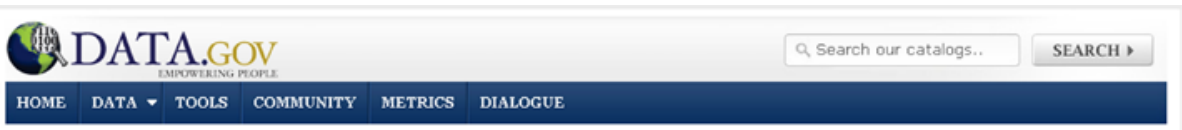

\section{Data.gov Catalogs}

Use the Data gov catalog below to access U. S. Federal Executive Branch datasets. Click on the name of a dataset to view additional netadata for that dataset. By accessing the data catalogs, you agree to the Data Policy. Data gov offers data in three ways: through the "raw" data catalog, using tools and through the geodata catalog. The "Raw" Data Catalog provides an instant download of machine readable, plattorm-independent datasets

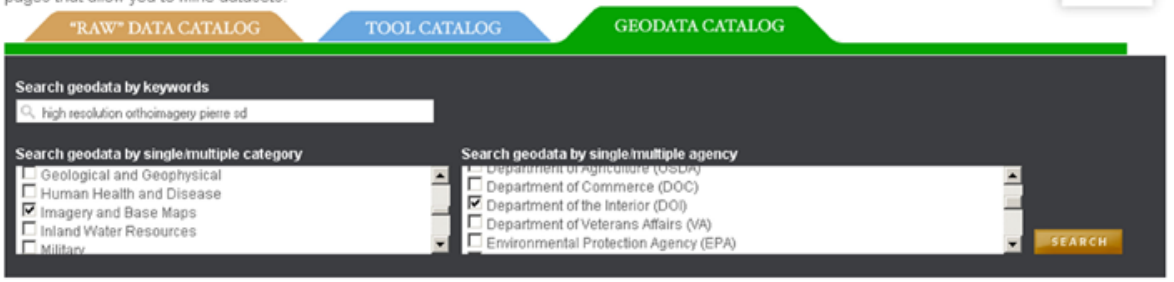

Page 1 of 10,149 (101,439 records) Q3 $1|2| 3|4| 5|6| 7|8| 9 \mid 1000$

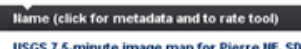

USGS 7.5. minute image map for Pierre Hif, so Image: Based 7.5 Minute Quadiangle Map.
ofthophoto image as

USGS High Resolution Orthoimagery for the Pierre, South Dakota Urban Area: 14TLO0960110_200504__ox3000m_ci

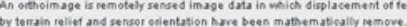

USGS High Resolution Orthoimagery for the Pierre, South Dakota Urban Area: 14TLO960095_200504_0x3000m_CL.

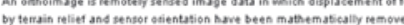
$1,000+$ Shuttle Radar Topography Mission files with DATA.gov.

This was accomplished by sending metadata records to the Environmental Systems Research Institute for registration in Geospatial One Stop (GOS). Once the metadata were registered in GOS, they were marked for inclusion in DATA.gov. Users now have the capability to search DATA.gov for High Resolution Orthoimagery and download the actual imagery of the search (figs. 94 and 95). EROS will continue to register metadata records in FY 2011. For further information, contact $\mathrm{S}$. Jean Paulson,Paulson@usgs.gov.

Figure 94. Search page at DATA.gov. 


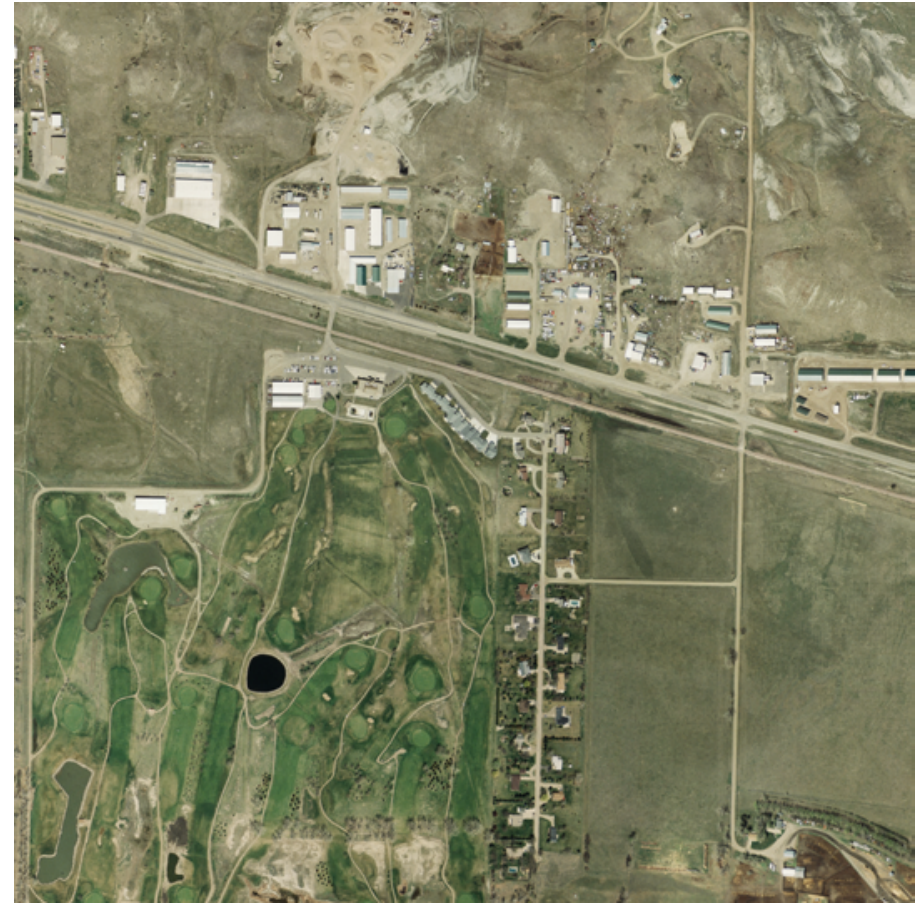

Figure 95. Downloaded image from search results. Pierre, South Dakota, 0.30-meter resolution natural color, April 2005 acquisition.

\section{Hazards Data Distribution System Graphical User Interface}

A new Hazards Data Distribution System graphical user interface (fig. 96) was developed and implemented in support of Emergency Operations. This interface offers a significant improvement in functionality from the previous system by giving users the capability to enter query criteria for their area of interest. The query can be selected by event, State and county, and/or by selecting a graphical area of interest. Other features include the capability of selecting ingested data and ad hoc data, the provision of a Rich Site Summary (RSS) feed, ability to refine the search results, and creation of an item basket. For further information, contact Wayne Miller, USGS EROS, wamiller@usgs.gov.

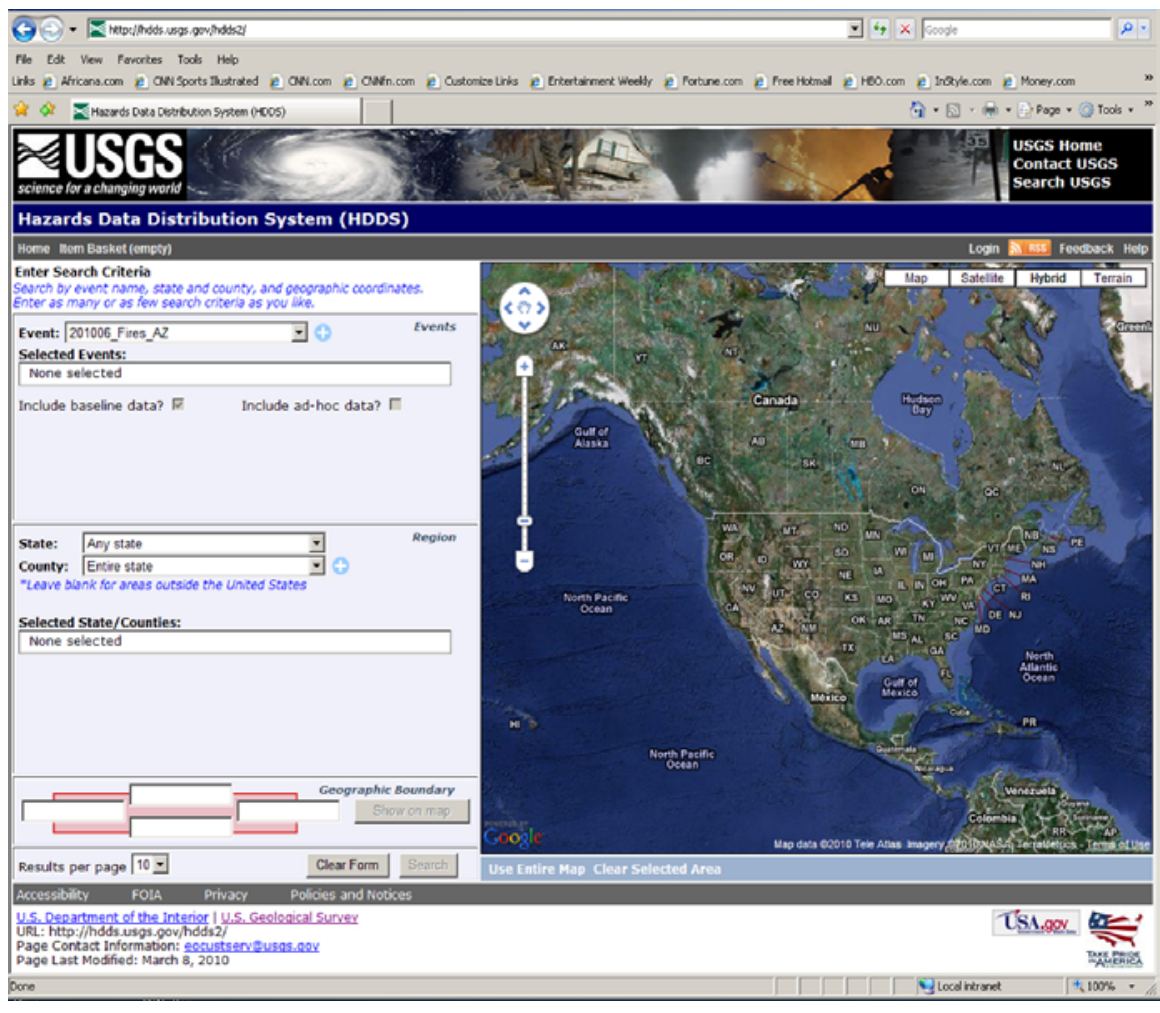

Figure 96. The new graphical user interface in the Hazards Data Distribution System. 


\section{New EarthExplorer Implementation}

The steadily increasing user demands for data, especially since offering all archive data at no-charge, prompted concerns about the scalability, performance, and overall architecture of the current EarthExplorer system. In addition, new support requirements for the upcoming Landsat platform presented an opportunity for the redesign of this interface. The new EarthExplorer system (fig. 97) will replace the current system with a distributable open source architecture that is designed to fulfill the mission requirements of the Long Term Archive and the Landsat Data Continuity Mission projects. It offers a scalable platform centered on new technology and framework design which will help to effectively meet future requirements for access and distribution into the future. For further information, contact Wayne Miller, USGS EROS, wamiller@usgs.gov.

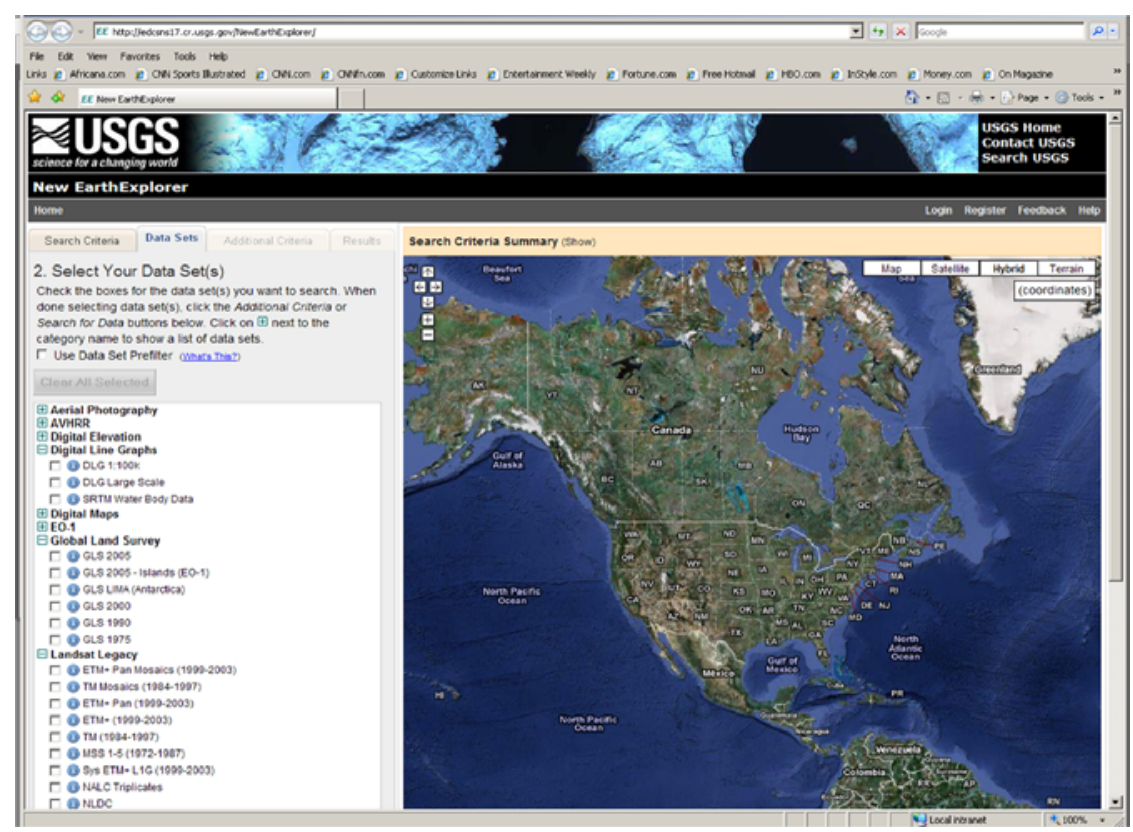

Figure 97. The new EarthExplorer System.

\section{SP0T 1-3 Historical Archive L1G Processing}

In 1999, the USGS EROS Center received, for archive purposes, satellite image data flown by the SPOT satellite systems. The USGS Satellite Pour l'Observation de la Terre (SPOT) archive contains North American coverage between 10 and 87 degrees north latitude acquired between 1986 and 1998 from SPOT 1, 2, and 3 satellites. Continuing work that began in FY 2009, the Long Term Archive project completed processing 615,000 additional FRED (Framed Raw Expanded Data) format images to

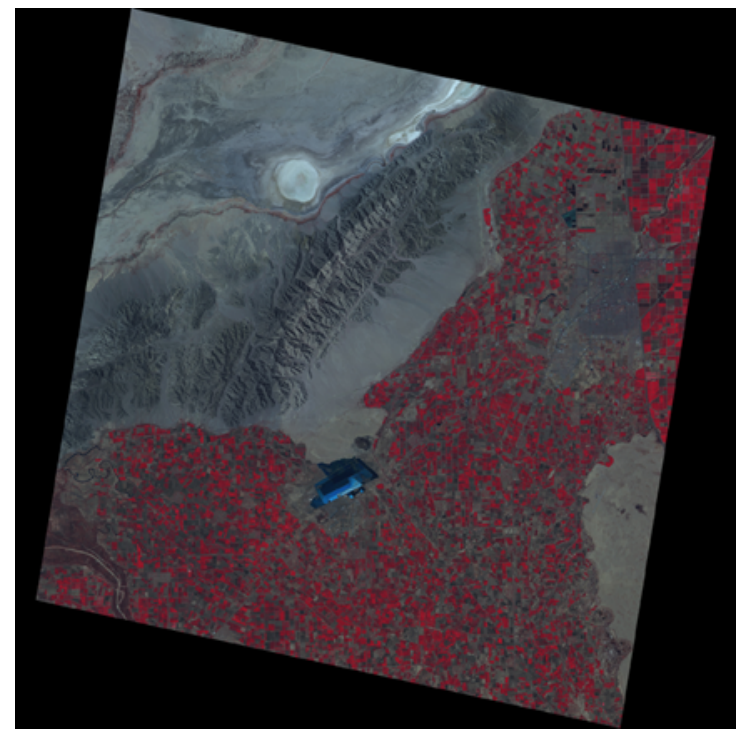
a L1G (systematic) GeoTIFF format. All processing was done through the National Landsat Archive Processing System (NLAPS). With the help of the Landsat project, NLAPS successfully processed a total of 814,424 images (fig. 98), all of which have been made available for download by authorized users. For further information, contact Wayne Miller, USGS EROS,wamiller@usgs.gov.

Figure 98. A sampling of one of the 814,424 images out of the SPOT 1,2, and 3 archive recently processed and now available for download by authorized users. (Copyright 2010 CNES Distribution Spot Image) 


\section{SPOT North America Data Buy}

In anticipation of a possible data gap before the Landsat Data Continuity Mission data arrival in late 2012, the USGS awarded a 1-year contract to Spot Image Corporation to receive moderate-resolution optical imagery (fig. 99) from the SPOT 4 and SPOT 5 satellites. The goal of the contract is to acquire and populate the archive with SPOT satellite coverage of the conterminous United States each month.

Starting in December 2009, USGS EROS began receiving SPOT imagery. Data acquisition relies on current antenna and data capture capabilities. Incoming scenes are processed to a L1A and L1Gst level in GeoTIFF format, and distributed at no charge via the Internet to U.S. Federal, civil, State, and local government users, per the licensing arrangements of the Data Buy contract. Data access is provided to registered users through USGS EarthExplorer (http://earthexplorer.usgs.gov). For further information, contact Wayne Miller, USGS EROS, wamiller@usgs.gov.

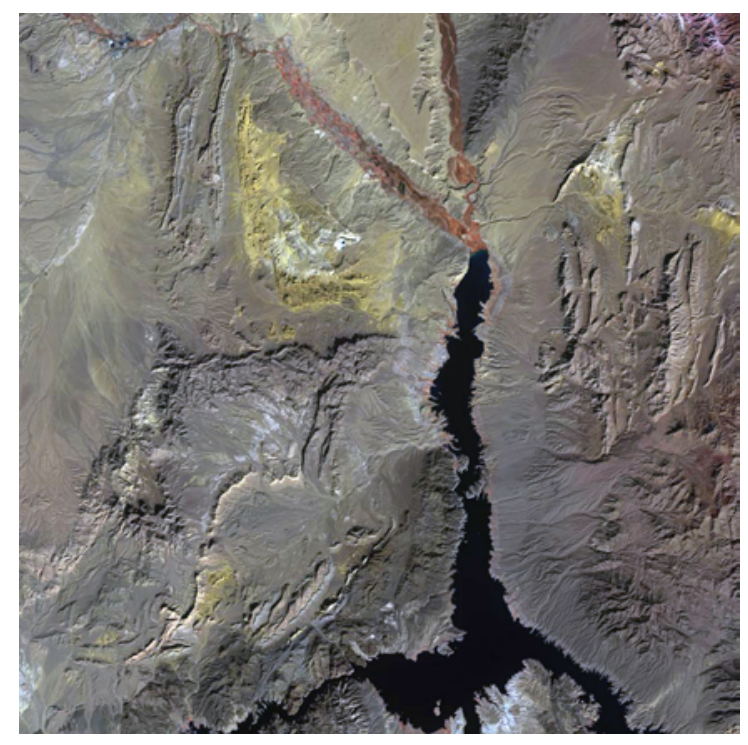

Figure 99. A sampling of the moderate-resolution optical imagery being received from the SPOT 4 and SPOT 5 satellites. (Copyright 2010 CNES Distribution Spot Image)

\section{Phoenix V Archive Scanning}

The objective of building and operating Phoenix V scanning systems was to create and web-enable a 25-micron digital copy of the USGS aerial film archives. Beginning with vinegar syndrome affected rolls, the Long Term Archive project is systematically generating a digital high-resolution copy of the entire USGS film collection.

Film scanning began in October 2009 with three systems operating 24 hours a day, 5 days a week. The fourth system was

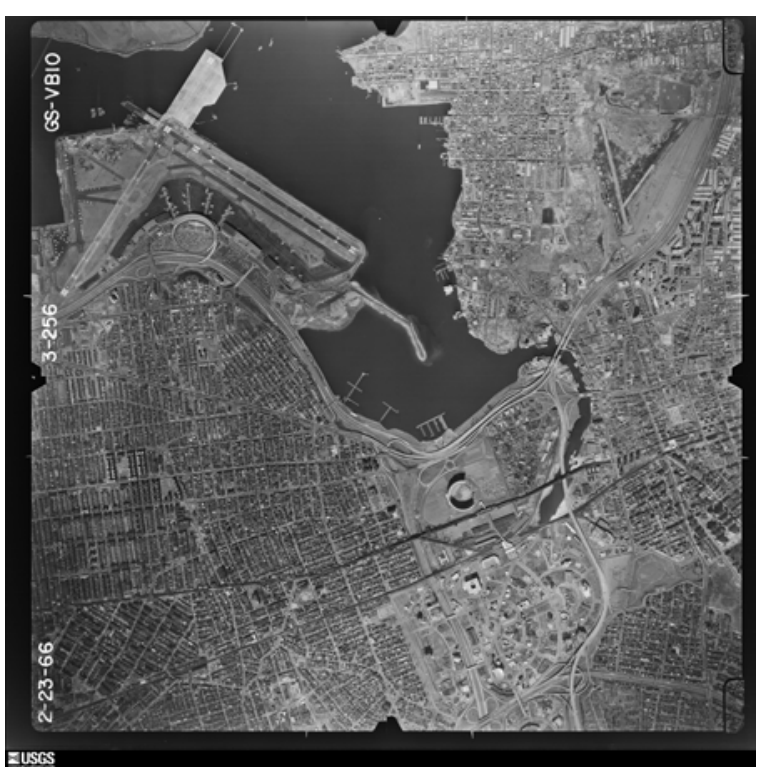
added in the first quarter, the fifth in the second quarter, and the sixth and final system in the fourth quarter of FY 2010. The production team averages digitizing more than 10,000 images a week. By the end of the third quarter, there were more than 260,000 images (fig. 100) scanned, archived, and made available for download at no charge via the Internet. For further information, contact Wayne Miller, USGS EROS, wamiller@usgs.gov.

Figure 100. A sampling of one of the $260,000+$ digital high-resolution images that originated from the USGS film collection that was scanned, archived, and made available for download. 


\section{eMODIS System Enhancements Support New Users}

NASA's MODIS is used to provide a range of land process products for the land science community, including vegetation indices (VI) such as the normalized difference vegetation index (NDVI) and enhanced vegetation index (EVI). The terrestrial monitoring community has been using MODIS data extensively since its release in 2000. The enhanced MODIS (eMODIS) production system was developed as an expedited VI time series delivery capability to replace the EROS Direct Broadcast System in 2006. To date, VI time series products have been developed for the conterminous United States and Alaska, including historical and forward processing of precision VI products and expedited products for CONUS. Beneficiaries of the eMODIS products include other USGS projects, such as drought monitoring and ecosystem performance modeling, and external agencies such as the U.S. Department of Agriculture, the Bureau of Land Management, and various other agencies throughout the conterminous United States and Alaska.

In FY 2010, the eMODIS product suite was both expanded geographically in scope and ported to a new processing framework. The USGS component of U.S. Agency for International Development's (USAID's) Famine Early Warning System (FEWS) formalized a product stream developed for the Haiti/Caribbean region and developed a new product stream for Africa (fig. 101). For each of these, historical VI time series (from 2000 to the present) were produced, and forward precision and expedited product streams were initiated for ongoing delivery. Conterminous U.S. and Alaska production also continued during FY 2010.

The older eMODIS system used lower level (L1B) MODIS data to produce surface reflectance and subsequent VIs (NDVI, VI) to be made into composites for varying time intervals. The new system exploits swath-based (Level 2) surface reflectance inputs from NASA's LAADS (Level 1 and Atmospheric Distribution System) for precision historical and forward processing, reducing production costs, and producing eMODIS products, which are more directly traceable back to standard MODIS surface parameters. As well, the new system uses Level 2 surface reflectance products from NASA's Land and Atmosphere Near real time Capability for EOS (LANCE) for the expedited VI streams. The system software was streamlined and ported to a clusterbased architecture for improved scalability, upgradeability, reliability, and performance. For further information, contact David Meyer, USGS EROS,dmeyer@usgs.gov.
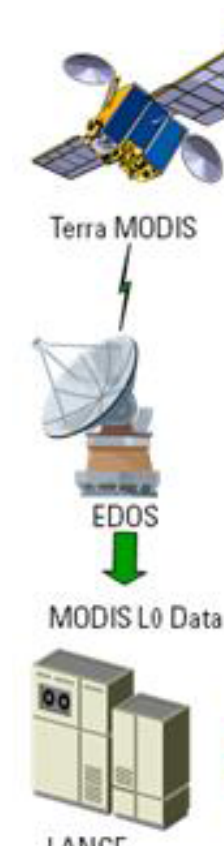

LANCE
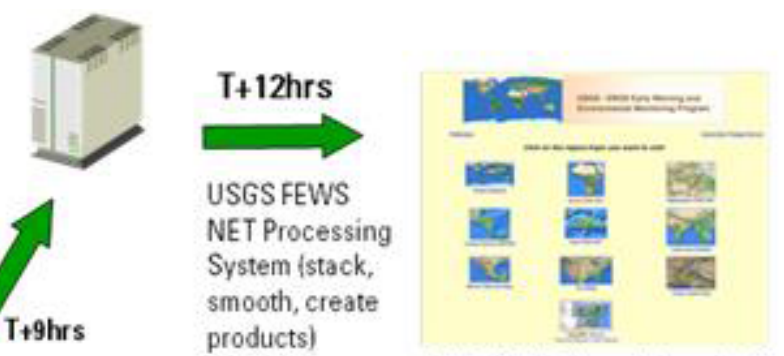

products)
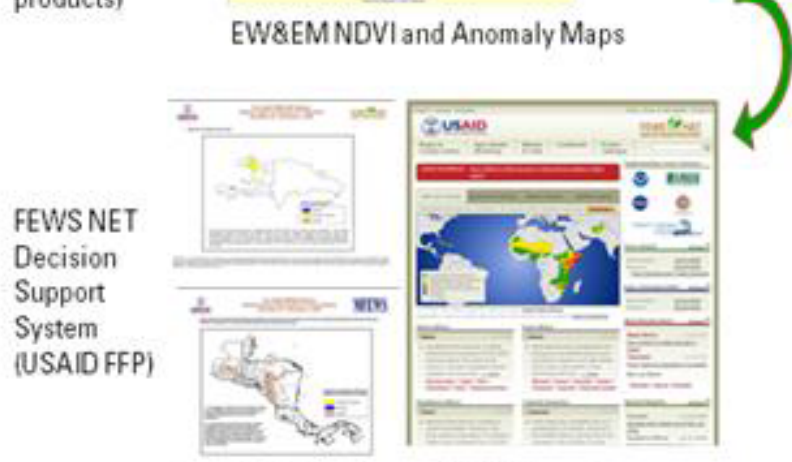

Input Data Deadline: FEWS Impact

Tuesday 10:00 a.m. Assessment Maps

Figure 101. Famine Early Warning System implementation of LANCE-based eMODIS expedited VI time series.

\section{NASA EOS Terra Mission Celebrates 10 Years at LP DAAC}

The NASA's Land Processes Distributed Active Archive Center (LP DAAC) located at the USGS EROS Center celebrated 10 years of providing land data products from instruments aboard the Earth Observing System (EOS) Terra spacecraft. These products, derived from the Moderate Resolution Imaging Spectroradiometer (MODIS) and Advanced Spaceborne Thermal 
Emission and Reflection Radiometer (ASTER), were first released publicly from the LP DAAC in 2000.

December 18, 2009, marked the 10th year since the launch of Terra, one of NASA's "flagship" Earth observing satellites. But the decade is more than just a mechanical milestone. With each additional day and year that the satellite monitors Earth, scientists achieve a lengthened record of Earth's vital signs. It's that record that helps scientists assess the health of Earth's ocean, land, and atmosphere, and determine how these systems are changing.

Since the public release in 2000, more than 98 million Terra data files have been distributed from the LP DAAC to the public. The mission was celebrated at EROS during August 2010 with a lobby display of earth science applications which, through the past 10 years, have benefitted from these MODIS and ASTER products. For further information, contact Thomas Sohre, USGSEROS, tsohre@usgs.gov.

\section{LP DAAC Moves Entire Archive Online}

As part of the NASA Earth Science Data and Information System (ESDIS) evolution and efficiency efforts, ESDIS has delivered a capability to store the holdings of all ASTER and MODIS datasets on spinning disk in the Land Processes Distributed Active Archive Center (LP DAAC) located at EROS. This archive today totals 1.1 petabytes (PB), with calendar year 2010 volume of more than 1.8 PB of disk space available for online storage of ASTER and MODIS product lines.

This online technology implementation has enabled the LP DAAC to remove 3 tape silos from our system architecture (fig. 102). The online architecture has also allowed the EOS Project to condense the footprint of computer room floor space holding the ESDIS Core System by half from 2007.

This capability also allows for a large number of possibilities in how to service our customer's remote sensing needs from the available archive. The EOS Project along with NASA ESDIS is working on modifications to system architecture and clients to leverage this new capability related to how the archive is searched, results are displayed, and the EOS data are downloaded. EOS Project results suggest that LPDAAC data distribution will continue to increase as the archive grows and the system architecture is modified to enable data to become more accessible under an on-demand model (fig. 103). For further information, contact Thomas Sohre, USGS EROS, tsohre@usgs.gov.

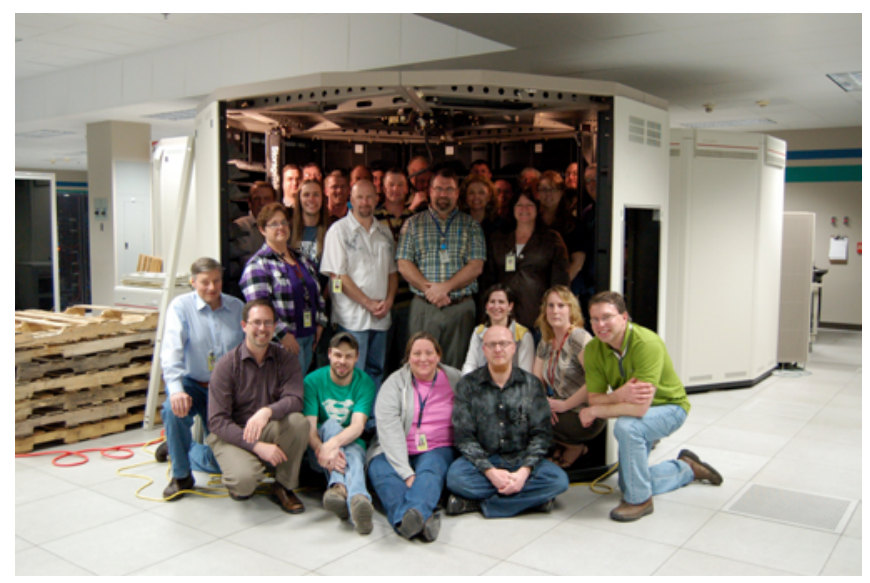

Figure 102. Land Processes Distributed Active Archive Center team shown inside and alongside one of the three tape silos removed from the system architecture.

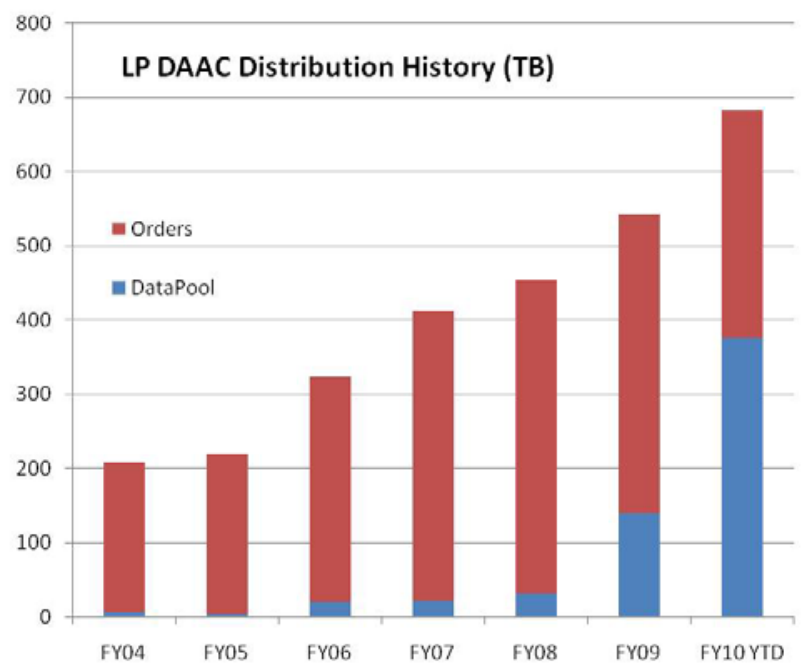

Figure 103. Trends indicate Land Processes Distributed Active Archive Center data distribution will continue to increase as the archive grows and is available on demand.

\section{LP DAAC Supports Emergency Response Activities}

NASA's Land Processes Distributed Active Archive Center (LP DAAC) located at EROS supported a number of emergency response activities in FY 2010 with Moderate Resolution Imaging Spectroradiometer (MODIS) and Advanced Spaceborne Thermal Emission and Reflection Radiometer (ASTER) data.

The California Station Fire: On August 26, 2009, the Station Fire, caused by arson, spread in the Angeles National Forest and San Gabriel Mountains north of Los Angeles, California (fig. 104). More than 160,000 acres had burned by the morning of September 9, with associated loss of life, destruction of numerous buildings, and threat to about 4,000 structures. Key commu- 
nication equipment and facilities on Mount Wilson were threatened, including the world-renowned astronomical observatory. Nearly 4,500 individuals were assembled to combat the blaze, at a cost of more than $\$ 70$ million for just the first two weeks of firefighting. NASA Earth Observing System satellites acquired data used to characterize the extent of the burned regions and the threat posed to adjacent areas. The ASTER and the MODIS instruments provided timely information for analysis.

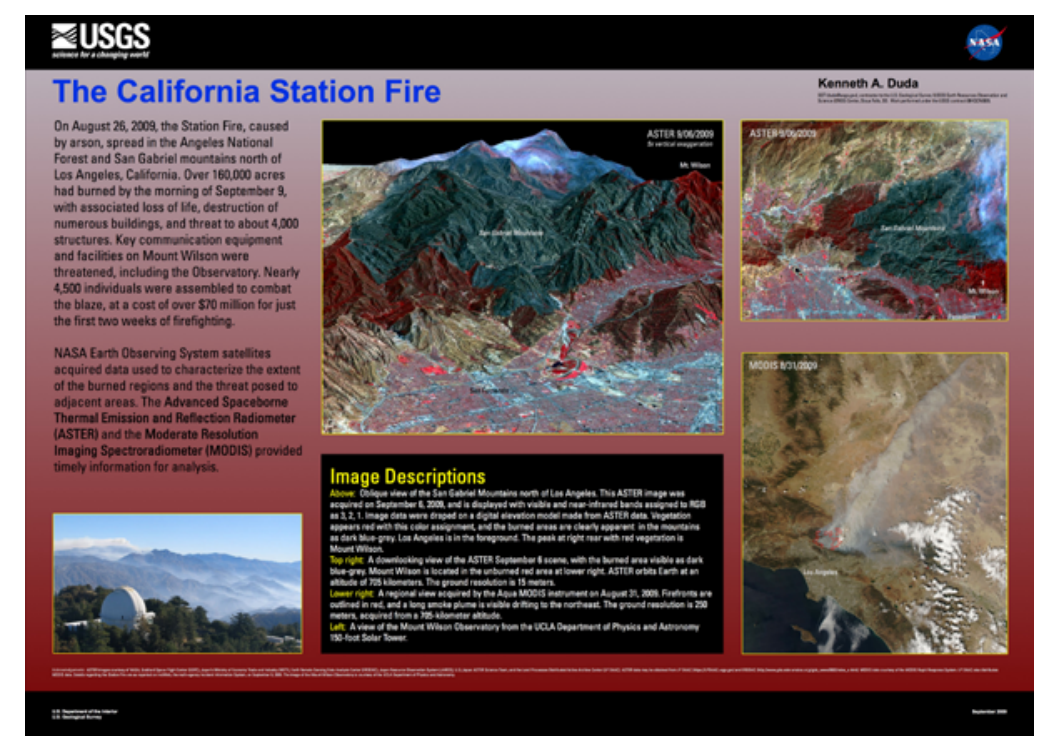

Figure 104. Land Processes Distributed Active Archive Center (LP DAAC) Advanced Spaceborne Thermal Emission and Reflection Radiometer (ASTER) California Station Fire poster.

Flooding Traps Travelers at Machu Picchu, Peru: Fatalities, severe flooding, landslides and extensive destruction occurred because of heavy wet-season rainfall in southern Peru during January 2010. Thousands of residents in Cusco were left homeless.
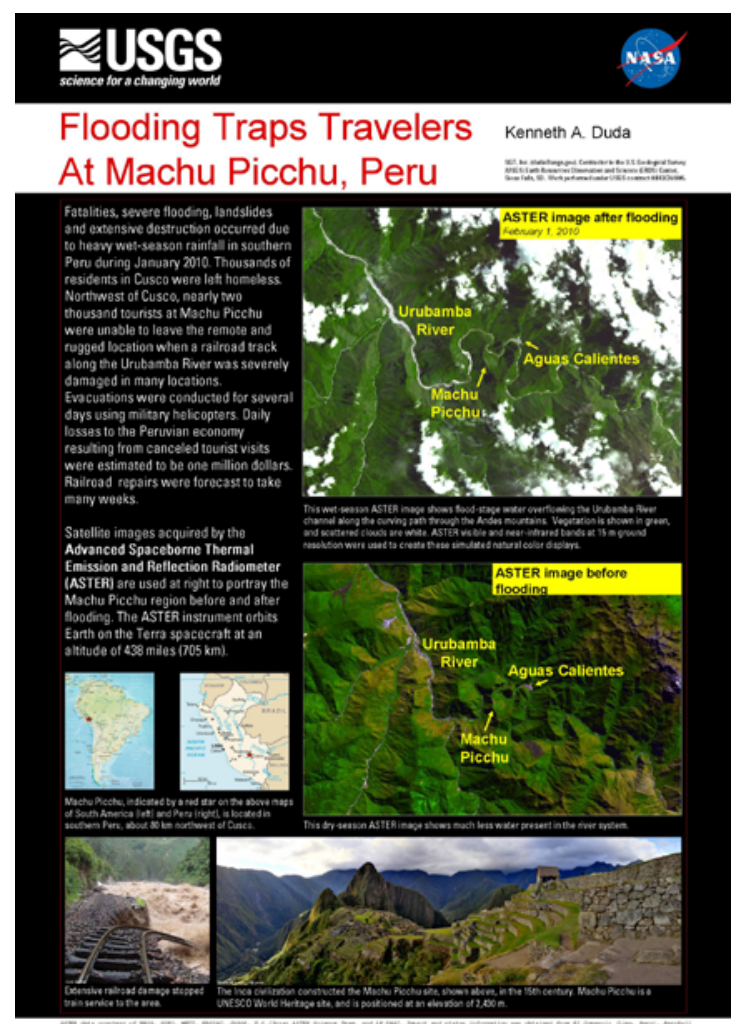

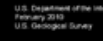

Northwest of Cusco, nearly 2,000 tourists at Machu Picchu were unable to leave the remote and rugged location when a railroad track along the Urubamba River was severely damaged in many locations. Evacuations were conducted for several days using military helicopters. Daily losses to the Peruvian economy resulting from canceled tourist visits were estimated to be $\$ 1$ million. Railroad repairs were forecast to take many weeks. Satellite images acquired by ASTER were used to portray the Machu Picchu region before and after flooding (fig. 105). The ASTER instrument orbits Earth on the Terra spacecraft at an altitude of 438 miles (705 kilometers).

Figure 105. Land Processes Distributed Active Archive Center (LP DAAC) Advanced Spaceborne Thermal Emission and Reflection Radiometer (ASTER) Machu Picchu, Peru, poster. 
Eyjafjallajökull Volcano, Iceland: A renewed eruptive period at Eyjafjallajökull Volcano commenced in March 2010. The plume posed significant risk to aviation and resulted in numerous flight cancellations throughout an extended period. The NASA Earth Observing System Terra satellite, launched in December 1999, continues to provide exceptional images of the Earth for scientific analysis. Land data from ASTER and MODIS on Terra revealed the status of volcanic activity on April 19, 2010. An ASTER thermal infrared (TIR) band was used to identify the hotter areas. In addition to providing temperatures, ASTER TIR

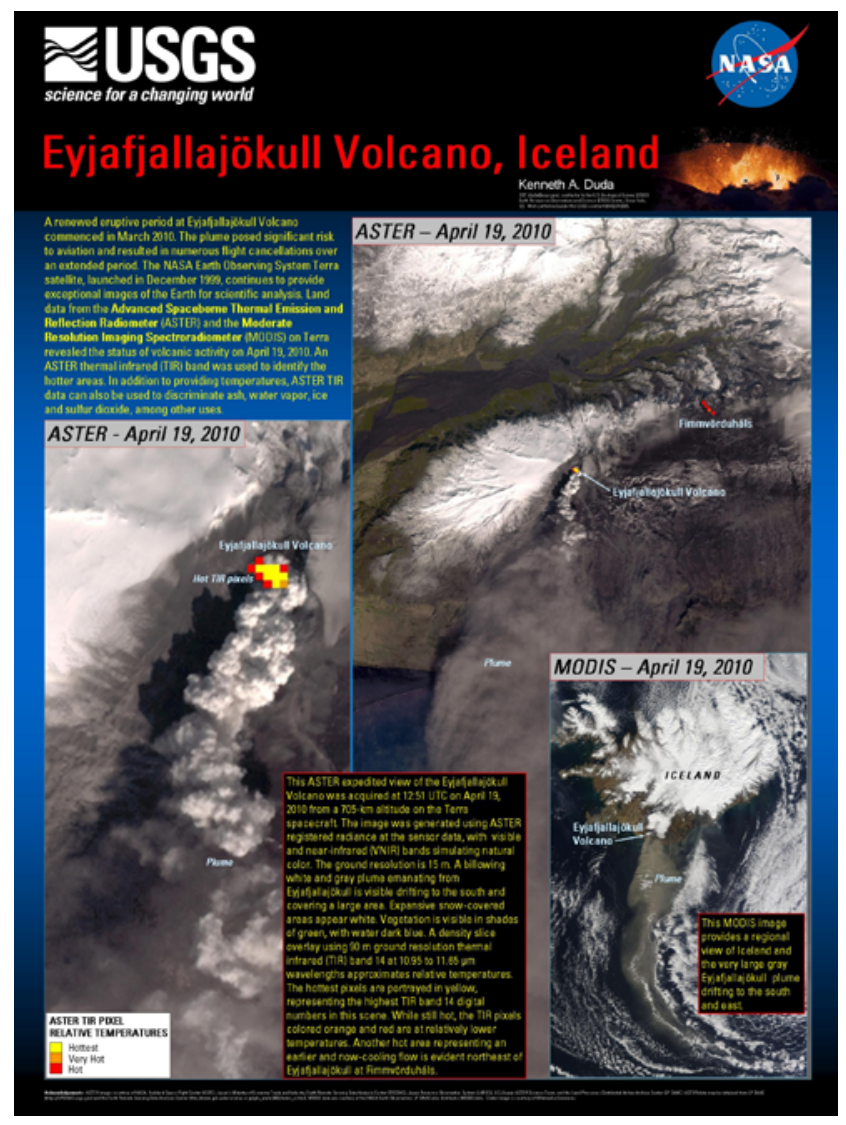
data can also be used to discriminate ash, water vapor, ice and sulfur dioxide, among other uses. An ASTER expedited view of the Eyjafjallajökull Volcano was acquired at 12:51 Coordinated Universal Time (UTC) on April 19, 2010, from a 705-kilometer altitude on the Terra spacecraft (fig. 106). The image was generated using ASTER registered radiance at the sensor data, with visible and near-infrared (VNIR) bands simulating natural color. The ground resolution is 15 meters. A billowing white and gray plume emanating from Eyjafjallajökull is visible drifting to the south and covering a large area. Expansive snow-covered areas appear white. Vegetation is visible in shades of green, with water dark blue. A density slice overlay using the 90 -meter ground resolution thermal infrared (TIR) band 14 at 10.95 to 11.65 micrometer $(\mu \mathrm{m})$ wavelengths approximates relative temperatures. The hottest pixels are portrayed in yellow, representing the highest TIR band 14 digital numbers in this scene. While still hot, the TIR pixels colored orange and red are at relatively lower temperatures. Another hot area representing an earlier and now-cooling flow is evident northeast of Eyjafjallajökull at Fimmvörduháls.

Figure 106. Land Processes Distributed Active Archive Center (LP DAAC) Advanced Spaceborne Thermal Emission and Reflection Radiometer (ASTER) Eyjafjallajökull Volcano, Iceland, poster.

Louisiana Oil Spill: The ASTER and MODIS instruments on Terra provided a lengthy series of imagery of the U.S. Gulf Coast region affected by the Deepwater Horizon oil spill. From the commencement of the event through mid-July 2010, 20 ASTER expedited taskings were scheduled in support of this activity. For further information, contact Thomas Sohre, USGS EROS, tsohre@usgs.gov.

\section{LP DAAC Develops ASTER GDEM Case Study}

The Land Processes Distributed Active Archive Center (LP DAAC) developed a case study of the ASTER Global DEM (GDEM) in support of the Group on Earth Observations (GEO) Data Sharing Task Force (DSTF). The DSTF is moving toward the GEO Plenary and Ministerial with an Action Plan. Supporting documents included eight case studies, of which the ASTER Global DEM is one.

The Advanced Spaceborne Thermal Emission and Reflection Radiometer (ASTER) remote sensing instrument on the Terra spacecraft has been acquiring images of Earth since it was launched in 1999. Throughout this time, data products have been openly available to the general public through sites in the United States and Japan. However, the release of a new product, the ASTER Global Digital Elevation Model (GDEM), has dramatically increased usage of ASTER data worldwide (fig. 107).

The GDEM was contributed by Japan's Ministry of Economy Trade and Industry (METI) and NASA to the Global Earth Observation System of Systems (GEOSS) for distribution at no cost to users via electronic download from the Earth Remote Sensing Data Analysis Center (ERSDAC) of Japan and from NASA's LP DAAC.

The release of the global tiled research-grade DEM resulted in a significant increase in demand for ASTER elevation models and increased awareness of related products. No-cost access to these data has also promoted new applications of remotely sensed data, increasing their use across the full range of the GEOSS societal benefit areas. The ASTER GDEM demonstrated the need and user demand for a global DEM product as well as the added benefit of not only "full and open" distribution but "free and open" distribution. 
During the first three months after product release, more than 4 million GDEM tiles were distributed from the LP DAAC and ERSDAC. The ASTER GDEM release generated nearly 20,000 new user registrations in the NASA ECHO/WIST (EOS ClearingHOuse/ Warehouse Inventory Search Tool) and the ERSDAC systems. By the end of 2009, more than 6.5 million GDEM tiles were distributed by the LP DAAC and ERSDAC. Users have requested tiles for specific areas of interest as well as the entire dataset for global research.

Intense global interest in the GDEM across all the GEOSS societal benefit areas was shown. The volume of GDEM distribution can be directly attributed to the adoption of fundamental GEOSS data sharing principles, which are directed toward expanded access by minimizing time delay and cost, thus facilitating data use for education, research, and a range of other applications. For further information, contact Thomas Sohre, USGS EROS, tsohre@usgs.gov.

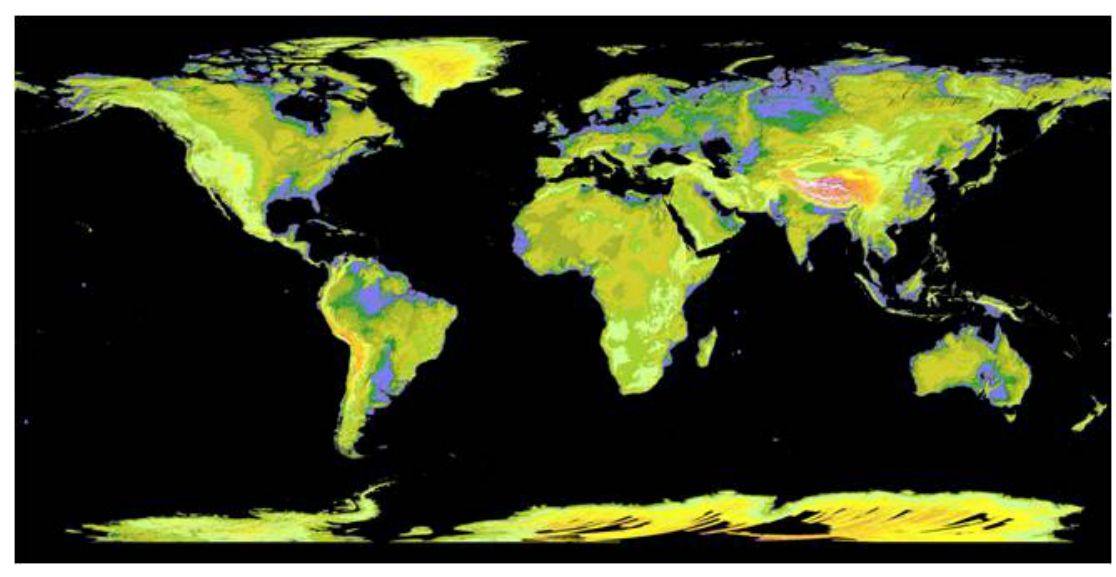

Figure 107. ASTER global digital elevation model visualization.

\section{Interagency Agreement Signed for FY 2010-14 Operation of LP DAAC at EROS}

The U.S. Department of the Interior (DOI) USGS EROS Center is currently managing and operating the Land Processes Distributed Active Archive Center (LP DAAC) in support of NASA requirements for the Earth Observing System Data and Information System (EOSDIS) devoted to the collection, processing, archiving, and distribution of land processes data.

For FY 2010, the DOI and USGS signed a follow-on agreement with NASA for the operations and maintenance of the LP DAAC at EROS during fiscal years 2010 through 2014. This agreement has existed since the mid-1990s and currently provides for robust ingest, archive, storage, and distribution capabilities. The LP DAAC is responsible for distributing more data than any other project within the USGS EROS and is proud to be recognized by NASA as a strong and supportive organization that fulfills the Earth Science Data and Information System (ESDIS) 2015 Vision Tenets.

NASA Earth Observing System (EOS) is a long-term, interdisciplinary, and multidisciplinary research mission to study global-scale processes that shape and influence the Earth as a system. The EOS mission is partially accomplished through the provision of a comprehensive data and information system to provide the earth science research community with easy, affordable, and reliable access to the EOS and other appropriate earth science data. For further information, contact Thomas Sohre, USGSEROS, tsohre@usgs.gov.

\section{Distribution of Earth Science Data}

EROS distributes approximately 200-250 terabytes (TB), or 200,000-250,000 gigabytes, of earth science data monthly. Of this total, an average of $50 \mathrm{~TB}$ is distributed via individual hard drives and the remainder is transferred via a high-speed network.

On average, EROS receives and distributes about one-half of all network traffic transferred through the Department of the Interior's four primary nodes serving the Department's 70,000 employees and contractors. The nodes are located in Reston, Virginia; Denver, Colorado; Menlo Park, California; and Sioux Falls, South Dakota. The Reston node serves approximately 35,000 users, whereas the Sioux Falls node serves less than 1,000. This suggests a substantial portion of the traffic at other nodes comprises incoming electronic mail and browser data, in contrast to the vast majority of Sioux Falls traffic being earth science data distributed worldwide. The pie chart (fig. 108) shows the quantity and percentage of traffic through the four nodes for a recent month.

The bar charts (figs. 109 and 110) depict the increasing inflow and distribution of earth science data for the last 8 years. The total incoming and outbound data flow is shown in figure 109; figure 110 shows outbound data only. The reduction in inbound 
data is due primarily to adoption of data compression techniques for data received by the Land Processes Distributed Active Archive Center, which ingests data from NASA's Earth Observing System satellites. The upturn of inbound data in 2010 reflects USGS Landsat data received from the Alaskan ground station. The first Landsat web-enabled datasets began to be distributed in 2008, and growth in user demand and data availability account for the tripling of outbound data volume. For further information, contact John Boyd, USGS EROS, boyd@usgs.gov.

DOI Gateway Traffic - August 2010 (in TB)

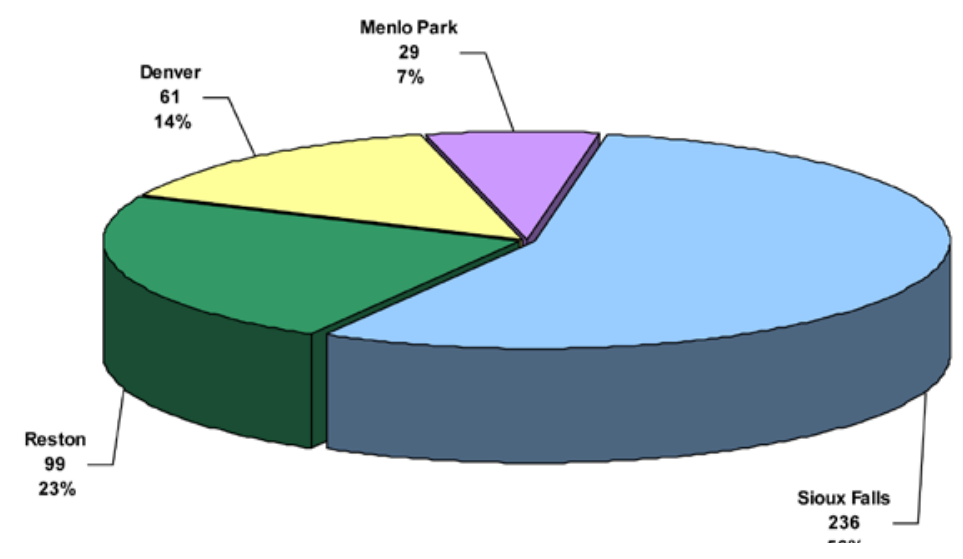

Figure 108. Quantity and percentage of traffic through DOI's four nodes for August 2010.
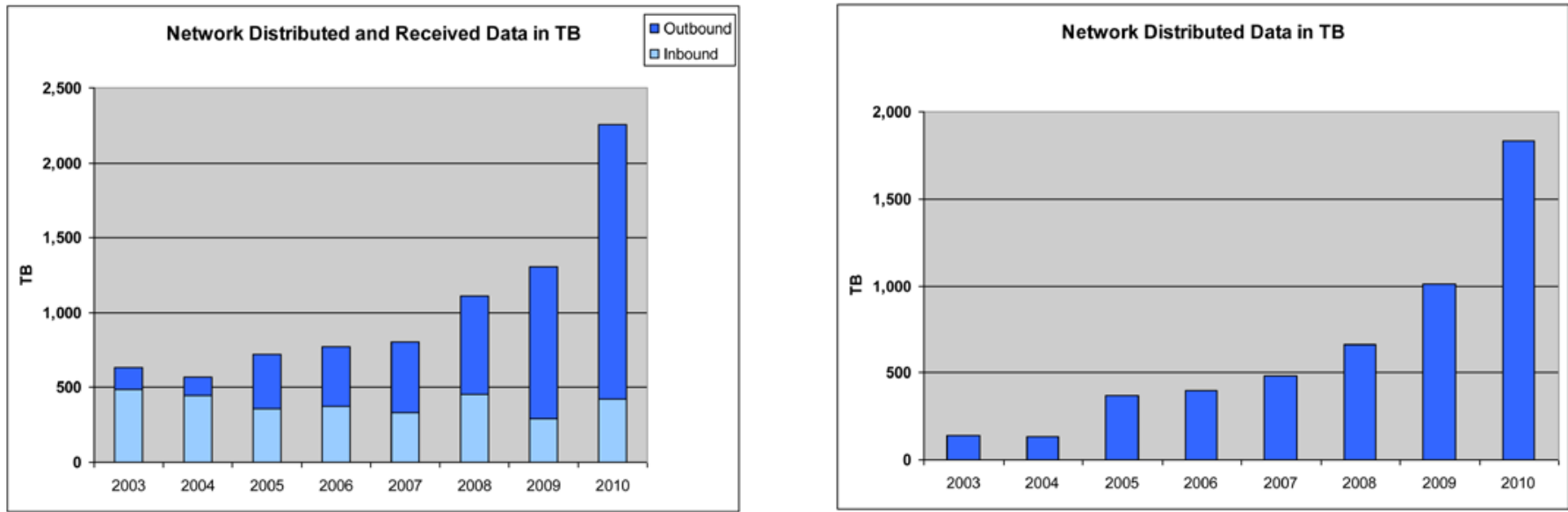

Figure 109. Total inbound and outbound data flow for the past 8 years.

Figure 110. Total outbound data only for the same time period.

\section{Archive Strategic Direction Committee}

The Archive Strategic Direction Committee, sponsored by the Land Remote Sensing Program and the EROS Director, recommended including the Large Format Camera collection to the National Satellite Land Remote Sensing Data Archive. The Committee also endorsed the Air Photo Scan Rate Review Team work that led to the EROS Science Branch evaluating 34 locations of multiple scanning rates and selecting 25 microns as the level that best captures the necessary land research information. For further information, contact John Faundeen, USGS EROS, faundeen@usgs.gov.

\section{Scientific Records Appraisal}

Significant work was accomplished this fiscal year in terms of reviewing earth observation collections housed at or offered to EROS. The 14 collections appraised included:

- Arc Digitized Raster Graphics

- Controlled Image Base 
- For Official Use Only DOQs

- GeoEye OrbView-3

- NASA Ames Aerial

- NASA Johnson Aerial

- NASA Marshall Aerial

- NASA Wallops Island Aerial

- NASA Stennis Aerial

- NASA Kennedy Aerial

- DoD Army Aerial

- DoD Air Force Aerial

- DoD Navy Aerial

\section{DoD Corps of Engineers Aerial}

A professional paper was published entitled, "Appraising U.S. Geological Survey Science Records" in Archival Issues, the journal of the Midwest Archives Conference. The paper detailed the USGS EROS Scientific Records Appraisal Process including our results to date. For further information, contact John Faundeen, USGS EROS, faundeen@usgs.gov.

\section{Represent USGS Records Management}

Several forums were exploited to represent USGS Records Management in FY 2010. Brief summaries of the more significant events are included:

A USGS-National Archive and Records Administration (NARA) Memorandum of Understanding (MOU) meeting held at the NARA headquarters involved senior management from NARA, the USGS Geography Discipline, and the EROS Director. Discussions included the way forward for topics included in the $2008 \mathrm{MOU}$. These discussions led to subsequent strategies being developed at EROS that accomplish multiple points addressed in the MOU leading to the completion of the Geography Scientific Records Disposition Schedule, which has been under review by NARA since 2005.

Records management training was co-provided to headquarters staff and Water Science Center personnel in San Antonio, TX; San Diego, CA; and Austin, TX. New EROS Government and contract personnel were also provided an introduction to Records Management with an emphasis on record-keeping responsibilities. A presentation was given in concert with the USGS Records Managers from headquarters and the Western Region at the ITEM2010 Conference.

A presentation entitled "Ensuring Geospatial Records Viability Through Time" was presented at the American Society for Photogrammetry and Remote Sensing (ASPRS) Annual Conference. The ASPSRS Digital Preservation and Archive Committee focused on ways the Committee could better serve its members.

An invited paper entitled "Archiving Strategy for USGS EROS Center and Our Future Direction" was presented at the National Institute of Standards and Technology during the U.S. Workshop on the Road for Digital Preservation Interoperability Framework.

Participated in an invitation-only workshop sponsored by the Library of Congress. The focus of the workshop was digital preservation best practices. Attendees included the National Archives and Records Administration, the Environmental Protection Agency, the Census Bureau, the National Oceanographic and Atmospheric Administration, and several universities.

Completed an extensive survey, in-person follow-up, and attended a workshop for a European Space Agency initiative to determine best practices for archiving Earth Observation records.

Invited to participate in the Library of Congress sponsored 2010 Digital Preservation Partners Meeting. The topics addressed included the role of collaboratives in promoting digital preservation, the challenges of preserving social media content, and issues going beyond archiving.

Participated in the Scientific Data Management (SDM) for Government Agencies Workshop to Improve SDM. Karen Siderelis from the Department of the Interior was a speaker at the event.

For further information, contact John Faundeen, USGS EROS, faundeen@usgs.gov. 


\section{USGS Data Rescue Initiatives}

Along with the Long-Term Archive Project, staff facilitated the first shipment of acetate-base (vinegar syndrome-affected) film to the National Archives and Records Administration. This preservation effort began several years ago and will take multiple years to complete.

Staff briefed the Geographic Information Office National Leadership Team on the USGS Data Rescue initiative documenting the efforts to date as well as documenting the tremendous need expressed by our scientists.

Staff compiled the FY 2010 USGS Data Rescue submissions by Discipline, coordinated rankings by the individual Disciplines, and assisted in the disbursement of more than $\$ 400,000$ in grants to scientists preserving and making more accessible our legacy science records. Through strong support provided by the Geographic Information Office, substantially more projects were funded this year than any other since the initiative began in FY 2007. For further information, contact John Faundeen, USGS EROS,faundeen@usgs.gov.

\section{EROS History Project}

A concerted effort by a small team of employees resulted in an internal EROS website dedicated to the history of the EROS Program and Center. Documents, still pictures, and movies have been assembled or scanned with many more planned. Several thousand files have been gathered to date and approximately 50,000 slides were reviewed by the team. Historical files dating to the early 1970s are now accessible. For further information, contact John Faundeen, USGS EROS, faundeen@usgs.gov.

\section{Consolidated Archive and Distribution Data Report: A Monthly “Consolidated Report” for All Data Managed and Distributed at EROS}

Working with input from projects, EROS prepared a report template to be used by the projects for inputting their respective data. The template has been reviewed by the projects and the USGS Land Remote Sensing Program. The report provides statistics in terabytes distributed and data managed in FY 2010.

Data distributed and managed for all projects, showing both monthly and cumulative totals is shown in figures $111-114$. Data distributed and managed are shown in figures 115-124 for the following groupings:

- Landsat (figs. 115-116)

- LP DAAC (figs. 117-118)

- Other Satellite (figs. 119-120)

- Non-Satellite (figs. 121-122)

- Geospatial (figs. 123-124) including Orthoimagery, Elevation, Land Cover, and Other

For further information, contact John Faundeen, USGS EROS, faundeen@usgs.gov.

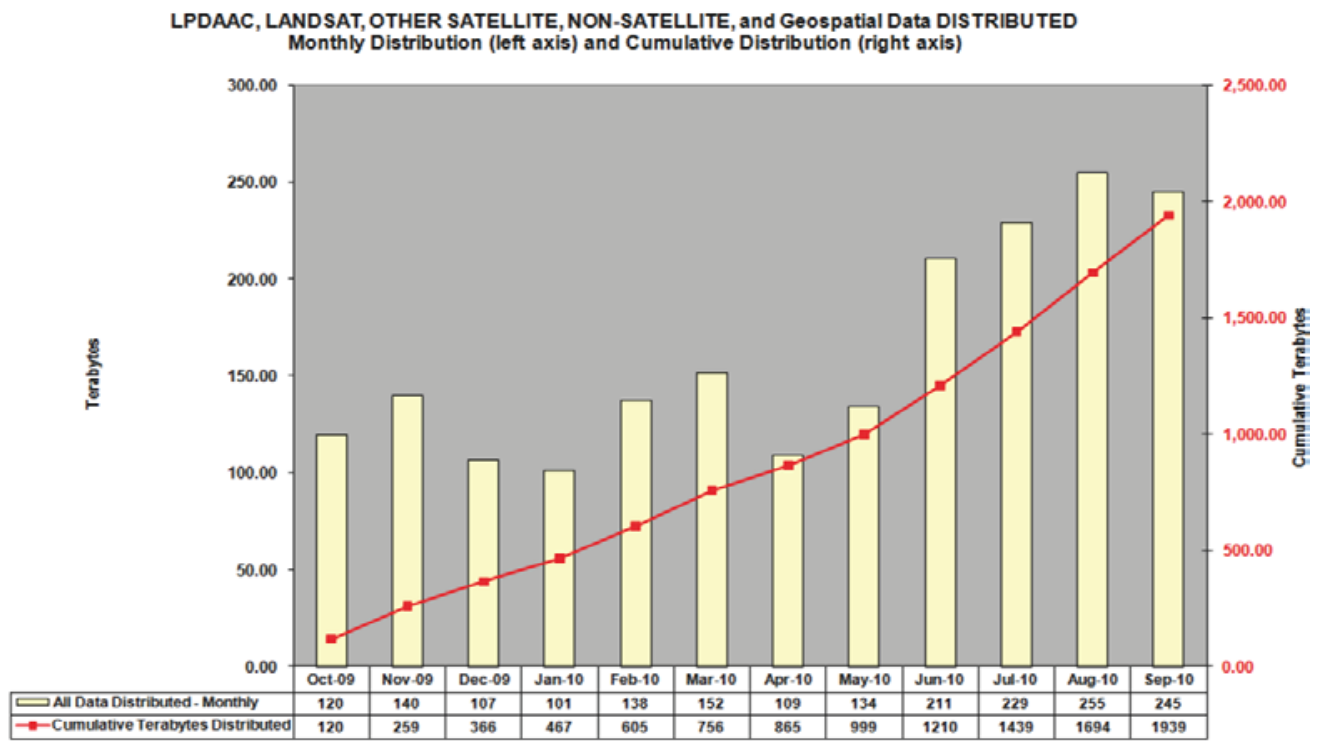

Figure 111. Fiscal year 2010 Land Processes Distributed Active Archive Center, Landsat, other satellite, non-satellite, and geospatial data distributed. 


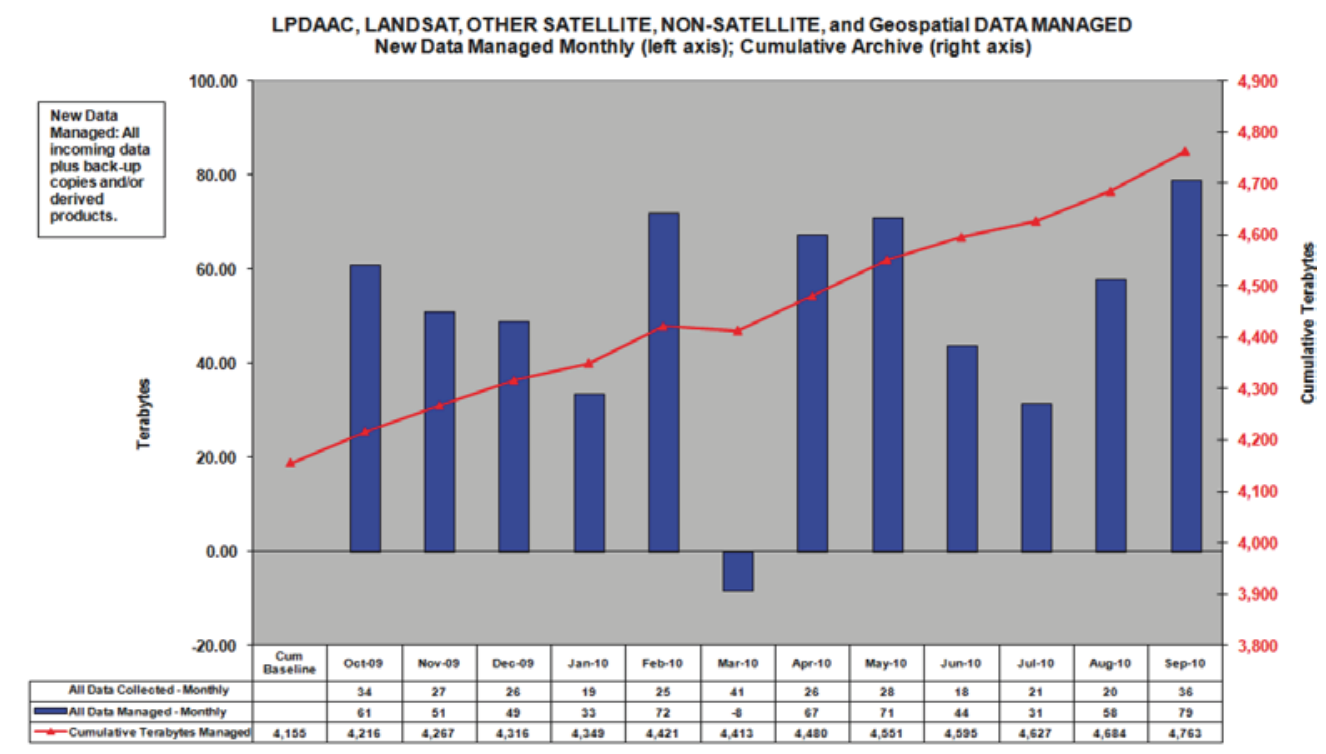

LPDAAC, LANDSAT, OTHER SATELLITE, NON-SATELLITE and Geospatial DATA DISTRIBUTED Monthly Distribution (left axis) and Cumulative Distribution (right axis)
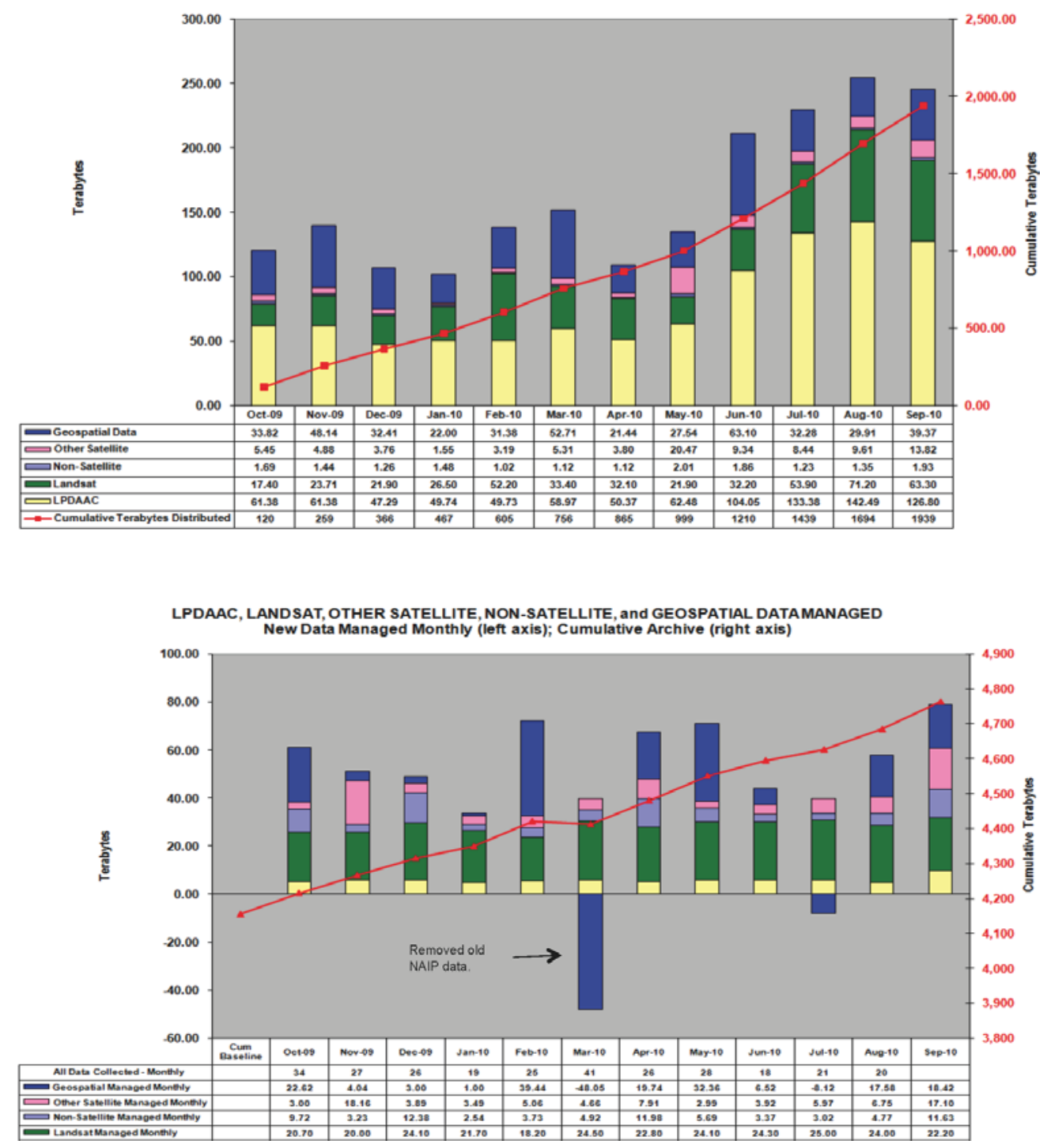

Figure 112. Fiscal year 2010 Land Processes Distributed Active Archive Center, Landsat, other satellite, non-satellite, and geospatial data distributed.

Figure 113. Fiscal year 2010 Land Processes Distributed Active Archive Center, Landsat, other satellite, nonsatellite, and geospatial data distributed.

Figure 114. Fiscal year 2010 Land Processes Distributed Active Archive Center, Landsat, other satellite, nonsatellite, and geospatial data managed. 

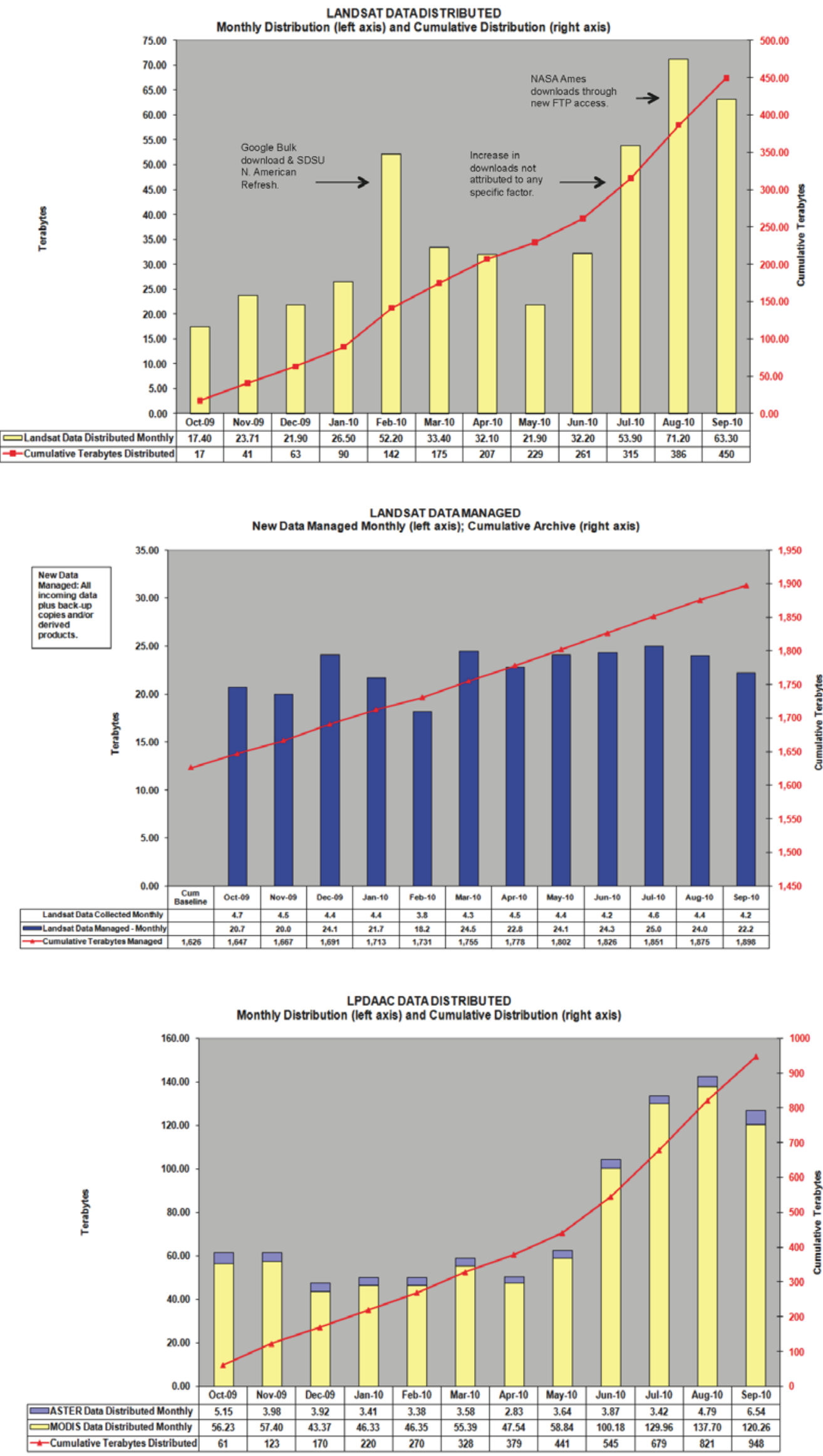

Figure 115. Fiscal year 2010 satellite data distributed.

Figure 116. Fiscal year 2010 satellite data managed.

Figure 117. Fiscal year 2010 Land Processes Distributed Active Archive Center data distributed. 

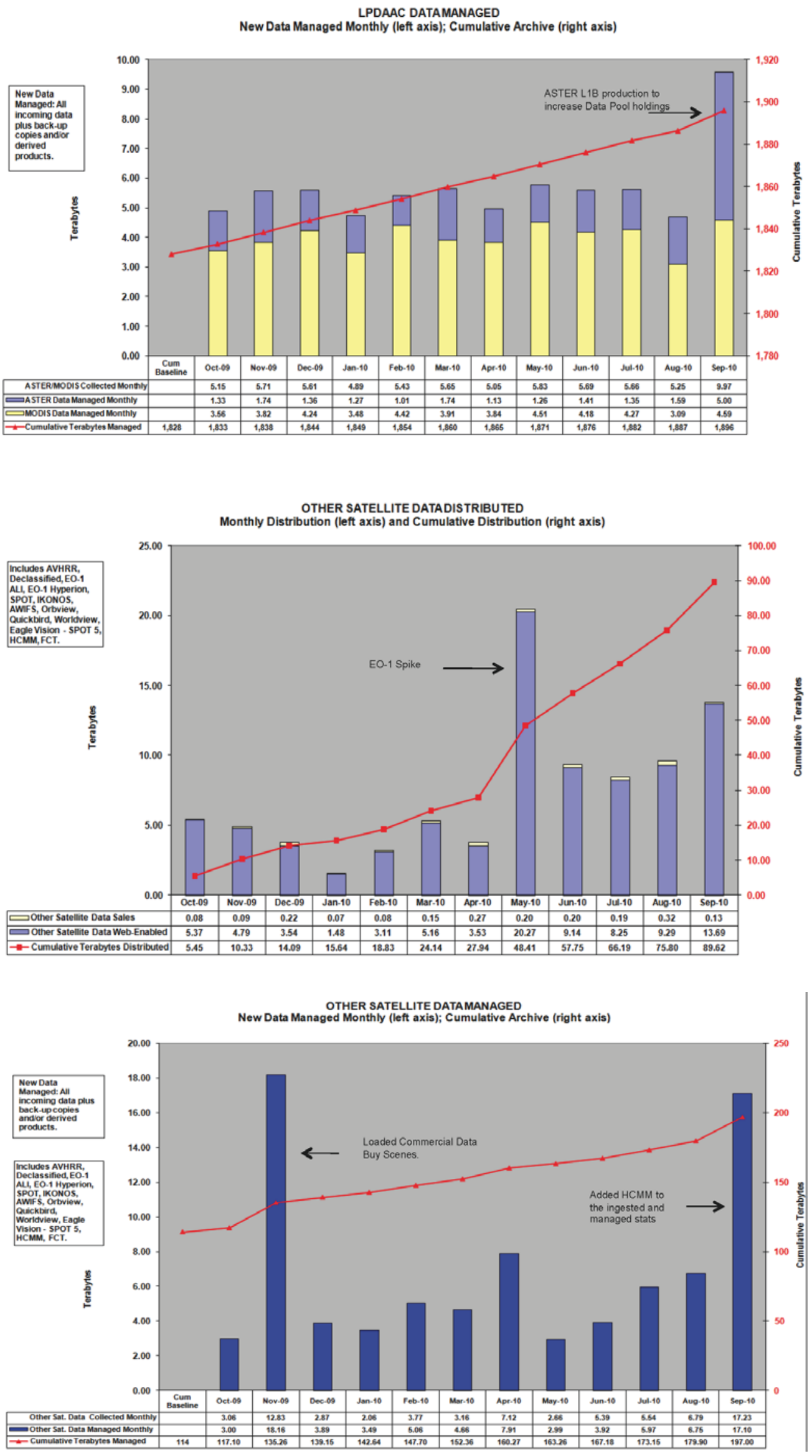

Figure 118. Fiscal year 2010 Land Processes Distributed Active Archive Center data managed.

Figure 119. Fiscal year 2010 other satellite data distributed.

Figure 120. Fiscal year 2010 other satellite data managed. 
NON-SATELLITE DATADISTRIBUTED

Monthly Distribution (left axis) and Cumulative Distribution (right axis)

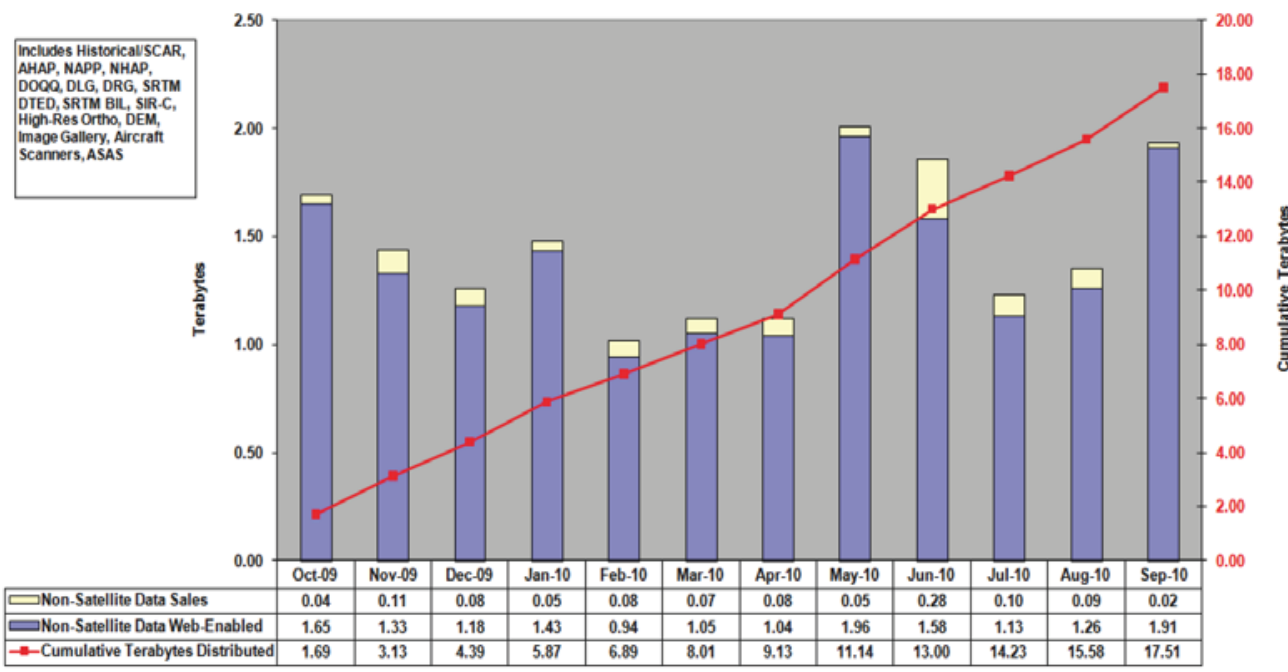

NON-SATELLITE DATAMANAGED
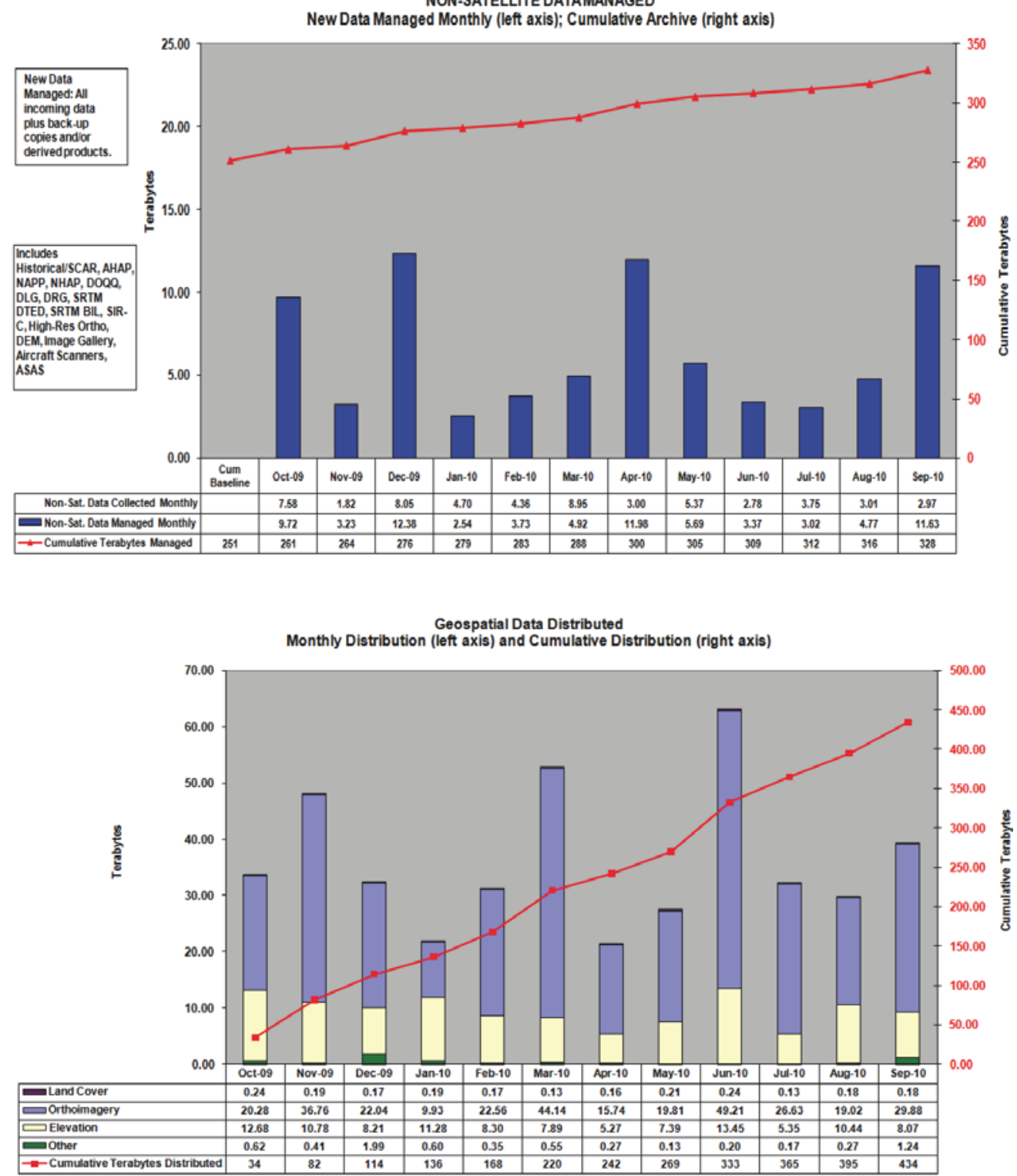

Figure 121. Fiscal year 2010 non-satellite data distributed.

Figure 122. Fiscal year 2010 non-satellite data managed.

Figure 123. Fiscal year 2010 geospatial data distributed. 


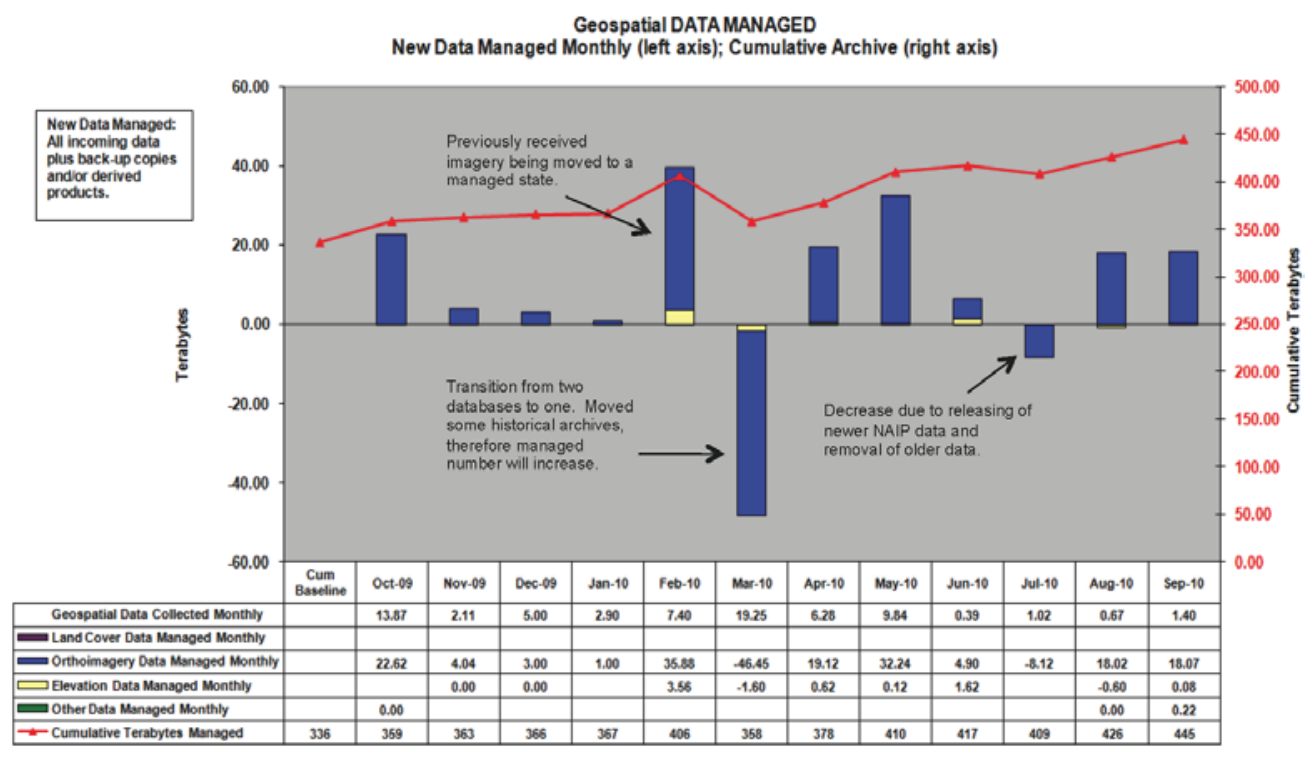

Figure 124. Fiscal year 2010 geospatial data managed.

\section{Calibration and Validation}

Remotely sensed data are a valuable tool in the management, study, and monitoring of the Earth's surface. The usability and reliability of these data for users and decision makers depends on the accuracy with which these data represent the surface of the Earth and the processes underway on it. The USGS, as a critical provider and user of remotely sensed data, products, and services, places a critical reliance on the accuracy, understanding, and limitations of the data because of the technologies used to generate them. Other agencies, as well as the broad user community in the United States and around the world, rely on the USGS to provide assessment of these data. The value of remote sensing observations is assessed according to its accuracy and ability to assess change required to address societal needs.

\section{Satellite Data Characterization and Joint Agency Civil Imagery Evaluation (JACIE) Team}

The USGS Remote Sensing Technologies (RST) Project continued research into the quality and usability of remotely sensed data from satellite and airborne platforms, public or private, U.S. or foreign. During FY 2010, system evaluations performed by Project staff included satellite system analysis of numerous systems and assessment of multiple aerial imaging and new technology systems. The major satellite assessment efforts included WorldView-1 and -2 (United States of America), the 5-satellite RapidEye constellation (Germany), DMC constellation satellites (United Kingdom), ResourceSat-1 (India), CBERS2B (Brazil), SPOT 4 and SPOT 5 (France), THEOS (Thailand), and COSMO-SkyMed (Italy). The Project also assessed remote sensing technologies via system owners, manufacturers, and partners in supporting recommendations for both new missions and the Landsat Data Gap. NASA understands the value that detailed calibrations of these and other system instruments provide, and funded the Project to support instrument calibration and validation processes in FY 2010 under their Land Cover Land Use Change (LCLUC) Program.

The Joint Agency Civil Imagery Evaluation (JACIE) Workshop is led by the USGS RST Project in partnership with the USGS, NASA, the National Geospatial-Intelligence Agency (NGA), and the United States Department of Agriculture (USDA). The USGS and the JACIE team partners co-sponsored the ninth annual Civil Commercial Imagery Evaluation Workshop March 16-18, 2010, in Fairfax, Virginia, to allow collaboration with other international, Federal, State, and local government agencies, academia, and industry. The Keynote speakers were the Department of Interior's Deputy Assistant Secretary for Water and Science, Deanna Archuleta, and Dr. Franz Leberl, founder of Microsoft's Vexel Corporation and current chaired professor of Computer Science at Graz University of Technology Graz, Austria. Attendees at the workshop numbered approximately 140 from various government and commercial organizations exchanging information regarding the characterization and application of civil commercial imagery used by Government and commercial groups to support independent system and product validation (fig. 125). The tenth annual JACIE workshop is planned for March 29-31, 2011, in Boulder, Colorado.

The following list highlights the international Earth observation calibration and validation working groups, meetings, and accomplishments the Project supported in FY 2010: 
- The Quality Assurance Framework for Earth Observation (QA4EO) Workshop on Facilitating Implementation in the Group on Earth Observations (GEO) community sought to harmonize and standardize satellite data quality throughout the international community. A short QA4EO "user" guide was made available from the QA4EO website at http://qa4eo. org/documentation.html.

- Attendance at the first-ever GEO Work Plan Symposium meeting in South Africa.

- Continued support to the Committee on Earth Observation Satellites (CEOS) through QA4EO and four major international Infrared and Visible Optical Sensors (IVOS) campaigns: CEOS Land Surface Imaging (LSI) Dome C Campaign, CEOS Infrared Spectral Emitted Radiance Comparison, and the CEOS Comparison of Land Surface Reflectance I and II.

- Development of a catalog of worldwide test sites for sensor characterization including the release on EarthExplorer (http://edcsns17.cr.usgs.gov/EarthExplorer/) of the CEOS-endorsed globally distributed reference standard test sites.

- Ongoing activities with the CEOS Working Group on Calibration and Validation (WGCV), the Infrared and Visible Optical Systems (IVOS) Subgroup, the Strategic Implementation Team, the WGCV chairmanship, the 31st WGCV Plenary, and joint 32nd WGCV Plenary/Working Group on Information Systems and Services (WGISS) Meeting.

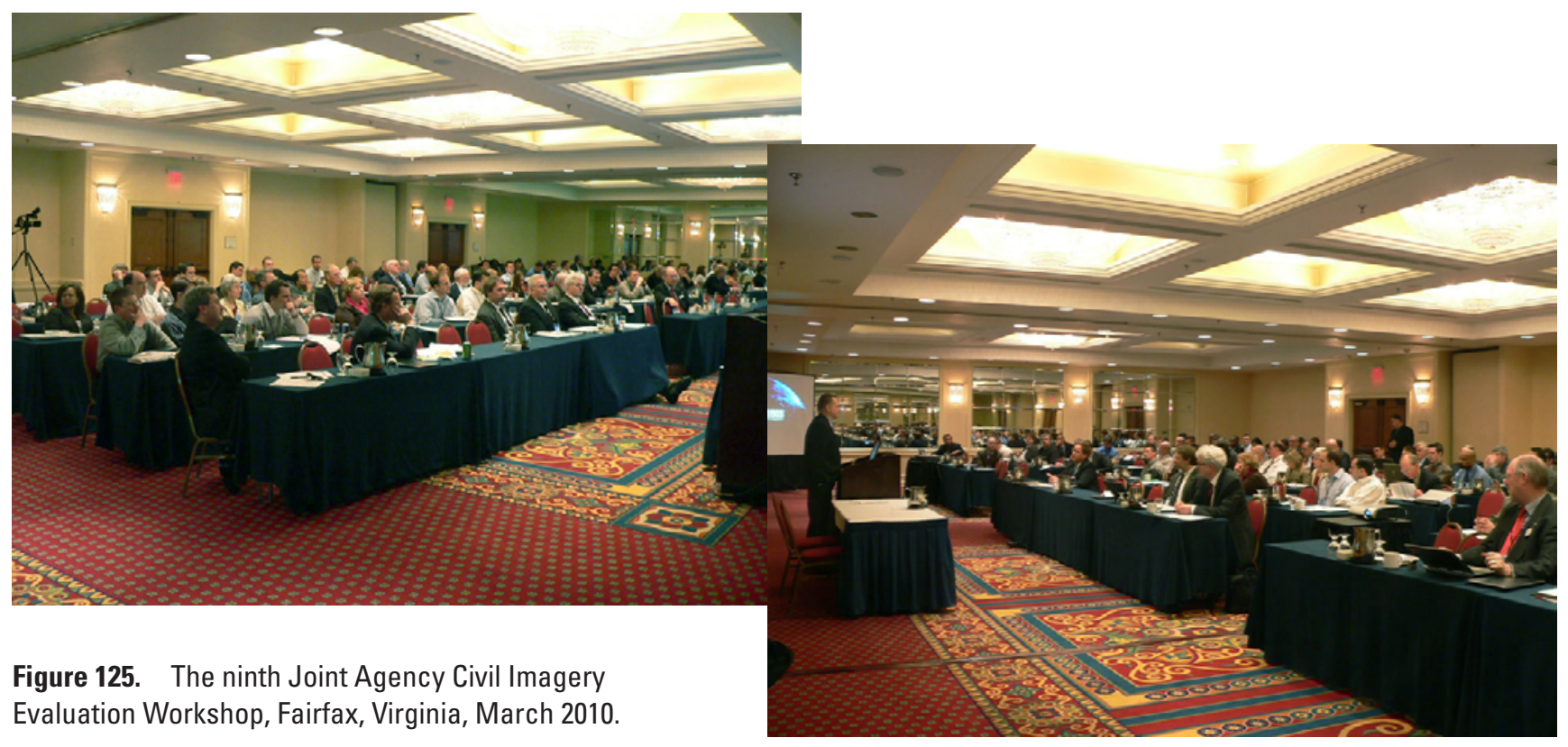

- Expertise to the International Society of Photogrammetry and Remote Sensing (ISPRS) Commission I (Data Acquisition - Sensors and Platforms) in camera and sensor calibrations from around the world, including coordinated research and standards development; and support to the International Standards Organization (ISO) 19159-Calibration and Validation of Remote Sensing Imagery Sensors and Data work.

- Remote sensing leadership and representation to the ASPRS and Management Association for Private Photogrammetric Surveyors (MAPPS) focused on (a) digital imagery, (b) the evolving technology options and innovative techniques for data analysis and fusion, and (c) lidar standards and best practices.

The Project plays a key role in assessment and coordination of civil government remote sensing user data requirements, in support of the Commercial Remote Sensing Space Policy (CRSSP) and its data requirements, as the USGS maintains its leadership and support to the Office of Science and Technology Policy, the National Geospatial-Intelligence Agency, and the U.S.

Space Policy. The Project operates the CRSSP Imagery Derived Requirements (CIDR) tool and actively works with users to define data requirements. During the first 10 months of FY 2010, a total of 550 new imagery requirements were received, of which 356 have been validated and coordinated with other Federal users previously submitting requirements. For further information, contact Greg Stensaas, USGS EROS, stensaas@usgs.gov, or visit http://calval.cr.usgs.gov/. 


\section{USGS Quality Assurance Plan for Digital Aerial Imagery}

The USGS led the effort in 2010 to establish a Quality Assurance (QA) framework for digital aerial imaging and mapping for the nation. Responding to requests and recommendations from the American Society of Photogrammetry and Remote Sensing and the digital imaging and mapping community, the USGS developed a Digital Imagery Quality Assurance Plan (DIQAP) that addressed the complete process of obtaining digital aerial data, beginning with the initial specification of data requirements through the capture and production of the image products to the final receipt and inspection of the data.

USGS Sensor Type Certifications in 2010 closely followed part of the traditional role that the USGS has had in the U.S. Government of giving procurers of aerial imagery an assurance that the camera/sensor system used in their project is capable of producing consistent quality metric aerial data products. The USGS accomplished this through a reimbursable process called Sensor Type Certification. In this process, the USGS certification team asks the manufacturer of a sensor type to answer questions describing the design and quality regime under which it is manufactured, tested, calibrated, sold, and supported. The USGS team then visits the manufacturer's facilities to observe and verify those processes. Once the USGS is satisfied the sensors are designed, manufactured, calibrated, and supported such that consistent metric imagery will be produced with the specified capabilities and performance measures, a certification of that sensor type is issued.
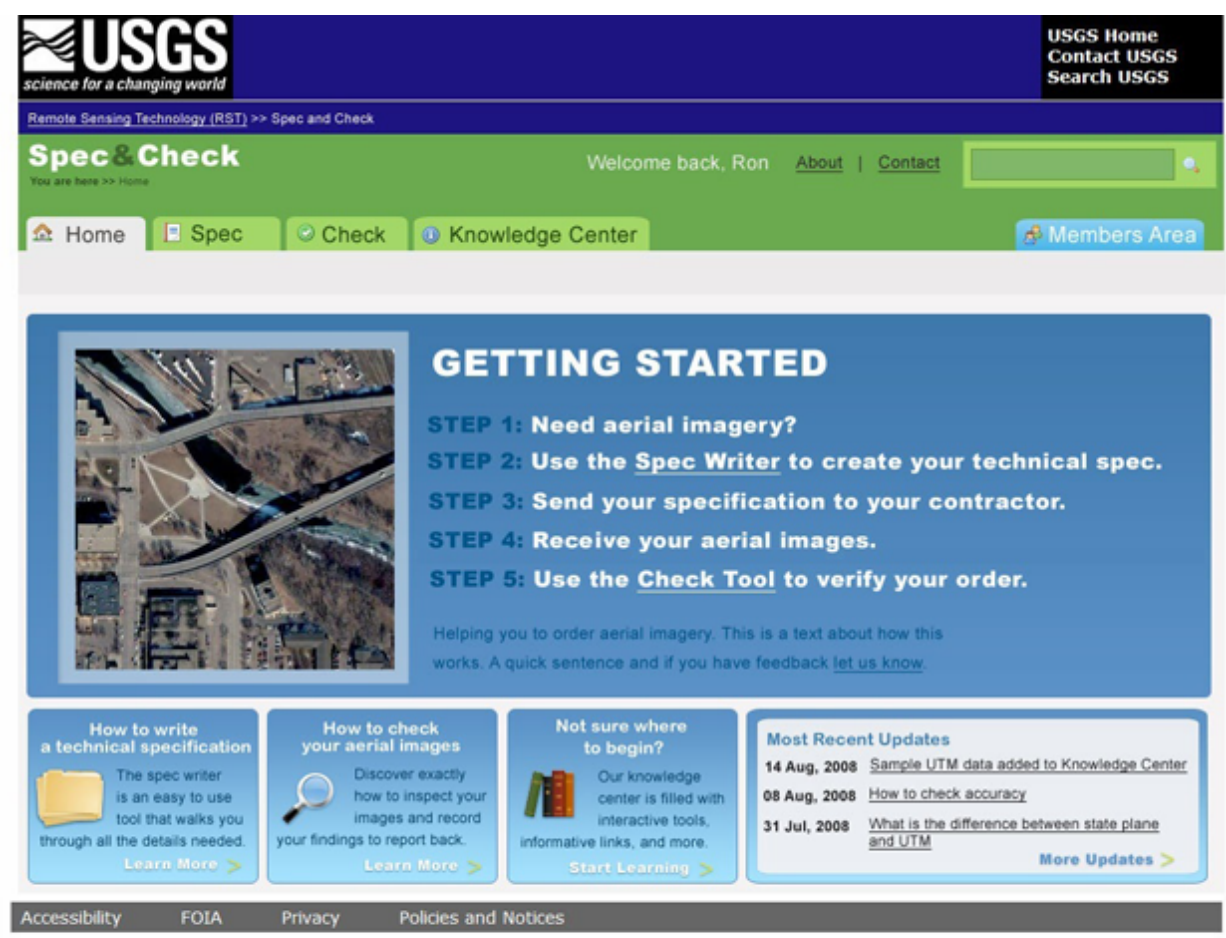

US. Department of the Interior I US. Geolocical Surver

URL: http://eros.usgs.gov/

Page Contact information: custserv@usgs.go

Page Last Modified: December 29th, 2008

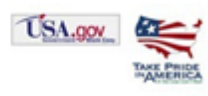

Figure 126. An illustration of the web-based "Spec \& Check Tool" developed as the basis of standard digital aerial imagery specifications and imagery product verification.

The USGS Manufacturer Sensor Type Certification team certified four sensor types from three manufacturers in 2010 and continues to work the certification reports for the GeoVantage, Pictometry, and Microsoft Vexcel sensors. The team also established a new reimbursable cost model in 2010 for the manufacturer sensor certification efforts and is including this model in new Technical Assistance Agreements (TAA) for four new camera certification agreements in FY 2011. Those companies and cameras are Zeiss Intergraph DMC II, Microsoft Vexcel UltraCam L and Lp, DiMAC Camera, and IGI Digital.

The Data Provider Evaluations using USGS National Ranges in 2010 consisted of requiring data provider's digital aerial products flown over one of five USGS-approved test ranges, a process defined as part of the QA plan. The ortho-mosaic products are then delivered to the USGS for assessment of accuracy. This accuracy and basic details about the company and staff are available in a public report. 
This effort progressed very well in 2010 with the completion of Calibration and Validation Range Specifications, a USGS Data Provider Evaluation Plan, a Range Development Plan, three completed ranges in Sioux Falls, South Dakota; Rolla, Missouri; and Pueblo, Colorado.

Another part of the QA Plan completed in FY 2010 was the development of a web-based digital imagery QA tool to assist with the specification and assessment portions of the plan. This application is known as the "Spec \& Check Tool" (fig. 126) and is being developed at EROS with strong support from National Geospatial Program staff in Rolla and Denver and advice from industry and USGS State Liaisons. When completed and utilized by the digital aerial community, this tool will form the basis of standard digital aerial imagery specification and imagery product verification. The Project completed "Phase I" development in FY 2010 of the digital aerial image specification and verification tool and provided the web framework and design so internal stakeholders are able to review and provide input. With funding support, the tool could become operational toward the end of FY 2011. For further information, contact Greg Stensaas, USGS EROS, stensaas@usgs.gov, or visit http://calval.cr.usgs.gov/.

\section{Aerial Mapping Camera Calibration and Characterization}

The USGS Optical Science Laboratory (OSL) has been responsible for providing calibration services for the airborne film mapping industry since 1973 and is the only certified analog film camera calibration capability in the United States. An FY 2010 review of customer requirements suggested that this work is considered critical to the national survey and must be continued by the USGS into the near future. The USGS OSL continues to calibrate between 60 and 80 analog cameras a year on a reimbursable basis. The number of film mapping cameras calibrated at the OSL for the last four years is shown in figure 127.

The photographic multicollimator calibration process used in the OSL for determining lens and camera coefficients relies on film emulsion coated glass plates. The OSL completed its annual 2-week National Institute of Standards and Technology traceable recalibration of the multicollimator assembly that is used to calibrate aerial film cameras from across the country and

OSL Calibrations

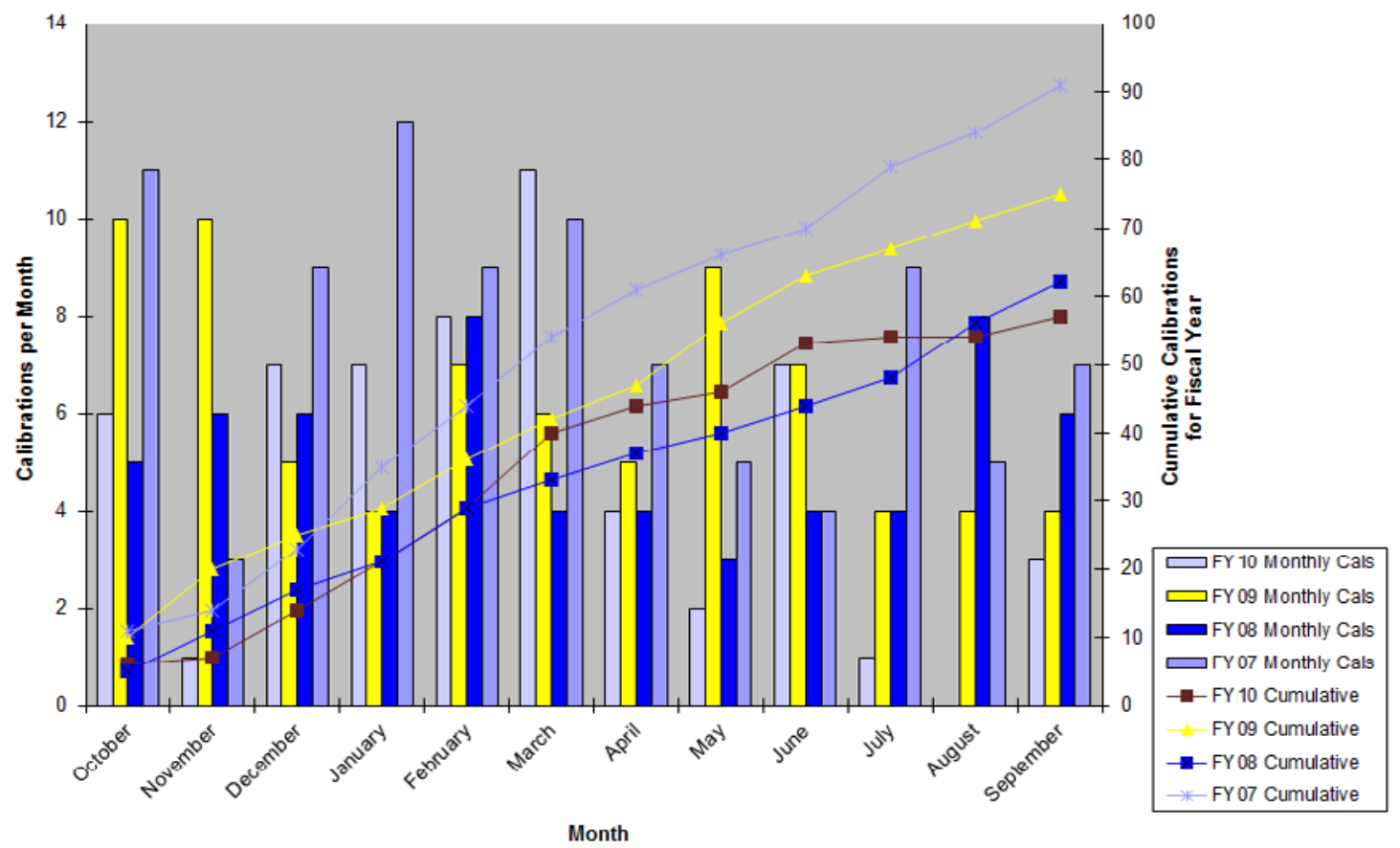

Figure 127. The graphic shows the number of film mapping cameras calibrated at the Optical Science Laboratory for the last four years.

around the world. This annual process is performed to ensure that the OSL is able to continue providing the highest accuracy calibrations for the aerial mapping community. Also in FY 2010, a substantially higher number of OSL camera calibration services were requested from international public and private sector entities primarily because of the closing of the last foreignbased analog calibration laboratory in Canada as well as locations in Europe operated by Zeiss and Wild camera manufacturers.

As part of aerial mapping camera calibration and characterization in FY 2010, the Project also added three partnerships with various universities and government agencies to research digital aerial camera calibration processes using the Calibration Laboratory at EROS software and assessment tools. 
The Project also experimented with and evaluated various laboratory and field calibration techniques and software for commercial digital cameras using short to relatively long focal lengths (6 to 150 millimeters). With the ever-increasing use of commercial digital cameras for aerial applications, one of the accomplishments of FY 2010 was determining the solution for a simple calibration technique for use of shorter focal length cameras, for example, those being used on Unmanned Aerial Vehicles (UAVs) and smaller aerial platforms. The solution was a small portable calibration box designed and built for field calibration that uses coded targets and the Australis software application that derives the calibration parameters. The method has been called "calibration in a box." Research on calibrating cameras with a long focal lens more than 200 millimeters (NASA's DC-8 research aircraft cameras used for Antarctica mapping mission) was completed with numerous partners, such as the Department of Energy's Lawrence Livermore National Labs (LLNL), the National Geospatial-Intelligence Agency (NGA), and the Army Corp of Engineers (COE) on the long focal length lens for the Buckeye system. For further information, contact Greg Stensaas, USGS EROS, stensaas@usgs.gov, or visit http://calval.cr.usgs.gov/.

\section{Coordination and Collaboration}

As the USGS endeavors to provide overall leadership for land imaging, nationally and internationally, the USGS continues to enhance leadership visibility, improve communications between and among the Federal and non-Federal sectors regarding remote sensing observations of the Earth, and promote excellence in remote sensing for understanding the Earth's land environment through education and training. A large part of the efforts to achieve these objectives will be accomplished through continued activities with Committee on Earth Observation Satellites (CEOS) plenary support and CEOS' standing working groups on calibration and validation, on information systems and services, and on education and training. The USGS also has the lead role in development of a prototype for the "Land Surface Imaging (LSI) Virtual Constellation"- a CEOS Global Earth Observation System of Systems (GEOSS) initiative (see web portal at http://wgiss.ceos.org/lsip/). The USGS continues to serve as the lead U.S. agency to the International Charter "Space and Major Disasters." Finally, EROS will continue to develop and offer a variety of ongoing education and training that together provide remotely sensed data users, and especially potential users, with opportunities to become more informed and educated about all aspects of the science and technology of land remote sensing.

\section{Haiti Earthquake Response}

On January 12, 2010, a 7.0 magnitude earthquake struck Haiti. The capital of Port-au-Prince suffered major damage, and there were several aftershocks greater than magnitude 5.0.

The International Charter Space and Major Disasters (fig. 128) was activated on January 13, 2010, by the French Civil Protection, the United Nations, Canada Civil Protection, and the USGS Earthquake Hazards program. USGS provided support to the Charter activations and other response activities by coordinating commercial and civilian satellite acquisitions and by hosting the satellite imagery along with aerial photography collected by many different sources on the Hazards Data Distribution System.

There are approximately 4.0 terabytes of imagery available, and more than 54 terabytes of imagery have been downloaded by the response community. For further information, contact Brenda Jones, USGS EROS, bkjones@ usgs.gov.

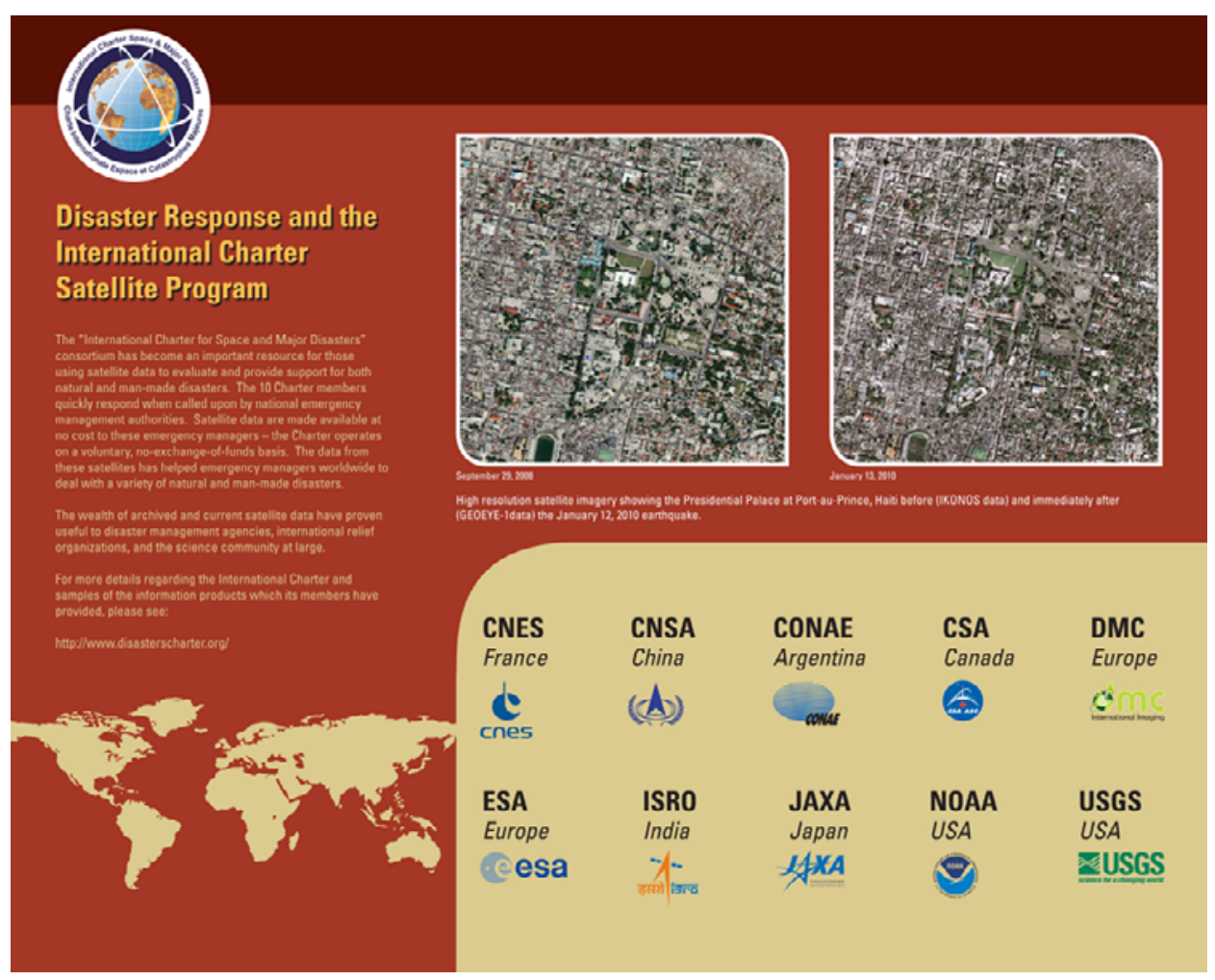

Figure 128. The illustration depicts the 10 International Charter members and satellite imagery showing the Presidential Palace at Port-au-Prince, Haiti, before (IKONOS data) and immediately after (GEOEYE-1 data) the January 12, 2010, earthquake. 


\section{Chile Earthquake Response}

An earthquake and tsunami struck Chile on February 27, 2010. The International Charter Space and Major Disasters was activated on behalf of ONEMI, the Chilean Civil Protection Agency, through the Argentine Space Agency, CONAE. There was much interest in providing support to the response efforts, and many agencies from around the world made their satellite assets available to capture imagery of the destruction.

The USGS provided support to CONAE and ONEMI by hosting a Remote Sensing Working Group call to discuss requirements and acquisition plans and by requesting collections from the U.S. high-resolution commercial satellites that were hosted along with imagery (fig. 129) from other agencies on the Hazards Data Distribution System. Because of the lack of high-speed Internet connections following the disaster, the USGS sent hard drives with copies of the imagery to ONEMI for their use in the response. The USGS is currently hosting about 500 gigabytes of imagery for the event and continues to post new collections as they are acquired. For further information, contact Brenda Jones, USGS EROS, bkjones@usgs.gov.
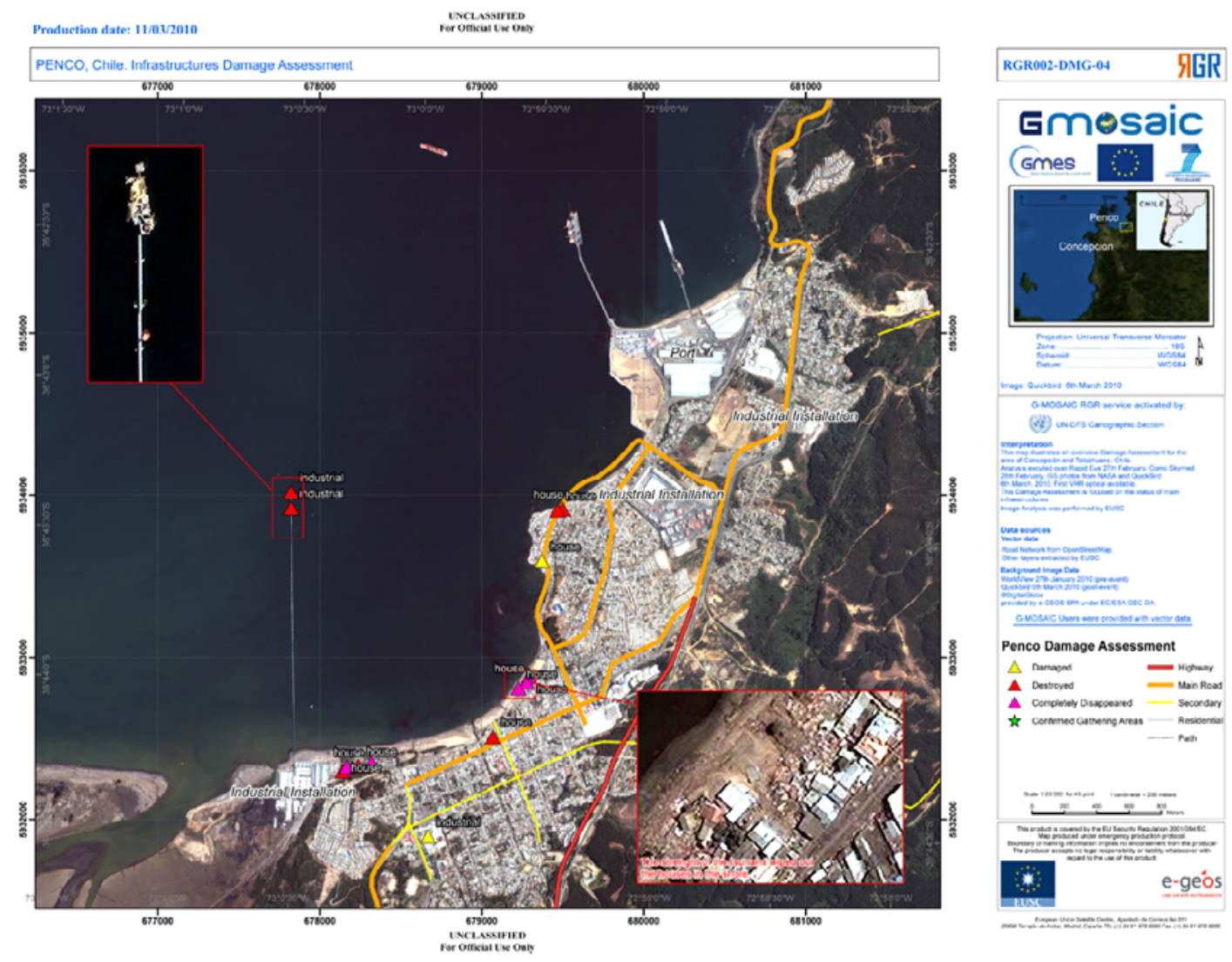

Figure 129. This map illustrates an overview damage assessment for the area of Concepcion and Talcahuano, Chile. 


\section{Deepwater Horizon Oil Spill Response}

The Deepwater Horizon explosion occurred on April 20, 2010, and the drilling rig collapsed and sank on April $22,2010$. On April 22, 2010, the U.S. Coast Guard sent a request to the USGS for activation of the International Charter Space and Major Disasters. The Charter provided radar imagery from the Radarsat, Envisat, and ALOS satellites, which were used to map the extent of the spill (fig. 130).

The USGS supported the National Oceanic and Atmospheric Administration oil spill mapping operations by leading the Remote Sensing Working Group telecon, hosting imagery and products on the Hazards Data Distribution System, and helping

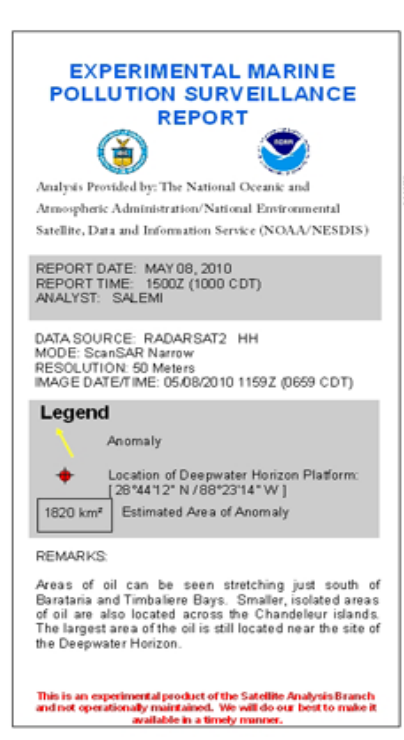

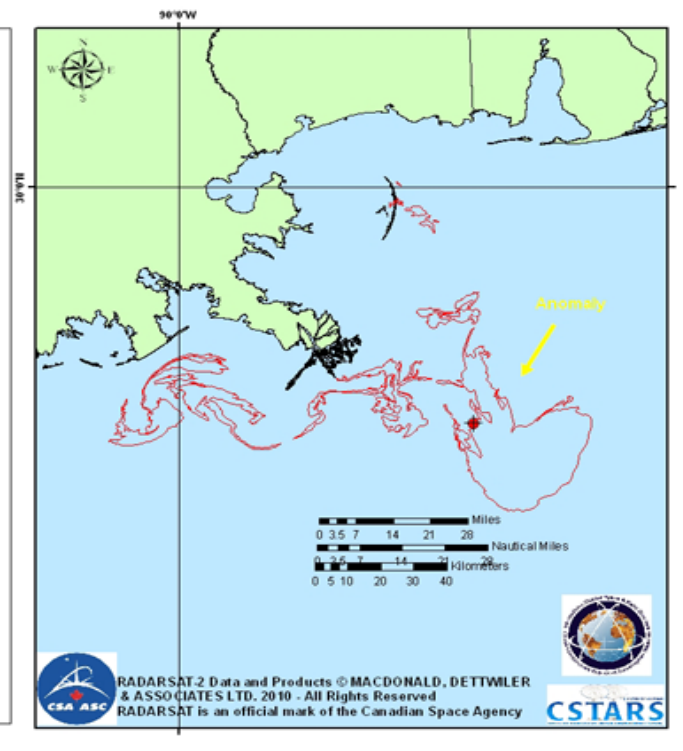

Figure 130. Experimental Marine Pollution Surveillance Report provided by National Oceanic and Atmospheric Administration on May 8, 2010, used in analysis of the Deepwater Horizon Oil Spill. Data source: RADARSAT2.

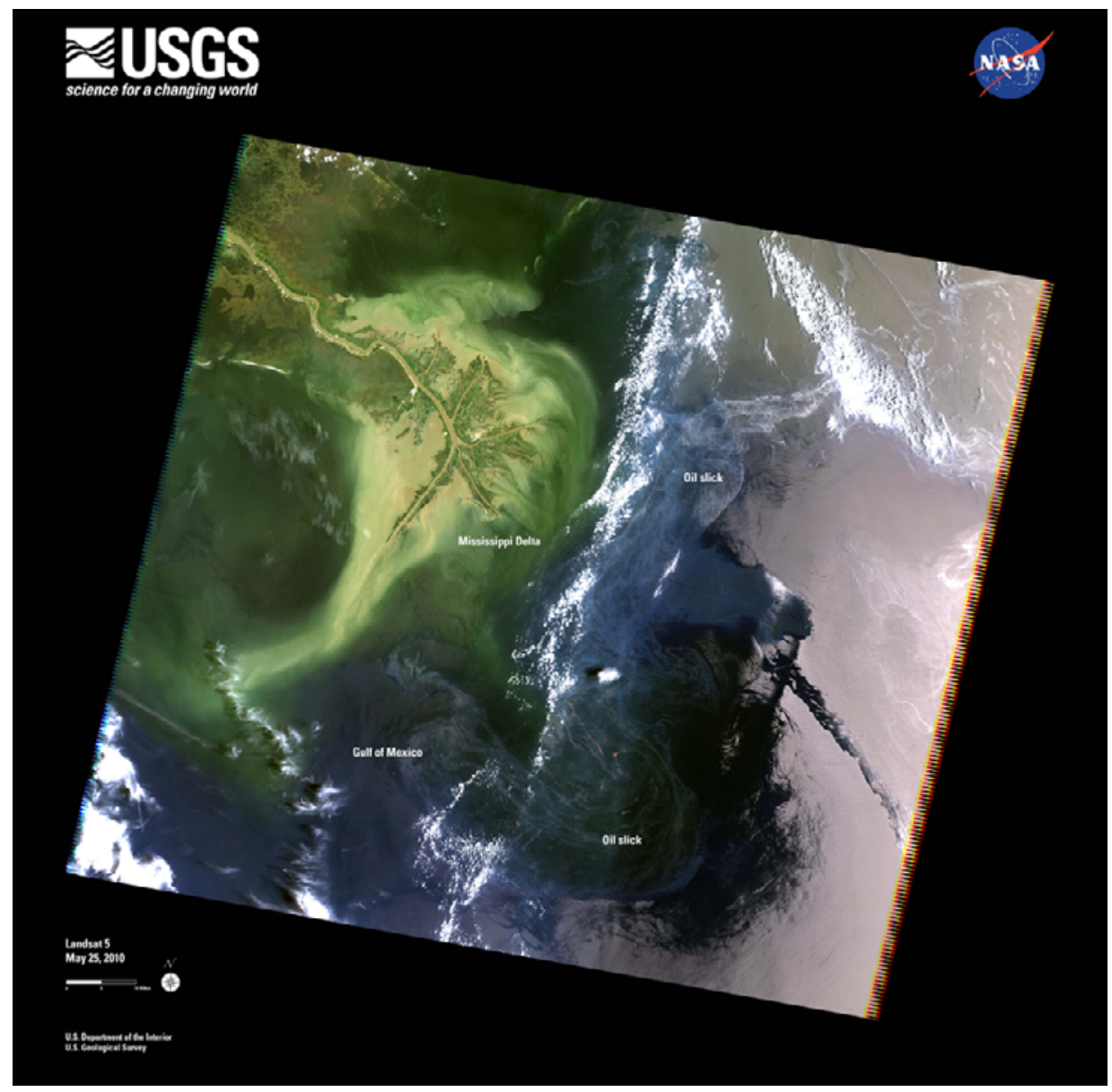

Figure 131. Oil swirls in the Gulf of Mexico off the Mississippi Delta in this natural-color image from Landsat 5, May 25, 2010. 
to acquire additional imagery from Charter members. As part of the Interagency Remote Sensing Coordination Cell, USGS is assisting in the collection of remote sensing requirements from State and Federal agencies and providing staffing support as required for the Unified Area Command. USGS is also working closely with National Geospatial Intelligence Agency and U.S. Air Force Eagle Vision on collection requirements and hosting of satellite imagery.

As of September 30, 2010, about 16.77 terabytes of imagery representing 466,292 files (fig. 131) have been downloaded from the Hazards Data Distribution System. A secure site has also been created for hosting USGS products for USGS only use while going through the approval process. For further information, contact Brenda Jones, USGS EROS, bkjones@usgs.gov.

\section{Facilitating Access to Landsat Data for Developing Countries}

A USGS policy change has enabled Landsat satellite data to be distributed via the Internet to users all over the world at no cost. The USGS is allowing all people to discover, use, and learn from these observations by creating "archives without walls." Developing countries are taking advantage of the data made available through the opening of the Landsat archive and are doing so with the support of the International Panel for Global Observation of Forest Cover/Global Observation of Landscape Dynamics (GOFC/GOLD). As a result, a second regional network data workshop was held at the USGS EROS Center May 17-27, 2010. The workshop was attended by six regional representatives from Asia (Mongolia, Kazakhstan, Turkmenistan, Indonesia, Vietnam, and Malaysia). The workshop was geared toward providing developing nation experts with training on how to access, manage, and apply data from USGS EROS archives. The six attendees are involved in various aspects of remote sensing applications, particularly land cover and fire activities, but are restricted in their use of Landsat and other data because of Internet limitations. With free Landsat data, there is a new opportunity for expanding applications. Specific goals achieved included: (1) disseminate Landsat data to the international science community in regions where currently available distribution methods are not effective, (2) compile regional and in-country datasets relevant to land cover and fire observations and make them freely available to the international community, and (3) engage regional science expertise in the global dataset development, evaluation, and validation. For further information, contact Thomas Holm, USGS EROS, holm@usgs.gov.

\section{USGS Supports CEOS Working Group on Information Systems and Services}

The 30th meeting of the Working Group on Information Systems and Services (WGISS) was hosted by the Canadian Space Agency (CSA) in Montreal, Quebec, Canada on September 13-17, 2010. The CEOS Working Group on Calibration and Validation (WGCV) was also meeting in Montreal during the same week and approximately 2 days of the meetings were held jointly with WGCV and focused on a number of areas of mutual interest and action. The following are key topics stemming from both the WGISS Subgroup and Plenary sessions as well as the joint sessions with the WGCV: (1) CEOS/WGISS Integrated Catalog (CWIC), (2) Land Surface Imaging (LSI) Constellation Portal, (3) Data Stewardship Interest Group, and (4) USGS Hosting of WGISS No.33 in the spring of 2012.

A major portion of the WGISS meeting agenda was allocated to the CWIC initiative. CWIC is intended to be a major contribution from CEOS to the GEOSS and demonstrates how common standards such as the Open Geospatial Consortium (OGC) Catalog Service for the Web (CSW), Web Coverage Service (WCS), and the Web Mapping Service (WMS) along with the International Standards Organization (ISO) 19115 metadata standard can be used to facilitate cross-agency inventory searches and data access through a single client interface. The LSI Portal is planned as the featured client for demonstrating to CEOS Plenary and GEO the initial CWIC prototype. The LSI Constellation Study Team has indicated that adding the capability of a map-based, granule-level search and access capability to the LSI Constellation Portal is the highest priority. Of all of the efforts through the years of achieving interoperability among the various agency satellite data inventory and access systems, CWIC has the most potential of succeeding given the evolution of international OGC and ISO standards, and the services oriented architecture thrusts of the day.

For several years, WGISS has discussed whether an interest group should be formed to address data management (data stewardship) needs experienced by WGISS members. USGS accepted an action from the previous WGISS meeting to determine if enough support is available to form such an interest group. An online survey was conducted for 6 weeks resulting in 13 responses. The results of the survey were presented in Montreal; and after open discussions, the Data Stewardship Interest Group was endorsed. The USGS will lead this interest group, which is expected to heavily leverage existing activities. For further information, contact Thomas Holm, USGS EROS, holm@usgs.gov. 


\section{Coordinating a Successful CEOS WGCV Plenary Meeting}

The Committee on Earth Observation Satellites (CEOS) Working Group on Calibration and Validation (WGCV) 31st plenary meeting was held jointly with the Quality Assurance Framework for Earth Observation (QA4EO) implementation board meeting at the Bolger Center in Potomac, Maryland, March 2-5, 2010. The meeting was hosted under the auspices of National Institute of Standards and Technology (NIST). The WGCV 32nd plenary meeting was held jointly with the CEOS Working Group on Information Systems and Services (WGISS) at the Canadian Space Agency facility in Saint-Hubert September 13-17, 2010 (fig. 132). The WGCV and WGISS meetings were combined in this instance to provide an integrated CEOS technical forum to support Global Earth Observation (GEO) objectives in data quality and availability and to contribute to the CEOS Implementation Plan for the GEO space segment. The WGCV agenda, meeting details, seed documents, and minutes from the meeting are posted on the WGCV website at $h t t p: / / w w w . c e o s . o r g / w g c v /$. For further information, contact Greg Stensaas, USGS EROS, stensaas@usgs.gov.

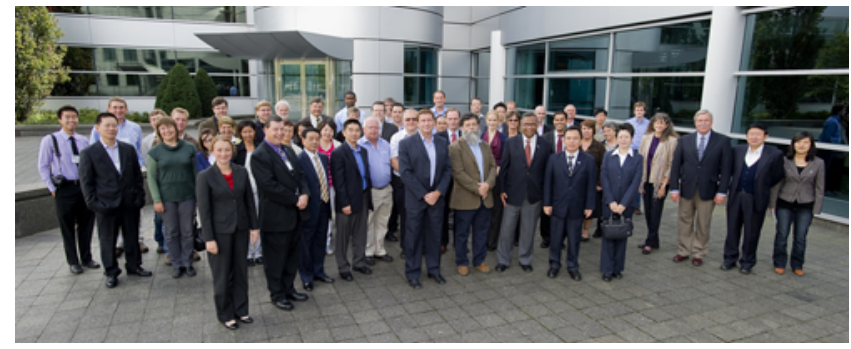

Figure 132. The Working Group on Calibration and the Validation and Working Group on Information Systems and Services participants at the Canadian Space Agency, Montreal, Canada.

\section{Coordinating a Successful QA4EO Workshop}

A Quality Assurance Framework for Earth Observation (QA4EO) Workshop on Facilitating Implementation to the Group on Earth Observations (GEO) community was hosted by the TUBITAK-UZAY (Space Technologies Research Institute) in Antalya, Turkey, September 29-October 1, 2009. The workshop was chaired by the GEO and organized by the Committee on Earth Observation Satellites (CEOS) Working Group on Calibration and Validation (WGCV) and Global Space-based Inter-calibration System (GSICS). Approximately 35 people attended the workshop, and the program included presentations, general and technical sessions, and a group discussion. The ultimate goal of the workshop was to facilitate implementation of the QA4EO guidelines. These guidelines will become the guiding principles that will be adopted and endorsed by the international community. If guidelines such as these are adopted, many difficult issues of traceability and inter-operability will be effectively addressed. The QA4EO agenda, meeting details, documents, and minutes from the meeting are posted on the website at http://qa4eo.org/ (fig. 133). A short QA4EO "user" guide has been produced to provide background into QA4EO and how one would start implementing it. This user guide is also available from the QA4EO website at http://qa4eo.org/documentation.html. For further information, contact Greg Stensaas, USGS EROS, stensaas@usgs.gov.

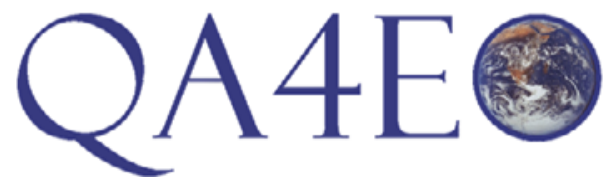

\section{A QUALITY ASSURANCE FRAMEWORK FOR EARTH OBSERVATION}

Figure 133. Screenshot of $\mathrm{QA} 4 \mathrm{EO}$ website banner.

\section{First Ever GEO Work Plan Symposium}

The Department of Science and Technology in South Africa hosted the first-ever Group on Earth Observations (GEO) Work Plan Symposium. The Symposium took place May 17-19, 2010, in Pretoria, South Africa, bringing together the Task Leads and contributors to the Tasks of the GEO 2009-2011 Work Plan. The main objectives of the Symposium were to (1) foster the Work Plan implementation across and within Global Earth Observation System of Systems (GEOSS) areas, (2) develop practical recommendations for the 2011 Work Plan update, (3) identify achievements that could be presented at Beijing Ministerial Summit Exhibition, and (4) initiate reflections and discussions in preparation of the GEO 2012-2015 Work Plan. The 3-day symposium was designed around parallel and plenary sessions in order to deliver concrete actions and proposals. These built upon the cross-fertilization of tasks and directly contribute to GEOSS implementation on a number of fronts including data sharing and registration of data, tools, and services in the GEOSS Common Infrastructure. For further information, contact Greg Stensaas, USGS EROS, stensaas@usgs.gov. 


\section{USGS Supports CEOS Working Group on Education: Fourth Jay Feuquay Memorial Workshop}

The USGS helped organize and participated in the CEOS Working Group on Education (WGEdu), training, and capacity building remote sensing workshop "Geotechnologies For Natural Disaster Monitoring in Latin America," hosted by the Instituto Nacional de Pesquisas Espaciais (INPE) of Brazil and held March 2010 in Santa Maria (fig. 134). The 3-day workshop was attended by more than 25 remote sensing practitioners and educators from 10 Latin American countries (fig. 135), who were welcomed on the opening day by Dr. Sergio Camacho Lara, Secretary General of INPE's CRECTEALC Program and by WGEdu Co-Chair, Dr. Tania Maria Sausen (INPE). The workshop was the fourth WGEdu remote sensing workshop held in memory of former USGS Land Remote Sensing Program Coordinator, Jay Feuquay, and was enabled by funding support from the USGS. For further information, contact Eric Wood, USGS EROS, woodec@usgs.gov.

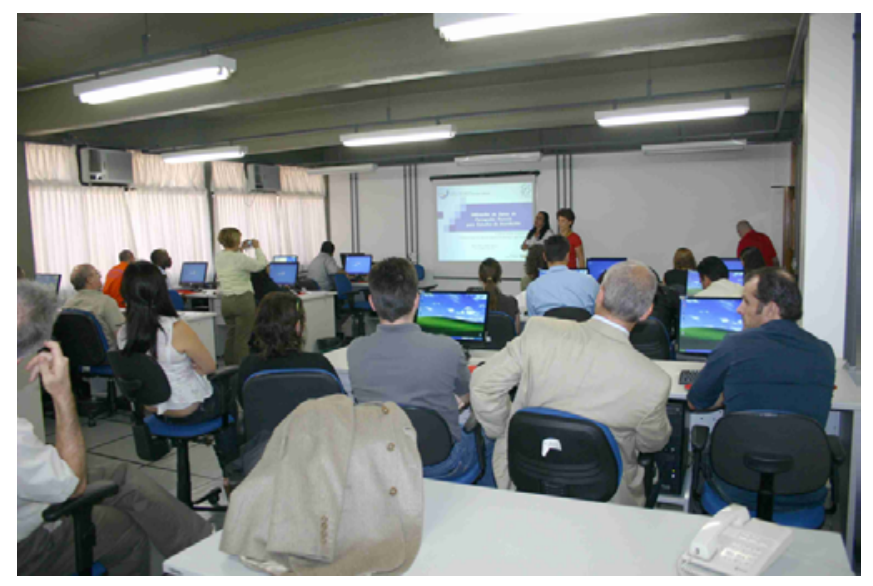

Figure 135. Participants of the Fourth Jay Feuquay Memorial Workshop.

Figure 134. Training session during the Fourth Jay Feuquay Memorial Workshop, Santa Maria, Brazil, 2010.

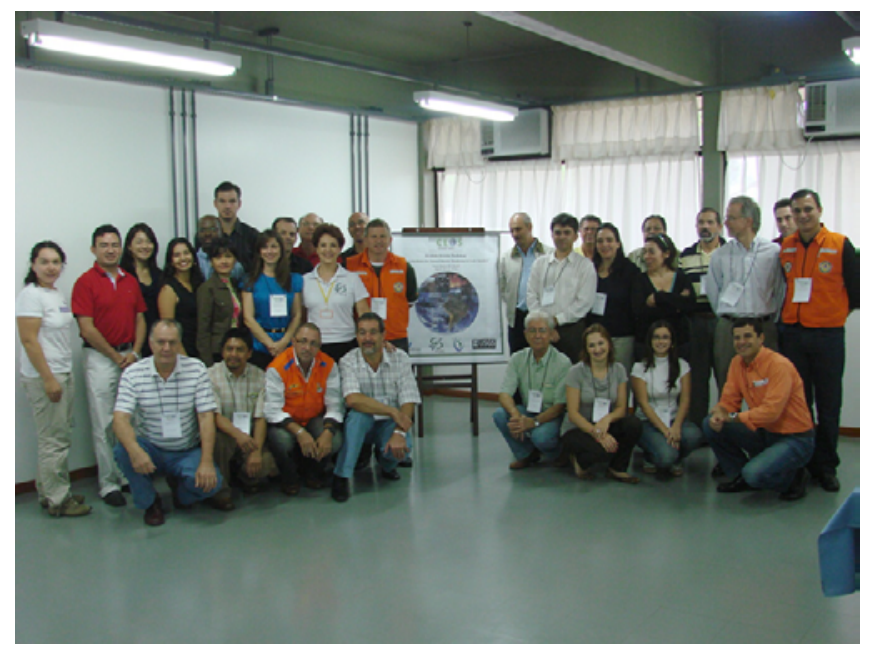

\section{CEOS Land Surface Imaging Constellation Portal for GEOSS}

The Committee on Earth Observation Satellites (CEOS, http://www.ceos.org) is an international group that coordinates civil spaceborne observations of the Earth and provides the space component of the Global Earth Observing System of Systems (GEOSS, http://www.earthobservations.org/geoss.shtml). The CEOS Virtual Constellations concept was implemented in an effort to engage and coordinate disparate Earth observing programs of CEOS member agencies and ultimately facilitate their contribution in supplying the space-based observations required to satisfy the requirements of the GEOSS. The CEOS initially established study teams for four prototype constellations that included precipitation, land surface imaging, ocean surface topography, and atmospheric composition. The basic mission of the Land Surface Imaging (LSI) Constellation [1] is to promote the efficient, effective, and comprehensive collection, distribution, and application of space-acquired image data of the global land surface, especially to meet societal needs of the global population, such as those addressed by the nine Group on Earth Observations (GEO) Societal Benefit Areas (SBAs) of agriculture, biodiversity, climate, disasters, ecosystems, energy, health, water, and weather. The LSI Constellation Portal is the result of an effort to address important goals within the LSI Constellation mission and provide resources to assist in planning for future space missions that might further contribute to meeting those goals.

The CEOS LSI Constellation Portal for GEOSS was designed and built by the LSI Constellation study team in response to input from the community of users of mid-resolution optical remotely sensed land satellite data and with strong support and assistance from the CEOS Working Group on Information Systems and Services (WGISS). CEOS agencies participating in development of this Portal include Centre National d'Etudes Spatiales (CNES), Comisión Nacional de Actividades Espaciales (CONAE), Instituto Nacional de Pesquisas Espaciais (INPE), Indian Space Research Organisation (ISRO), NASA, Japan Aerospace Exploration Agency (JAXA), Geo-Informatics and Space Technology Development Agency (GISTDA), and the U.S. Geological Survey (USGS). Currently, the website provides information and links to mid-resolution optical data (fig. 136) that are being collected by the aforementioned agencies or have been collected by them for the past 35 years. 


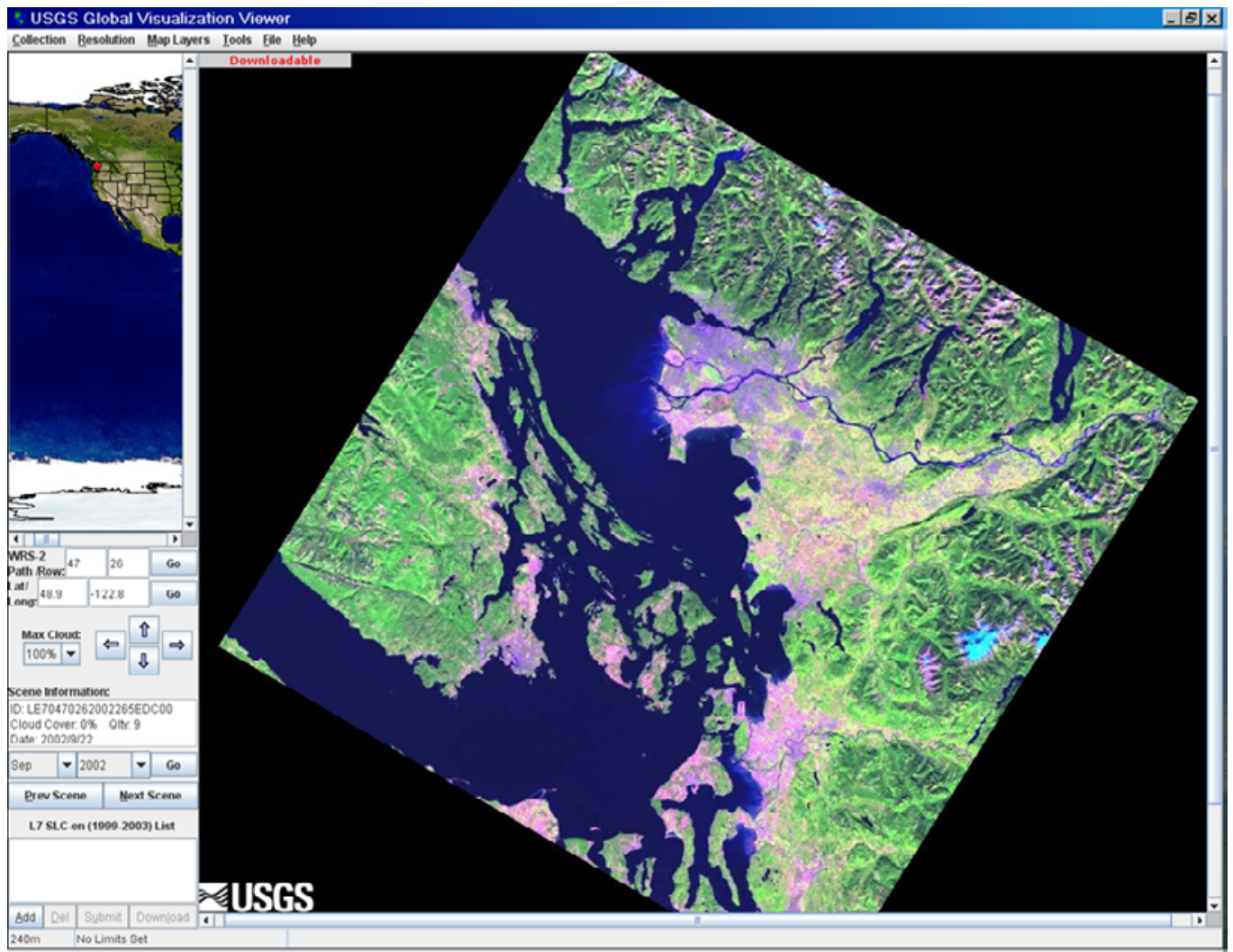

Figure 136. Example browse image that includes the Vancouver, Canada, region, acquired by Landsat 7 on September 22, 2002.

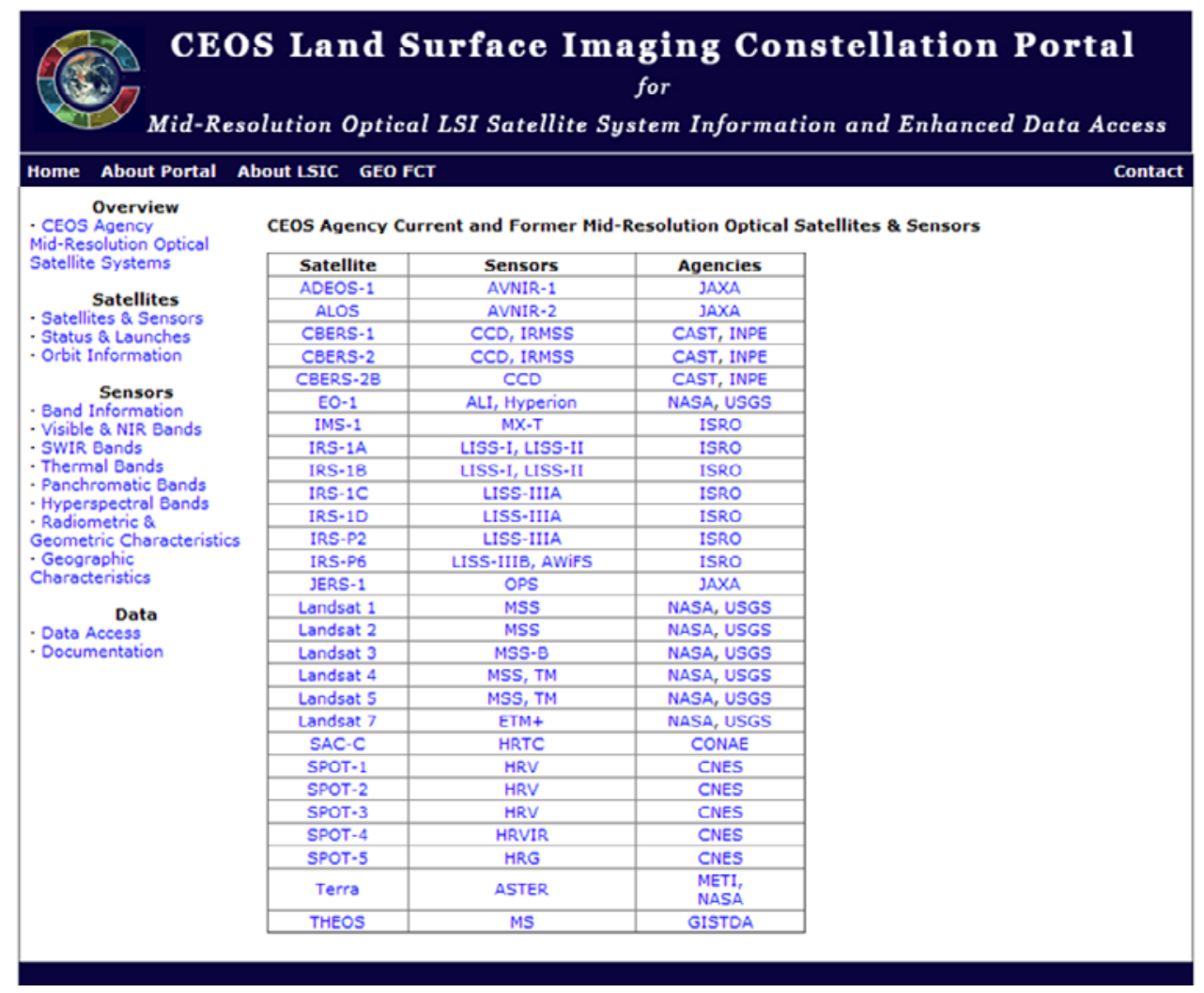

Figure 137. Committee on Earth Observation Satellites Land Surface Imaging Constellation Portal web page for additional information about mid-resolution, optical satellites and sensors. 


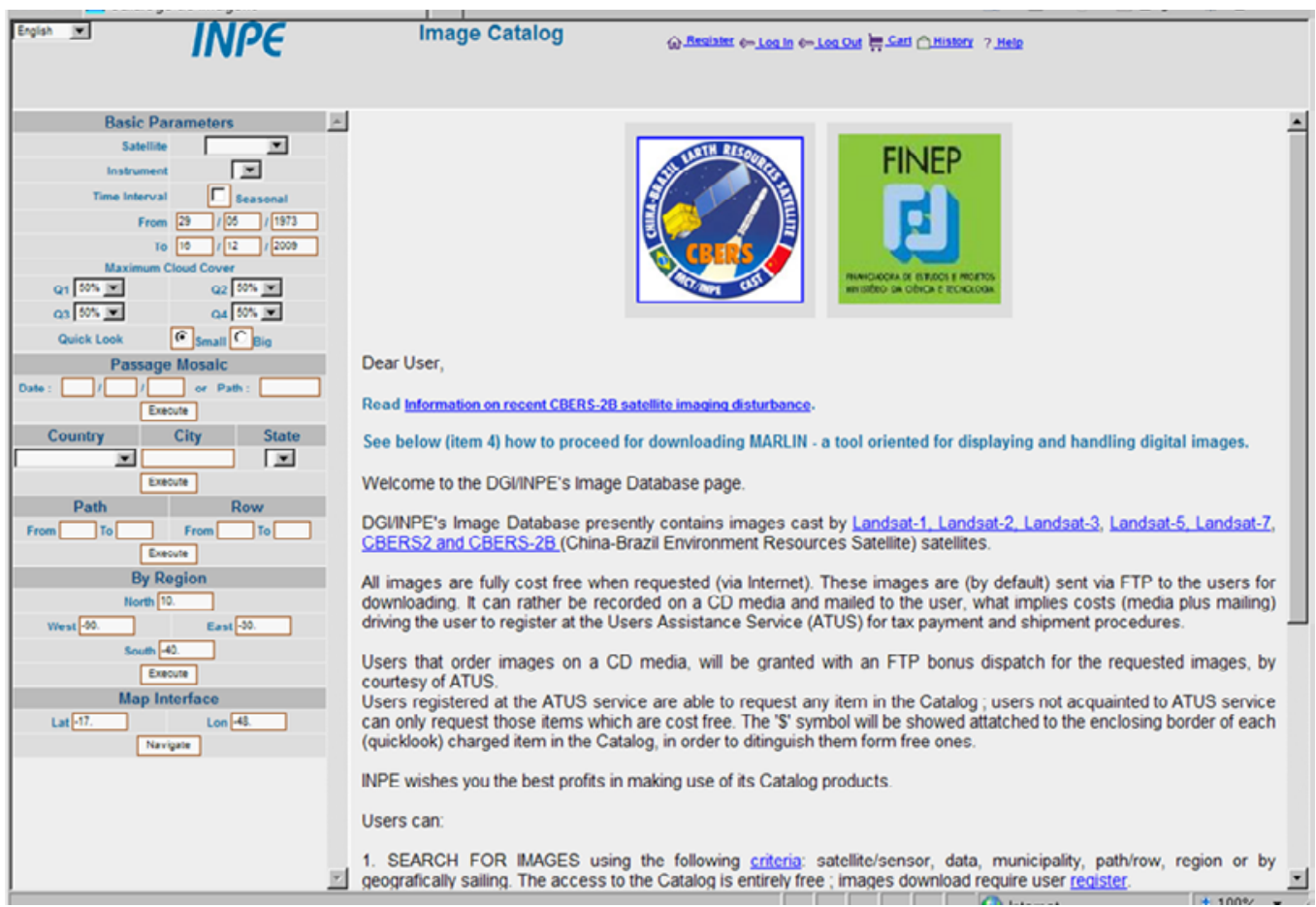

Figure 138. National Institute for Space Research (INPE) web page linked from Committee on Earth Observation Satellites Land Surface Imaging Constellation Portal web page for additional information about mid-resolution, optical satellites and sensors.

The LSI Portal (http://wgiss.ceos.org/lsip/) serves as a single web location for information about current and previous mid-resolution optical satellite systems and data. Mid-resolution optical systems are those that acquire reflected and/or emitted electromagnetic radiation in the visible, shortwave infrared, and thermal infrared (VNIR, SWIR, and TIR) wavelengths with spatial resolutions nominally between 10 meters and 100 meters. The Portal provides users with (1) basic information about the mid-resolution, optical LSI satellites and sensors (fig. 137), (2) information helpful for applications of the data, and 3) active links to data search and order tools for CEOS agencies that offer open user access to mid-resolution, optical satellite data (fig. 138). For further information, contact Thomas Holm, USGS EROS, holm@usgs.gov.

\section{Coordination of Space Data Acquisition in Support of GEO Forest Carbon Tracking}

The Group on Earth Observation (GEO) established the Forest Carton Tracking (FCT) task in 2008 to provide operational support to countries wishing to establish a national system for forest monitoring and carbon reporting (http://www.geo-fct.org). The task follows the guidelines set out by the United Nations Framework Convention on Climate Change (UNFCCC) and it

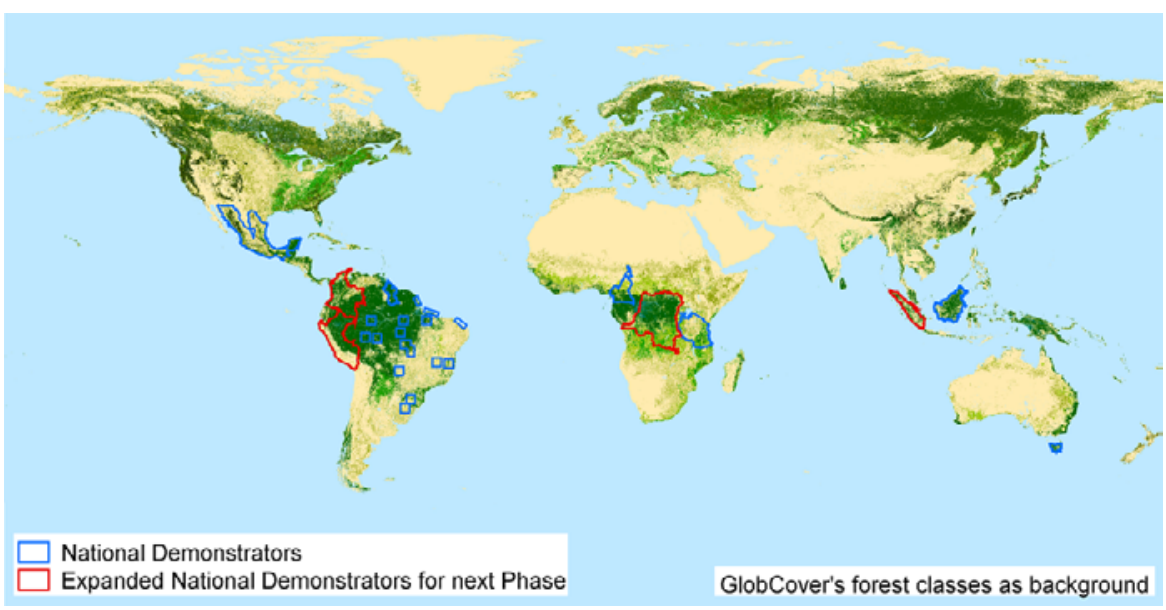
seeks to provide the technical capability and continuity to support the monitoring, reporting, and verification information required by future regulatory frameworks for the inclusion of forests in post-Kyoto climate agreements through global, annual, medium resolution wall-to-wall national-scale coverage of the world's forests.

The GEO FCT task dependence on Earth Observation (EO) data makes the Committee on Earth Observation Satel-

Figure 139. Group on Earth Observation established the Forest Carton Tracking national demonstrators. 
lites (CEOS) and member agencies' support vital. CEOS coordinates civil spaceborne observations of the Earth to enhance international coordination and data exchange to optimize societal benefits (http://www.ceos.org/). CEOS space agencies agreed to implement a coordinated satellite data acquisition strategy from 2009 onward including both optical and SAR sensors within key areas of interest in support of the GEO FCT task.

In 2009, the GEO FCT task required an initial CEOS coordination effort for a number of "National Demonstrator" (ND) activities. The ND represents countries or large areas in the Americas, Africa, Asia, and Oceania with tropical forests. The ND included were Brazil (several regions), Guyana and Mexico (the forest main region), Cameroon and Tanzania, Borneo Island, and Tasmania Island (blue outlined countries/regions, fig. 139). In mid-2010, the areas were expanded with Peru, Columbia, Democratic Republic of Congo, and Sumatra Island (red outline countries/regions, fig. 139). For further information, contact Thomas Holm, USGS EROS, holm@usgs.gov.

\section{GEO Forest Carbon Tracking Science and Data Summit and Space Data Coordination Meeting}

The Woods Hole Research Center (WHRC) and the USGS hosted a Science and Data Summit and a Space Data Coordination Meeting of the Group on Earth Observations Forest Carbon Tracking Task (GEO FCT) on May 11-14, 2010, at WHRC in Falmouth, Massachusetts (fig. 140). The purpose of the meeting was to (1) report on the progress of the GEO FCT Product Development Teams on their prototype product development activities for the National Demonstrator countries (Mexico, Guyana, Brazil, Cameroon, Tanzania, Borneo, and Tasmania); (2) produce a clear statement of what data and results will be provided ahead of the GEO Beijing Ministerial Summit scheduled for November 5, 2010; (3) further the development of methodological processing standards; and (4) develop recommendations to the Committee on Earth Observation Satellites (CEOS) Space Agencies for 2010 satellite data (optical and synthetic aperture radar (SAR)) acquisition requirements for the forthcoming coordinated FCT acquisition campaigns. For further information, contact Thomas Holm, USGS EROS, holm@usgs.gov.

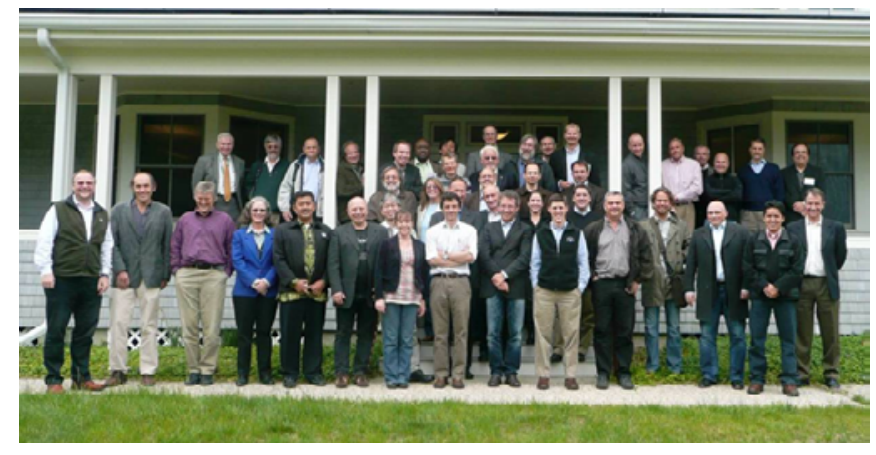

Figure 140. Participants at Group on Earth Observation established the Forest Carton Tracking meetings in Woods Hole Research Center.

\section{UNEP 3D Tours and Videos}

The Team at UNEP GRID located at EROS in Sioux Falls produced videos with the intent of communicating examples of environmental changes from around the world to the public. They have been made available to view at http://www.youtube. $\mathrm{com}$, reaching around 2 million people. Short tours using Google Maps were also produced by the team with the same intention. These 3-D tours are available at Google Earth under the UNEP Layer in Global Awareness to more than 700 million users of Google Earth, and these videos have been widely used in education institutions to raise awareness of environmental changes. Statistics show that these videos have become popular among YouTube viewers in this short span of time (table 3). For further information, contact Charles Trautwein, USGS EROS, trautwein@usgs.gov.

Table 3. UNEP 3-D environmental change videos and YouTube viewer statistics.

[UNEP, United Nations Environment Programme]

\begin{tabular}{lc}
\hline \multicolumn{1}{c}{ UNEP 3-D environmental change video } & Number of views \\
\hline Aral Sea: UNEP \& Google Earth highlights environmental change & $1,799,659$ views \\
UNEP - Amazon Deforestation in Google Earth & 913,112 views \\
Lake Chad: UNEP \& Google Earth highlights environmental change & 349,349 views \\
Shenzhen, China: UNEP \& Google Earth highlights environmental change & 241,798 views \\
UNEP - Mt. Kilimanjaro in Google Earth & 130,947 views \\
\hline
\end{tabular}




\section{Center Support Activities}

Center support at the USGS EROS provides a wide range of services for numerous and highly complex science, engineering, and operational projects, diverse contracts, intricate partner and customer relationships, and national and international activities. Center support functions are located within the internal organizational units of the Center Director's Office, Administrative Services Branch, Data Management Branch, and the Project Management Team. The FY 2010 accomplishments highlighted include achievements related to communication and outreach, implementing the Financial Business Management System, partnering, student and volunteer programs, facility updates, and contract management.

\section{Communications and Outreach Project}

The Communications and Outreach $(\mathrm{C} \& \mathrm{O})$ Project at the USGS EROS Center successfully developed and launched two new websites, a search tool for publications, and a third collection of the Earth As Art imagery in FY 2010. These are among the numerous accomplishments of $\mathrm{C} \& \mathrm{O}$ as they worked diligently to present, promote, and highlight USGS science and remote sensing research locally and nationwide.

The beginning of the fiscal year brought an addition to the walls of EROS as a 12' x 7.9' display of the United States and an 8' x 7.9' display of Alaska were hung outside of the training rooms. EROS C\&O designed the displays for the National Land Cover Dataset (NLCD) project (fig. 141). Each display features several 2.1' X 1.7' pop-outs highlighting the data within the displays. A large display measuring 15.5' x 4' was created for the Sioux Falls, SD, airport. The display entitled "Fell Asleep on the Flight?" highlighted satellite and high-resolution orthoimagery of landscape as they could be seen through the windows of an airplane (fig. 142).
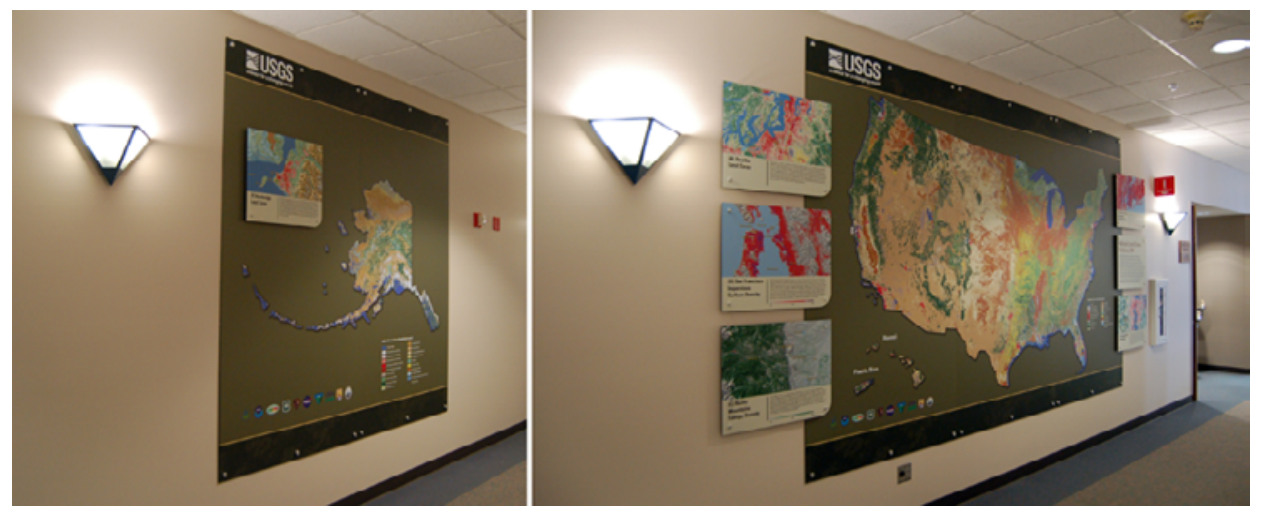

Figure 141. Communications and Outreach designed the National Land Cover Dataset 2001 display, which now hangs outside the training rooms at EROS.

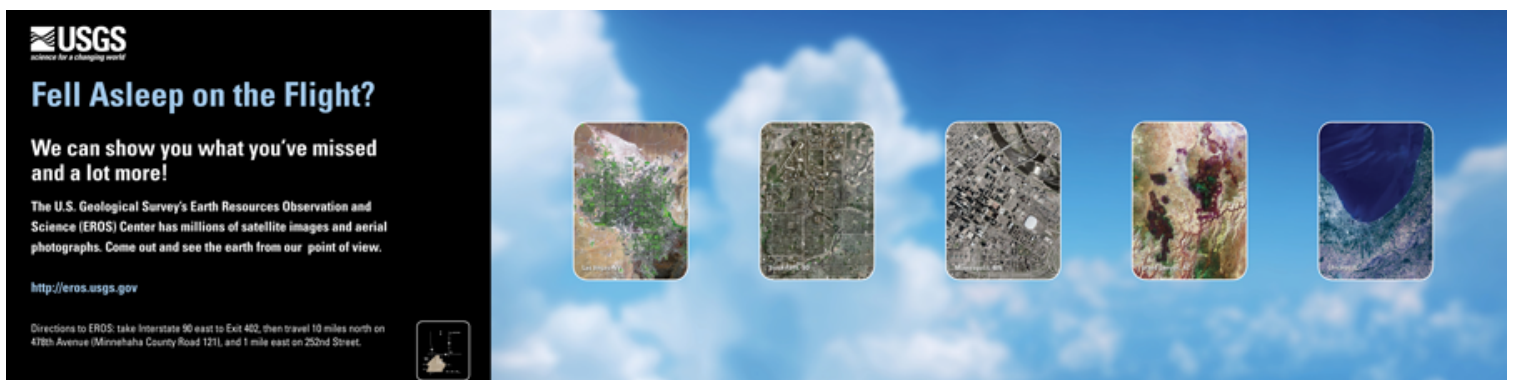

Figure 142. The new display at Sioux Falls Regional Airport shows satellite and high-resolution orthoimagery.

A major achievement was the addition of a third collection to the Earth As Art series. C\&O brought out the intricate features displayed in the 40 Landsat images showing fresh and inspiring glimpses of different parts of our planet's complex surface. The collection includes an eye-catching booklet, two traveling displays of 26' x $28^{\prime}$ canvas images, and user access to download the imagery at no cost from the EROS Image Gallery located on the EROS external website (fig. 143).

FY 2010 also saw the growth of information sharing through the release of the new internal Bulletin Board System, the new EROS internal website, and the EROS Publication Search Tool. The new Bulletin Board System added numerous features, including easier usability and reliable email notifications in response to updates on forums, discussions, and other information. 


\section{EROS Image Gallery » Earth as Art 3}
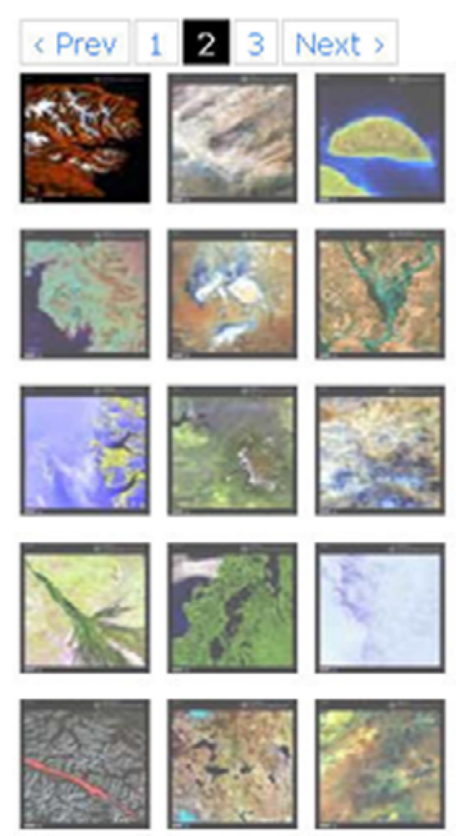

$<$ Prev

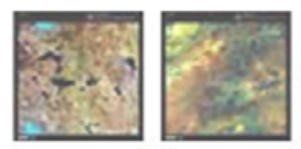

23 Next >

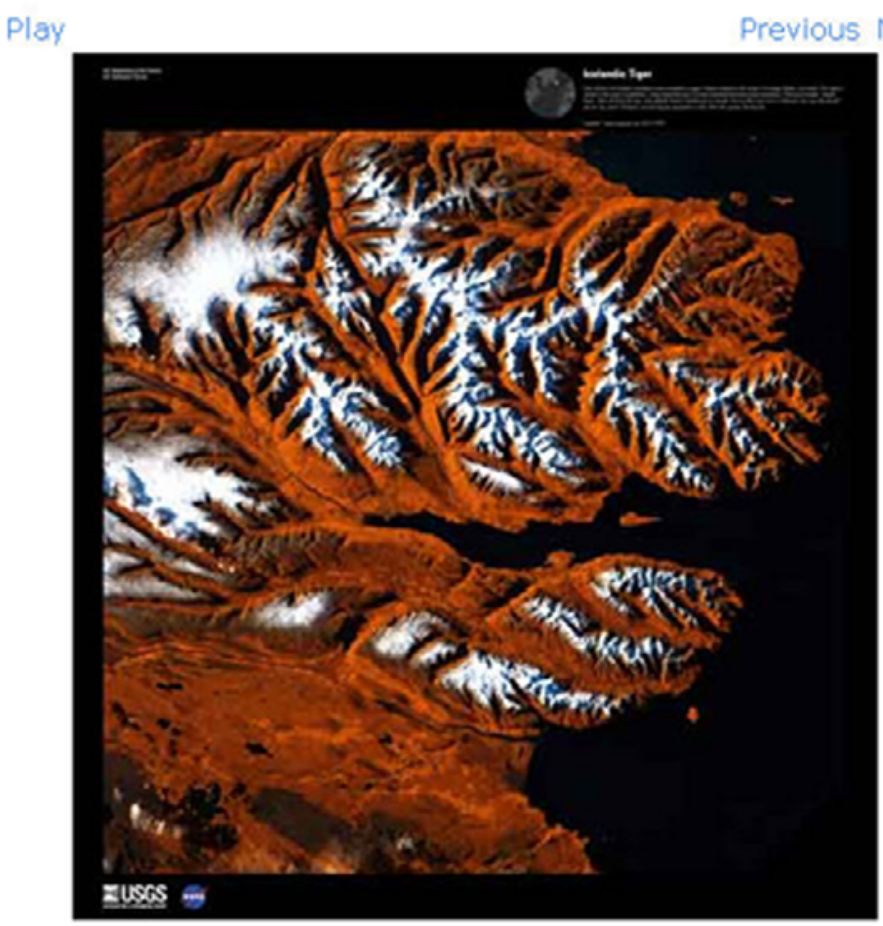

\section{Icelandic Tiger - October 21st, 1999}

Description: This stretch of Iceland's northern coast resembles a tiger's head complete with stripes of orange, black, and white. The tiger's mouth is the great Eyjafjorour, a deep fjord that juts into the mainland between steep mountains. The name means "island fjord," derived from the tiny, tear-shaped Hrisey Island near its mouth. The ice-free port city of Akureyri lies near the fjord's narrow tip, and is Iceland's second largest population center after the capital, Reykjavik.

Collection: Earth as Art 3

Source: Landsat 7 Download: $B$ JPG $\theta$ TIF

Readme: (1) View readme.txt

Figure 143. Example from the Earth As Art 3 image gallery.

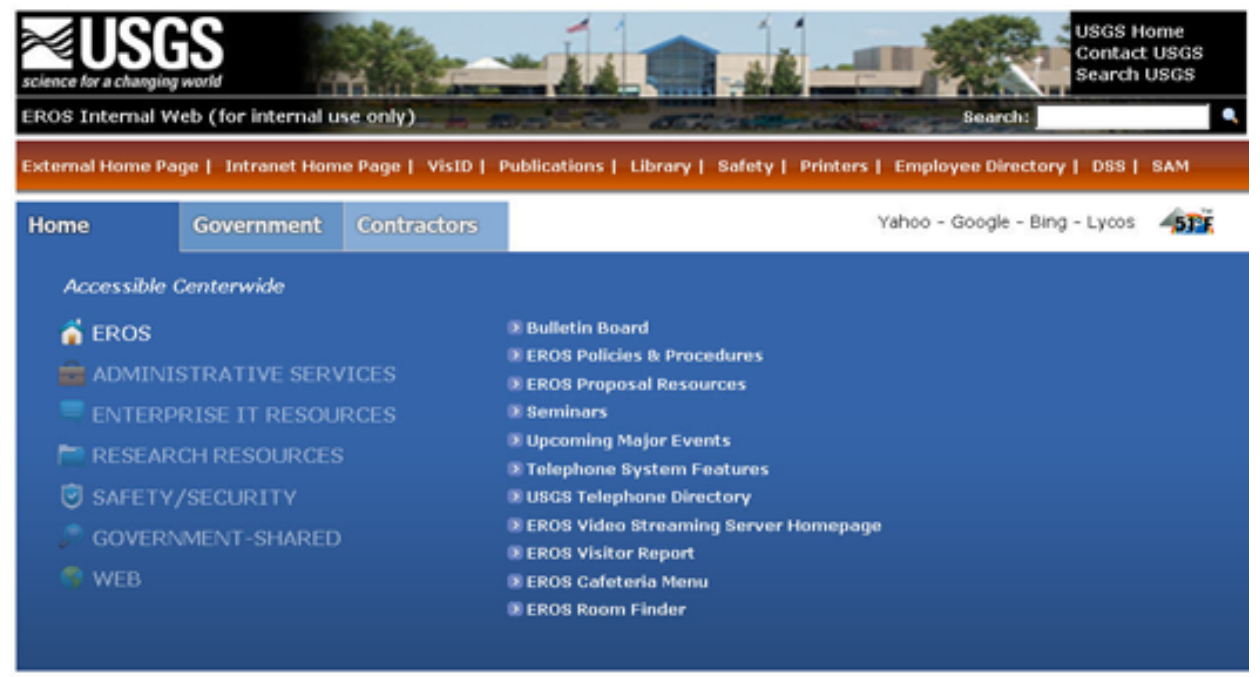

U.S. Aesartment of the interise U.S. Geological Survey URL: http://homedev.cr.usgs.gov/s/Home

Uscoov 答

Figure 144. Screenshot of new internal home page. 
The new EROS internal web (fig. 144) provides a consistent, professional look throughout the entire website while allowing shareholders access to adding, updating, and linking information to their specific areas. The website consists of three main access points: information shared throughout the Center; information for Government use only; and information for Contractor use only. Although it is not necessary to login to view any shared information, an advanced login system is available when needed that recognizes each staff members' affiliation and permits access to the appropriate Government or Contractor pages. The development and release of the new Publication Search tool answered a need to have access to the publications of EROS authors. The archive supporting the search tool took approximately two years to build and includes publications dating from 1973 to the present.

C\&O coordinated EROS staff participation in seven Bureau-sponsored conferences around the Nation: the Geological Society of America (GSA) Annual Meeting, the American Geophysical Union (AGU) Fall Meeting, the Association of American Geographers (AAG) Annual Meeting, the American Society for Photogrammetry and Remote Sensing (ASPRS) Annual Conference, the ESRI International User Conference, the International Geoscience and Remote Sensing Symposium (IGARSS), and the National Science Teacher Association (NSTA) National Conference. EROS support included designing exhibit backdrops, staffing, supplying handouts that highlight EROS science and activities; and individual demonstrations to participants on how to search for and download web-enabled imagery through EarthExplorer and GloVis.

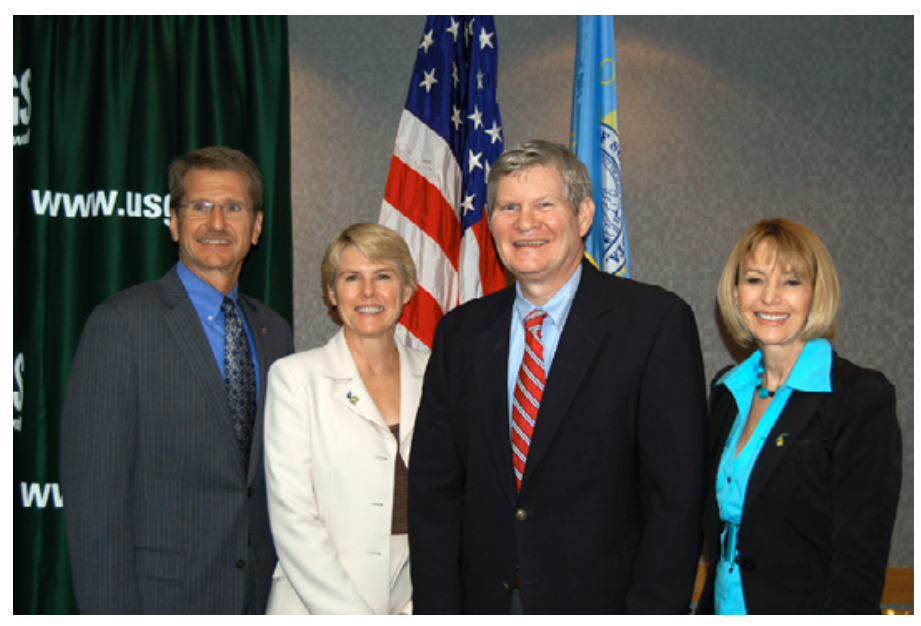

Figure 145. Left to right - South Dakota State University President, David Chicoine; Acting EROS Director, Leslie Armstrong; SD Senator, Tim Johnson; and USGS Director, Marcia McNutt. Photo taken during visit to EROS on September 1st.

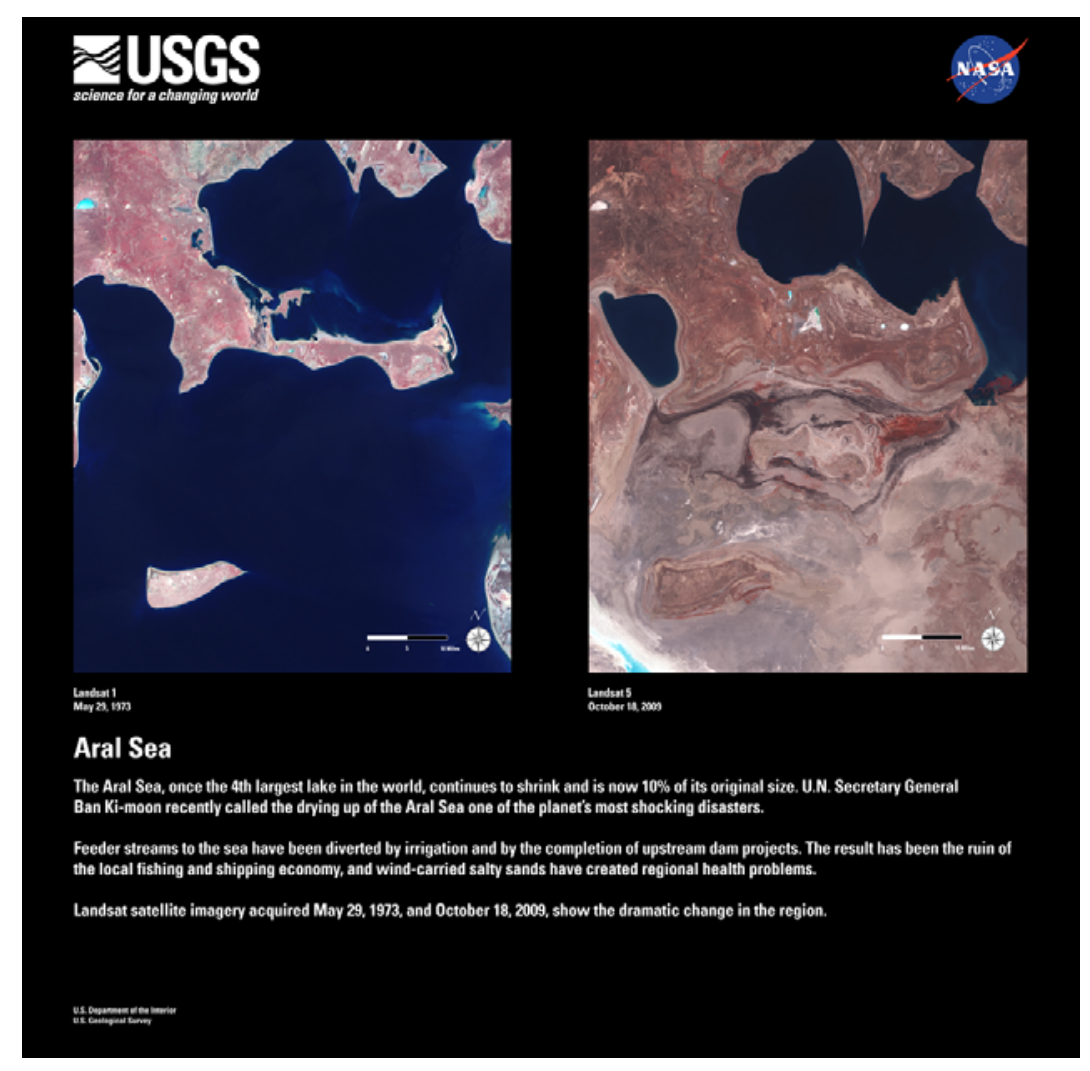

Figure 146. Image of the Week poster depicting the shrinking of the Aral Sea as revealed by Landsat imagery. 
Closer to home, C\&O provided logistic support for a September 1st visit to EROS by USGS Director Marcia McNutt and South Dakota Senator Tim Johnson. In conjunction with the visit, Director McNutt and Senator Johnson visited South Dakota State University (SDSU) to review collaborative activities between the USGS and SDSU. Following the visit to SDSU, Director McNutt, Senator Johnson, and SDSU President, David Chicoine, toured EROS and reviewed numerous EROS science and operations activities (fig. 145).

In addition, $\mathrm{C} \& \mathrm{O}$ coordinated staff participation in nine local or regional conferences and expos: the South Dakota Space Grant Consortium's (SDSGC) Annual Space Days, the American Society for Photogrammetry and Remote Sensing (ASPRS) Fall and Annual Conferences, the International Geoscience and Remote Sensing Symposium (IGARSS), the Sioux Falls Women In Science Conference, the South Dakota State University Annual Geography Convention, the Western South Dakota Hydrology Conference, the Visitor Expo at Ellsworth Air Force Base in South Dakota, and the Annual Neutrino Science Days Expo.

C\&O also developed graphics in support of USGS Headquarters' work involving the Gulf Oil Spill crisis (fig. 147). Additional support was provided in the development of Image of the Week posters (fig. 146), current event posters, conference posters and backdrops, and publications.

For further information contact, Jan Nelson, USGS EROS,jsnelson@usgs.gov.

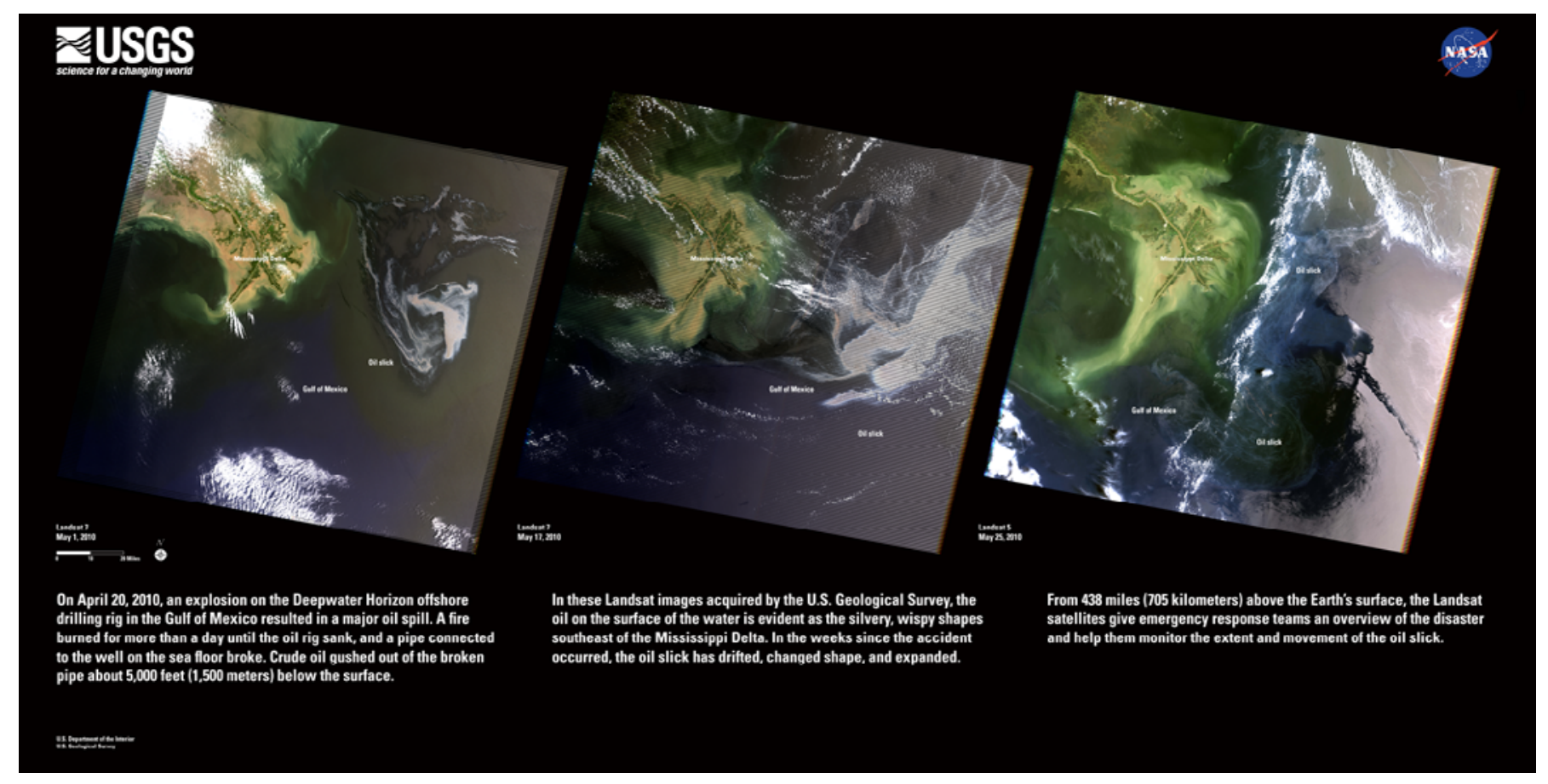

Figure 147. C\&O developed posters of the Gulf Oil Spill to show the public how satellite imagery was helping responders assess the crisis.

\section{Preparing for the Financial Business Management System Implementation}

Fiscal year 2010 was a year of change preparation for the EROS Administrative Service Branch (ASB). ASB, in conjunction with the USGS Financial Business Management System (FBMS) Team, will implement FBMS to provide standardization and integration of business processes across DOI. The ASB Financial Management Team will be the primary users of FBMS and will strive to provide a fully integrated business management system in support of projects and common service activities at EROS. For further information, contact Jane Strand, USGS EROS, strand@usgs.gov.

\section{Partnering}

In today's global world, partnerships are key to achieving long-term, high-quality customer service and innovation. One avenue for pursuing partnerships is through formal agreements. EROS typically establishes and updates 60 to 100 agreements each fiscal year. These agreements establish cooperative partnerships with other countries; domestic and international corporations; internal DOI programs and activities; other Federal, State, county, city organizations; universities, and tribal governments. Examples include: 
- International entities: Landsat agreements with China, Australia, Brazil, Mexico, and Russia; (Department of Natural Resources, Canada), Chinese Academy of Science

- Other Federal Agencies: NASA, DOD (NGB, USAF), USDA, EPA, USFWS, USAID, NIH

- Native America Tribes: Montana-Wyoming Tribal Leaders Council, United Sioux Tribes of South Dakota

For further information, contact Doug Spelhaug, USGS EROS, spelhang@usgs.gov.

\section{Student and Volunteer Programs}

In support of Secretary Salazar's Youth Initiative, EROS has been proactive and committed in hiring students to temporarily support all areas of the organization. These positions, which included administrative, computer, scientific, and engineering oriented students, have increased creativity and innovation in the workplace. Students bring fresh perspectives and ideas to EROS. Additionally, the Youth Initiative has provided EROS the opportunity to form more collaborative, long-term relationships with the universities the students attend. Along with the increase in student hires this fiscal year (2010), we have also seen a significant interest and increase in the Volunteers for Science Program by high school students, college students, and retired individuals. For more information, contact Krislyn Constant, USGS EROS, kconstant@usgs.gov.

\section{Facility Updates}

Award of ARRA Projects. EROS benefited from approximately \$836,000 in American Recovery and Reinvestment Act (ARRA) funding this year and is currently pursuing another $\$ 887,000$ in projects. The Facility Manager coordinated with USGS headquarters to fund a number of items from the USGS Deferred Maintenance List using ARRA monies. Projects included replacing a boiler, recoating the water tower, replacing the roof, designing an HVAC system, upgrading the security access booth, and repairing numerous roads.

Award of Operations and Maintenance (O\&M) Contract. As a large USGS-owned facility, EROS requires approximately 12,000 Preventative Maintenance actions and an additional 3,600 work orders to be performed each year to keep the Center in working order. In support of these requirements, an O\&M contract is awarded every five years. The contract was recompeted in FY10, with the award going to DKC Enterprises of Houston, TX, starting on June 1, 2010.

USGS Facilities Cost Modeling. The USGS Facilities uses cost models to estimate budgets for utilities, facilities staff, and maintenance costs based on the square footage of like buildings. For example, the goal of a cost model is to predict how much it costs to run similar types of buildings, such as office buildings, laboratories, warehouses. Local staff reviewed the Headquarters' cost model and identified areas of concern and suggested factors and data to make the model more accurately project real operating costs. This process is ongoing and further refinements are planned to better align costs for the EROS Mundt Federal Building Model.

EROS National Environmental Policy Act (NEPA) Simplified Contract. Under the NEPA, EROS must ensure no sites of historical significance (for example, churches or tribal grounds) are disturbed as a result of any construction activities. This requires that an archaeological review be completed. These reviews can include comprehensive files research and intensive pedestrian surveys. Frequently, issuing contracts for these services can be time consuming and expensive. Facilities identified a method to more quickly and cost effectively contract for these services. This information was shared with other USGS Regions.

For additional information, contact Bruce Potter, USGS EROS, bpotter@usgs.gov.

\section{Support Service Contracts at the USGS EROS}

In 2008, the Technical Support Services Contract (TSSC) and the Landsat Data Continuity Contract (LDCC) were awarded under separate contracts. A decision was made to recompete these two contracts as one TSSC contract, based on two significant factors. First, the launch date for Landsat 8 slipped to December 2012. The LDCC was scheduled to end March 2012, which would have occurred at a critical point before launch, and the TSSC was scheduled to end March 2013, which would have occurred at a critical postlaunch system checkout phase. The second factor pertained to the modified programmatic direction of the LDCM ground system. The new approach, involving augmentation to the existing Landsat ground system, could be performed more efficiently and for less cost under the new acquisition strategy aligned with the revised launch schedule. The new TSSC was awarded to SGT, Inc. on June 1, 2010, with a contract start date of August 1, 2010. It is an Indefinite Delivery Indefinite Quantity (IDIQ) Task Order contract.

SGT successfully completed Option Year 1 of the Technical Support Services Contract on March 31, 2010. Because of delays in awarding the new TSSC, the contract was extended through July 31, 2010. The TSSC's approximately 350 employees 
provided extensive and varied support critical to USGS EROS missions and responsibilities in science, research, remote sensing, and geographic data and information operations projects. Since this is a performance-based, cost-reimbursement contract, USGS EROS provided quarterly performance evaluations to SGT. The evaluations were based on six performance criteria used to measure TSSC's performance throughout the quarter.

On March 31, 2008, USGS awarded a new Scientific Support Services Contract to Arctic Slope Regional Corporation (ASRC) Research and Technology Solutions (ARTS). ARTS successfully completed the first year of the contract, and Option Year 2 was exercised on March 31,2010. ARTS' 26 employees provided comprehensive support and expertise in advanced and specialized scientific research critical to assisting the USGS EROS in fulfilling its science mission nationally and internationally. For further information, contact Joy Hood, USGS EROS, jhood@usgs.gov.

\section{Selected Research and Technical Publications}

The work cited was published in FY 2010. Names in bold type are affiliated with EROS. Online addresses are provided where available. If a problem or an error is experienced while attempting to access an address, you may need to copy and paste that address into your web browser for access.

\section{Journal Articles}

Albright, T.P., Anderson, D.P., Keuler, N.S., Pearson, S.M., and Turner, M.G., 2009, The spatial legacy of introduction-Celastrus orbiculatus in the southern Appalachians, USA: Journal of Applied Ecology, v. 46, no. 6, p. 1,229-1,238. (Also available online at $h t t p: / / d x . d o i . o r g / 10.1111 / j .1365-2664.2009 .01707 . x$ ).

Albright, T.P., Chen, H., Chen, L., and Guo, Q., 2010, The ecological niche and reciprocal prediction of the disjunct distribution of an invasive species - the example of Ailanthus altissima: Biological Invasions, v. 12, no. 8, p. 2,413-2,427. (Also available online at $h t t p: / / d x$.doi.org/10.1007/s10530-009-9652-8).

Angal, A., Xiong, X., Choi, T. Y., Chander, G., and Wu, A., 2010, Using the Sonoran and Libyan Desert test sites to monitor the temporal stability of reflective solar bands for Landsat 7 Enhanced Thematic Mapper Plus and Terra moderate resolution imaging spectroradiometer sensors: Journal of Applied Remote Sensing, v. 4, no. 1, citation identifier 043525, available only online at $h t t p: / / d x$.doi.org/10.1117/1.3424910.

Balogun, A., Adegoke, J., Vezhapparambu, S., Mauder, M., McFadden, J., and Gallo, K.P., 2009, Surface energy balance measurements above an exurban residential neighbourhood of Kansas City, Missouri: Boundary-Layer Meteorology, v. 133, no. 3, p. 299-321. (Also available online at http://dx.doi.org/10.1007/s10546-009-9421-3).

Barlow, J., Silveira, J.M., and Cochrane, M.A., 2010, Fire scars on amazonian trees - exploring the cryptic fire history of the Ilha de Maracá: Biotropica, v. 42, no. 4, p. 405-409. (Also available online at http://dx.doi.org/10.1111/j.17447429.2010.00646.x.

Bergen, K.M., Goetz, S.J., Dubayah, R.O., Henebry, G.M., Hunsaker, C.T., Imhoff, M.L., Nelson, R.F., Parker, G.G., and Radeloff, V.C., 2009, Remote sensing of vegetation 3-D structure for biodiversity and habitat-review and implications for lidar and radar spaceborne missions: Journal of Geophysical Research-Biogeosciences, v. 114, citation number G00E06. (Also available online at $h t t p: / / d x$.doi.org/10.1029/2008JG000883).

Bliss, N.B., and Maursetter, J., 2010, Soil organic carbon stocks in Alaska estimated with spatial and pedon data: Soil Science Society of America Journal, v. 74, no. 2, p. 565-579. (Also available online at http://dx.doi.org/10.2136/sssaj2008.0404).

Boschetti, L., Roy, D.P., Justice, C.O., and Giglio, L., 2010, Global assessment of the temporal reporting accuracy and precision of the MODIS burned area product: International Journal of Wildland Fire, v. 19, no. 6, p. 705-709. (Also available online at http://dx.doi.org/10.1071/WF09138).

Broich, M., Stehman, S.V., Hansen, M.C., Potapov, P., and Shimabukuro, Y.E., 2009, A comparison of sampling designs for estimating deforestation from Landsat imagery - a case study of the Brazilian Legal Amazon: Remote Sensing of Environment, v. 113, no. 11, p. 2,448-2,454. (Also available online at http://dx.doi.org/10.1016/j.rse.2009.07.011). 
Bruins, R.J.F., Muins Jr., W.R., Botti, S.J., Brink, S., Cleland, D., Kapustka, L., Lee, D., Luzadis, V., McCarthy, L.F., Rana, N., Rideout, D.B., Rollins, M.G., Woodbury, P., and Zupko, M., 2010, A new process for organizing assessments of social, economic, and environmental outcomes - case study of wildland fire management in the USA: Integrated Environmental Assessment and Management, v. 6, no. 3, p. 469-483. (Also available online at http://dx.doi.org/10.1897/IEAM_2009-075.1).

Budde, M.E., Rowland, J.D., and Funk, C.C., 2010, Agriculture and food availability—remote sensing of agriculture for food security monitoring in the developing world: EarthZine, v. 2, no. 2, available only online at http://www.earthzine.org/.

Bwangoy, J.R.B., Hansen, M.C., Roy, D.P., Grandi, G.D., and Justice, C.O., 2010, Wetland mapping in the Congo Basin using optical and radar remotely sensed data and derived topographical indices: Remote Sensing of Environment, v. 114, no. 1, p. 73-86. (Also available online at $h t t p: / / d x . d o i . o r g / 10.1016 / j . r s e .2009 .08 .004)$.

Chander, G., Huang, C., Yang, L., Homer, C.G., and Larson, C., 2009, Developing consistent Landsat data sets for large area applications-the MRLC 2001 Protocol: IEEE Geoscience and Remote Sensing Letters, v. 6, no. 4, p. 777-81. (Also available online at $h t t p: / / d x$. doi.org/10.1109/LGRS.2009.2025244).

Chander, G., Xiong, X., Choi, T., and Angal, A., 2010, Monitoring on-orbit calibration stability of the Terra MODIS and Landsat 7 ETM+ sensors using pseudo-invariant test sites: Remote Sensing of Environment, v. 114, no. 4, p. 925-939. (Also available online at $h t t p: / / d x$.doi.org/10.1016/j.rse.2009.12.003).

Chen, W., and Henebry, G.M., 2009, Change of spatial information under rescaling - a case study using multi-resolution image series: ISPRS Journal of Photogrammetry and Remote Sensing, v. 64, no. 6, p. 592-597. (Also available online at http:// dx.doi.org/10.1016/j.isprsjprs.2009.05.002).

Chen, W., and Henebry, G.M., 2010, Spatio-spectral heterogeneity analysis using EO-1 Hyperion imagery: Computers and Geosciences, v. 36, no. 2, p. 167-170. (Also available online at $h t t p: / / d x . d o i . o r g / 10.1016 / j . c a g e o .2009 .05 .005$ ).

de Beurs, K.M., and Henebry, G.M., 2010, A land surface phenology assessment of the northern polar regions using MODIS reflectance time series: Canadian Journal of Remote Sensing, v. 36, no. Suppl. S1, p. S87-S110. (Also available online at http://pubservices.nrc-cnrc.ca/rp-ps/inDetail.jsp?jcode=cjrs\&lang=eng\&vol=36\&is=S1).

de Beurs, K.M., Wright, C.K., and Henebry, G.M., 2009, Dual scale trend analysis for evaluating climatic and anthropogenic effects on the vegetated land surface in Russia and Kazakhstan: Environmental Research Letters, v. 4, no. 4, article number 045012, available only online at $h t t p: / / d x$.doi.org/10.1088/1748-9326/4/4/045012.

DeFries, R.S., Rudel, T., Uriarte, M., and Hansen, M., 2010, Deforestation driven by urban population growth and agricultural trade in the twenty-first century: Nature Geoscience, v. 3, no. 3, p. 178-181, available only online at http://dx.doi.org/10.1038/ ngeo 756 .

Drummond, M.A., and Loveland, T.R., 2010, Land-use pressure and a transition to forest-cover loss in the Eastern United States: BioScience, v. 60, no. 4, p. 286-298. (Also available online at $h t t p: / / w w w . b i o o n e . o r g / d o i / a b s / 10.1525 / b i o .2010 .60 .4 .7$ ).

Faundeen, J.L., 2010, Appraising U.S. Geological Survey science records: Archival Issues, v. 32, no. 1, p. 7-22.

Fosnight, E.A., 2009, Earth imagery for the masses-TerraLook delivers free satellite imagery for monitoring change: Earth Imaging Journal, v. 4, no. 5, p. 32-36. (Also available online at http://www.eijournal.com/Featured_Articles_directory. asp? cattypeid=7).

Franks, S., Masek, J.G., Headley, R.M., Gasch, J., and Arvidson, T., 2009, Large area scene selection interface (Lassi)-methodology of selecting Landsat imagery for the Global Land Survey 2005: Photogrammetric Engineering and Remote Sensing, v. 75, no. 11, p. 1,287-1,296. (Also available online at http://www.asprs.org/publications/pers/).

Gesch, D.B., 2009, Analysis of lidar elevation data for improved identification and delineation of lands vulnerable to sea level rise: Journal of Coastal Research, v. 53, no. SI, p. 49-58. (Also available online at $h t t p: / / d x$.doi.org/10.2112/SI53-006.1).

Grovenburg, T.W., Jacques, C.N., Klaver, R.W., and Jenks, J.A., 2010, Bed site selection by neonate deer in grassland habitats on the Northern Great Plains: Journal of Wildlife Management, v. 74, no. 6, p. 1,250-1,256. (Also available online at http:// dx.doi.org/10.2193/2009-399). 
Grovenburg, T.W., Jenks, J.A., Jacques, C.H., Klaver, R.W., and Swanson, C.C., 2009, Aggressive defensive behavior by free-ranging white-tailed deer: Journal of Mammalogy, v. 90, no. 5, p. 1,218-1,223. (Also available online at $h t t p: / / d x . d o i$. org/10.1644/08-MAMM-A-360.1).

Grovenburg, T.W., Jenks, J.A., Klaver, R.W., Swanson, C.C., Jacques, C.N., and Todey, D., 2009, Seasonal movements and home ranges of white-tailed deer in north-central South Dakota: Canadian Journal of Zoology, v. 87, no. 10, p. 876-885. (Also available online at $h t t p: / / d x . d o i . o r g / 10.1139 / Z 09-076$ ).

Gu, Y., Brown, J.F., Miura, T., van Leeuwen, W.J., and Reed, B., 2010, Phenological classification of the United States-a geographic framework for extending multi-sensor time-series data: Remote Sensing, v. 2, no. 2, p. 526-544, available only online at $h t t p: / / d x$.doi.org/10.3390/rs2020526.

Gu, Y., and Wylie, B.K., 2010, Detecting ecosystem performance anomalies for land management in the Upper Colorado River Basin using satellite observations, climate data, and ecosystem models: Remote Sensing, v. 2, no. 8, p. 1,880-1,891, available only online at $h t t p: / / d x . d o i . o r g / 10.3390 / r s 2081880$.

Hansen, M.C., Stehman, S.V., and Potapov, P.V., 2010, Quantification of global gross forest cover loss: Proceedings of the National Academy of Sciences, v. 107, no. 19, p. 8,650-8,655. (Also available online at $h t t p: / / d x . d o i . o r g / 10.1073 /$ pnas.0912668107).

Henebry, G.M., and Betancourt, J.L., 2010, Toward a U.S. national phenological assessment: Eos, Transactions, American Geophysical Union, v. 91, no. 1, p. 3. (Also available online at $h t t p: / / d x . d o i . o r g / 10.1029 / 2010 E O 010003$ ).

Holm, T.M., Gallo, K.P., and Bailey, G.B., 2010, The CEOS-Land Surface Imaging Constellation Portal for GEOSS-a resource for land surface imaging system information and data access: Earthzine, available only online at $h t t p: / / w w w . e a r t h-$ zine.org/.

Houet, T., Loveland, T.R., Hubert-Moy, L., Gaucherel, C., Napton, D.E., Barnes, C.A., and Sayler, K.L., 2010, Exploring subtle land use and land cover changes - a framework for future landscape studies: Landscape Ecology, v. 25, no. 2, p. $249-266$. (Also available online at $h t t p: / / d x . d o i . o r g / 10.1007 /$ s10980-009-9362-8).

Houet, T., Verburg, P.H., and Loveland, T.R., 2010, Preface -- Monitoring and modelling landscape dynamics: Landscape Ecology, v. 25, no. 2, p. 163-167. (Also available online at $h t t p: / / d x . d o i . o r g / 10.1007 / s 10980-009-9417-x$ ).

Huang, C., Goward, S.N., Masek, J.G., Thomas, N., Zhu, Z., and Vogelmann, J.E., 2010, An automated approach for reconstructing recent forest disturbance history using dense Landsat time series stacks: Remote Sensing of Environment, v. 114, no. 1, p. 183-198. (Also available online at $h t t p: / / d x . d o i . o r g / 10.1016 / j . r s e .2009 .08 .017$ ).

Ji, L., Wylie, B.K., Ramachandran, B., and Jenkerson, C.B., 2010, A comparative analysis of three different MODIS NDVI data sets for Alaska and adjacent Canada: Canadian Journal of Remote Sensing, v. 36, no. Suppl. 1, p. S149-S167. (Also available online at $h t t p: / / p u b s . n r c-c n r c . g c . c a / c j r s / c j r s . h t m l)$.

Ji, L., Zhang, L., and Wylie, B.K., 2009, Analysis of dynamic thresholds for the normalized difference water index: Photogrammetric Engineering \& Remote Sensing, v. 75, no. 11, p. 1,307-1,317. (Also available online at http://www.asprs.org/publications/pers/).

Ju, J., Roy, D.P., Shuai, Y., and Schaaf, C., 2010, Development of an approach for generation of temporally complete daily nadir MODIS reflectance time series: Remote Sensing of Environment, v. 114, no. 1, p. 1-20. (Also available online at http:// dx.doi.org/10.1016/j.rse.2009.05.022).

Kovalskyy, V., and Henebry, G.M., 2009, Change and persistence in land surface phenologies of the Don and Dnieper river basins: Environmental Research Letters, v. 4, no. 4, article number 045018, available only online at http://dx.doi. org/10.1088/1748-9326/4/4/045018.

Lannoo, M., Kinney, V., Heemeyer, J., Engbrecht, N., Gallant, A.L., and Klaver, R.W., 2009, Mine spoil prairies expand critical habitat for endangered and threatened amphibian and reptile species: Diversity, v. 1, no. 2, p. 118-132, available only online at http://dx.doi.org/10.3390/d1020118.

Lin, W., Wang, B., Li, J., Wang, X., Zeng, L., Yang, L., and Lin, H., 2010, The impact of urbanization on the monthly averaged diurnal cycle in October 2004 in the Pearl River Delta region: Atmosfera, v. 23, no. 1, p. 37-51. (Also available online at http://www.scielo.org.mx/scielo.php?script=sci_issuetoc\&pid=0187-623620100001\&lng=en\&nrm=iso). 
Lioubimtseva, E., and Henebry, G.M., 2009, Climate and environmental change in arid Central Asia-impacts, vulnerability, and adaptations: Journal of Arid Environments, v. 73, no. 11, p. 963-977. (Also available online at http://dx.doi.org/10.1016/j. jaridenv.2009.04.022).

Lu, Z., and Dzurisin, D., 2010, Ground surface deformation patterns, magma supply, and magma storage at Okmok volcano, Alaska, from InSAR analysis - 2. Coeruptive deflation, July-August 2008: Journal of Geophysical Research B-Solid Earth, v. 115, citation number B00B03. (Also available online at $h t t p: / / d x$.doi.org/10.1029/2009jb006970).

Lu, Z., Dzurisin, D., Biggs, J., Wicks Jr., C., and McNutt, S., 2010, Ground surface deformation patterns, magma supply, and magma storage at Okmok volcano, Alaska, from InSAR analysis-1. Intereruption deformation, 1997-2008: Journal of Geophysical Research B-Solid Earth, v. 115, citation number B00B02. (Also available online at $h t t p: / / d x$.doi. org/10.1029/2009jb006969).

Lu, Z., Dzurisin, D., Jung, H.-S., Zhang, J., and Zhang, Y., 2010, Radar image and data fusion for natural hazards characterisa-

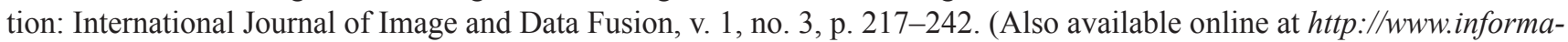
world.com/10.1080/19479832.2010.499219).

Lu, Z., and Wicks, C., 2010, Characterizing 6 August 2007 Crandall Canyon mine collapse from ALOS PALSAR InSAR: Geomatics, Natural Hazards and Risk, v. 1, no. 1, p. 85-93. (Also available online at http://www.informaworld. com/10.1080/19475701003648077).

Lu, Z., Zhang, J., Zhang, Y., and Dzurisin, D., 2010, Monitoring and characterizing natural hazards with satellite InSAR imagery: Annals of GIS, v. 16, no. 1, p. 55-66. (Also available online at http://prod.informaworld. com/10.1080/19475681003700914).

Maxwell, S.K., Meliker, J.R., and Goovaerts, P., 2010, Use of land surface remotely sensed satellite and airborne data for environmental exposure assessment in cancer research: Journal of Exposure Science and Environmental Epidemiology, v. 20, no. 2, p. 176-185. (Also available online at $h t t p: / / d x . d o i . o r g / 10.1038 / j e s .2009 .7$ ).

Melesse, A.M., Loukas, A.G., Senay, G.B., and Yitayew, M., 2009, Preface-Climate change, land-cover dynamics and ecohydrology of the Nile River Basin: Hydrological Processes, v. 23, no. 26, p. 3,651-3,652. (Also available online at $h t t p: / / d x$.doi. org/10.1002/hyp.7522).

Michimi, A., and Wimberly, M.C., 2010, Spatial patterns of obesity and associated risk factors in the conterminous U.S.: American Journal of Preventive Medicine, v. 39, no. 2, p. e1-e12. (Also available online at $h t t p: / / d x . d o i . o r g / 10.1016 / j$. amepre.2010.04.008).

Napton, D.E., Auch, R.F., Headley, R.M., and Taylor, J.L., 2010, Land changes and their driving forces in the southeastern United States: Regional Environmental Change, v. 10, no. 1, p. 37-53. (Also available online at $h t t p: / / d x . d o i . o r g / 10.1007 /$ s10113-009-0084-x).

Numata, I., Cochrane, M.A., Roberts, D.A., Soares, J.V., Souza, C.M., Jr., and Sales, M.H., 2010, Biomass collapse and carbon emissions from forest fragmentation in the Brazilian Amazon: Journal of Geophysical Research—Biogeosciences, v. 115, no. G3, citation number G03027. (Also available online at $h t t p: / / d x$.doi.org/10.1029/2009JG001198).

Pierce Jr., K.B., Ohmann, J.L., Wimberly, M.C., Gregory, M.J., and Fried, J.S., 2009, Mapping wildland fuels and forest structure for land management - a comparison of nearest neighbor imputation and other methods: Canadian Journal of Forest Research, v. 39, no. 10, p. 1,901-1,916. (Also available online at http://dx.doi.org/10.1139/X09-102).

Pijanowski, B.C., Iverson, L.R., Drew, C.A., Bulley, H.N.N., Rhemtulla, J.M., Wimberly, M.C., Bartsch, A., and Peng, J., 2010, Addressing the interplay of poverty and the ecology of landscapes: A Grand Challenge Topic for landscape ecologists?: Landscape Ecology, v. 25, no. 1, p. 5-16. (Also available online at $h t t p: / / d x . d o i . o r g / 10.1007 / s 10980-009-9415-z$ ).

Rover, J.A., Wylie, B.K., and Ji, L., 2010, A self-trained classification technique for producing 30-m percent-water maps from Landsat data: International Journal of Remote Sensing, v. 31, no. 8, p. 2,197-2,203. (Also available online at http://www. informaworld.com/10.1080/01431161003667455).

Roy, D.P., Boschetti, L., Maier, S.W., and Smith, A.M.S., 2010, Field estimation of ash and char colour-lightness using a standard grey scale: International Journal of Wildland Fire, v. 19, no. 6, p. 698-704. (Also available online at http://dx.doi. org/10.1071/WF09133). 
Roy, D.P., Ju, J., Kline, K.L., Scaramuzza, P.L., Kovalskyy, V., Hansen, M., Loveland, T.R., Vermote, E., and Zhang, C., 2010, Web-enabled Landsat Data (WELD)-Landsat ETM+ composited mosaics of the conterminous United States: Remote Sensing of Environment, v. 114, no. 1, p. 35-49. (Also available online at http://dx.doi.org/10.1016/j.rse.2009.08.011).

Roy, D.P., Ju, J., Mbow, C., Frost, P., and Loveland, T.R., 2010, Accessing free Landsat data via the Internet-Africa's challenge: Remote Sensing Letters, v. 1, no. 2, p. 111-117. (Also available online at http://www.informaworld. com/10.1080/01431160903486693).

Senay, G.B., Asante, K., and Artan, G., 2009, Water balance dynamics in the Nile Basin: Hydrological Processes, v. 23, no. 26, p. 3,675-3,681. (Also available online at http://dx.doi.org/10.1002/hyp.7364).

Sohl, T.L., Loveland, T.R., Sleeter, B.M., Sayler, K.L., and Barnes, C.A., 2010, Addressing foundational elements of regional land-use change forecasting: Landscape Ecology, v. 25, no. 2, p. 233-247. (Also available online at http://dx.doi.org/10.1007/ s10980-009-9391-3).

Spindler, B.D., Chipps, S.R., Klumb, R.A., and Wimberly, M.C., 2009, Spatial analysis of pallid sturgeon Scaphirhynchus albus distribution in the Missouri River, South Dakota: Journal of Applied Ichthyology, v. 25, no. Suppl. 2, p. 8-13. (Also available online at http://dx.doi.org/10.1111/j.1439-0426.2009.01283.x).

Stohlgren, T.J., Jarnevich, C.S., and Giri, C.P., 2010, Modeling the human invader in the United States: Journal of Applied Remote Sensing, v. 4, no. 1, citation number 043509, available only online at http://dx.doi.org/10.1117/1.3357386.

Stoker, J.M., 2010, Making Lidar more photogenic - creating band combinations from Lidar information: Photogrammetric Engineering and Remote Sensing, v. 76, no. 3, p. 216-220. (Also available online at http://www.asprs.org/publications/ pers/2010jour.html).

Stoker, J.M., Tyler, D.J., Turnipseed, D.P., Van Wilson, K., and Oimoen, M.J., 2009, Integrating disparate Lidar datasets for a regional storm tide inundation analysis of Hurricane Katrina: Journal of Coastal Research, v. 53, no. SI, p. 66-72. (Also available online at http://dx.doi.org/10.2112/SI53-008.1).

Stryker, T. and Jones, B.K., 2009, Disaster response and the International Charter Program: Photogrammetric Engineering and Remote Sensing, v. 75, no. 12, p. 1,342-1,344. (Also available online at http://www.asprs.org/publications/pers/).

Tadesse, T., Wardlow, B., Hayes, M., Svoboda, M., and Brown, J.F., 2010, The Vegetation Outlook (VegOut)—a new method for predicting vegetation seasonal greenness: GIScience and Remote Sensing, v. 47, no. 1, p. 25-52. (Also available online at http://dx.doi.org/10.2747/1548-1603.47.1.25).

Tan, Z., Tieszen, L.L., Liu, S., and Tachie-Obeng, E., 2010, Modeling to evaluate the response of savanna-derived cropland to warming - drying stress and nitrogen fertilizers: Climatic Change, v. 100, no. 3-4, p. 703-715. (Also available online at http:// dx.doi.org/10.1007/s10584-009-9688-x).

Tang, X., Liu, S., Liu, J., and Zhou, G., 2010, Effects of vegetation restoration and slope positions on soil aggregation and soil carbon accumulation on heavily eroded tropical land of Southern China: Journal of Soils and Sediments, v. 10, no. 3, p. 505-513. (Also available online at http://dx.doi.org/10.1007/s11368-009-0122-9).

Tang, X., Liu, S., and Zhou, G., 2010, Erosion and vegetation restoration impacts on ecosystem carbon dynamics in South China: Soil Science Society of America Journal, v. 74, no. 1, p. 272-281. (Also available online at http://dx.doi.org/10.2136/ sssaj2009.0007).

Weng, Y.-L., Gong, P., and Zhu, Z., 2010, A spectral index for estimating soil salinity in the Yellow River Delta region of China using EO-1 Hyperion data: Pedosphere, v. 20, no. 3, p. 378-388. (Also available online at http://dx.doi.org/10.1016/s 10020160(10)60027-6).

Wey, C.L., Griesse, J., Kightlinger, L., and Wimberly, M.C., 2009, Geographic variability in geocoding success for West Nile virus cases in South Dakota: Health and Place, v. 15, no. 4, p. 1,108-1,114. (Also available online at http://dx.doi. org/10.1016/j.healthplace.2009.06.00). 
White, M.A., de Beurs, K.M., Didan, K., Iinouye, D.W., Richardson, A.D., Jensen, O.P., O’Keefe, J., Zhang, G., Nemani, R.R., van Leeuwen, W.J.D., Brown, J.F., de Wit, A., Schaepman, M., Lin, X.A., Dettinger, M.1., Bailey, A.S., Kimball, J., Schwartz, M.D., Baldocchi, D.D., and Lee, J.T., 2009, Intercomparison, interpretation, and assessment of spring phenology in North America estimated from remote sensing for 198222006: Global Change Biology, v. 15, no. 10, p. 2,335-2,359. (Also available online at $h t t p: / / d x$. doi.org/10.1111/j.1365-2486.2009.01910.x).

Wickham, J.D., Stehman, S.V., Fry, J.A., Smith, J.H., and Homer, C.G., 2010, Thematic accuracy of the NLCD 2001 land cover for the conterminous United States: Remote Sensing of Environment, v. 114, no. 6, p. 1,286-1,296. (Also available online at http://dx.doi.org/10.1016/j.rse.2010.01.018).

Wright, C.K., De Beurs, K.M., Akhmadieva, Z.K., Groisman, P.Y., and Henebry, G.M., 2009, Reanalysis data underestimate significant changes in growing season weather in Kazakhstan: Environmental Research Letters, v. 4, no. 4, article number 045020, available only online at $h t t p: / / d x . d o i . o r g / 10.1088 / 1748-9326 / 4 / 4 / 045020$.

Xian, G., and Homer, C.G., 2010, Updating the 2001 National Land Cover Database impervious surface products to 2006 using Landsat imagery change detection methods: Remote Sensing of Environment, v. 114, no. 8, p. 1,676-1,686. (Also available online at $h t t p: / / d x . d o i . o r g / 10.1016 / j . r s e .2010 .02 .018)$.

Xiong, X., Cao, C., and Chander, G., 2010, An overview of sensor calibration inter-comparison and applications: Frontiers of Earth Science in China, v. 4, no. 2, p. 237-252. (Also available online at $h t t p: / / d x . d o i . o r g / 10.1007 / s 11707-010-0002-z$ ).

Xue, Y.-J., Liu, S., Hu, Y.-M., and Yang, J.-F., 2010, Soil quality assessment using weighted fuzzy association rules: Pedosphere, v. 20, no. 3, p. 334-341. (Also available online at http://dx.doi.org/10.1016/s1002-0160(10)60022-7).

Yuan, W., Liu, S., Liu, H., Randerson, J.T., Yu, G.-R., and Tieszen, L.L., 2010, Impacts of precipitation seasonality and ecosystem types on evapotranspiration in the Yukon River Basin, Alaska: Water Resources Research, v. 46, citation number W02514. (Also available online at $h t t p: / / d x$.doi.org/10.1029/2009WR008119).

Yuan, W., Liu, S., Yu, G., Bonnefond, J.-M., Chen, J., Davis, K., Desai, A.R., Goldstein, A.H., Gianelle, D., Rossi, F., Suyker, A.E., and Verma, S.B., 2010, Global estimates of evapotranspiration and gross primary production based on MODIS and global meteorology data: Remote Sensing of Environment, v. 14, no. 7, p. 1,416-1,431. (Also available online at http://dx.doi. org/10.1016/j.rse.2010.01.022).

Zhang, J., Xu, Y., Yao, F., Wang, P., Guo, W., Li, L., and Yang, L., 2010, Advances in estimation methods of vegetation water content based on optical remote sensing techniques: Science China Technological Sciences, v. 53, no. 5, p. 1,159-1,167. (Also available online at $h t t p: / / w w w . s p r i n g e r l i n k . c o m / c o n t e n t / r 777367 u 5565612 h /)$.

Zhang, L., Wylie, B.K., Ji, L., Gilmanov, T.G., and Tieszen, L.L., 2010, Climate-driven interannual variability in net ecosystem exchange in the northern Great Plains grasslands: Rangeland Ecology \& Management, v. 63, no. 1, p. 40-50. (Also available online at $h t t p: / / d x$.doi.org/10.2111/08-232.1).

Zhang, Y., Zhang, J., Lu, Z., and Gong, W., 2009, A new numerical method for calculating extrema of received power for polarimetric SAR: IEEE Geoscience and Remote Sensing Letters, v. 6, no. 4, p. 666-670. (Also available online at $h t t p: / / d x . d o i$. org/10.1109/LGRS.2009.2022958).

Zhao, S., Liu, S., Li, Z., and Sohl, T.L., 2010, Federal land management, carbon sequestration, and climate change in the Southeastern U.S. - a case study with Fort Benning: Environmental Science \& Technology, v. 44, no. 3, p. 992-997. (Also available online at $h$ ttp://dx.doi.org/10.1021/es9009019).

Zhao, S., Liu, S., Li, Z., and Sohl, T.L., 2010, A spatial resolution threshold of land cover in estimating terrestrial carbon sequestration in four counties in Georgia and Alabama, USA: Biogeosciences, v. 7, no. 1, p. 71-80. (Also available online at http://www.biogeosciences.net/7/71/2010/).

Zhao, S., Liu, S., Yin, R., Li, Z., Deng, Y., Tan, K., Deng, X., Rothstein, D., and Qi, J., 2010, Quantifying terrestrial ecosystem carbon dynamics in the Jinsha Watershed, Upper Yangtze, China from 1975 to 2000: Environmental Management, v. 45, no. 3, p. 466-475. (Also available online at $h t t p: / / d x . d o i . o r g / 10.1007 / s 00267-009-9285-9$ ).

Zhu, Q., Jiang, H., Liu, J., Wei, X., Peng, C., Fang, X., Liu, S., Zhou, G., Yu, S., and Ju, W., 2010, Evaluating the spatiotemporal variations of water budget across China over 1951-2006 using IBIS model: Hydrological Processes, v. 24, no. 4, p. 429-445. (Also available online at http://dx.doi.org/10.1002/hyp.7496). 


\section{Book Chapters}

de Beurs, K.M., and Henebry, G.M., 2010, Spatio-temporal statistical methods for modelling land surface phenology, chap. 9 in Hudson, I.L., and Keatley, M.R., eds., Phenological research - methods for environmental and climate change analysis: London, Springer, p. 177-208. (Also available online at $h t t p: / / d x$.doi.org/10.1007/978-90-481-3335-2_9).

Duda, K.A., Ramsey, M., Wessels, R., and Dehn, J., 2009, Optical satellite volcano monitoring - a multi-sensor rapid response system, chap. 22 in Ho, P-G.P., ed., Geoscience and remote sensing: Vukovar, Croatia, IN-TECH Press, p. 473-496. (Also available online at http://sciyo.com/articles/show/title/optical-satellite-volcano-monitoring-a-multi-sensor-rapid-responsesystem).

Funk, C.C., and Verdin, J.P., 2010, Real-time decision support systems - the Famine Early Warning System Network, chap. 17 in Gebremichael, M., and Hossain, F., eds., Satellite rainfall applications for surface hydrology: New York, Springer, p. $295-320$.

Liu, S., 2009, Quantifying the spatial details of carbon sequestration potential and performance, chap. 7 in McPherson, B. and Sundquist, E., eds., Carbon sequestration and its role in the global carbon cycle: Washington, D.C., American Geophysical Union, p. 117-128.

Lu, Z., and Kwoun, O., 2009, Interferometric synthetic aperture radar (InSAR) study of coastal wetlands over southeastern Louisiana, chap. 2 in Wang, Y.Q., ed., Remote sensing of coastal environments: Washington, D.C., CRC Press, p. $25-60$.

Reij, C., Tappan, G.G., and Smale, M., 2009, Re-Greening the Sahel-farmer-led innovation in Burkina Faso and Niger, chap. 7 in Spielman, D.J., and Pandya-Lorch, R., eds., Millions fed - proven successes in agricultural development: Washington, D.C., International Food Policy Research Institute, p. 53-58. (Also available online at http://www.ifpri.org/book-5826/millionsfed/pubs).

Yang, L., Lin, W., Zhang, L., Lin, H., and Du, D., 2009, Contemporary land use and land cover change in coastal Pearl River Delta and its impact on regional climate, chap. 19 in Wang, Y.Q., ed., Remote sensing of coastal environments: Washington, D.C., CRC Press, p. 369-394.

Yang, L., Sang, H., Lin, H., and Chen, J., 2009, Quantifying biophysical conditions of herbaceous wetland vegetation in Poyang Lake of coastal China via multi-temporal SAR imagery and in-situ measurements, chap. 14 in Wang, Y.Q., ed., Remote sensing of coastal environments: Washington, D.C., CRC Press, p. 281-296.

\section{Reports}

\section{USGS Fact Sheets}

Funk, C.C., 2010, A climate trend analysis of Kenya-August 2010: U.S. Geological Survey Fact Sheet, 2010-3074, 4 p. (Also available online at $h t t p: / / p u b s . u s g s . g o v / f s / 2010 / 3074 /)$.

Headley, R.M., 2010, Landsat-A global land-imaging project: U.S. Geological Survey Fact Sheet, 2010-3026, 4 p. (Also available online at $h t t p: / / p u b s . u s g s . g o v / f s / 2010 / 3026 /)$.

Jones, B.K., and Bewley, R.D., 2010, The Hazards Data Distribution System is updated: U.S. Geological Survey Fact Sheet, 2010-3053, 1 p. (Also available online at $h t t p: / / p u b s . u s g s . g o v / f s / 2010 / 3053 /)$.

Jucht, C., 2010, Joint Agency Commercial Imagery Evaluation (JACIE): U.S. Geological Survey Fact Sheet, 2010-3080, 2 p. (Also available online at $h t t p: / / p u b s . u s g s . g o v / f_{s} / 2010 / 3080 /$ ).

Poppenga, S.K., Evans, G.A., Gesch, D.B., Stoker, J.M., Queija, V., Worstell, B.B., Tyler, D., Danielson, J.J., Bliss, N.B., and Greenlee, S.M., 2010, Topographic Science: U.S. Geological Survey Fact Sheet, 2010-3049, 4 p. (Also available online at $h t t p: / / p u b s . u s g s . g o v / f s / 2010 / 3049 /)$. 


\section{USGS Open-File Reports}

Balser, A.W., and Wylie, B.K., 2010, Multitemporal L- and C-band synthetic aperture radar to highlight differences in water status among boreal forest and wetland systems in the Yukon Flats, interior Alaska: U.S. Geological Survey Open-File Report 2010-1027, 18 p. (Also available online at http://pubs.usgs.gov/of/2010/1027/).

Jenkerson, C.B., Maiersperger, T.K., and Schmidt, G.L., 2010, eMODIS - a user-friendly data source: U.S. Geological Survey Open-File Report 2010-1055, 10 p. (Also available online at http://pubs.er.usgs.gov/usgspubs/ofr/ofr20101055).

Karstensen, K.A. and Sayler, K.L., 2009, Land-cover change in the Lower Mississippi Valley, 1973-2000: U.S. Geological Survey Open-File Report, 2009-1280, 12 p. (Also available online at http://pubs.er.usgs.gov/usgspubs/ofr/ ofr20091280? from=home).

Sundquist, E.T., Ackerman, K.V., Bliss, N.B., Kellndorfer, J.M., Reeves, M.C., and Rollins, M.B., 2009, Rapid assessment of U.S. forest and soil organic carbon storage and forest biomass carbon sequestration capacity: U.S. Geological Survey OpenFile Report, 2009-1283, 15 p., available only online at http://pubs.er.usgs.gov/usgspubs/ofr/ofr20091283.

Williams, A.P., and Funk, C.C., 2010, A westward extension of the tropical Pacific warm pool leads to March through June drying in Kenya and Ethiopia: U.S. Geological Survey Open-File Report, 2010-1199, 7 p. (Also available online at http://pubs. usgs.gov/of/2010/1199/).

Zhu, Z., ed., Bergamaschi, B., Bernknopf, R., Clow, D., Dye, D., Faulkner, S., Forney, W., Gleason, R., Hawbaker, T., Liu, J., Liu, S., Prisley, S., Reed, B., Reeves, M., Rollins, M.G., Sleeter, B., Sohl, T.L., Stackpoole, S., Stehman, S.V., Striegl, R., Wein, A., and Zhu, Z., 2010, Public review draft—a method for assessing carbon stocks, carbon sequestration, and greenhouse-gas fluxes in ecosystems of the United States under present conditions and future scenarios: U.S. Geological Survey Open-File Report, 2010-1144, 196 p. plus nine appendixes, available only online at http://pubs.er.usgs.gov/usgspubs/ofr/ ofr20101144.

\section{USGS Scientific Investigations Reports}

Gesch, D.B., 2009, Mapping and visualization of storm-surge dynamics for Hurricane Katrina and Hurricane Rita: U.S. Geological Survey Scientific Investigations Report, 2009-5230, 26 p. (Also available online at http://pubs.er.usgs.gov/usgspubs/ sir/sir20095230).

Johnston, C.M., Dewald, T.G., Bondelid, T.R., Worstell, B.B., McKay, L.D., Rea, A.M., R.B., and Goodall, J.L., 2009, Evaluation of catchment delineation methods for the medium-resolution National Hydrography Dataset: U.S. Geological Survey Scientific Investigations Report, 2009-5233, 88 p. (Also available online at http://pubs.er.usgs.gov/usgspubs/sir/sir20095233).

Mack, T.J., Akbari, M.A., Ashoor, M.H., Chornack, M.P., Coplen, T.B., Emerson, D.G., Hubbard, B.E., Litke, D.W., Michel, R.L., Plummer, L.N., Rezai, M.T., Senay, G.B., Verdin, J.P., and Verstraeten, I.M., 2010, Conceptual model of water resources in the Kabul Basin, Afghanistan: U.S. Geological Survey Scientific Investigations Report, 2009-5262, 240 p. (Also available online at http://pubs.er.usgs.gov/usgspubs/sir/sir20095262).

Poppenga, S.K., Worstell, B.B., Stoker, J.M., and Greenlee, S.M., 2010, Using selective drainage methods to extract continuous surface flow from 1-meter Lidar-derived digital elevation data: U.S. Geological Survey Scientific Investigations Report, 2010-5059, 12 p. (Also available online at http://pubs.er.usgs.gov/usgspubs/sir/sir20105059).

\section{Non-USGS Discussion Paper}

Reij, C., Tappan, G.G., and Smale, M., 2009, Agroenvironmental transformation in the Sahel—another kind of "Green Revolution”: International Food Policy Research Institute Discussion Paper, 914, 52 p. (Also available online at http://www.ifpri.org/ book-5826/millionsfed/pubs). 


\section{Conference Papers}

Irons, J.R., and Dwyer, J.L., 2010, An overview of the Landsat Data Continuity Mission, in Shen, S.S., and Lewis, P.E., eds., Algorithms and Technologies for Multispectral, Hyperspectral, and Ultraspectral Imagery XVI, Orlando, Fla., April 2010, Proceedings of SPIE Vol. 7695: Bellingham, Wash., Society of Photo-Optical Instrumentation Engineers, paper number 769508. (Also available online at $h t t p: / / d x$. doi.org/10.1117/12.850416).

Seifert, F.M., Costa, H., Rosenqvist, A., Holm, T.M., and Crevier, Y., 2010, Coordination of space data acquisition in support of geo forest carbon tracking, in European Space Agency Living Planet Symposium, Bergen, Norway, 28 June-2 July 2010.

\section{Conference Presentations}

Allen, J.E., Johnson, A., and Headley, R.M., 2009, Integrated Geospatial Education and Technology Training (iGETT) for workforce development [abs.], in Fall Meeting, San Francisco, Calif., 14-18 December 2009, Eos Transactions, Suppl., v. 90, no. 52: Washington, D.C., American Geophysical Union, abstract number ED41D-0545. (Also available online at $h t t p: / / w w w$. agu.org/meetings/fm09/waisfm09adv.html).

Auch, R.F., 2010, Contemporary U.S. industrial forestry - a geographical exploration of America's wood baskets [abs.], in Annual Meeting, Washington, D.C., 14-18 April 2010, Proceedings: Washington, D.C., American Association of Geographers, abstract ID 28708. (Also available online at http://meridian.aag.org/callforpapers/program/AbstractDetail. cfm? AbstractID $=28708$ ).

Behnke, J., Hall, A., Meyer, D.J., Sohre, T., and Doescher, C., 2009, Recent release of the ASTER global DEM product [abs.], in Fall Meeting, San Francisco, Calif., 14-18 December 2009, Eos Transactions, Suppl., v. 90, no. 52: Washington, D.C., American Geophysical Union, abstract number IN12A-07. (Also available online at http://www.agu.org/meetings/fm09/waisfm09adv.html).

Bennett, B., Wood, E.C., Meyer, D.J., Maynard, N., and Pandya, R.E., 2009, NASA NDATC global climate change education initiative [abs.], in Fall Meeting, San Francisco, Calif., 14-18 December 2009, Eos Transactions, Suppl., v. 90, no. 52: Washington, D.C., American Geophysical Union, abstract number ED33A-0555. (Also available online at $h t t p: / / w w w . a g u$. org/meetings/fm09/waisfm09adv.html).

Bliss, N.B., 2010, Detailed soil properties from SSURGO for USGS modeling [abs.], in Understanding and predicting for a changing world, USGS Modeling Conference, 3rd, Denver, Colo., 7-11 June 2010, U.S. Geological Survey.

Bliss, N.B., Waltman, S.W., and West, L., 2009, Detailed mapping of soil organic carbon stocks in the United States using SSURGO [abs.], in Fall Meeting, San Francisco, Calif., 14-18 December 2009, Eos Transactions, Suppl., v. 90, no. 52: Washington, D.C., American Geophysical Union, abstract number B51F-0367. (Also available online at http://www.agu.org/ meetings/fm09/waisfm09adv.html).

Bouchard, M.A., Dwyer, J.L., and Granneman, B.J., 2009, A Yukon River Basin Landsat mosaic for assessing environmental change [abs.], in Fall Meeting, San Francisco, Calif., 14-18 December 2009, Eos Transactions, Suppl., v. 90, no. 52: Washington, D.C., American Geophysical Union, abstract number GC51A-0708. (Also available online at http://www.agu.org/ meetings/fm09/waisfm09adv.html).

Boyte, S.P., Wylie, B.K., Gu, Y., and Major, D.J., 2010, Ecosystem performance models for multiple land types and climate change effects on Big Sagebrush in the Owyhee Uplands [abs.], in Understanding and predicting for a changing world, USGS Modeling Conference, 3rd, Denver, Colo., 7-11 June 2010, U.S. Geological Survey.

Boyte, S.P., Wylie, B.K., Gu, Y., and Major, D.J., 2010, Modeling future climate change effects on Big Sagebrush (Artemisia tridentata) and the ecosystem performance of five rangeland types in the Owyhee Uplands, USA [poster], in Understanding the past, informing decisions for the future, Climate Change Science Conference, Denver, Colo., 9-11 March 2010, U.S. Geological Survey.

Boyte, S.P., Wylie, B.K., Gu, Y., and Major, D.J., 2010, Modeling rangeland performance and climate change effects on Big Sagebrush in the Owyhee Uplands [poster], in Workshop on natural resource needs related to climate change in the Great Basin and Mojave Desert—research, adaptation, mitigation, Las Vegas, Nev., 20-22 April 2010, USGS/EPA/USFWS/NPS. 
Brown, J.F., Anderson, M.C., Wardlow, B.D., and Svoboda, M.D., 2009, Remote sensing techniques for monitoring drought hazards - an intercomparison (Invited) [abs.], in Fall Meeting, San Francisco, Calif., 14-18 December 2009, Eos Transactions, Suppl., v. 90, no. 52: Washington, D.C., American Geophysical Union, abstract number NH41D-01. (Also available online at http://www.agu.org/meetings/fm09/waisfm09adv.html).

Brown, J.F., Wardlow, B.D., and Tadesse, T., 2010, Advantages of real-time satellite data for operational drought monitoringthe utility of MODIS and AVHRR [abs.], in Annual Meeting, Washington, D.C., 14-18 April 2010, Proceedings: Washington, D.C., American Association of Geographers, abstract ID 28284. (Also available online at http://communicate.aag.org/eseries/ aag_org/program/index.cfm?mtgID=55).

Budde, M.E., Ward, D.H., Ely, C.R., Handel, C.M., and Hupp, J.W., 2009, Altering their ecological niche—investigating the response of avian migrants to changes in vegetation phenology at northern latitudes [abs.], in Fall Meeting, San Francisco, Calif., 14-18 December 2009, Eos Transactions, Suppl., v. 90, no. 52: Washington, D.C., American Geophysical Union,

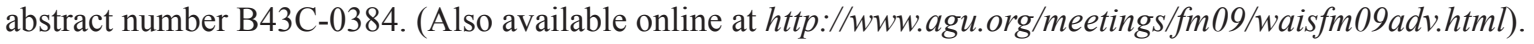

Chen, M., Liu, S., Yuan, W., Liu, H., and Randerson, J.T., 2009, Sequential parameter estimation of a terrestrial ecosystem model against eddy covariance measurements by smoothed Ensemble Kalman Filter [abs.], in Fall Meeting, San Francisco, Calif., 14-18 December 2009, Eos Transactions, Suppl., v. 90, no. 52: Washington, D.C., American Geophysical Union, abstract number B33B-0392. (Also available online at $h t t p: / / w w w . a g u . o r g / m e e t i n g s / f m 09 / w a i s f m 09 a d v . h t m l$ ).

Danielson, J.J., 2010, A new enhanced global digital elevation model (DEM) — final accuracy assessment and hydrological comparisons [abs.], in Annual Meeting, Washington, D.C., 14-18 April 2010, Proceedings: Washington, D.C., American Association of Geographers, abstract ID 29570. (Also available online at http://communicate.aag.org/eseries/aag_org/program/index.cfm? $m \operatorname{tg} I D=55)$.

Dinardo, T., and Dwyer, J.L., 2010, Developing essential climate variables for terrestrial modeling and monitoring [abs.], in Understanding and predicting for a changing world, USGS Modeling Conference, 3rd, Denver, Colo., 7-11 June 2010, U.S. Geological Survey.

Foster, J.H., Cherubini, T., Manjunath, D.V., Murphy, M., Brooks, B.A., Businger, S., Albers, S.C., Lu, Z., Poland, M.P., Chen, S., and Mass, C., 2009, Numerical weather models and mitigating atmospheric artifacts in InSAR [abs.], in Fall Meeting, San Francisco, Calif., 14-18 December 2009, Eos Transactions, Suppl., v. 90, no. 52: Washington, D.C., American Geophysical Union, abstract number G23A-0664. (Also available online at $h t t p: / / w w w . a g u . o r g / m e e t i n g s / f m 09 / w a i s f m 09 a d v . h t m l$ ).

Gesch, D.B., 2010, Elevation uncertainty in sea-level rise assessment- - how much land is really at risk? [abs.], in Annual Meeting, Washington, D.C., 14-18 April 2010, Proceedings: Washington, D.C., American Association of Geographers, abstract ID 28054. (Also available online at http://communicate.aag.org/eseries/aag_org/program/index.cfm?mtgID=55).

Gu, Y., Brown, J.F., and Hawbaker, T.J., 2009, The relationship between climate and satellite-derived vegetation phenology [abs.], in Fall Meeting, San Francisco, Calif., 14-18 December 2009, Eos Transactions, Suppl., v. 90, no. 52: Washington, D.C., American Geophysical Union, abstract number B43C-0385. (Also available online at http://www.agu.org/meetings/ fm09/waisfm09adv.html).

Gu, Y., and Wylie, B.K., 2010, Detecting ecosystem performance anomalies in the upper Colorado River Basin-implication for land management [poster], in Conference on the environment, Portland, Oreg., 26-30 May 2010, U.S. Department of the Interior.

Hato, M., Tsu, H., Tachikawa, T., Abrams, M., and Bailey, G.B., 2009, The ASTER Global Digital Elevation Model (GDEM)— for societal benefit [abs.], in Fall Meeting, San Francisco, Calif., 14-18 December 2009, Eos Transactions, Suppl., v. 90 ,

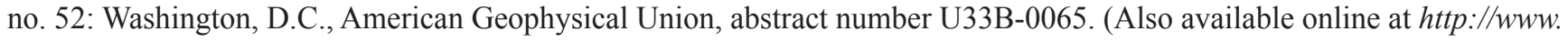
agu.org/meetings/fm09/waisfm09adv.html).

Hawbaker, T.J., Rollins, M.G., Vogelmann, J.E., Shi, H., and Sohl, T.L., 2009, A national disturbance modeling system to support ecological carbon sequestration assessments [abs.], in Fall Meeting, San Francisco, Calif., 14-18 December 2009, Eos Transactions, Suppl., v. 90, no. 52: Washington, D.C., American Geophysical Union, abstract number B52C-03. (Also available online at $h t t p: / / w w w . a g u . o r g / m e e t i n g s / f m 09 / w a i s f m 09 a d v . h t m l)$.

Hawbaker, T.J., Rollins, M.G., Vogelmann, J.E., Shi, H., and Zhu, Z., 2010, Disturbances on ecological carbon sequestration and greenhouse gas emissions [abs.], in Understanding and predicting for a changing world, USGS Modeling Conference, 3rd, Denver, Colo., 7-11 June 2010, U.S. Geological Survey. 
Headley, R.M., 2009, Enabling new research with free Landsat data [abs.], in Fall Meeting, San Francisco, Calif., 14-18 December 2009, Eos Transactions, Suppl., v. 90, no. 52: Washington, D.C., American Geophysical Union, abstract number

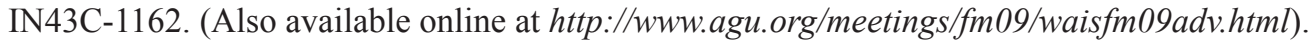

Headley, R.M., and Allen, J., 2010, Enabling educators with free Landsat data [abs.], in Annual Meeting, Washington, D.C., 14-18 April 2010, Proceedings: Washington, D.C., American Association of Geographers, abstract ID 28193. (Also available online at http://communicate.aag.org/eseries/aag_org/program/index.cfm?mtgID=55).

Heidemann, H.K., 2010, The role of common standards, practices, and specifications in national Lidar [abs.], in Annual Meeting, Washington, D.C., 14-18 April 2010, Proceedings: Washington, D.C., American Association of Geographers, abstract ID 33495. (Also available online at http://communicate.aag.org/eseries/aag_org/program/index.cfm?mtgID=55).

Homer, C.G., 2010, The National Land Cover Database, current status and future plans [abs.], in Annual Meeting, Washington, D.C., 14-18 April 2010, Proceedings: Washington, D.C., American Association of Geographers, abstract ID 28209. (Also available online at http://communicate.aag.org/eseries/aag_org/program/index.cfm?mtgID=55).

Huang, C., Li, A., Shi, H., Sun, G., Zhu, Z., Goward, S.N., and Masek, J., 2009, Developing a fine resolution forest height map for Mississippi using Landsat time series observations and GLAS lidar data [abs.], in Fall Meeting, San Francisco, Calif., 14-18 December 2009, Eos Transactions, Suppl., v. 90, no. 52: Washington, D.C., American Geophysical Union, abstract number B23F-03. (Also available online at http://www.agu.org/meetings/fm09/waisfm09adv.html).

Huang, S., Liu, S., Young, C., Rover, J.A., Heidemann, H.K., Mushet, D., Euliss, N., and Feng, M., 2010, Combining National Wetland Inventory, Landsat, and LIDAR to model the wetland water storage in the prairie pothole region of the United States [abs.], in Understanding and predicting for a changing world, USGS Modeling Conference, 3rd, Denver, Colo., 7-11 June 2010, U.S. Geological Survey.

Jenkerson, C.B., Meyer, D.J., and Didian, K., 2009, Case study for EOSDIS support to MEaSUREs - the vegetation index and vegetation phenology ESDRs [abs.], in Fall Meeting, San Francisco, Calif., 14-18 December 2009, Eos Transactions, Suppl., v. 90, no. 52: Washington, D.C., American Geophysical Union, abstract number IN43C-1165. (Also available online at http:// www.agu.org/meetings/fm09/waisfm09adv.html).

Ji, L., Wylie, B.K., Ramachandran, B., and Jenkerson, C.B., 2009, Comparison of eMODIS and standard MODIS NDVI products for Alaska and adjacent Canada [abs.], in Fall Meeting, San Francisco, Calif., 14-18 December 2009, Eos Transactions, Suppl., v. 90, no. 52: Washington, D.C., American Geophysical Union, abstract number IN33D-1069. (Also available online at http://www.agu.org/meetings/fm09/waisfm09adv.html).

Ji, L., Wylie, B.K., Ramachandran, B., and Jenkerson, C.B., 2010, Comparison of eMODIS and standard MODIS NDVI products for Alaska and adjacent Canada [poster], in Understanding the past, informing decisions for the future, Climate Change Science Conference, Denver, Colo., 9-11 March 2010, U.S. Geological Survey.

Ji, L., Zhang, L., and Wylie, B.K., 2010, Evaluation of normalized difference water index for mapping surface water bodies [abs.], in Annual Meeting, Washington, D.C., 14-18 April 2010, Washington, D.C., American Association of Geographers, abstract ID 31688. (Also available online at http://communicate.aag.org/eseries/aag_org/program/index.cfm? mtgID=55).

Jones, B.K., 2009, USGS emergency response and the International Charter Space and Major Disasters [abs.], in Fall Meeting, San Francisco, Calif., 14-18 December 2009, Eos Transactions, Suppl., v. 90, no. 52: Washington, D.C., American Geophysical Union, abstract number NH42A-08. (Also available online at $h$ ttp://www.agu.org/meetings/fm09/waisfm09adv.html).

Killough, B.D., Chander, G., and Gowda, S., 2009, A Web-based Google-Earth coincident imaging tool for satellite calibration and validation [abs.], in Fall Meeting, San Francisco, Calif., 14-18 December 2009, Eos Transactions, Suppl., v. 90, no. 52: Washington, D.C., American Geophysical Union, abstract number U51B-0016. (Also available online at http://www.agu.org/ meetings/fm09/waisfm09adv.html).

Li, Z., Liu, S., and Tan, Z., 2009, Simulating regional $\mathrm{CO}_{2}$ fluxes in the mid-continent region using GEMS [abs.], in Fall Meeting, San Francisco, Calif., 14-18 December 2009, Eos Transactions, Suppl., v. 90, no. 52: Washington, D.C., American Geophysical Union, abstract number B51E-0336. (Also available online at http://www.agu.org/meetings/fm09/waisfm09adv.html).

Liu, J., Liu, S., Oeding, J., Sohl, T.L., and Bliss, N.B., 2010, Estimating soil erosion and deposition under future climate and land cover change scenario-USPED model application in the Mississippi plains [abs.], in Understanding and predicting for a changing world, USGS Modeling Conference, 3rd, Denver, Colo., 7-11 June 2010, U.S. Geological Survey. 
Liu, J., Sleeter, B.M., Key, C., Zhu, Z., Liu, S., Sohl, T.L., Vogelmann, J.E., Price, D., Chen, J., Cochrane, M., Eidenshink, J.C., Howard, S.M., Bliss, N.B., and Jiang, H., 2010, Estimating vegetation carbon changes in the western United States because of land use change, climate change, and natural disturbance-1951-2006 [abs.], in Understanding and predicting for a changing world, USGS Modeling Conference, 3rd, Denver, Colo., 7-11 June 2010, U.S. Geological Survey.

Liu, S., and Land Carbon Team, 2010, Ecological carbon sequestration under projected land cover and climate change in Mississippi plains - model intercomparison and analysis [abs.], in Understanding and predicting for a changing world, USGS Modeling Conference, 3rd, Denver, Colo., 7-11 June 2010, U.S. Geological Survey.

Liu, S., Li, Z., and Chen, M., 2010, Integrating remote sensing data with GEMS to improve simulation of carbon dynamics [abs.], in Understanding and predicting for a changing world, USGS Modeling Conference, 3rd, Denver, Colo., 7-11 June 2010, U.S. Geological Survey.

Long, J., and Giri, C.P., 2010, Mapping mangrove forest distribution in Australia using Landsat imagery [abs.], in Annual Meeting, Washington, D.C., 14-18 April 2010, Proceedings: Washington, D.C., American Association of Geographers, abstract ID 30992. (Also available online at $h t t p: / / c o m m u n i c a t e . a a g . o r g / e s e r i e s / a a g \_o r g / p r o g r a m / i n d e x . c f m ? m t g I D=55$ ).

Meyer, D.J., and Gallo, K.P., 2009, Enabling data access and interoperability at the EOS Land Processes Distributed Active Archive Center [abs.], in Fall Meeting, San Francisco, Calif., 14-18 December 2009, Eos Transactions, Suppl., v. 90, no. 52:

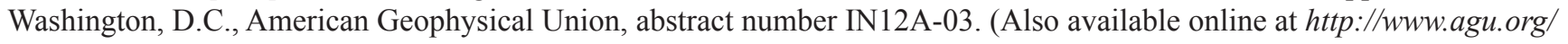
meetings/fm09/waisfm09adv.html).

Miura, T., Brown, J.F., and Gu, Y., 2009, Cross-calibration of AVHRR and MODIS NDVI conterminous United States datasets [abs.], in Fall Meeting, San Francisco, Calif., 14-18 December 2009, Eos Transactions, Suppl., v. 90, no. 52: Washington,

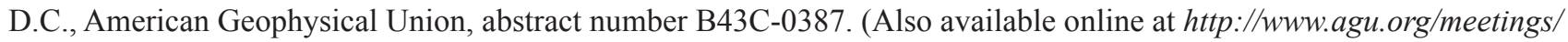
fm09/waisfm09adv.html).

Morisette, J.T., Brown, J.F., and Henebry, G.M., 2009, The USA National Phenology Network Land Surface Phenology/ Remote Sensing Phenology Program [abs.], in Fall Meeting, San Francisco, Calif., 14-18 December 2009, Eos Transactions, Suppl., v. 90, no. 52: Washington, D.C., American Geophysical Union, abstract number B43B-0370. (Also available online at http://www.agu.org/meetings/fm09/waisfm09adv.html).

Napton, D.E., 2010, Developed land conversion in the eastern United States-1980 to 2000 [abs.], in Annual Meeting, Washington, D.C., 14-18 April 2010, Proceedings: Washington, D.C., American Association of Geographers, abstract ID 28128. (Also available online at $h t t p: / / c o m m u n i c a t e . a a g . o r g / e s e r i e s / a a g \_o r g / p r o g r a m / i n d e x . c f m ? m t g I D=55$ )

Pervez, M.S., and Brown, J.F., 2009, Accuracy assessment of the Moderate Resolution Imaging Spectroradiometer (MODIS) irrigated agriculture dataset for the conterminous United States (MIrAD-US) [abs.], in Fall Meeting, San Francisco, Calif., 14-18 December 2009, Eos Transactions, Suppl., v. 90, no. 52: Washington, D.C., American Geophysical Union, abstract

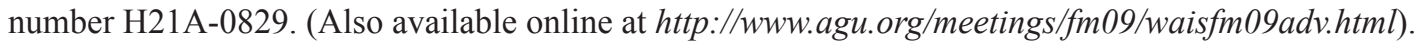

Queija, V., 2010, Lidar analysis of vegetation changes for post-fire chaparral [abs.], in Annual Meeting, Washington, D.C., 14-18 April 2010, Proceedings: Washington, D.C., American Association of Geographers, abstract ID 31236. (Also available online at http://communicate.aag.org/eseries/aag_org/program/index.cfm?mtgID=55).

Ramsey, M.S., Dehn, J., Duda, K.A., Hughes, C.G., Lee, R., Rose, S., Scheidt, S.P., and Wessels, R.L., 2009, Ten years of ASTER thermal infrared data from Terra - discoveries, lessons learned, and insights into future missions [abs.], in Fall Meeting, San Francisco, Calif., 14-18 December 2009, Eos Transactions, Suppl., v. 90, no. 52: Washington, D.C., American Geophysical Union, abstract number U32A-06. (Also available online at $h$ ttp://www.agu.org/meetings/fm09/waisfm09adv.html).

Rover, J.A., Wylie, B.K., and Dahal, D., 2010, Analysis of surface water dynamics in the Yukon Flats of Alaska [abs.], in Annual Meeting, Washington, D.C., 14-18 April 2010, Proceedings: Washington, D.C., American Association of Geographers, abstract ID 30002. (Also available online at http://communicate.aag.org/eseries/aag_org/program/index. $c f m ? m \operatorname{tg} I D=55)$.

Rover, J.A., Wylie, B.K., and Ji, L., 2009, A new self-trained classification model for producing 30-m percent-water maps from Landsat imagery [abs.], in Fall Meeting, San Francisco, Calif., 14-18 December 2009, Eos Transactions, Suppl., v. 90, no. 52: Washington, D.C., American Geophysical Union, abstract number H53L-05. (Also available online at http://www.agu.org/ meetings/fm09/waisfm09adv.html). 
Rover, J.A., Wylie, B.K., Wickland, K., and Griffith, B., 2010, Quantifying surface water in the Yukon River Basin [poster], in Understanding the past, informing decisions for the future, Climate Change Science Conference, Denver, Colo., 9-11 March 2010, U.S. Geological Survey.

Roy, D., Ju, J., Vermote, E.F., Zhang, C., Egorov, A., Kovalskyy, V., Loveland, T.R., Hansen, M.C., Scaramuzza, P.L., Kline, K., Yeom, J., and Kommadreddy, I., 2009, Web-enabled Landsat Data (WELD) - demonstration of MODIS-Landsat data fusion to provide a consistent, long-term, large-area data record for the terrestrial user community [abs.], in Fall Meeting, San Francisco, Calif., 14-18 December 2009, Eos Transactions, Suppl., v. 90, no. 52: Washington, D.C., American Geophysical

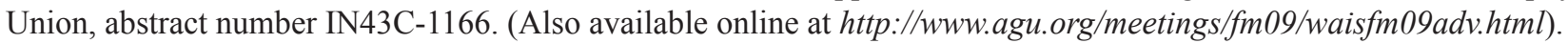

Sayler, K.L., 2010, Detecting land cover change in the United States northern Great Plains, 1973-2006 [abs.], in Annual Meeting, Washington, D.C., 14-18 April 2010, Proceedings: Washington, D.C., American Association of Geographers, abstract ID 32037. (Also available online at $\left.h t t p: / / c o m m u n i c a t e . a a g . o r g / e s e r i e s / a a g \_o r g / p r o g r a m / i n d e x . c f m ? m t g I D=55\right)$.

Senay, G.B., Bohms, S., Morgan, D.S., Moreo, M.T., Qi, S., and Christenson, S.C., 2010, Characterizing landscape evapotranspiration dynamics using remote sensing and global weather datasets [abs.], in Understanding and predicting for a changing world, USGS Modeling Conference, 3rd, Denver, Colo., 7-11 June 2010, U.S. Geological Survey.

Senay, G.B., Bohms, S., and Verdin, J.P., 2010, Using remote sensing for estimating regional evapotranspiration and basin water balance components [abs.], in Annual Meeting, Washington, D.C., 14-18 April 2010, Proceedings: Washington, D.C., American Association of Geographers, abstract ID 33110. (Also available online at http://communicate.aag.org/eseries/aag org/program/index.cfm?mtgID=55).

Shi, H., Hawbaker, T.J., Rollins, M.G., Vogelmann, J.E., and Yang, L., 2009, Predicting burn severity and patterns of biomass consumption in support of national-scale carbon assessment [abs.], in Fall Meeting, San Francisco, Calif., 14-18 December 2009, Eos Transactions, Suppl., v. 90, no. 52: Washington, D.C., American Geophysical Union, abstract number B53D-0425. (Also available online at $h t t p: / / w w w . a g u . o r g / m e e t i n g s / f m 09 / w a i s f m 09 a d v . h t m l$ ).

Singh, R., Liu, S., and Tieszen, L.L., 2010, Satellite-based evapotranspiration and gross primary productivity for the midcontinent intensive campaign [abs.], in Understanding and predicting for a changing world, USGS Modeling Conference, 3rd, Denver, Colo., 7-11 June 2010, U.S. Geological Survey.

Sleeter, B.M., and Liu, J., 2009, Land-use and land-cover change in California-implications for regional carbon flux [abs.], in Fall Meeting, San Francisco, Calif., 14-18 December 2009, Eos Transactions, Suppl., v. 90, no. 52: Washington, D.C., American Geophysical Union, abstract number B11D-0502. (Also available online at $h t t p: / / w w w . a g u . o r g / m e e t i n g s / f m 09 /$ waisfm09adv.html).

Sohl, T.L., Sleeter, B.M., Sayler, K.L., Acevedo, W., Bouchard, M., and Bennett, S., 2010, Developing a land-use modeling framework to support analyses of carbon sequestration and flux [abs.], in Understanding and predicting for a changing world, USGS Modeling Conference, 3rd, Denver, Colo., 7-11 June 2010, U.S. Geological Survey.

Stoker, J.M., 2010, A national Lidar dataset—implications for science [abs.], in Annual Meeting, Washington, D.C., 14-18 April 2010, Proceedings: Washington, D.C., American Association of Geographers, abstract ID 33454. (Also available online at http://communicate.aag.org/eseries/aag_org/program/index.cfm? $m$ tgID=55).

Tolk, B.L., 2010, Advanced Wide Field Sensor (AWiFS) imagery-a viable data substitute for LANDFIRE update mapping? [abs.], in Annual Meeting, Washington, D.C., 14-18 April 2010, Proceedings: Washington, D.C., American Association of Geographers, abstract ID 32845. (Also available online at http://communicate.aag.org/eseries/aag_org/program/index. cfm? $m \operatorname{tg} I D=55)$.

Verdin, J.P., Funk, C.C., Budde, M.E., Lietzow, R.W., Senay, G.B., Smith, R., Pedreros, D.H., Rowland, J.D., Artan, G.A., Husak, G.J., Michaelsen, J., Adoum, A., Galu, G., Magadzire, T., and Rodriguez, M., 2009, Monitoring and modeling agricultural drought for famine early warning (Invited) [abs.], in Fall Meeting, San Francisco, Calif., 14-18 December 2009, Eos Transactions, Suppl., v. 90, no. 52: Washington, D.C., American Geophysical Union, abstract number H13F-02. (Also available online at $h t t p: / / w w w . a g u . o r g / m e e t i n g s / f m 09 / w a i s f m 09 a d v . h t m l)$.

Verdin, J.P., Funk, C.C., and Peters-Lidard, C., 2010, A land data assimilation system for famine early warning [abs.], in Understanding and predicting for a changing world, USGS Modeling Conference, 3rd, Denver, Colo., 7-11 June 2010, U.S. Geological Survey. 
Vermote, E.F., Justice, C.O., Csiszar, I.A., Eidenshink, J.C., Myneni, R.B., Baret, F., Masuoka, E., and Wolfe, R.E., 2009, A terrestrial surface climate data record for global change studies [abs.], in Fall Meeting, San Francisco, Calif., 14-18 December 2009, Eos Transactions, Suppl., v. 90, no. 52: Washington, D.C., American Geophysical Union, abstract number IN42A-08. (Also available online at $h t t p: / / w w w . a g u . o r g / m e e t i n g s / f m 09 / w a i s f m 09 a d v . h t m l$ ).

Wood, E.C., Bennett, B.T., Meyer, D.J., Pandya, R.E., and Maynard, N.G., 2010, Tribal college climate change education in the Dakotas [abs.], in Annual Meeting, Washington, D.C., 14-18 April 2010, Proceedings: Washington, D.C., American Association of Geographers, abstract ID 33918. (Also available online at http://communicate.aag.org/eseries/aag_org/program/index. cfm? $m \operatorname{tg} I D=55)$.

Wu, Y., and Liu, S., 2010, Impacts of climate change on hydrological components in the upper Mississippi River Basin [poster], in Understanding and predicting for a changing world, USGS Modeling Conference, 3rd, Denver, Colo., 7-11 June 2010, U.S. Geological Survey.

Wylie, B.K., Boyte, S.P., and Gu, Y., 2010, Normalized Difference Vegetation Index for restoration monitoring [abs.], in NRDA Restoration Program National Workshop, Phoenix, Ariz., 19-23 April 2010, U.S. Department of Interior.

Wylie, B.K., Ji, L., Waldrop, M.P., Rover, J.A., Nossov, D., McFarland, J.W., and Hollingsworth, T., 2010, Quantifying changes in terrestrial and aquatic ecology in the Yukon River Basin [poster], in Understanding the past, informing decisions for the future, Climate Change Science Conference, Denver, Colo., 9-11 March 2010, U.S. Geological Survey.

Wylie, B.K., Murnaghan, K., Rover, J.A., Tieszen, L.L., and Brisco, B., 2009, Modeling boreal forest performance with MODIS, site characteristics, and weather to monitor climate, management, and disturbance impacts [abs.], in Fall Meeting, San Francisco, Calif., 14-18 December 2009, Eos Transactions, Suppl., v. 90, no. 52: Washington, D.C., American Geophysical Union, abstract number B43C-0388. (Also available online at http://www.agu.org/meetings/fm09/waisfm09adv.html).

Xian, G., and Homer, C.G., 2009, Evaluation of urban land cover and land use-large scale quantification and characterization from satellite-based remote sensing [abs.], in Fall Meeting, San Francisco, Calif., 14-18 December 2009, Eos Transactions, Suppl., v. 90, no. 52: Washington, D.C., American Geophysical Union, abstract number B33D-0426. (Also available online at http://www.agu.org/meetings/fm09/waisfm09adv.html).

Young, C., Liu, S., Mushet, D., Euliss, N., Feng, M., and Huang, S., 2010, Modeling wetland floristic quality change in space and time in the prairie pothole region of the United States [abs.], in Understanding and predicting for a changing world, USGS Modeling Conference, 3rd, Denver, Colo., 7-11 June 2010, U.S. Geological Survey.

Zhang, L., Wylie, B.K., Ji, L., Gilmanov, T.G., and Howard, D., 2010, Interannual variability in net ecosystem exchange in United States Great Plains grasslands [abs.], in General Assembly, European Union of Geosciences, Vienna, Austria, 2-7 May 2010, Geophysical Research Abstracts, v. 12: Katlenburg-Lindau, Germany, European Geophysical Society, abstract number EGU2010-7424. (Also available online at $h$ ttp://meetingorganizer.copernicus.org/EGU2010/poster programme/1859).

Zhang, L., Wylie, B.K., Ji, L., Gilmanov, T.G., Howard, D., and Tieszen, L.L., 2010, Upscaling carbon fluxes over Great Plains grassland - sinks and sources [abs.], in Conference on the environment, Portland, Oreg., 26-30 May 2010, Proceedings: Washington, D.C., U.S. Department of Interior. (Also available online at http://www.regonline.com/builder/site/Default. aspx?eventid=782504). 


\section{Conclusion}

In FY 2010, EROS Management rolled out the Center's new strategic plan: "Moving Forward: A 2010-2015 Strategic Plan for USGS EROS.” In FY 2011, the Center is intent on achieving results against this plan through its mission goals:

- Understand the Nation's remote sensing requirements;

- Expand our multimission capabilities so that those requirements can be addressed;

- Develop a terrestrial monitoring system that provides the data, services, and assessments needed to understand and manage environmental change; and

- Maintain a strong remote sensing science, applications, and development program that addresses the Nation's most pressing needs.

EROS will be working with USGS Leadership and the network of USGS Science Centers to achieve these goals.

Communication with our expanding constituent and customer base is vital to the success of our programs and projects, and we encourage your feedback. Please let us know how well we are meeting your needs and share your suggestions for improvement with us directly.

To communicate with us, or for more information about EROS, contact:

Communications and Outreach

USGS EROS Center

47914 252nd Street

Sioux Falls, South Dakota 57198

jsnelson@usgs.gov

http://eros.usgs.gov/

\section{References Cited}

Funk, C.C., 2010, A climate trend analysis of Kenya-August 2010: U.S. Geological Survey Fact Sheet, 2010-3074, 4 p. (Also available online at http://pubs.usgs.gov/fs/2010/3074/).

Funk, C.C., and Verdin, J.P., 2010, Real-time decision support systems - the Famine Early Warning System Network, chap. 17 in Gebremichael, M., and Hossain, F., eds., Satellite rainfall applications for surface hydrology: New York, Springer, p. 295-320.

Hansen, M.C., Stehman, S.V., Potapov, P.V., Loveland, T.R., Townshend, J.R.G., DeFries, R.S., Pittman, K.W., Arunarwati, B., Stolle, F., Steininger, M.K., Carroll, M., and DiMeceli, C., 2008, Humid tropical forest clearing from 2000 to 2005 quantified by using multitemporal and multiresolution remotely sensed data: Proceedings of the National Academy of Sciences of the United States of America, v. 105, no. 27, p. 9,439-9,444. (Also available online at http://dx.doi.org/10.1073/ pnas.0804042105).

Ji, L., Wylie, B.K., Ramachandran, B., and Jenkerson, C.B., 2010, A comparative analysis of three different MODIS NDVI data sets for Alaska and adjacent Canada: Canadian Journal of Remote Sensing, v. 36, no. Suppl. 1, p. S149-S167. (Also available online at http://pubs.nrc-cnrc.gc.ca/cjrs/cjrs.html).

Selkowitz, D.J., 2010, A comparison of multi-spectral, multi-angular, and multi-temporal remote sensing datasets for fractional shrub canopy mapping in Arctic Alaska: Remote Sensing of Environment, v. 114, no. 7, p. 1,338-1,352.

Williams, A.P., and Funk, C.C., 2010, A westward extension of the tropical Pacific warm pool leads to March through June drying in Kenya and Ethiopia: U.S. Geological Survey Open-File Report, 2010-1199, 7 p. (Also available online at http://pubs. usgs.gov/of/2010/1199/).

Yarie, J., Kane, E., and Mack, M., 2007, Aboveground biomass equations for the trees of interior Alaska: University of Alaska Fairbanks Agricultural and Forestry Experiment Station Bulletin 115, 16 p., available online at http://www.uaf.edu/files/snras/ B115.pdf. 



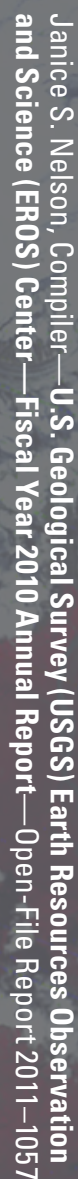

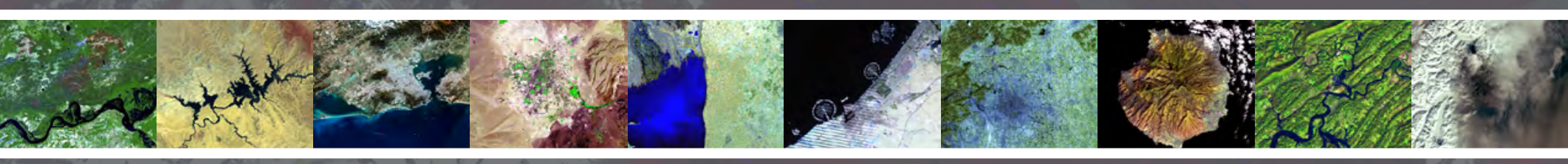

